
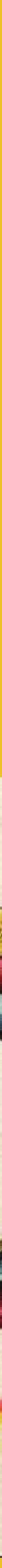


\section{ITALIAN JEWRY IN THE EARLY MODERN ERA}

Essays in Intellectual History 
Perspectives in Jewish Intellectual Life

Series Editor:

Giuseppe Veltri (University of Hamburg)

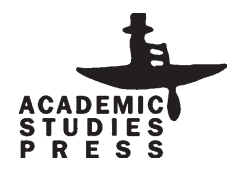




\section{ITALIAN JEWRY IN THE EARLY MODERN ERA}

Essays in Intellectual History

ALESSANDRO GUETTA 
Library of Congress Cataloging-in-Publication Data:

A catalog record for this book as available from the Library of Congress.

Copyright @ 2014 Academic Studies Press

All rights reserved

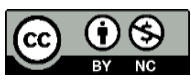

Effective November 16, 2016, this book will be subject to a CC-BY-NC license. To view a copy of this license, visit https://creativecommons.org/licenses/by-nc/4.0/. Other than as provided by these licenses, no part of this book may be reproduced, transmitted, or displayed by any electronic or mechanical means without permission from the publisher or as permitted by law.

ISBN 978-1-61811-208-8 (hardback)

ISBN 978-1-61811-209-5 (electronic)

Cover design by Ivan Grave

Published by Academic Studies Press in 2014

28 Montfern Avenue

Brighton, MA 02135, USA

press@academicstudiespress.com

www.academicstudiespress.com 


\section{Contents}

Acknowledgments . . . . . . . . . . . . . . . . 6

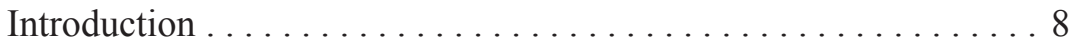

1: From Philosophy to Kabbalah:

Yehiyel Nissim of Pisa and the Critique of Aristotelianism. . . 12

2: Can Fundamentalism be Modern?

The Case of Avraham Portaleone, the Repentant Scientist. . . . 30

3: Allegorical Space and Geometrical Space:

Representations of the Temple of Jerusalem in the Works of Italian Jewish Authors . . . . . . . . . . . . . . . . . . . . . . 62

4: The Myth of Politics in the Jewish Communities of the Italian City-States. . . . . . . . . . . . . . 78

5: A Link to Humanity:

Judaism as Nation and Universal Religion. . . . . . . . . . . . 92

6: The Italian and Latin Works of Lazzaro da Viterbo, Sixteenth-Century Jewish Humanist . . . . . . . . . . . . . 105

7: Leone Modena's Magen we-herev as an Anti-Catholic Apologia . . . . . . . . . . . . . . . . . . 134

8: The Immortality of the Soul and Opening Up to the Christian World . .

9: Kabbalah and Rationalism in the Works of Mosheh Hayyim Luzzatto and some Kabbalists of his time.

Notes 


\section{Acknowledgments}

The chapters of this book were originally published separately as articles. They have all been modified and updated, in some cases translated from French and Italian.

Chapter 1: "Religious Life and Jewish Erudition in Pisa: Yehiel Nissim da Pisa and the Crisis of Aristotelianism." In Cultural Intermediaries, Jewish Intellectuals in Early Modern Italy, edited by David B. Ruderman and Giuseppe Veltri, 86-108. Philadelphia: University of Pennsylvania Press, 2004.

Chapter 2: "Avraham Portaleone: From Science to Mysticism." In Jewish Studies at the turn of the Twentieth Century. Proceedings of the $6^{\text {th }}$ European Association for Jewish Studies Congress, edited by J. Targarona Borràs et A. Sàenz-Badillos, 40-47. Leiden: Brill, 1999. "Avraham Portaleone, le scientifique repenti. Science et religion chez un savant juif entre le $16^{\text {ème }}$ et le17 $7^{\text {ème }}$ siècle." In Torah et science: perspectives historiques et théoriques. Études offertes à Charles Touati, edited by G. Freudenthal, J.-P. Rothschild, G. Dahan, 213-227. Peeters: Louvain-Paris, 2001. "Can Fundamentalism be modern? The Case of Avraham Portaleone (1542-1612)." In Acculturation and Its Discontents: The Jews of Italy from Early to Modern Times, edited by N. Meyers and M. Ciavolella, 99-118. Toronto: University of Toronto Press, 2009.

Chapter 3: "Le Temple de Jérusalem, de l'allégorie à la représentation réaliste chez les auteurs juifs italiens." In Le noyau et l'écorce. Les arts de l'allégorie XVe - XVIIe siècles, edited by Colette Nativel, 135-148. Paris: Collections d'histoire de l'art de l'Académie de France à Rome, 2009.

Chapter 4: "Le mythe du politique chez les Juifs dans l'Italie des Cités." In Politik und Religion im Judentum, Romania Judaica Band 4, edited by Cristoph Miething, 119-131. Tübingen: Niemeyer, 1999.

Chapter 5: "Ebraismo come nazione e come religione universale: Forme del pensiero ebraico in Italia tra "500 e "700." Italia 19 (2009): 23-42.

Chapter 6: "Le opere italiane e latine di Lazzaro da Viterbo, ebreo umanista del XVI secolo." In Gacobbe e l'angelo, edited by Irene Kajon et al., 31-69. Roma: 2012. 


\section{Acknowledgments}

Chapter 7: "Leone Modena's Magen wa-Herev as an Anti-Catholic Apologia." Jewish Studies Quarterly 7 (2000): 296-318.

Chapter 8: "The Immortality of the Soul and Opening up to the Christian World: A Chapter in Early-Modern Jewish-Italian Literature." In Hebraic Aspects of the Renaissance: Sources and Encounters, edited by I. Zinguer et al., 80-115. Leiden-Boston: Brill, 2011.

Chapter 9: "Qabbalah e razionalismo nell'opera di Moshe Hayyim Luzzatto." In Ramhal. Pensiero ebraico e kabbalah tra Padova ed Eretz Israel, edited by G. Luzzatto Voghera and M. Perani, 39-86. Esedra: Padua, 2010. 


\section{Introduction}

Research does not always proceed according to a predetermined plan. In some cases, the opposite is true: only when a work is completed can we observe its fundamental inspiration, which was implicit from the start. The essays presented in this book demonstrate the latter: the coherence of the collected pieces - the common elements that connect them-was visible only post factum. Only in collecting some of the articles I wrote between 1998 and 2012 was I able to see clearly the common elements in theoretical approach and conclusions which, when viewed as a whole, reveal a rather uniform result.

The motivations that drive the scholar to choose a certain field of research, a specific subject within that field, and the way that subject will be approached are difficult to pin down, perhaps even mysterious. But within that choice itself lies a large measure of the results: in the sciences, or at least in the human sciences, the answers one finds are guided largely by the questions one asks.

My field of research is the intellectual history of Italian Judaism. Though this choice obviously stems from my own experiences and cultural training, my choice of eras is the result of an attraction that is difficult to explain, whose motivations are probably found in that murky area between emotion and intellect, or in the inputs from emotion to the intellect, guiding its choices.

The period covered in this book is called "Modern" in the French and Italian historiographical traditions and "Early Modern" in Anglophone countries. It ranges from the the Renaissance at its height in the first decades of the sixteenth century to the first half of the eighteenth century, on the threshold of the Enlightenment. According to the classical scansion of Jewish history, this period is called the "Age of the Ghetto"-long considered by historians, from the nineteenth century until the revision of a few decades ago, as an era when the repressive policies of the Catholic Church caused Italian Jewish communities to fold in on themselves, an era of intellectual obscurantism and demographic decline.

However, scholars like Baruch Sermoneta and Robert Bonfil ${ }^{1}$ (and many others in their wake) have shown that exchange with non-Jewish society became more intense in the Age of the Ghetto, and that some of the intellectual 
forms that developed in the Jewish world were completely analogous to those in the Christian world. The era of emancipation, situated in the second half of the eighteenth century, was actually preceded by a series of apparently contradictory processes. Though, on the one hand, philosophical and scientific rationalism spread among Catholic and Jewish intellectuals, this period also saw the diffusion of an opposite attitude: a religious devotion that in the Catholic world inspired the values of the Counter-Reformation and that in the Jewish world took the form of Kabbalah. The history of these two hundred years is, at its base, the history of tension and dialectic between these two positions.

It was an age marked by contrasts, paradoxes, and extremely significant personal crises. Authors who denounced the inadequacy of medieval science, which was founded on fossilized and superseded knowledge, became devoted penitents and adherents to religious tradition; the most intransigent kabbalists recognized the obscurity of their doctrine in the form in which it had been handed down, and tried to adapt it to the rationalism of contemporary science. Hebrew prose and poetry were transformed, while at the same time literary translations into Italian multiplied, and the use of Italian (the "national" and "modern" language) became increasingly frequent under the pen of many Jewish authors.

In sum, it was a time when many of the elements of the era of emancipation were being prepared, yet the richness of Jewish culture, its intellectual forms and its linguistic expression, was maintained; in other words, a time before the rapid abandonment of culture that resulted from the integration of a small minority into a much more populous society, leading to so-called "assimilation."

However, the common traits of this period became clear to me only in collecting and combining these essays - and perhaps even in the drafting of these present lines, which must serve as a general and unifying introduction.

A similar observation can be made regarding the topics and authors that I chose to study. It is not always easy for researchers to remember their first encounters with an author or a work, and the considerations (in that early stage, we usually rely on simple intuition) that led to the dedication of months or years of study.

Post factum, I can say that all of the authors discussed in this book simultaneously demonstrate a strong anchoring in traditional Jewish culture (biblical-rabbinic) and a clear tendency toward engagement with non-Jewish 
culture, whether philosophical, scientific, literary (Italian and, less commonly, Latin), or theological (Christian). The first three areas have, a priori, a neutral valence insofar as they do not touch on the foundations of the Jewish religion and can represent a zone of exchange and encounter with non-Jews: Italian rabbi-philosophers cited Muslim authors like Averroes and Christian authors like Thomas Aquinas, doctors corresponded with their Catholic colleagues, and poets were explicitly inspired by prestigious Italian authors, above all Dante. For a large portion of the era we are studying here, during which fundamentalism prevailed, these "neutral" areas were considered "impure" and extraneous with respect to the "authentic" tradition handed down to the Jews (and only to the Jews). But connections with "the other" never stopped: they simply took other forms.

Some of these authors tried to establish contact with Christians on the (obviously very sensitive) level of theology. There were those who tried to show the common threads of Judaism and Christianity and those who, through polemicizing on some essential points of Christian belief, showed respect and openness to a religion that represented otherness par excellence.

The figures reviewed in this book do not necessarily seek harmony between Jewish and non-Jewish elements: in some cases, each of these sets of elements belonged to separate and seemingly mutually exclusive phases in their biographies; in other cases, the non-Jewish elements are implicit, buried beneath a thick layer of apparently self-sufficient Jewish elements, leaving it to the researcher to find and feature them - a good example of the answers being guided by the questions.

One of the recurring terms in this book is modernity. The concept is suggested by the anti-traditionalist positions of some authors (like Avraham Portaleone in his younger period) and explicitly used by another fundamental figure of this period, Leone Modena. Indeed, this term appears in the original titles of some of my articles, as well as in publications or research seminars I have coordinated over the last several years.

There are no doubt some good reasons to attribute a kind of "primogeniture" in terms of modernity to Italian Jewish society and the culture it expressed. If no one doubts the Ashkenazi (German and Eastern European) origins of many fundamental realities of contemporary Judaism (Zionism, Jewish Socialism, Hasidism, the rebirth of the Hebrew language, and the scientific study of traditional heritage), if we can, with extremely good reason, see the Jews of seventeenth-century Amsterdam as the "prototype" for 
modern Jews who incline toward secularization (of whom Baruch Spinoza is only the most visible representative), ${ }^{2}$ it is equally true that, as far as the size and duration of the phenomenon is concerned, the Italian community is most anciently and most broadly "modern."

But what do we mean by "modern"?

Is modernism identified with secularization? Does it suggest an anti-traditionalist, progressive, and optimistic ideology? Or does it simply designate a chronological period between the Medieval, perhaps Renaissance era and the contemporary age, which is defined by many as "post-modern"?

Although founded on solid grounds, the term "modernity" presents (along with a certain dose of the arbitrariness inherent in all denominations of temporal scansion) the inconvenience of finality. When we talk about modernity, there is the implication that the preceding age was the preparation and the modern age was the fulfillment. Despite the fact that nineteenth-century historical philosophies, with their visions of the present as the completed and somehow final result of a long process, seem to have been eclipsed, the idea of the present as the perfection of the past dies hard.

Of course, there is no reason to consider the contemporary Jewish condition any more perfected than that of, say, the 1600s. This is why one should be careful when using a debatable term like modernity, and instead emphasize the constant dialectic, among Italian Jews in those years, between the tendency to exploit traditional Jewish cultural heritage and the explicit, unconfessed, or unconscious appeal to different forms of Italian culture. At base, theirs was, as Moritz Steinschneider defined it (referring to linguistic levels), an "amphibious" life, in which Jewish and Italian elements combined with considerable ductility. ${ }^{3}$

I would like to express an intellectual debt to Robert Bonfil. In addition to the general formulation of the book, which was certainly influenced by his approach, some of the essays contained here were developments of the Greek-Italian-Israeli scholar's concisely expressed intuitions.

My hope is that these elaborations and other original contributions will help others to see things a little differently, showing them new aspects of the fascinating Jewish-Italian intellectual history of the period.

Alessandro Guetta Paris, November 2012 


\section{From Philosophy to Kabbalah: Yehiyel Nissim of Pisa and the Critique of Aristotelianism}

We know a good deal about the Da Pisa family, as well as about the financial and intellectual activities of its members, thanks to the research of David Kaufmann, Umberto Cassuto, and Michele Luzzati. ${ }^{1}$ By now we know that the Da Pisa family included money-lenders of great importance even on a national scale, as well as rabbinical authorities who were extremely productive in the fields of juridical decisions, thought (both kabbalistic and philosophic), and even poetry. For at least three generations, from the late fifteenth century to the mid-sixteenth century, the Da Pisas were one of the main reference points of the entire Italian Jewish community.

Much attention has been given recently to the figure of Yehiyel (Vitale) Nissim of Pisa (1493? - before 1572), author of the important philosophical text Minhath Kenaoth (The Gift of Zeal), dated 1539, ${ }^{2}$ and two other shorter works, the Discourse on the Ten Sefyroth (Hebrew), previous to the Minhat, and the Discourse on the Righteous Man and the Purpose of the World (Hebrew), dated 1559, ${ }^{3}$ as well as a juridical text on loans with interest, the (Maamar Hayyey 'Olam (Discource on Eternal Life). ${ }^{4}$ In Rabbis and Jewish Communities in Renaissance Italy, Robert Bonfil dedicated several dense pages to this scholar, reading his work in the context of the crisis of medieval rationalism, a crisis that interested Christians as well as Jews. ${ }^{5}$ The present study intends to develop a few parts of Bonfil's interpretation, following his general orientation. We will then try to sketch an intellectual portrait of Yehiyel, in reference to both Jewish tradition and the Italian culture of his time.

All of Yehiyel's works circulated as manuscripts, even though some of them (such as the Discourse on Eternal Life) were probably meant to be published. ${ }^{6}$ In its scope and ambition, the Minhath Kenaoth distinguishes itself from the others. It is a punctual confutation of the Iggereth Hithnatzeluth (Letter of Justification) written by the Provençal philosopher and moralist Yeda'yiah Bedersi (known as "ha-Penyny," 1270-1340) in reaction to 
Shelomo ben Adret's decision to prohibit the study of the natural sciences and philosophy before the age of twenty-five. ${ }^{7}$

Bedersi's Letter is a brief, clear list of the advantages that religion draws from the study of philosophy; Yehiyel examines it in detail and replies to all of Bedersi's arguments, furthering the discourse remarkably. The result is an actual treatise, in which the main problems of the philosophical tradition are analyzed according to the classical structure of the scholastic quaestio: first the adversary's opinion is presented, along with a detailed analysis of the argument according to the main philosophers, and then the author describes his own position based on what he considers to be the authentic Jewish tradition.

It goes without saying that by philosophy, or free rational research, Yehiyel means Aristotelianism as it developed from Aristotle through his Greek, Arab, and Jewish commentators up until the more recent discussions of the Italian "university philosophy." The work's objective is clearly presented from the very introduction, which is written in a careful, sophisticated prose: it opposes the position of "those who want to show the great advantages to be gained from the study and knowledge of that science called philosophy, as if without it the sacred Torah did not have the right to be placed in the highest ranks and as if its beliefs [...] did not make any sense without her: in short, [as though it is] the maid who passes as a lady [...] But we have the obligation to destroy and shatter these confused opinions and bad beliefs: this is what ruins our people and corrupts our patrimony. [...] The Torah deserves the primogeniture, it is the light of all other sciences." 8

Further on, Yehiyel nuances and clarifies his idea:

My objections do not regard the intensive study of philosophy as such, because science qua science makes possible the knowledge of the causes or the natural hierarchy of things, and thus can be pursued with profit; as long as it helps to know the reality of the entities, as these were created, and as to their use, but not when it claims to be the main moment and the evaluating criterion of the Torah. ${ }^{9}$

The book's long introduction continues, developing the following fundamental points:

1) the centrality of the Torah as a source of knowledge;

2) the refutation of allegory as a means by which to explain the Bible. According to the allegorists: "In the Torah there would not be teachings 
relative to what is permitted and what is prohibited, to the guilty and the innocent, to the sacrifices and the offerings; instead, it would overflow with notions of incommensurable value, like the primary material called hyle that is ready to assume any form, towards which it is attracted like a man to a young woman, or the rotation of the spheres, and so forth."10

3) the self-sufficiency of the Torah, if accompanied by its esoteric explanations: "Everything is included in brief mentions in its letters, in its vocalization and cantillation signs, in the closed passages and in the open ones, in the marks to be added over some of the letters, just as it was delivered to the greatest of the shepherds from the mouth of the Lord. [...] Such is the Kabbalah, orally transmitted unto us." 11

All this is accompanied by an affirmation of proud particularism ("Why turn to others? [...] Why return to Egypt in search of help? Why embrace a foreign breast?"), ${ }^{12}$ in which argumentation is replaced by a peremptory affirmation, and the concatenation of rational discourse by the rhetoric of suggestion.

\section{The Components of Yehiel's Thought}

According to Yehiyel, the alternative way to philosophy develops through these successive phases:

1) the anti-intellectualism of Yehudah ha-Levy (1075-1141), author of the book Kuzary (The King of the Khazars), considered the champion of the traditional attitude vis-à-vis the rational; ${ }^{13}$

2) the interpretative attitude - also profoundly anti-intellectualistic — of Mosheh ben Nahman (Nahmanides, 1194-1270);

3) the vision of the sefyroth, according to the Italian kabbalistic tradition.

1) The Spanish scholar and poet is cited at length by Yehiyel, who quotes in extenso his strong declarations against the philosophical notion of prophecy as the highest level in the scale of intellection: one does not prophesy, according to Yehudah ha-Levy, after the union of the potential intellect with the agent intellect, but thanks to the constant application of the Torah's commandments. We will consider this argument in detail later on. Yehiyel also appropriates ha-Levy's declarations of the uniqueness of the Jewish people as the object of a special divine love and in whom alone the authentic 
prophecy could be realized. Yehiyel is not the only Jewish intellectual in Italy to turn to Yehudah ha-Levy as an alternative to Aristotelian-Maimonidean rationalism. During this period, the Kuzary reached the great level of dignity of Maimonides' Guide of the Perplexed.${ }^{14}$ At the end of the previous century, with the typical Italian Jewish respect for Maimonides, the kabbalist Eliyah di Genazzano had already said that he would not insist on his critique of the Andalusian philosopher, because there already existed a book which could function as a perfect counterweight to the Guide: the Kuzary, "which does not have equals in its accordance with truth and its harmony with the Kabbalah," a book worthy of being the object of constant attention "of the eyes and of the heart." 15

2) Yehiyel claims to have founded his ideas entirely on Nahmanides, ${ }^{16}$ whom he cites in support of the fundamental idea that the Torah is the origin of all the other sciences, as well as in support of several theological issuesfor example, the question of individual providence - and esoteric notions, such as the transmigration of souls. ${ }^{17}$ One needs to remember that Mosheh ben Nahman is an uncompromising upholder of the tradition, which he naturally sees as going back to Moses, and therefore to the divine revelation, which he seemingly paradoxically considers to be in antithesis to autonomous reflection. He concludes his dense introduction to the commentary on the Pentateuch, "What I write on the secrets of the Torah certainly does not result from individual reasoning and understanding, but was transmitted to me by a master; in like manner the student is taught to become a person who understands."

Close to Nahmanides' sensibility is also the idea of God's absolute freedom with regard to the world; his action is not limited by the separate intellects, and even less so by the laws of nature. ${ }^{18}$ Omniscience corresponds to absolute freedom. Therefore Yehiyel's total opposition to the Provençal philosopher Gersonides (1288-1344) is entirely logical, for the latter denied to God knowledge of man's individual and freely performed acts. The freedom of man - which, as we will see, is vast, although not absolute - does not for Yehiyel contradict the idea of divine knowledge, to which providence and justice are linked. ${ }^{19}$

3) Thanks to the studies of Moshe Idel, we can distinguish a kabbalistic tradition specific to Italian Jews. This tradition, which refers back to Menahem Recanati (thirteenth - fourteenth centuries) and was developed by Yohanan Alemanno, is characterized by a strong philosophical bent, as well 
as by its relative degree of freedom from the influence of the Zohar's mythical thought, typical instead of the Spanish Kabbalah. ${ }^{20}$ One of the most remarkable points of divergence concerned the nature of the sefyroth. The problem, whose delicacy and importance become clear when considering the question of the attributes in Spinoza's Ethics, is whether the sefyroth belong to the divine substance ('atzmuth). Recanati, the author of an important esoteric commentary on the Torah, defines the sefyroth as instruments or receptacles (kelym) of the divine activity ("as instruments in the hands of an artisan [...] yet tightly united among themselves and with a single spirit for all"), ${ }^{21}$ and as such knowable, thereby distinguishing them from the substance of God (the eyn sof), which remains unknowable. In his commentary on the Song of Songs, Alemanno returns to this distinction and illustrates it through the similitude of soul and body - a comparison which can give an idea of both the relationship between invisible cause and visible effects, and the relationship between the unity of God and the multiplicity of forces ruling the world. ${ }^{22}$ Yehiyel's uncle, Yitzhaq of Pisa, who certainly knew Alemanno, who was his contemporary and a frequent guest of the Da Pisas, is the protagonist of an epistolary exchange with a rabbi of Spanish origin, Yitzhaq Mar Hayyim. This correspondence reveals a position different from Alemanno's, in that the sefyroth are not considered solely as an instrument of God, but also-at least in the case of the first two or three-as participating in God's essence. ${ }^{23}$

We will not delve into a discussion of these difficult, though fundamental, classifications. Naturally, one must wonder about the degree of philosophical awareness with which these minute distinctions were made. We take it for granted that the scholars in question did not limit themselves to a servile repetition of themes whose depth they ignored. Obviously, pedagogical traditions played an important - albeit not exclusive - role in determining their various stances; nevertheless, even beyond what may appear to be mere formulas (the status of the sefyroth; the relationship between the eyn sof and the sefyrah keter; the classification of the sefyroth in subcategories), the main question is whether these authors were aware of the fact that they were discussing issues of enormous importance, such as the relationship between God and the world, between the mystery and the knowable, between the ineffable and the sayable.

After recalling that Yehiyel seems to uphold his uncle Yitzhaq's theory, ${ }^{24}$ it is important to note that this debate combines philosophy's conceptual terminology with the Kabbalah's: he describes the sefyroth as "attributes," and 
the eyn sof is the "primary cause." For Yehiyel, critic of philosophy, the relationship between God and the world - a relationship of entirely kabbalistic inspiration - is made to overlap with Aristotelian physics and metaphysics:

God transmits his spiritual energy (shefa) and strength to his attributes, without undergoing any changes; from there, this transmission of energy descends to the world of the intellects, and thereafter to the spheres, and finally to the sublunar world. ${ }^{25}$

This is a real overlay, which according to the kabbalistic, esoteric doctrine may complete, rather than refute, the philosophical: the first begins where the second leaves off. Alemanno had been clear on the subject: "The wise of Israel speak of a world which is not that of the philosophers: the world of the sefyroth is superior to that of the corruptible entities, as well as to the world of circular movements and that of the angels." ${ }^{26}$

\section{Kabbalah and Philosophy}

Yitzhaq Mar Hayyim had already warned his correspondent about the relationship between tradition and autonomous reflection, inviting him to choose the first as his reference point, that is, to adapt philosophy to the Kabbalah, and not the contrary. "Rational research in this field is prohibited to us," Yitzhaq Mar Hayyim contends elsewhere; "instead, it is to the prophetic Kabbalah that we must turn, because it is superior to reason." 27

This testimony of a Spanish teacher confirms a contrario the Italian Kabbalah's philosophical tendency, of which Yehiyel is a typical representative. The rest of Yehiyel's philosophical forma mentis is confirmed by the scholastic course of his juridical argument. In the Discourse on Eternal Life, his brief text on loans with interest, written as a juridical synthesis and reference book for the numerous Jews who supported themselves on financial activities, Yehiyel (a) pronounces the most general principles on which the arguments are constructed; (b) elaborates a syllogism from which to deduce the general conclusion; (c) announces the necessity of studying each particular case; and (d) proceeds to the definitions, which delimit the problems to be discussed and facilitates their solution. ${ }^{28}$

Presented only to be confuted, the abundance and precision of the philosophical arguments in the Minhath Kenaoth illustrate Yehiyel's deep 
understanding of the discipline. His culture was naturally based on the ArabJewish Aristotelian tradition, in addition to the Zohar. Yehiyel had personally copied Averroes' commentary on books 3 and 4 of Aristotle's Physics ${ }^{29}$ thanks to his knowledge of Latin, he was also acquainted with the most recently published works in Italy. A precious source for him were the extensive philosophical syntheses of his contemporary Agostino Nifo, to whom Yehiyel refers many times in his thorough analyses of particular questions. ${ }^{30}$

Several philosophical expositions - on the intellect, for example - are wide-reaching and exemplary in terms of their order and clarity. They could have been more convincing if the author had presented a more unified and coherent thought. Roberto Bonfil has therefore argued that Yehiyel finds himself between two cultural eras, and that he masters the discourse of the older era, which he rejects, but not that of the new, which is not yet well defined. This statement, important from the point of view of historical perspective, should perhaps be nuanced with regard to Yehiyel's specific competence not only in rabbinical tradition but also in Kabbalah itself. The Pisan scholar masters basic texts like the Zohar, just as he also establishes a precise position for himself within kabbalistic thought, one that reveals technical knowledge and deliberate intellectual choices. ${ }^{31}$

Kabbalah is not simply a philosophy, or at least not simply a philosophy in the Aristotelian sense..$^{32}$ Apart from its origins (traditional or rational), Kabbalah represents an intuitive attitude that would function as an alternative (or complement, as we have seen) to Aristotelian discursive reason. The relationship between unity and plurality as the kabbalists intend it (as do, ultimately, the Neoplatonists) cannot be analyzed with Aristotelian conceptual instruments. When Yehiyel refrains from analyzing these subjects in depth, ${ }^{33}$ it is not because of any superficiality or incompetence on his part; rather, he is aware of the fact that they can only be treated in allusive and intuitive terms, with a metaphoric or even mythical lexicon:

The question of the attributes is one of the most profound of all theology (hokhmah elohyth, divine science). [...] All actions that manifest themselves in reality are potentially qualities (middoth) through which God acts, as instruments in the hands of an artisan; however, they are not separated from God; rather they are united in Him in a total unity that words are not capable of describing. ${ }^{34}$ 
Yehiyel's adherence to the philosophical dimension and, at the same time, the distance that he keeps from it, are visible in his definition of the stars' and celestial spheres' constitution. They are of "sefirotic material": the ontological character of the substance serves to define an element, be it celestial or Aristotle's "fifth element." Beyond this coincidence in terminology, however, the difference between the Aristotelians' position and Yehiyel's is evident from the very beginning. Maimonides, who in this regard referred back to Aristotle, had defined the fifth element negatively (it is neither light nor heavy, and so forth), for the obvious reason that we do not have any direct experience of it. ${ }^{35}$ Where the philosopher had prudently stopped for lack of proof, Yehiyel advances without any scruples. The combination of his antiintellectual and intuitive attitudes culminates in a need for positive contents, which the schools' philosophy could not provide. This is perhaps the most historically significant aspect of Yehiyel's work, which we will discuss in further detail.

\section{Yeḥiyel, Renaissance man}

Once again, it is to Idel's research that we owe the particular attention given to the magic - and Neoplatonic - character of a certain Kabbalah. This aspect had been well known for a while, thanks in part to the Christian Kabbalah and its magic-alchemic elements. However, its importance had been forgotten in the shadow of the great figure of Gershom Scholem, who, in his reconstruction of the historical development of Jewish esotericism, had not highlighted this aspect.

The magical aspect is emphasized by Idel, in the same studies mentioned above in regards to Yohanan Alemanno and Yitzhaq of Pisa. This step marked considerable progress in linking Jewish historiography - for a long time the prisoner of a reductive rationalism - and European historiography, which instead had learned to see magic as an important step in the development of a "modern" consciousness. To a certain extent, Yehiyel shares this trust in magic: clearly a Renaissance man in his behavior, he was also one in his mental attitudes.

After having reached the highest level of spirituality, man can attach his soul to the superior worlds and cause divine energies to descend onto the world by means of his moral virtues and performance of the commandments. Thanks to this union, in a way he, too, becomes divine and is thus able to 
intervene in the normal course of nature, which, as we have seen, is totally dependent on divine will:

When man ascends from one level to another thanks to those steps which are represented by the virtues that the Torah indicates and that our teachers call pietas [hasiduth], and after the accomplishment of the Torah in its general rules as well as in its details, his soul strongly adheres to and unites itself with the superior worlds, attracting and propagating the divine presence [shekhynah]; he will therefore provide the people with true knowledge, and will conduct them along the right way. That man will then be able to accomplish prodigies and miracles, and change the course of nature. ${ }^{36}$

At this level he will become entirely spiritual and divine, and while remaining in this world he will belong to the superior worlds, and these will obey him as it happened with the prophets. Thus even the teachers of Israel, when the prophecy was interrupted, by virtue of their absolute adhesion [devequth] to God caused the dead to resurrect and the living suddenly to die. They overturned the order and nature of the world, because they adhered to blessed God, and he "fulfills the desires of those who fear him" (Ps 145:19). ${ }^{37}$

All the different components of these propositions are already in Alemanno, and many of them can be found in Florentine Neoplatonism. Alemanno speaks explicitly of the descent of spiritual energies onto the world thanks to the intervention of the man who is capable of receiving and directing divine emanations and their powers. ${ }^{38}$ And if Giovanni Pico della Mirandola describes man as "et caelestium et terrestrium vinculum et nodus si in se ipso pacem et foedera sancit," ${ }^{39}$ Yehiyel recalls the Zohar's image of the tabernacle and the terrestrial Temple (both the historical and the future ones) as places in which the superior and inferior worlds have been, and will be, strongly linked, thereby fulfilling the will of God. ${ }^{40}$ One should note, however, that despite these important references, in Yehiyel's writing magic does not have the weight that it seems to possess in Alemanno's. Yehiyel does not insist on the subject, and more importantly, he ignores all descriptions of magical practices, on which Alemanno dwells at length (for example, how to prepare to receive the divine energy through the reading of the Torah, which is the equivalent of reading the names of God); ${ }^{41}$ in the Minhath 
Kenaoth, there is a single and cursory reference to the mystical properties of the letters and the vocalization and cantillation signs. ${ }^{42}$

Yehiyel is interested, on the one hand, in establishing the privileged role of man within the universe, and of the Jewish people in their relationship to God in particular; on the other hand, he wishes to demonstrate the inadequacy of conceptual instruments to fulfill their destinies. He therefore limits the importance of magic, inserting it within the traditional and anti-intellectualistic framework that we have already described. As he exalts man's calling, Yehiyel appears to emphasize the descent of divine energies onto the world by virtue of the just man's work, while he neglects the Zoharic concept of harmony between the sefyroth themselves as a consequence of human action. The affirmation of the absolute freedom of God is combined with the anthropocentric vision of the world as created for the good and perfection of man. ${ }^{43}$

Moreover, to this problem Yehiyel dedicated his whole Discourse on the Righteous Man and the Purpose of the World, a short treatise written in answer to the letter of a certain Ya'akov from Modena, which contained the following questions: Is man more important than the angels? Was the world created for man? Yehiyel correctly links the two questions and, as he already had in the Minhath Kenaoth, reviews the philosophical doctrines on the subject, to which he then opposes others drawn from the rabbinical-kabbalistic tradition.

To understand Yehiyel's answers, it is necessary to remember that, according to Maimonides, who is in this regard a faithful follower of Aristotle, man cannot be seen as the object of creation because every entity was created for the good of that same entity, and not for any other. Furthermore, there is a hierarchy of the purity of beings, within which man occupies an inferior position in relation to the separate and celestial intellects (identified with the angels). ${ }^{44}$

Yehiyel's answer is the opposite of Maimonides': man is a microcosm, a model of all worlds. When he is just, he is superior to the angels; his soul originates on the throne of God's glory, to which it returns when it separates from the body, even before death. It is the Torah, which preceded the existence of the world, that allows corruptible man to ascend to the superior worlds and unite himself with God, leaving the angels beneath him. ${ }^{45}$ It seems almost superfluous to point out how close this idea is to Renaissance Neoplatonism, of which it represents the Jewish version. ${ }^{46}$ 


\section{The Uniqueness of Israel}

Speaking of Yehiyel Nissim of Pisa, Bonfil underlines how his opposition to scholastic thought also implies the re-evaluation of the idea of the uniqueness of the Jew - as an individual and as a people - which this same thought had somewhat disregarded. ${ }^{47}$ We have not only seen how the Torah is an instrument of elevation, but have also noted the privileged position of the Jewish people among men: it is like the heart among the members of the body. ${ }^{48}$

Yehiyel emphasizes the uniqueness of Israel time and again. This idea is highlighted especially in the "classical" argument, bent on proving the insufficiency of philosophy in comparison with authentic prophecy. Indeed, if prophecy really was a union, favored by the imaginative faculty, of the potential intellect with the agent intellect, as Avicenna and Maimonides contended, it is not clear why the philosophers were not prophets, and why among the latter only the Jews prophesied in truth and at length. In reality, it is the performance of the mitzwoth and the knowledge of the Torah 's secrets, both reserved to Israel, that allow a person to acquire prophetic abilities. ${ }^{49}$

Regarding divine providence, Yehiyel establishes a hierarchy of entities that views animals as the object of divine providence qua species, humans as the object of that providence qua individuals, and the Jews as individuals who receive a particular attention, in that

their form is particular and separated from the rest of mankind, and it is therefore right that providence be more individualized in their regard. Indeed, the more a man is close to God, thanks to his accomplishment of the precepts, the more He who provides is close to the one who enjoys this providence, and never does He abandon him with His gaze..$^{50}$

Yehiyel alters Maimonides' argument, whose influence he explicitly acknowledges, at the end. According to the Andalusian philosopher, divine providence applies to animals as species and to men as individuals. The latter receive a particular attention from God in proportion to their degree of perfection, which is mainly of an intellectual order and which, in the Guide, does not require them to be Jews. ${ }^{51}$ Yehiyel replaces this hierarchy of intelligence with an essentialist hierarchy of form and with performance of the commandments, an essentialist act in that, by virtue of their nature, the commandments are close to God. 
Furthermore, the Pisan rabbi's argument differs from the beliefs of many of his Jewish contemporaries. As humanists, they argued for the superiority of Israel on the basis of the antiquity of its laws, a claim which was also informed by a cultural pride which could represent itself in the idea of an "Israel redeemer of humanity," as well as in the practice of proselytism, however limited. ${ }^{52}$

The real purpose of the world is the actualization of Israel, the just people. Yehiyel therefore rejects the Aristotelian and Maimonidean idea of the internal actualization of every created thing, and develops this through a parable: A man owns a field perfect for planting. He performs all the necessary preparations and plants a tree. This tree grows, and starts bearing fruit, but many of the fruits rot on the branches, and others fall before they have ripened. There remains one single fruit which grows and ripens as it should, and it reaches its final state. If it is true that the field was the cause of the tree, as also the tree was the cause of the fruit, the farmer's intention and objective in this work would be to obtain that one perfect fruit; indeed, he knew very well that most of his crop would be lost. In the same way, God has prepared the world for the planting of the tree-mankind-with the intention of obtaining in the end one single fruit, the people of Israel with their just men. ${ }^{53}$

This particularism is probably not characteristic of the Jews only, as it manifests itself as well in the Christian milieu associated with traditionalism and the almost exclusive reference to the Scriptures. In his Examen Vanitatis (1520), for example, Gianfrancesco Pico della Mirandola, nephew of Giovanni, affirmed that he "preferred the old theologians of our faith, who contended that one should undertake some action against the pagan philosophers (gentium philosophos) and destroy their teachings, rather than philosophize according to their doctrines (like those who cultivated such studies in the past centuries). ${ }^{\prime 54}$ These affirmations clearly recast the ethnic character of Jewish particularism. The equivalence made here - of a cultural, not an ethnic, character-is therefore between an "us" and the heirs of the dogmatic tradition (to whatever camp they may belong), on the one hand, and, on the other, a "them" and the rationalists who place themselves outside this tradition.

Yehiyel's contemporary, 'Ovadiyah Sforno (1470-1550), in his important philosophical work Or 'amym (Light of the Peoples, 1537), ${ }^{55}$ returns to the subject of man as the purpose of the universe, adapting this Renaissance idea to Aristotelian, and in particular Averroist, coordinates, to which he remains 
faithful. Sforno contends that, even admitting that superior entities cannot exist to ensure the perfection of inferior ones, one cannot deny that man's rational soul is superior to the heavens insofar as it is separate from matter. Indeed, the heavens, with their circular and perfect movement, are the cause of the combinations among the elements of the corruptible world. It is precisely in this world that man happens to act in order to accomplish his two goals of getting closer to God by means of his intellect and of resembling him in accordance with the divine precept.

Within this conceptual framework, the Jews occupy a privileged position, not as the executors of the Torah that God himself has reserved for them, but because they accepted his covenant and are better disposed than any other people to recognize his sovereignty and to serve Him. Further on, we will see how Sforno believes that the superiority of the Jews is justified for reasons opposite those of Yehiyel: in his mind, the people of Israel are the true repositories of a rational tradition. ${ }^{56}$

Though Yehiyel exalts the centrality of man in the universe (and, among men, the Jews), nevertheless he is not ready to grant him absolute freedom. Several years before he wrote the Minhath Kenaoth, a heated debate had developed about free will, stimulated by the Protestant reform. Yehiyel deliberately and explicitly places himself within this debate, denying any validity to the reformist doctrine of the "servant will." Even without sufficient philosophical proofs, he argues, the mere fact that the Torah presents man with commandments implies that there is a freedom of choice: free will is therefore an indispensable element in the construction of beliefs. ${ }^{57}$ However, Yehiyel expresses one important reservation:

free will is not absolute, and the help of God is necessary to perfect the inclination that permits man to develop fear and follow the good. This is one of the principles of the Torah: if and when, on his part, man disposes his heart to good actions and to the mitzwoth, he will receive from God help and energy which will give him sufficient strength to accomplish them. Most worthy actions that regard the Torah and the mitzwoth, and the beginning of fear, depend on man: the help he receives from God is to be considered a reward. ${ }^{58}$

In its basic structure (man's actions are completed by divine intervention), this idea is similar to the Catholic doctrine of justification, as sanctioned 
a few years later by the Council of Trent. According to this doctrine, faith in a "propitiatory" Christ can compensate for the weakening of freedom after the original sin. Only in this way can man be born again to grace. ${ }^{59}$

\section{Modernity and Tradition}

One can take Yehiyel's work to be utterly attached to a traditionalistic vision, as the expression of a spirit hostile to philosophy, which within Judaism manifested itself in a critique of Maimonides and a return to internal sources ${ }^{60}$ However, we know that renewal-without loading this term with the value judgments of any philosophy of history — can easily appear to be a finalistic return to tradition, at least initially. In this case the historian must discover, within traditional arguments, the accent or the few significant details which nuance them in new ways.

We have seen Yehiyel's reservations about philosophy. Naturally, his position was far from new. Yehudah ha-Levy takes it as one of the principles informing the Kuzary: philosophy is conceived as the ancilla prophetiae, where prophecy mainly means that of Moses, preserved and passed on through the oral and written tradition. ${ }^{61}$ What characterizes Yehiyel's position, within this anti-rationalist vein, is his insistence on the insufficiency of the philosophical method, which rests all explanations on empirical observation and on the subsequent search for the causes of the phenomenon. This search from the posterior to the anterior is deemed inappropriate by Yehiyel if one wants to reach truth. The inductive procedure leads one to determine the cause through its effect, attested by the senses; but both the starting point and this procedure are marred by imprecision.

Prophetic knowledge, on the contrary, captures the effect through its cause, that is the posterior along with the anterior, and this is free from errors or confusion. ${ }^{62}$

His opposition to Peripatetic epistemology is clear, even if there is a tendency to emphasize its empirical aspect. One should consider, for a comparison, the Aristotelian statement made by Agostino Nifo, to whose works Yehiyel referred readers: true, Nifo writes, "Scire proprissimum est scire propter quid" (i.e. according to the essence of the object, a priori), but valid knowledge can be of two kinds: "Quae sunt per se notae vel per sensum, vel seipsis." ${ }^{\prime 3}$ 
The same opposition is expressed toward logic, for according to Aristotle logic is the instrument of the sciences and, as such, is external to them. According to Yehiyel, to understand the Torah there is no need to refer to external means; the necessary interpretative rules were revealed and transmitted along with the text. The Hebraic system of knowledge is configured as unitary and is in itself complete and self-sufficent. ${ }^{64}$

Yehiyel's tradition-based certainties are clearly very different from the torments of a philosopher like Pietro Pomponazzi, for example, just as their two works also differ in intellectual scope. ${ }^{65}$ The Pisan rabbi certainly would not have reached the skeptical conclusions of the Paduan philosopher. However, one should not conclude that Yehiyel's thought was not somewhat in consonance with the questions addressed in Christian society. The issues he considers (included that of the transmigration of the soul, which will be developed at length after the end of the sixteenth century with the Lurianic Kabbalah) were of current interest even within the philosophical debate, ${ }^{66}$ and he faces, just as his Christian contemporaries do, a philosophical tradition and possibly a whole way of thinking that by then had become insufficient. Yehiyel's anti-intellectualistic vis and Pomponazzi's rigorously rational knowledge ultimately reach the same conclusions: on fundamental questions, such as the soul's immortality, thought conducted according to the old rules cannot give convincing answers. The Pisan's answer is to turn to tradition; the Paduan's more prudent and perhaps more skeptical solution also tends toward a religious horizon - in which, however, it is not tradition but faith that is highlighted. ${ }^{67}$

In a certain sense, the extremely traditionalist Yehiyel was more "modern" than figures like Sforno, the teacher of reason, and another prominent Italian Jewish intellectual, Mosheh Provenzali (1503-1575).

Sforno critiqued blind tradition harshly, exalting reason as the only means by which one can distinguish truth from falsehood:

The fear and zeal for the Torah (of the pure traditionalist) are founded on a story passed on from father to child. [...] God never ordered that one believe in His existence, in His power and in His providence, because faith does not depend on will, as experience has shown and as the Philosopher has demonstrated in De anima II, 153 [...] but He presented true and just ideas along with their rational argumentation. ${ }^{68}$ 
Finding in Aristotle many conclusions that contradicted their beliefs, the traditionalists, Sforno contends, simply denied them, without any proof. The Jews, by contrast, are the heirs of a rational tradition, founded by 'Ever and continued by Abraham, and concerned with the existence of God, his attributes, and many other similar questions. Rational Jewish science survived on the ruins of Chaldean science. ${ }^{69}$

As for Mosheh Provenzali, rabbi in Mantua and a jurist, grammarian, and philosopher of interest, his fame is essentially linked to the extremely liberal attitude of his ritual decisions, which provoked heated debates and caused him numerous difficulties in the exercise of his functions within the Jewish community. From a philosophical point of view, however, he is a conservative, or a rationalist-conservative. In his commentary on Maimonides' Axioms, he tries in fact to reestablish, within the Maimonidean alveolus, that division between substantial and accidental causality which had radically called into question an important moment of Aristotelian metaphysics. The issue at stake here is infinity in the causal chain, as well as in time and space, which, according to Aristotelian presuppositions, was impossible. Hasday Crescas had attacked these conclusions in depth and with productive results, formulating the idea of an infinite space and an infinity of worlds, an idea that is rightly considered to be one of the main foundations of modern thought.

Provenzali overturns Crescas' argument. As he follows Crescas in demolishing the distinctions between accidental causality (whose possible infinity had already been acknowledged) and essential causality (whose infinity had been denied), Provenzali considers accidental causality (potentially infinite) as the reference for essential causality (never infinite), instead of considering the latter as the reference for the former, as the Spanish philosopher had done. This inverted perspective allows him to establish the non-eternity of the world and its having been created, thereby accomplishing the traditional objective of religious scholars. Thus, Provenzali tries to integrate Crescas' explosive criticism within Aristotelian-Maimonidean thought, using the new to reinforce the old - a defensive action which will not be crowned with success. $^{70}$

The great edifice of Aristotelianism is therefore about to become the legacy of a superseded past, even for the Jews. The new is constructed through the very negation of a rational structure whose conceptual precision and internal coherence were very advanced. The interiorized experience of the 
Florentine Neoplatonists ${ }^{71}$ - like Yehiyel's turning to the Kabbalah, as many others did after him - might respond to similar needs that will later emerge in the new philosophy of nature and in modern science. But before Galileo and the establishment of a new rationality, the rebellion against the old seems to present itself as a reaction against rationalism qua rationalism: modernity emerges, in a way, from within an anti-rational position.

With his constant reliance on suggestion, rather than argumentation, and with his difficult elaboration of an alternative worldview to that of Maimonides - which tried to reconcile revealed religion and rationalismYehiel moves in unison with the Italian culture of his time. An important author such as Gianfrancesco Pico della Mirandola formulates a critique of Aristotelianism in exactly the same terms as the Pisan rabbi ("Aristoteli demonstrandi ars incerta, quia fundatur in indicio iudicioque sensum"), ${ }^{72}$ and he shares his idea of an authentic prophecy as something which one reaches through a free gift of God and distinct from the inauthentic one, which originates in evil spirits. ${ }^{73}$

While Gianfrancesco bemoaned the uncertainty and unreliability of philosophy's results, the object of continuous debates, Yehiyel emphasizes their insufficiency. The practical criterion of the quantity and amplitude of the answers replaces the theoretical one of demonstrability. Philosophy's caution represents for him not only a symptom, but also a reason for its inferiority vis-à-vis traditional doctrines. He voices his opinion on the matter on many occasions with a surprising candor. The conclusions that philosophers can reach on the issue of the angels (corresponding to the intellects), for example, is nothing but "a drop of water in the large sea of truths revealed to the prophets by the sacred doctors." 74

Furthermore, philosophy cannot conceive of the attributes of God merely through a negative definition, saying God is not corporeal, and so forth. But Yehiyel declares that he cannot be content with this: "I would like to know what one finally knows this way, given that negation does not produce knowledge." 75

Yehiyel takes up Crescas' famous critique of Maimonides. However, while the Spanish philosopher's observations had an epistemological starting point (the negation of an attribute is equal to the affirmation of its opposite; therefore God's attributes can be predicated as analogous to men's, but infinite and original), Yehiyel emphasizes the entirely practical need of positive contents. ${ }^{76}$ 
The move from rational argumentation to traditional-kabbalistic narrative is particularly clear in regards to prophecy, as already mentioned. Let us follow it in its development.

As a first step, Yehiyel critiques Maimonides' semi-naturalistic framework, which granted much importance to man's imaginative faculty, as well as to his ability to capture the images created by God and sent to him by means of the active intellect. ${ }^{77}$ The next step consists of replacing the faculty of imagination with the intellect: God, in his great goodnes, causes a knowledge, similar to that of the primary cause, to pass from potentiality to actuality in the prophet's intellect. In this way, every naturalistic aspect of the prophecy is eliminated, and the accent is definitely shifted onto the will of God and away from human disposition. ${ }^{78}$ The third step consists of an allusion to esoteric doctrines, which concern the vision of the merkavah (Ezechiel's divine chariot) and include the tradition relative to the "Throne of Glory" and the "Celestial Man." The rabbis had explicitly prohibited speech on these doctrines, the "extraordinary secrets," but this does not prevent one from speaking of the divine origin of the prophecy in positive terms. This is the last step of Yehiyel's work, after the traditional distinction between Moses and the other Jewish prophets. ${ }^{79}$ On the basis of Recanati's commentary on the Torah, Yehiyel distinguishes the various sefyroth appointed to the prophecy of Israel and of the other peoples. In his examination of the maledictions of Bilam, which transform themselves to benedictions (Numbers 22-24, Deuteronomy 22:6), he arrives at the conclusion that

the nations receive the prophecy from the energy of the attribute of judgment (dyn), as it had happened until then to Bilam. Thanks to the great mercy that he nourishes for his people, God caused the energy of the attribute of mercy (rahamym) to descend upon them. ${ }^{80}$

In this oscillation between philosophical tradition, esotericism, and a need for positive content, the characteristic method of Yehiyel Nissim of Pisa is well represented. 


\section{Can Fundamentalism be Modern? The Case of Avraham Portaleone, the Repentant Scientist}

Recent studies on the involvement of Jews in European scientific research during the pre-modern era (sixteenth-seventeenth century) have emphasized the delicate balancing act of belonging to two worlds: that of modern culture and science, which developed new concepts and methodologies, and that of the Jewish tradition. The difficulties were similar to those encountered by traditionalist Christians, with an additional element of identity. The traditional religious beliefs and practices were, in effect, the building blocks of the life of the Jewish community and justified its separateness: a crisis in these could lead to a crisis of "national" Jewish identity itself.

It is true that, with a few exceptions, the science of the time rarely led to an extreme rationalism that could jeopardize Jewish traditional beliefs. On the contrary, it was generally associated with traditionalist stances that followed different paths. ${ }^{1}$

As far as the literary manifestation is concerned, it must be said that Jewish authors' attempts at balancing between the two worlds are often implicitly expressed through changes in references or slight but meaningful changes in language in a text that otherwise followed the usual rabbinical pattern. This makes the study of their works a delicate and sometimes difficult operation, but also a fascinating one.

In the context of this issue, the intellectual profile of Avraham ben David Portaleone, a physician who lived in the second half of the sixteenth century, presents us with a number of interesting aspects. Portaleone is not unknown to historians. Born in Mantua in 1541, he was descended from a long line of great Jewish Italian doctors ${ }^{2}$ and trained in traditional Jewish studies with his father and then with other masters in Bologna. After the 1553 Papal Bull condemning the Talmud and commanding that all copies be burned, he returned to Mantua to study with the Rosh Yeshivah, kabbalist, and physician Avraham ben David Provenzali (or Provenzalo), who still owned a copy of the condemned text. (Portaleone uses a circumlocution in order to avoid censorship, 
describing it as "all parts of the oral Torah." ") In addition to the Talmud, Portaleone studied Latin and logic with his master. He then devoted himself to medicine and philosophy at the University of Pavia, where he received his doctorate in 1563 . He became a renowned doctor, was very involved with the nobility of Mantua and other cities, and wrote some Consilia medica, compilations of answers to questions asked by doctors from Lombardy and adjacent regions, in Latin and Italian; ${ }^{4}$ he also established a descriptive list of the drugs and surgical operations he claimed to have invented. In addition, he offered his services for circumcisions and as a "doctor for the poor people" in the Jewish community of Mantua.

Upon Duke Guillaume of Gonzaga's request ${ }^{5}$, he wrote a Latin dialogue, the De auro dialogi tres (1584), ${ }^{6}$ about the possibilities of a medical use of gold, a topic halfway between alchemy and medical studies that still created heated scientific debate. ${ }^{7}$ In reality, these dialogues go well beyond discussions about the properties of gold and present the author's general theory on the abilities elements have to affect each other: gold, in this general theory, is an element amongst others, with no exceptional status conferred upon it by a mystical aura. The technical argument comes with a reflection on the appropriate scientific method and on the abilities and limitations of knowledge - meaningful cultural aspects that we shall explore further.

\section{One Author, Two Languages, Two Rhetorics}

These Latin Dialogi seek to address a question which was debated by scientists at that time (and which would continue to be for over a hundred years after the book's publication): can gold cure certain illnesses? The prestige gold had enjoyed since Antiquity had given it a special status among metals, to the extent that ancient and modern scientists shared the conviction that gold, if used in the right way, could be a panacea capable of treating all illnesses. Medical literature prescribed grinding it into a very fine powder and ingesting it mixed with water, or slicing it into thin strips to be heated in the fire and then cooled with wine to produce vinum aureum, golden wine, believed to have great powers.

Contemporary medical authorities were divided into two camps on this: those who denied gold's powers and those convinced of them. Portaleone's position lay midway between the two. In his view, the hypothesis that gold had powerful medicinal properties was true; nevertheless, it remained a mere 
hypothesis, since such properties do not reside within gold as we know it (aurum vulgare) but in its quintessence (succum aurum), a substance perfectly pure and balanced in composition. ${ }^{8}$ In truth, nobody had yet succeeded in extracting this essence, on which the Ars chimica had focused its efforts; consequently, the long list of healings that ancient and modern doctors had attributed to the ingestion of "common gold" mixed with water or wine was the fruit of ignorance and charlatanism. ${ }^{9}$ As for gold's capacity to cauterize wounds, it has this in common with many other metals with the same characteristics.

As was often the case with scientific works of the period, the subject provided the author an opportunity to discuss other, sometimes unrelated subjects. In De auro, alongside the strictly medical argument, there are incursions into Greek, Latin, and Italian literature, mythology, and a host of other disciplines. ${ }^{10}$ Two themes, however, stand out for their importance and de facto constitute a sort of epistemological framework which organizes the book's empirical observations and gives them coherence: 1) the relationship between the ancients and moderns; and 2) the closely related theme of the place of experience in scientific argumentation or, in a more general sense, the roles of reason and experience in human knowledge. This Latin book belongs by full right to the history of science, and must be apprehended as such.

Near the end of his life, Portaleone published an important book in Hebrew inspired by his desire to repent for having devoted himself too much to "profane sciences." In Shiltey ha-Gibborym (The Shields of the Braves, published in Mantua in 1612), his tremendous secular erudition was used for religious knowledge and practice. The main theme of Shiltey ha-Gibborym was the description of the architecture of the Temple of Jerusalem, as well as its furniture and rites. This description precedes a collection of passages from the Bible and rabbinical literature and is meant, according to the author, to supply a better sense of the physical place where the sacrifices were offered, thus adding to the reading of those passages a deeper intention-making it possible to feel "as if" sacrifices were presented, Portaleone writes. In fact, the model of the Temple is used as a scheme for a sort of encyclopedia wherein Jewish legal arguments inspired by the Talmud and the great decision-makers are mixed into long chapters about a variety of contemporary sciences. This Hebrew work belongs to the history of religious mentalities, specifically to the relationships between religion and modern European culture. 
It is worth quoting here, in its entirety, the dramatic incipit to Shiltey ha-Gibborym.

When God wanted to chasten me, I fell ill. Two years ago the whole left side of my body became as if dead and I could no longer touch my hand to my breast nor walk in the street, even leaning on a cane, because of the loss of feeling and the ability to move my limbs.

I searched my behavior and saw (after Him who sees all) that in addition to my sins, which were more numerous than the hairs on my head, the clamor of my neglecting the Torah had risen before the face of God. For I had dealings with the children of Greek wisdom, I sought to reach the heights through philosophy and medicine, which lured me with their honeyed words to seek salvation in the ways of darkness, and thus prevented me from devoting myself to the heritage of the community of Jacob, as I should have done.

This is why God was angered against me, dire maladies have darkened my days and defeated me; my nerves are ruined, my sighs do not cease, so that with the bitterness of my soul, sleep has left me and I cannot recover my strength. Happiness has fled and pain increased. So I raised my eyes upward and made repentance in my heart. I told myself that sin might be forgiven if, after repairing what he had damaged, the father were to teach his children that they would be victorious with God if they would put His Law in their hearts, meditate on it day and night and observe prudence and good counsel; by so doing they would be blessed.... ${ }^{11}$

The study — never tackled ${ }^{12}$ —o the relationship between the two phases of his creation shall provide us with interesting insights about the scientific and religious mind-frames of Italian Jews in the pre-Modern time. Beyond the psychological motivation that drew this prestigious Jewish doctor of Mantua to "conversion," we shall try to analyze what is left of the scientist in the work of the "repentant." In other words, we shall see whether the pietas of the old man careful to make up for the harm done in his youth completely erased the former experience. Or, more generally: what was the strategy, even an unconscious one, of this sudden and complete change? To what extent is the "return" (in Hebrew teshuvah, or repentance) just a conversion and not a complex variation in which the "old" is another form of the "new"? The comparison between the two books practically imposes itself, the first one being written in Latin, with a brilliant tone, and marked by an unapologetic 
rationalism, whereas the second one, in Hebrew, showing a deep religious attitude and including prayers and pious reflections.

\section{"Experience, guide of all natural knowledge"13}

An important aspect of the Latin dialogues on gold is the necessity for the doctor (considering the role of doctors at the time, we should instead say for scientists in general) to consider experience to be the only legitimate source of knowledge. This is why, according to the author, alchemists should be praised for their endless and repeated experiments with metals, but simultaneously, a clear distinction should be made between their practice and their ridiculous and "barbaric" theoretical premises. ${ }^{14}$

At the beginning of the first dialogue, Dynachrysus, the author's alter ego (a name referring to the "power" of gold), is visited by Achryvasmus (meaning, approximately, "without gold"). The latter is surprised by the peculiar attire of his friend: a tunic tied up with a few belts. Dynachrysus explains that this is the outfit of the alchemists, and it allows faster access to the "burning volcano," the oven where metals were melted.

Achryvasmus: Are you looking for the density of Mercury, the philosopher's stone, the adultery sun, would you like to face financial bankruptcy by exposing yourself to tremendous expenses to send to the moon-following the example of the alchemists - terrible howling and barking of all kinds, like a rabid dog? ${ }^{15}$

Dynachrysus firmly denies being affected by such irrationality. If he behaves like an alchemist, it is only in order to experiment: while pursuing different objectives, alchemists reach interesting results, important for the advancement of scientific knowledge. ${ }^{16}$ The venerable medical tradition of Hippocrates and Galen is certainly not to be rejected, but one should be open to innovation.

Dynachrysus: The same way a man would prepare himself for a duel without knowing the weapons he will be using, practicing with the usual tools as well as the less common ones, in order to protect life and repress his opponent's aggressiveness; the same way, I would like to be trained in the two kinds of therapeutics to make available, according to the different inclinations of men, dogmatic as well as empirical elements. ${ }^{17}$ 
This stance, clearly in favor of experience, and cautiously critical of the Greek-Arabic medical tradition, which had become "dogmatic," was not an innovation, since it was a growing trend in Italian universities at the time. ${ }^{18}$ Nevertheless, one must appreciate the clarity of Portaleone's position, which is sometimes expressed with an iconoclast tone: Dynachrysus almost plays around with his topic, and shocks his interlocutor by talking about such an authority as Pliny the Elder. One should dare contradict the great Pliny, he says, because

He assumed a lot of things that were still to be demonstrated. ${ }^{19}$

Dynachrysus also explains, in a peremptory manner, that the true dividing line between man and an animal deprived of reason is the ability to perform experiments. The extent of this statement is remarkable: man is defined by his ability to experiment, not to formulate abstract concepts - following the Aristotelian-Platonic philosophical tradition — nor by his ability to have a religion. His task consists of experiencing in order to know and knowing in order to transform (since the knowledge of doctors is supposed to be applied); thus, the author's ideal is not contemplative but pragmatic - a feature adapted to the social and economic context of Italy in the late sixteenth century, where pre-industrial activities of extraction and transformation were in full expansion.

Portaleone constantly repeats that experience is the only legitimate source of knowledge, and formulates this in a manner reminiscent, on another level, of Martin Luther's sola scriptura: even where reason is incapable of inferring the cause of a natural phenomenon, we can have a certain knowledge of it through experience, without other aids, experientia sola. ${ }^{20}$ The two interlocutors agree on this: "Experience [says Achryvasmus] is celebrated as a source of knowledge for all natural things. If you were to deny this, you would deserve not only to be reproached but also to be punished." 21

Can one find a similar experimental vision in the Hebrew work?

Shiltey ha-Gibborym was inspired precisely by the regret occasioned by spending too much time studying the "seductive words" of philosophy and medicine, the "children of the Greek scholars," neglecting Jacob's legacy. A careful analysis of the Hebrew book shows that this vision does not disappear: it is incorporated in a different conceptual pattern. Shiltey ha-Gibborym is paved with descriptions of contemporary reality, included under random 
pretexts over the course of the argument. One can find, for example, the depiction of a hypothetical Jewish society amid a discourse on the classes of people in charge of the cult of the Temple, which is, in fact, a sociological analysis of the urban reality of the Italy of his time. ${ }^{22}$ Portaleone sometimes describes in detail a technical process, such as the preparation of powder for military use, ${ }^{23}$ or of invisible ink meant to send messages to people trapped in cities under siege. ${ }^{24}$ At the same time, he develops here biblical notions, in this case that of Kohen meshuah milhamah, the priest mandated to military issues in the Bible. ${ }^{25}$

But the neutrality of the experimenter can also be found in the deep logic that justifies the writing of the book. The author, afflicted with disease, thinks that he was cursed for, among other matters, his intellectual efforts in "foreign" fields. He thinks that he may be forgiven if he teaches children, and this is why he prepares ma'amadoth, that is to say, anthologies of texts from the Bible and rabbinical literature that his children - and all the Jews who do not have time to devote themselves entirely to the study of the Bible-will be able to read from every day, thus accomplishing their duty to study. This reading shall be efficient in the sense that it shall allow them to accumulate merits for the after-life, even if it is performed without the proper intention. ${ }^{26}$ In support of his theory, Portaleone quotes a passage of the Zohar that, if read in a physical context, can be seen as the description of a mechanical experience in which a cause is linked to an effect: a scientific outlook is thus transposed to the religious realm. Not only study, Portaleone adds, but even the simple reading of certain psalms acquires a particular dimension, as the kabbalist Yosef Gikatilla (thirteenth and fourteenth centuries) points out in Sha 'arey Orah (Doors of Light): the psalms, called in Hebrew mizmorym, function as mazmeroth, billhooks that open the way to prayer and allow it to reach the "Residence of its Holiness.", 27

This attitude is expressed with strength in the midrash quoted over the course of the argument:

God made you aware that the Torah and the soul are compared to a lamp. Indeed, he writes about the soul: "The soul of man is a lamp of God"; and about the Torah: "Because the commandment is a lamp, and the Torah is a light. The holy man, may he be blessed, said to the man: "My lamp is in your hands, and your lamp is in my hands. If you keep mine, I keep yours; but if you turn my lamp off, I turn yours off [...]." ${ }^{28}$ 
The man acts on Godhead and provokes a reaction from Godhead. The midrash chooses to illustrate the conception of the rapport between man and God with the example of material order, showing well how the mechanical system is formally close to the experimental scientific system of cause and effect. Theurgy (the effects of human behavior on Godhead) reproduces the attitude of science: the first by intervening with God, the second by intervening with things.

\section{The Limits of Knowledge}

Portaleone's reflection, leaning towards a pragmatic rationalism, is free of scientific hubris. As he writes in the Latin dialogue, the knowledge man reaches by means of experience is far from exhaustive. The power of the elements, for instance, can be identified only by way of generalization, because the world is made of an almost unlimited number of things, whose qualities are infinite. That being said, the insurmountable boundaries of human knowledge cannot justify negligence, nor lack of intellectual rigor, nor sophism.

D. - [...] Reason [...] tries to match a cause with certain effects in order to predict why a certain element has an emollient power and another one has a stiffening one, why one is drying while the other one is astringent $[\ldots]$, but to solve a question, Reason only proceeds by way of generalization, as if it were holding on to a sacred anchor; it soon brings back the power of medication and its remarkable abilities to its specific form, or general substance.

A. - $\ldots$ and takes the ship in quite a frail haven, ${ }^{29}$ in a light shelter, because the exact substance of the element which produces these remarkable effects is perfectly known by God the very mighty: by Him only, the creator of the entire universe.

D. - And it is certain that since the things of the world are almost infinite, and also that their characteristics are infinite, man, who is mortal, deserves indulgence. One should, however, vigorously blame whoever among us ignores, out of negligence, what human intellect would be able to reach, or the one who ignores the truth for a misleading reason or a false distinction. ${ }^{30}$

A consequence of this declaration of scientific ethics underwritten with epistemological caution as well as intellectual voluntarism ${ }^{31}$ is the separation 
between the scientific and the religious spheres. The knowledge of the effects belongs to man (as does the hypothesis of the causes); the knowledge of the real causes belongs to God. The human realm is that of experience, the divine one that of mystery; the unproven notion of quintessence represents the hypothetical solution to which the human intellect resorts when it is incapable finding something out by merely observing phenomena. It is, therefore, a notion destined to remain void.

One shall also notice that the mention of God appears in Achryvasmus's lines, here and there, ${ }^{32}$ whereas Dynachrysus, the author's alter ego, restricts himself to an argument of the logical type: man, a finite and mortal being, cannot lay claim to a total and definite understanding of the elements and of their powers because this task would require infinite time. As for Dynachrysus's allusion to the "specific form," the author explains well, quoting Galen, that this form with "unknown characteristics" is nothing other than harmony, or proportion, between hot and cold, humid and dry; the entirety, that is, of a substance which cannot be easily divided into its constitutive elements. Thus, it is a perfectly natural situation, where the occult character of its quality depends only on our ignorance. Portaleone appears in these dialogues to be a rationalist who completely skips the religious dimension, placing it in the realm of the unknown and unknowable.

The dialogue De auro appears to be a scientific essay where the inadequacy of analytic techniques is considered a serious handicap in the development of knowledge. This explains the indulgence for alchemy that can help one - in spite of its declared aims - to better understand the nature of elements and their transformations.

The division between the scientific and the religious spheres disappears in the Shiltey ha-Gibborym, the book written after his religious turn: the project underlying this book is one that subordinates science to religion. Here the scientist, with a deep and modern encyclopedic knowledge, envisions secular science merely as ancilla of sacred science: the botanic and musical sciences are put to the service of better understanding the rites of the Temple of Jerusalem; a short alphabet lesson is useful to a proper reading of Greek words that appear in rabbinical literature; and the study of the punctuation of Latin texts can help one better grasp the te 'amym, the cantillation signs of the Torah, which makes for a better understanding of the sacred text. 
Portaleone's approach was indeed so unusual that one of the first contemporary researchers who dealt with his work put forth the hypothesis that the real aim of Shiltey ha-Gibborym was to transmit modern knowledge under the cover of pious intentions. ${ }^{33}$ The Counter-Reformation era was not the right time to extol the autonomy of science and religion. These were the years of the unhappy attempt of Galileo to seek a new kind of harmony between scientific discoveries and revealed religion, from here came the precautions taken by Portaleone who, to express his rational and "modern" knowledge, has to advance them in a disguised form, much as Descartes did later on. Portaleone's project, therefore, probably attempted to modernize Jewish culture by bringing in new content in a form that would be more palatable to the traditionalists. It is impossible, of course, to decide whether this interpretation is correct, or to settle this question with any certainty.

However, an example taken from the very first pages of the volume can give an idea of the author's complex procedure. One finds a description of punctuation inserted into the broadest description of the alphabets known at that time, a prelude that the author deemed necessary before plunging into the real work of scholarship. Speaking of the Latin alphabet, Portaleone states that there is no need to reproduce it typographically in order to describe it, as - he notes- "All the children of our people know it perfectly, in both its printed and its cursive versions."

But punctuation did need to be explained.

Portaleone teaches his readers the names, shapes, and functions of the main punctuation marks, that is, the comma, the colon, and the full stop, or period. He gives their names in Greek and Latin (carefully spelling them in Hebrew), and then in Italian. Then, to insure better understanding, he describes their function, taking as reference the te amym, the cantillation signs of traditional Bible reading. In the same spirit as we find in the Kuzary of Yehudah Ha-Levy, he seizes the opportunity to proclaim that the te amym were in existence prior to the Latin signs.

To make sure he will be correctly understood, he cites a long biblical verse (Deuteronomy 12:11) into which he inserts Latin punctuation marks. He supposes that the reader, familiar with the Masoretic text, will learn the Latin signs by associating them with the te amym.

This procedure is both complex and strange. It is unlikely that the readers for whom the Shiltey ha-Gibborym is intended were unaware of the existence and usage of these signs, as they had been in use in printing for several 
decades, particularly in Italy, and as the educated Italian Jews were perfectly familiar with the culture of the country. Portaleone writes here on two levels, one intentional and the other perhaps unintentional. He begins by reducing the basic elements of secular culture to Jewish culture. The te amym of the Torah, according to Jewish tradition, are revealed, just as its letters are.$^{34}$ But Portaleone slips over this subject; what interests him is not only the fact that the Hebrew signs preceded Latin punctuation but that they were the model for it, both logically and didactically. This first movement is typical of the fundamentalist attitude, in that it reduces external knowledge to traditional knowledge, thus neutralizing it. And Portaleone the penitent was-if we take him at his word - motivated by a fundamentalist piety.

However, at the same time - and this is the second line of thought — by applying these signs to a biblical verse he opens the possibility of a reading of the biblical text governed not by the rabia ' and atnah but by commas and periods. By bringing the secular into the sacred sphere, in an attempt to reduce the one to the other, he is in fact accomplishing a work of modernization. If we compare a verse in Portaleone's punctuated version with the same verse in volumes published in Protestant or Evangelical circles, for instance the one by Antonio Brucioli (published in Italian in 1532) and another by Pierre Robert Olivétan (published in French in 1535), we can judge the effective modernity of Portaleone's version, which is closer to our modern, usual standards. ${ }^{35}$

\section{The Silence of Ancient Books}

In the Latin dialogues, the constant call for experience and the refusal to blindly submit to authorities of the past corresponds to a vision of history in which the past does not hold a beautiful, mythical status. On the contrary, the time called the "golden age" 36 was in reality, according to the author, a time of misery, cruelty, and rebellion against God. It was called "golden" only because men lived for a long time, and gold, like them, is indestructible. ${ }^{37}$ Between Ovid and Horace, who celebrated the ideal virtues of this mythical time (or even Torquato Tasso, whose pastoral poem Aminta was performed the same years Portaleone wrote De auro), on the one hand and the epicurean Lucretius, who fought this image and opposed to it that of a savage humanity, physically strong but unfit to social life and ignorant of technical knowledge (De rerum natura, V, 925-1010), on the other, Portaleone clearly chooses the latter. 
The scientist distances himself from the available scientific legacy; the knowledge accumulated in the past cannot be used-it's a dead end. Portaleone expresses these difficulties in a suggestive staging, at the beginning of the third dialogue..$^{38}$

A. - What are you doing locked up in the library, O Dynachrysus, in such a way that you do not hear my loud knocking?

D. - I am calling the dead ones, I am begging them with special care.

A. - O dear friend, so you wish to lose your soul!

D. - God forbid!

A. - Let me in already, do not keep me any longer out in the open!

D. - Push the door, they shall open right away.

A. - Hello, my Dynachrysus. What a strange thing: it is the daytime, and on a chandelier, close to you, burns a candle.

D. - This is what the magicians, the sorcerers, the charmers and others do to ask the dead ones for the truth.

A. - Are you kidding, Dynachrysus, or are you talking seriously? And what kind of relationship do you have with the dead people?

D. - I was trying to know if those dead people could help me, a living one; but I am so unhappy and miserable, the living ones are the cause of so much trouble to me, and the dead ones do not seem to defend me in any way!

A. - But where are these dead people?

D. - What? Are you still held in sleep? Can't you see that this house is full of them?

A. - Oh, now I understand my foolishness! You were thinking about the books, and I thought that you were talking with the dead ones!

D. - Let the dead ones leave: there is not any relation between us.

The erudite knowledge of the past is useless for the progress of science; the library is a cemetery and the books cannot help with the problems ( $m o-$ lestia) of the present.

The library-cum-cemetery, dimly lit by a candle, corresponds in every way to the image formulated by other scientists of Portaleone's generation and the next. The Jesuit astronomer Giovan Battista Riccioli (1598-1671) criticized those who exercised their minds purely theoretically, "intra sua cubicula meditando" (in meditating in their little rooms). ${ }^{39}$ To represent this 
science of the past, Galileo, Francis Bacon, and Descartes proposed the same metaphor of an enclosed space where light never reaches, full of books which seem to offer protection from new things outside rather than constitute a source of knowledge. ${ }^{40}$

This is an attitude which returns twenty-five years later in Portaleone's second book, in an entirely different existential context and with its own very different rhetoric. A quotation from this second book immediately conveys the intervening change of tone. The author is still reserved concerning the authorities of the past, but gives his attitude a strong religious and national (i.e. Jewish) tone:

Understand and see that, just as one has to accept that precious stones and some animals possess - by God's decree - many virtues for avoiding man's illnesses and for preserving their health, for us it would be a fault, an impediment, an obstacle, a great sin to believe in everything these philosophers [i.e., non Jewish scientists] have to say on the subject; theirs are vain, false, and untrue words in which one must not have faith. One must attribute these effects to God alone, to Him alone belong the riches, the glory, the kingdom ... in heaven and on earth, only He has the power to make all grow and give it strength. We praise His Name always since he is God above all blessings.... He created the sky ... and all its armies, the Earth and everything on it, the oceans and all they contain. He gave life to us all ... and we are His people and the flock He leads ... and we prostrate ourselves before Him in fear. ${ }^{41}$

What is left, in the Shiltey ha-Gibborym, of "Latin" Portaleone's reservations toward past? The same general and harsh dismissal of past authorities could not be expressed in a work whose religious inspiration commanded respect for the masters of the past, namely for the rabbis of the Talmud, who were considered to be indisputable authorities. The scholars of the Talmud cannot be mistaken: such is the implicit rule of the work.

For example, Portaleone writes that some Greek words supposedly misspelled by the rabbis were actually distorted by typographers, implying a correct knowledge on the part of the rabbis. ${ }^{42}$ The description he gives of the forty alphabets known during his time is justified because it highlights the great knowledge of the members of the Sanhedrin, who had mastered the seventy languages of the world. 
His knowledge - about the composition of incense, for example - makes him sometimes refute not the undisputable rabbis of the Talmud, but the medieval rabbinical authorities: Portaleone is on these occasions quite embarrassed, and precedes his opinion with apologies for contradicting these great men of the past as well as with statements of humility taking up to a dozen lines. ${ }^{43}$

Another example of the difficulty of reconciling science and religion, this time not on the level of knowledge but on the level of practice, is in regard to the manufacture of oil for the anointment of the Priest. The long and detailed description of the manufacture of this oil can certainly not lead to a concrete execution, because:

we are exiled due to our sins, soiled with impurity from the contact of the dead people; and the impure person should not take care of this holy manufacture of herbs but rather should wait for the divine commandment to be in a condition of purity. And God, thanks to His great goodness and mercy, will make us come back to Him and what is written shall come true: "I will throw pure water on you, and you shall become pure." 4

But though it is forbidden to manufacture oil for the unction, the theoretical knowledge of its preparation cannot be censored, as "Our masters allowed us the simple study of all subjects," on the condition that forbidden practices are not performed. ${ }^{45}$ If this applies to permanent interdictions as well, the study of the holy rituals, which are only temporarily forbidden, should all the more be allowed.

A plant mentioned in the Bible is not identifiable through the description given by the rabbis of the Talmud, but as the assertions of these hakhamym cannot be denied, an answer that sounds like an escape clause, whose religious tone borders on unintentional irony, is provided. This answer is the result of the subscription to two belief systems that are a priori incompatible, and that Portaleone, twenty-eight years before and in a different context, had reconciled by pushing away the value of the auctoritates:

Neither I, ever since I have been studying medicine, nor my famous professors have seen the "squinante flower," or fragrant rush, with all the characteristics required [by the Talmud] [...]. Maybe God, for some reason, took the aforementioned squinante flower, the right one, which shall 
be missing until the coming of the Messiah; because then the angel put in charge of this flower by God shall plant it back (yakke oto) and say: "Grow healthy, with an excellent fragrance and an exquisite taste, like in the time of creation." ${ }^{* 46}$

Unconditional acceptation of Talmudic authorities; awkwardness when it comes to contradicting medieval authorities; unlimited open-mindedness to theoretical knowledge, even in the case of forbidden practices; great attention paid to data provided by experiences, which are a primary source of truth: such are the epistemological premises of the scientist Portaleone after his religious repentance. Their combination forms a peculiar work where empirical passion comes into contact with messianic impulses. ${ }^{47}$

As we said, Avraham Portaleone's description of the architecture of the Temple in Jerusalem and its ceremonies in ninety chapters is a preparation for the reading of the sacred texts which, conducted with the right kavvanah, will have an effect on God and consequently on the children of Israel.

Despite a certain mysticism in the introduction - the author declares his admiration for the kabbalists by acknowledging that he has not had the privilege of penetrating their secret garden ${ }^{48}$ - this description is absolutely realist in style, with one highly significant exception which I will discuss further on. Portaleone the scientist never wavers in his pious work, despite the affirmations in the introduction mentioned above. He is extremely clear and precise and concerned with verifying the coherence of his sources. When these seem in conflict with one another he embarks on lengthy discussions, which do not always achieve a satisfactory outcome, as he acknowledges. One should add that, despite expressing regret for his profane studies at the beginning of Shiltey ha-Gibborym, Portaleone does not seem to be denying the value of the experiments he carried out in his youth. He even refers the reader of the Hebrew book to De Auro for fuller information on his scientific opinions. One can therefore conclude that they have not changed; what has changed is the overall conception within which they are set. ${ }^{49}$

Naturally Portaleone's scathing criticism of the authorities of the past is obsolete in this context. On the contrary, we saw that he, as a repentant, sees the sages of the Mishnah and the Talmud as absolute, infallible authorities, and when perceptible experience contradicts their affirmations (we are in the thick of Galileo's problematic here), he resorts to strange balancing acts to 
justify two truths - one addressing the man of religion, the other the scientist. Nevertheless, instead of looking forward with the optimism of the explorer, here Portaleone looks back, following the typical schema of the traditionalist Jew for whom all has already been said and generations to come have only to organize the knowledge that is progressively forgotten.

\section{"My quill is clouded by terrible darkness"}

In the Latin Dialogues, Portaleone puts a humility statement in Dynachrysus' mouth:

A. - [...] Why did you leave out in your writings several praiseworthy things?

D. - Lack of time and an arduous topic mutilated the text. I left to other scholars and erudite men the opportunity to reach, with elegance and subtlety, a deeper understanding of the nature of things. $\mathrm{O}$, what kinds of wonderful elegance are they adorned with, what sort of ability to philosophize are they enlightened with! Their doctrine has a superior degree of perfection and shines everywhere: its nature is visible, equally in the absence and presence of the sun; whereas my quill is clouded by a terrible darkness that brings out the brightness of this very science. ${ }^{50}$

This statement of humility in the De auro about the author's poor writing is nothing other than a figure of speech with a reverse function. It is, actually, asking the reader to give him credit for his excellent stylistic work. Dynachrysus claims to be inferior to the knowledgeable and elegant writers, who are able to reach the depth of things, but his statement can be read as an underlying criticism of subtle and sophist rhetoricians, who are the opposite of scientists who wants to make things (and not mere ideas) talk.

The phrase "lack of time and an arduous topic" is obviously an excerpt from Maimonides' Guide of the Perplexed (I:34). ${ }^{51}$ The dialogues De auro have a very high degree of intertextuality, since they are sprinkled with numerous references to Latin and also, unusually, Jewish literature which can only be brought to light by a detailed analysis.

The intertextuality was a rhetorical game aiming at showing the readers the extent of the author's knowledge; it is a sort of implicit, reciprocal acknowledgement between scholars who shared the same intellectual training. 
Sometimes, especially for comments on a moral aspect, references are made explicit by a character who sends the reader back to the source, usually Plato or Aristotle. Such sources should not be ignored by the reader, as the author sometimes uses them in order to "expand" his text implicitly. The rest of the quoted passage demonstrates this usage. The author develops, through a simile, the motif of his poor style that would, by contrast, bring out the excellence of the other authors:

D. : [...] My quill is clouded by a terrible darkness that brings out immensely the brightness of this science: the same way in a group of white doves, the blackness of the bird of satire [a black swan] $]^{52}$ brings out their beauty and their elegance; something the fairness of a swan could not do.

Achryvasmus praises the comparison, and adds that it is from Boccaccio's Decameron. The diligent reader who follows the hint finds a short story (day IX, story X) too obscene to be narrated in its entirety in a sixteenthcentury scientific study, and even more inappropriate in a twenty-first-century essay. ${ }^{53}$ What is the reason for this quotation, and why did the author put the reader on its track by indirectly inviting them to read the source? This short story deals with an attempt at a special kind of transformation involving sexual desire; its actors are a monk, a poor merchant, and his young wife. Maybe Portaleone wanted to mock the transformations attempted by the alchemists, their pipe dreams supported by desire; and he did so in an indirect and playful manner. Furthermore, when one considers that the quick and apparently innocent reference to Juvenal's satire (Portaleone writes of the "bird of satire" rather than the "black crow" mentioned by Boccaccio's text) refers indeed to this "rare bird" of a woman who is beautiful, with a good figure, rich, "fertile," and even "chaste"-in short, an exceptional being - one shall see the full extent of "Latin" Portaleone's textual implications. The black swan who replaces, in Dynachrysus's simile, Boccaccio's crow reminds the informed reader that the author's humility is a mere rhetorical statement.

Irony and allusion are indeed amongst the most prominent features of the dialogues on gold. Portaleone leaves it to the reader to process his synthetic statements, which are sometimes on more serious matters. An example is at the end of the second dialogue: Dynachrysus, who already denied the 
medicinal virtues of gold, is being ironic about its true powers, connected with wealth: gold is indeed "able to reinforce a weak heart, to treat melancholia and give life back, it favors pleasures and good deeds," and the like. In another example, Dynachrisus is quick to criticize the morally and socially harmful effects of gold, which changes life into death, and, on the other hand, he glorifies the "almost divine" moral virtue. Achryvasmus, who, in contrast, has a weak spot for material gold, accuses him of talking like Dionysodorus, the sophist, and treats him like Ctesippus, the victim of deceitful reasoning. However, Dynachrysus, who very soberly identified himself a few lines earlier as a Jew, invites him to reread Plato's dialogue Euthydemus, where these two characters interact: he will find there the clearest condemnation of the deception of material gold.

In this short passage, Portaleone indirectly developed an apologetics for Jews on the moral and cultural level. He does so, remarkably, using elements of Greek philosophical literature. The fact that the Jewish character glorifies morality and severely condemns the effects of gold, at the time Shylock was being written, seems to be a defense and a counter-attack. Dynachrysus in this sequence had actually just pointed out the absence of gold in the clothes of the High Priest when he enters into the main area of the Jewish ritual, the Holy of Holies.

The author also uses the reference to Euthydemus in order to reverse the accusation of "sophism." Dynachrysus strongly reacts to the accusation of being a sophist, and in turn accuses Achryvasmus of falling precisely for the bad judgment stigmatized by Plato. One can sense in this exchange the implicit defense of the Talmud, the book that is in the eyes of Christians characterized by its content and seemingly deceitful (thus, "sophist") reasoning.

It is difficult to overemphasize the liveliness of these dialogues: they are, taken as a whole, not just a scientific dispute but a true literary work, full of digressions and amusing statements, with the two characters (one of them acting as the alter ego of Portaleone himself) exchanging learned and sometimes witty remarks, in many cases winking at the reader and implicitly inviting him to finish their sentences.

Sometimes (as in the third dialogue, p. 105), the literary play goes as far as mixing classical Greek sources for amusing purposes; this is the case of the tale of Aesculapius's death, where Pindarus's and Plato's texts are used to compose a new story so as to inject a little humor into a long and tiring 
scientific discussion. In this instance, the play culminates in a biblical quotation (from 2 Kings 7:15), whose meaning is also distorted.

Dynachrisus: You must know, dear Achryvasmus, that this joke does not make me less good than the harmony of music made the prophet Elisha, when he says in the book of Kings "'Nunc autem adducite mihi Psaltem,' cumque caneret Psaltes, facta est super eum manus Domini," (Portaleone quotes from the Vulgate version; the line reads, according to the King James version, “'But now bring me a minstrel.' And it came to pass, when the minstrel played, that the hand of the Lord came upon him.")

"The hand of the Lord"- meaning a state of mind which enables prophecy-resting on Elisha when he hears music playing is compared to the pleasure of a joke after an intellectual effort. We are not far from a smiling blasphemy (which would not have been scandalous at all in the Jewish culture of that time, if occurring in a comic context, either poetic or narrative); an admissible explanation is that behind this remark there is Maimonides's theory of prophecy, which is that it is possible only if the recipient of revelation is good-humored. ${ }^{54}$

The brightness, irony, and subtlety of the allusions present in the three dialogues on gold are completely absent from the Shiltey ha-Gibborym. Here, the main figures of speech are apostrophe - to his children and to the reader, so they fulfill the precepts included in the reading and avoid forbidden activities - invocation - to God, so that he restores Israel in its glory-, and statements of humility - willfully sincere as opposed to rhetorical.

Just like his Latin book, wherein the classical body of work was used as a pool of words and phrases, the Shiltey ha-Gibborym is interwoven with biblical and rabbinical quotations. Still, the language in this work is nimble, Portaleone manages to explain scientific discourses in Hebrew with great ease. This obviously is the expression of a "fundamentalist" project, according to which all kinds of information and secular disciplines were essential to religious knowledge and acts: let us remember that Shiltey ha-Gibborym is not an explicit general encyclopedia but a description of the Temple of Jerusalem, for which scientific knowledge is necessary. At the same time, it serves as an amazing defense for Jews' access to modernity. This defense is of course formulated in an indirect way and not ostentatiously, being justified by the quasi-mystical necessity for modern Jews to identify with the Jews 
of the Temple, and it contains a strong sense of a national and distinctive identity.

Avraham Portaleone was not a rabbi; the role of spiritual and intellectual teacher he would take on was a late personal choice, without any institutional investiture. In that respect, one would say he was an outsider, but as such he could probably allow himself certain liberties that would have been unthinkable for a rabbi. On the other hand, he was a physician, and being a physician at this time meant having an extensive knowledge not only of medical science, but also of the literary and philosophical corpus that nourished the intelligentsia of the time - a knowledge that basically defined the European intellectual. As a doctor, and consequently a lettered man, Portaleone was in the ideal place to serve as a mediator between the Jewish and Christian cultures, performing a mediation that was not accomplished through theology (there is no theological reference in Portaleone's work), but through literature, philosophy, and science.

As a pedagogical project meant for Jews, Portaleone's mediation was not followed upon; still, it gets credit for ignoring the traditional demarcations and dealing with rabbinical literature and with science, both ancient and modern. ${ }^{55}$ Portaleone also reached two results he probably did not aim for.

The first of these is that he created a Hebraic, scientific prose, clear and synthetic, distinct from the Hebrew used by contemporary rabbis, which was full of technical, talmudic, and juridical expressions.

Portaleone's work in a number of disciplines thus anticipated what Yosef Shelomo Delmedigo would achieve later by using a scientific style which was at once clear and precise, far from what Delmedigo called the "awkward phraseology" of Arabic philosophical traditions, the "language of rabbinical texts, which makes one's ears tingle and often resorts to Aramaic," and the "flowery and untranslatable rhetoric of the Bible." 56

Over the longer term, Portaleone was in the lineage of authors such as Yehudah ben Yehiyel, "Messer Leon." Already in 1475 this prestigious scholar invited Jewish intellectuals to "return" the "lost sciences," especially rhetoric, which led him to give a stylistic reading of the Bible, to the Nations; in other words, he suggested a literary approach to the sacred text, bracketing off its religious value. ${ }^{57}$ A comparison between Portaleone's style and the style of his older fellow citizen Azariyah de' Rossi (in his Meor 'eynayim) would stress how Portaleone succeeded in freeing himself from the difficult prose of Italian rabbinic literature in the Renaissance. In this sense, he was 
modern. It is also important to consider the number of neologisms he invented to translate into Hebrew words taken from the world of realia or from the scientific lexicon.

The second result is that the "classical" rabbinical culture gains - through his work-dynamism, relevance, and legitimacy, thanks to its insertion in the context of European culture. Indeed, quite ironically, the "repentant" Portaleone will become famous mainly as the author of volumes of Antiquitates hebraicae, and with Christian scholars much more than with Jewish ones.

\section{"To see with the eyes of imagination": The Jesuitic Model of Portaleone}

Portaleone's method in Shiltey ha-Gibborym calls for a comparative analysis, which ends in interesting, even surprising results, especially if we take into account the fact that this work is centred on Jewish culture, which is considered as a whole preserved from external influences. One remarkable example is the use of the notion of kawwanah, "intention" or "direction," which enjoyed an important diffusion in the lurianic kabbalah, and that Portaleone applies to the complex psychological operations linked to the representation of the Temple.

Portaleone reminds his reader that for the Jews, after the destruction of the Temple of Jerusalem prayer was substituted for sacrifice. Reading the biblical passages concerning the sacrifices, as well as their rabbinical interpretations, reinforces this substitution: it is as if one had really offered the sacrifice. Therefore, continues Portaleone, in order to have clearly in mind the situation of the worshiper offering the sacrifice, to have the necessary kawwanah, you must be able to imagine the concrete scene in which the rite took place.

Portaleone puts great emphasis on this aspect, writing, for example (f. 3b):

And now, in order that you may be able to direct (lekhawwen) your entire being to heaven while you are in your House of Prayer, as if (keillu) you were in that other great and holy House [the Temple] [...] I will copy for you $[\ldots$.

There are many passages of this sort in the Shiltey ha-Gibborym. The author insists on the need to reproduce a situation of the past mentally, 
through the imagination, so that the religious acts of the present should have the same effect as those of the past. The expressions that recur are: "You must imagine being there [in the Temple]" and "It will be in our eyes just as if you were there, presenting your offerings." This mental recreation of a disappeared situation is more than symbolic: it can be called mystical, because in order to address God in an effective way, according to Portaleone, one has to transport one's self to a determined time and space. Once the worshipper is there, his words will be able to transform reality (including Godhead).

How ought one to encourage this psychological transfer; how to flesh out, as it were, one's memory? By describing the situation, in this case the Temple, in all its concrete reality. And indeed it is the description of the Temple which makes up the first part of the book that will render the second part more effective. Only through visualizing the scene will one be able to read with the right kawwanah and to identify more completely with the worshiper in the Jerusalem of the past.

This multiple chain (prayers replace religious actions and sacrifices, study or reading replaces prayer, and study necessitates a description of the place of sacrifice) makes it possible for Portaleone to look at the past in a realistic manner. He undertakes the task of describing the Temple as it really was, setting aside all allegorical significance: one might say the mystical need to identify with the worshipper of the past leads one to see that past in a historical light. If in order to "be there" one needs to render the past present, then one must first reconstruct it faithfully.

To this end, Portaleone mobilizes his remarkable knowledge of science, history, and philology to reconstitute the Temple and its site as they actually were. In doing so, as we saw, he composes a series of treatises typical of the scholarship of his time, speaking of music when he describes the songs of the Levites, of botany when he comes to the offerings of incense, and so on. In his treatment of these subjects, Portaleone juxtaposes traditional Jewish science - from the Talmud through Maimonides to his contemporary commentators - and modern science, including a great many references to ancient science, Greek, Latin, and Arabic. We will return later on to this idea of inserting modern content with a religious aim.

It is interesting to note, before proceeding with this analysis, that Portaleone's approach, that is, the approach of recreating the scene of a religious event of the past so that the religious practice of the present should be 
well-oriented (have the right kawwanah), closely resembles that of the spiritual exercises of Ignatius Loyola (1491-1556), the founder of the Jesuit Order, which were first published in Rome in 1548. I will cite as an example the preamble to Loyola's first exercise:

The First Prelude is a composition, seeing the place. Here it is to be noted that, in a visible contemplation or meditation — such as, for instance, when one contemplates Christ our Lord, Who is visible - the composition will be intended to show with the sight of the imagination the corporeal place where the thing which I want to contemplate is found. I say the corporeal place, as for instance, a Temple or Mountain where Jesus Christ or Our Lady is found, according to what I want to contemplate.

Speaking of these exercises, Roland Barthes uses the term "transferential relation." The expression "to see with the eyes of imagination," which occurs repeatedly in the preambles of the spiritual exercises, is identical in meaning to the expressions used by Portaleone. We can note that the second part of the Spiritual Exercises consists of a collection of quotations from the Gospels, following the life of Christ from the Annunciation to the Ascension: these are known as the Mysteries of the Life of Christ our Lord. It is very tempting to see a parallel between this second part of the Spiritual Exercises and the Shiltey ha-Gibborym.

\section{Experimental Science and Rabbinic Tradition: The Distortion of Historical Time}

We saw that Shiltey ha-Gibborym is a work based on experience, like the Latin Dialogi, and its declared aim is to describe the Temple of Jerusalem as it was, avoiding any recourse to symbols or allegories.

But there is one remarkable exception to the author's realism; it concerns his perception of historical time. One should add that Shiltey ha-Gibborym is not a straightforward description of the Temple in the manner of traditional Jewish texts (essentially the Mishnah with Bertinoro's commentary and the relevant chapters of Maimonides' Mishneh Torah): rather, whenever the opportunity arises the author adds little essays in various disciplines. Together the essays comprise a kind of encyclopedia, for which the description of the Temple, like a Theatrum memoriae, acts as a supporting structure. ${ }^{58}$ 
Let us give an example. Discussing the music and songs of the Levites, Portaleone resolutely denies that that theirs was simple, primitive music and describes in minute detail the shir mahshavty (which could be translated as "artistic song") of his time with evident admiration. Remember that he lived in Mantua, then one of Europe's musical capitals. Contemporary music, which was highly elaborate, was for him the music of the Temple, and he makes this explicit by using the expression "like today" in statements like, "They played and sang the psalms of David son of Yshay with many kinds of instrumental and vocal music, basing this on books, like today. ${ }^{59}$

This foreshortening of present and past, which naturally meets the wellknown exigency of the Jews to appropriate contemporary knowledge which was elaborated by others and which they consider remarkable by claiming its paternity, must be put in parallel to the spiritual displacement into the past recommended for the pious Jew. These anachronisms - there are many in the work - indicate an acute perception of historic time rather than great naïvete. It is as if the man who twenty-five years earlier had taken a clear stance in a scientific quarrel between ancient people and modern ones now found himself in the uncomfortable position of wanting to glorify the Jewish past while recognizing the greatness of contemporary culture, which was non-Jewish in origin. He beholds two privileged eras, that of the Judaism of the First and Second Temple and the contemporary age, out of which he fashions an imperfect synthesis bespeaking a tension that is difficult to resolve.

We have evoked Portaleone's methodological probity in this work full of religious piety. One would have expected at least a selective choice of sources excluding everything non-Jewish, in conformity with his admission of having sinned by allowing himself to be fascinated by "foreign" sciences, but this was not in fact the case. True, he proposes the above-mentioned model of "Israel mother of all sciences" (including the art of war, which suggests a frustration vis-à-vis the affairs of the real world and alludes to the still-embryonic notion of Israel as a "normal" nation among others), and he attributes infallibility to the rabbis of the Talmud, which can lead a reader to define him as a "fundamentalist." But elsewhere, he cites a great many non-Jewish sources, past and present, and openly declares this; better, at the end of his introduction, when he gives a list of 196 Jewish and non-Jewish authors and books, he assigns to the ensemble, as a mnemonic verse: "As for me, I will behold thy face in righteousness ("be-tzedeq," 196): I shall be satisfied, when I awake, with thy likeness (Psalms XVII, 15)." ${ }^{\circ 0}$ In other 
words, by subtle allusion, Portaleone links the contemplation of the face of God or, from his perspective, the obtaining of truth, to the use of all sources, Jewish and non-Jewish, which together form righteousness, a human and religious value. He makes a point of indicating that none of these authors of the Nations took up a position against the Torah; and one should add that they were scientists, not theologians, which suggests the idea of the establishment of a neutral ground, that of science, on which the pious Jew can move freely and without danger.

Not only does Portaleone not renounce non-Jewish scientific contributions, he does not abstain from using numerous languages, indispensable for the mastery of his rich bibliography. Above all, he manifests his appreciation, even love, for the Greek language. He justifies its constant use in his book by the use the sages of the Talmud made of it, which requires that one establishes its correct spelling, given the mistakes made by typographersfor the rabbis, remember, never made mistakes. This justification smacks of dissimulation, and the following passage bears this out.

In chapter thirty-five, Portaleone describes the three chests in the Temple in which worshippers left money for sacrifices. In the mishnah to which he refers (Shekalym, chapter 3), it is written that the letters aleph, beth, and gimel or, according to another authority, the Greek letters alpha, beta, and gamma were inscribed on the chests. Portaleone unhesitatingly accepts the second hypothesis and cites Bertinoro: "It is written that (Genesis IX:27): God shall enlarge Japheth, and he shall dwell in the tents of Shem, [implying that] the beauty of Japheth may dwell in the tents of Shem. But, for Japeth, nothing is more beautiful than the Greek language." (In Bertinoro's text, this reads, "For Japheth, there is no more beautiful language than Greek.") ${ }^{61}$ By citing the Jewish authorities, Portaleone is surreptitiously expressing an opinion on the Greek language - evidently the famous and controversial Azariyah de' Rossi, although never mentioned, had not written in vain. It is, moreover, almost certainly to de' Rossi's Meor 'Einayym (Part 3, chapter 4) that Portaleone is referring in the rest of the passage, in which, by developing Bertinoro's commentary, he explains that the Jews during the Second Temple period were better versed in Greek than in Hebrew. The development consists of taking Philo, the Jewish philosopher from Alexandria, as an example of poor knowledge of Hebrew. He calls him Yedidiyah, the Hebrew version of Philo according to de' Rossi, and some of the lines he writes about him are identical to those in the Meor 'Einayim. This work, considered one 
of the first examples of modern Jewish erudition, which Italian rabbis were far from unanimously agreeing with, has, in certain respects, an unexpected continuation in the Shiltey ha-Gibborym. ${ }^{62}$

Let us now examine another striking example of Avraham Portaleone's oscillation between modernity and tradition, his discourses on the properties of precious stones in De Auro and Shiltey ha-Gibborym. In both works, the author discusses the subject at length. In De Auro, he does so by inserting it into a broader examination of the classification of beings as animal or mineral. His conclusions are categorical: metals and stones are inanimate beings, since their growth process does not depend on any kind of nutrition or process one could call "organic" (and which he calls "intrinsic") but on a juxtaposition of parts:

Dynachrisus: Note, Achryvasmus, that when one says that stones feed and grow one uses an inappropriate expression (aequivoce nutriuntur, \& aequivoce augmentatur). Indeed, they do not increase in volume for an internal but for an external reason, and grow through the juxtaposition of parts, which should not be considered as true nutrition or autonomous growth (propria auctio) but rather as an addition. This is why we affirm that these mixed bodies are totally lacking in soul. ${ }^{63}$

In Shiltey ha-Gibborym, the discussion of precious stones is introduced via the description of the breastplate of the High Priest, which was adorned with twelve precious stones. As usual in this work, the description of a ritual garment is transformed into a veritable little treatise in which Portaleone displays his scientific knowledge. The phenomenon of the growth of stones is discussed here by bringing to the fore its quasi-miraculous aspect, without bothering to give general definitions. When he writes about the diamond, Portaleone cites the mineralogist Francesco Roheo's account of the phenomenon of diamonds occasionally, over time, giving birth to other, identical diamonds, ${ }^{64}$ an observation which he does not doubt but explains by natural laws: "If one wanted to understand this using natural laws, one could say that the celestial energy that God gave them and which enables them to produce similar diamonds is first transformed by the pure air around it into water, which solidifies and becomes ice. Then, thanks to the energy inherent in precious stones, the water changes into diamonds." He continues in this vein, citing Theophrastus and Pliny, who respectively talk of precious stones 
"giving birth" using the divine energy animating them, and of the "pregnancy" of another stone lasting three months. ${ }^{65}$

This un-critical acceptance of quasi-miraculous phenomena related by others clashes with the empirical attitude to which Portaleone has accustomed us, especially as it contrasts completely with the very clear position set out in De Auro. But in the cases already examined, the difference between the two works lies in their general frames of reference, scientific in one, religious in the other, not in the recourse to experience and observation as the true sources of truth.

To understand this discrepancy, one has to return to the general examination of the virtues of precious stones in De Auro. Having discussed the curative properties of certain fossils and several animals - about which his interlocutor is skeptical-Dynachrisus enumerates the qualities of precious stones. The almandine garnet protects one from or heals one from all poisons, renders its wearer invincible in battle, and enables one to interpret dreams; beryl wards off arguments and danger from enemies and makes one calm and sincere; jasper stops the menstrual cycle, wards off lust, and heals fever and dropsy, and so on. True, Dynachrisus does take pains to attribute these opinions to other authors (dixit ... fertur ... asseverant ... affirmant), but at the same time he readily sings the praises of the stones, whose transparency and luminosity enable them to receive their particular properties, which he likens to various parts of the heavens. ${ }^{66}$

In the Hebrew work, the lengthy description of the qualities of precious stones follows a philological and scientific analysis of the identification of the stones on the breastplate of the High Priest, attempting to put some order into the multiplicity of often erroneous identifications suggested by traditional Jewish exegetes. Here the Hebrew book is more "scientific" than the Latin one. But immediately after Portaleone inserts a rather strange passage:

Some of my masters, having read these pages, were dissatisfied when they noticed I had not discussed the essences of precious stones on the mantelet and breastplate [of the High Priest]. Numerous authorities vigorously requested, ordered me to do everything in my power to seek these essences so as to consign them to my book, in which case they would have been satisfied. But, for me, this is very difficult, particularly because the great [non-Jewish] scientists of the past never agree. 
But I did my utmost, I hastened to find pertinent answers through the light of my reason ... by trying to attain good results through well-conducted reasoning, and I wrote them in conformity with the orders of many great sages.

If I have said true things, I thank God for his bounty in opening my eyes to the way: from his mouth comes knowledge and intelligence. I may not have attained complete knowledge of their essences and qualities, in which case those who have confidence in me should not blame me, as I must write only what my eyes have seen, in a just, correct, and true way (be-tzedeq). ${ }^{67}$

It seems clear from these lines that Portaleone had come under pressure from rabbis to include edifying notions regarding a religious subject such as the High Priest's clothing, and not to limit himself to the work of the scientist or philologist. This the Mantuan doctor duly did, imbuing the precious stones adorning the sacerdotal vestments with manifold properties, finding correspondences between the twelve stones and the twelve tribes of Israel, ${ }^{68}$ and identifying fanciful etymological links between Hebrew and Italian words. In one instance, he even creates an interpretation from a gematria, i.e. a correspondence between the equal numerical value of two different Hebrew words - a method which has nothing to do with science.

In short, in the many pages he devotes to precious stones, the scientist is eclipsed by the preacher. But he does from time to time recall the "sin" of those who deny perceptible experience, ${ }^{69}$ and concludes his peculiar mineralogical treatise by insisting on the primacy of "plain experience" (nisayon pashut) over theoretical study, adding, "Without experience, the doctor would have no superiority over other men," ${ }^{\prime \prime 0}$ which seems to be a warning to the reader about the profound convictions which rabbinic pressure has forced him to depart from.

Complex, strange, and fascinating, the Shiltey ha-Gibborym can be read as an attempt to give Jews a concise handbook of general culture, written in Hebrew and keeping Talmudic knowledge as its basis of reference. ${ }^{71}$ But one should not forget that this text is above all a description of the Temple, even if modern researchers are understandably attracted by its divergences, discrepancies, disparities, deviations, and originality, above all in its reference to non-Jewish knowledge. In order to evaluate its characteristics, 
a systematic examination of this description in comparison to the sources must be undertaken. An initial analysis yields the following results:

1. Shiltey ha-Gibborym is more synthetic than its sources, to which the reader is sometimes referred. It is also more systematic (or follows another system), since it brings together subjects which in the sources are scattered in different parts.

2. It is interested in the halakha only when it gives details of the Temple's realia. The book aims to be a historic reconstruction, not a book of laws.

3. In places, we are dealing with a veritable exegesis in the traditional sense. In particular, one finds explanations of the Mishnah, in which Portaleone develops hypotheses rendered necessary by the impossibility of consulting the Talmud, which was forbidden at the time, or he adopts a position among ancient and modern commentators whose opinions differ.

4. The author sometimes enlarges on his sources when he thinks that his scientific experience and readings can help one develop a better understanding of the subject. In so doing he produces a kind of "scientific midrash." This amplificatio can develop into a full-blown fictional account in which the author imagines scenes which could have taken place in the Temple, complete with dialogues and oratories. This is the case in chapters 18-21, in which he stages a conflict between priests, Levites, and Israelites, or in chapters 41-2, with the speech of the priest in charge of war.

In the works of Avraham Portaleone, one recognizes the intellectual tensions of his time: the great broadening of the horizons of knowledge, the manifestation of both a scientific vision of reality and great religious devotion, a change in the perception of space and, for the Italian Jews in particular, an oscillation between openness and closure to the non-Jewish world, together with a shift toward an increased use of Latin and then Italian as a written language (Shiltey ha-Gibborym contains many Italian terms, which are used to better explain the subject to the reader). This work, with its reversals and difficulties, is part of what one could call the movement of Italian Jewish culture towards modernity, or the Jewish declension of a movement throughout European culture. 


\section{The Latin Destiny of a Fundamentalist Jewish Work}

It was not surprising that a book of this kind was not successful at all among Jewish readers. In spite of its religious, even mystical, inspiration, and its repeated statements that the true science was authentically Jewish, Shiltey ha-Gibborym was still too open to the external intellectual world to be accepted in a period of growing hardening on both the Jewish and the Christian sides. As far as I can tell, only Yosef Shelomo Delmedigo, one of the rare outstanding Jewish scientists of the seventeenth century, recommended reading it (in his ambiguous book Matzref la-hokhmah, Purification of Science, printed in Basel in 1629). Hanukath ha-bayith (The Inauguration of the House), a later description of the Temple by Mosheh ben Gershom Hefetz, published in Venice in 1696, almost ignores Portaleone's book, and makes reference to Jewish sources alone.

A hundred and fifty years after its first appearance, however, Shiltey ha-Gibborym found a new life. This time, it was in a Latin version, totally stripped of its religious frame, as a learned and authoritative - maybe the most authoritative - textbook of "Jewish antiquities" on the subject of the Temple of Jerusalem.

Large sections of Portaleone's book were translated in Latin by the Venetian scholar Biagio Ugolini (1702-1775), who included them in his monumental Thesaurus antiquitatum sacrarum, a series of 34 volumes in folio devoted to the research on Antiquitates judaicae. ${ }^{72}$ Ugolini wrote some chapters of the Thesaurus himself, but for the most part he included both classical Jewish texts he had translated for the first time (thus pioneering in the field) and Latin works by Christian authors. Portaleone is the only relatively modern Jewish author within the compilation, and wherever his contributions are inserted, they occupy a privileged place. The first thirty-six chapters of Shiltey ha-Gibborym - now referred to as Clypei fortium - by "Abraham e Porta Leonis Mutinensis" open the ninth volume of the series (Venice: 1748): "Commentarius de Templo Hierosolomytano ex R. Abrahami ben David Scilte Haggiborim excerptus maximam huius Voluminis partem amplectetur, in quo tanta sese ubique offert rerum praestantia et eruditio, ut merito ceteris, qui hoc argumentum illustarunt, preferendus esse videatur."

The homage paid to the Jewish author is evident; never, except once, does Ugolini interfere with his text, thus recognizing Portaleone's broad and 
unbiased culture. Bear in mind that recognizing a Jewish source as an authority was not common, even in the eighteenth century. That is made clear by the introduction for one of the volumes (volume XI, published in Venice in 1750), in which Ugolini feels the need to add:

I think I should not neglect to mention here the criticism of those who remark that most of my explanations of the sacred philology are taken from very ancient Jewish sources; [by this criticism] they seem to accuse and denounce those who deduce the Greek things from Greek sources, and the Roman matters from Roman texts. I invite these people to show me the way to get to Judaea - which until now has been inaccessible to people not accompanied by those [ancient Jewish] escorts - and to explore it more easily.

Avraham Portaleone's book had been already noticed by another important historian of Jewish antiquities, Johannes Opitius, who mentions him as an "egregium opus" in his Disquisitio Historico-Philologica de Candelabri Mosaici Admirabili Structura, published in Jena in $1708 .{ }^{73}$ However, with the translation by Ugolini, the book finds a place in the library of every learned Christian interested in Philologia sacra, even if its new destiny probably does not correspond to the true original intentions of the Jewish author. In any case, a quick reading of some passages of this translation shows a perfect adherence to the Hebrew text and, at the same time, a fluent and elegant Latin. This is certainly due to the talent of Biagio Ugolini, whose knowledge of Hebrew was so good that some modern researchers wrongly believed him to be a converted Jew. Or, perhaps, some of the reason for such a good Latin translation lies in the original Hebrew text itself.

Portaleone, as we have said, was a brilliant Latin author before being a Hebrew one. In his Hebrew book he almost creates a scientific Hebrew style, which is clear, precise, and simple, without being simplistic; it is extremely different in style from the Hebrew of Azariyah de' Rossi, as we noticed before. De' Rossi, who wrote thirty years before Portaleone on similar matters, was striving for a Hebrew style that would allow him to deal with subjects new to the Jewish tradition: his sentences are long, complicated, full of biblical and rabbinic quotations, and definitely hard for a modern reader. 
We suggest that Portaleone's Hebrew was innovative because it had implicit Latin structures underneath; these structures were indeed modern-as they are in the Dialogues on Gold, and thus suitable for a scientific language; they were most probably influenced by contemporary Italian, even though both Latin and Hebrew peculiarities are entirely respected. This explains the liveliness of his Latin dialogues and the clarity of his Hebrew treaty.

In a sort of circle, the literary work of the Jew Portaleone started in Latin, and ended in Latin. The language of modern science found its way into Hebrew, and eventually expressed itself on a neutral ground, common to Christians and Jews. 


\section{3 \\ Allegorical Space and Geometrical Space: Representations of the Temple of Jerusalem in the Works of Italian Jewish Authors}

The reservations expressed in the Bible and reinforced in Jewish normative literature concerning divine representation have significantly limited the production of images in the Jewish world. ${ }^{1}$ In practice, this position was backed up by Jewish religious behavior and intellectual productions until the so-called "modern" era: whether at a popular or scholarly level, images were not an instrument of knowledge for the Jews, and visual allegories in particular had no place whatsoever in Judaism, despite being a privileged means of expression in other cultures. Although Jewish culture definitely had allegories, these took the form of written texts, rather than images. Moreover, a second restriction was added to this important limitation: even on an exclusively literary level, allegories were seldom based on human representation.

It was the Temple of Jerusalem which was to become a catalyst for allegorical representation, having always played a central role in both Jewish thought and the Jewish imaginary. For this reason, the changes its representation underwent over the course of time make it possible to track the evolution of Jewish perceptions and representations of space.

To the Temple of Jerusalem - or "Temples" of Jerusalem, rather-one should add the Tabernacle, which was erected in the desert under divine guidance and prefigured the Temple. The first Temple was erected by King Solomon and destroyed by the Babylonian king Nebuchadnezzar in $587 \mathrm{BCE}$; the second was built by Zerubbavel on his return from exile and largely remodeled by Herod, before being torn down by the Romans in 70 B.C. From this date onward, until the modern period, Jews have never ceased to consider the destruction of the Temple to be the most salient and distressing sign of their lost national autonomy and disaffection from God; indeed, many Jewish thinkers have argued that the physical subjection of the people of Israel and 
their imperfect relationship with God has led them into intellectual decline and confusion. There was also the idea of a third Temple, which the prophet Ezekiel had seen in a detailed vision and which was expected to reinstate Judaism in Jerusalem, return the people of Israel to prosperity, and rekindle their privileged relationship with God.

Profound disillusionment and the hope of a future reinstatement both crystallized around the Temple, as the Jewish intellectual need for representation focused on the volumes, spaces, buildings, courtyards, fortifications, furniture, and rites of that - real or imaginary — architectural structure.

A survey of the evolution of the representations of the Temple throughout Jewish culture as a whole would be an ambitious project, beyond the scope of the present chapter. More modestly, we wish to focus on a specific geographical area defined by a certain internal coherence and historical continuity: Italy. However, before tackling significant authors from the medieval and modern periods, we must say a few words on the founder of the allegorical method in Jewish medieval culture, Maimonides.

\section{Maimonides and Allegories}

Allegories play a central part in Maimonides' Guide of the Perplexed, which was composed around 1190 and is the most celebrated and influential work in the history of Jewish thought. In his introduction, the author clearly states that his text is exclusively intended for Jews who both believe in the truth of the Torah and are conversant with philosophical thought. In particular, it addresses Jews perplexed by the gap between the conceptual registers of narratives wherein God assumes human characteristics (he speaks, is visible, has feelings, etc.) as he intervenes into the world, on the one hand, and of abstract speculations on a transcendent and incorporeal God, on the other. Very cautiously, Maimonides proposes a radical solution, arguing that there is a perfect correspondence between the Torah and philosophical thought, despite their different languages. He compares the Torah to a golden apple wrapped in a silver mesh: whereas the overwhelming majority of readers will only perceive the mesh - the Torah's immediate or literal meaningknowledgeable readers (i.e., philosophers) will be able to discern the goldthe figurative meaning-lying beneath that surface. For Maimonides, the Torah as a whole (and in particular the stories of Creation and the description 
of the Chariot, i.e., the celestial vision of the prophets Ezekiel and Isaiah) is a mashal - an allegory — which must be deciphered to grasp the text's philosophical nimshal - its hidden meaning. Thus, all the anthropomorphisms in the biblical narrative lose their immediate meaning, instead pointing to a philosophical discourse on God.

In reality, Maimonides' thought is more complex. Not only is the Torah as a whole an allegory, but allegories also constitute a method of interpretation. For Maimonides, devising allegories in order to evoke metaphysical contents is akin to making a rope by tying pieces of string to each other until it is long enough to draw from the depths of the Torah. In other words, for Maimonides good interpreters are allegorists, as exemplified by the prophets and the masters of the Talmud, who used allegories when they wished to evoke metaphysical realities beyond the reach of common intellects and everyday language. ${ }^{2}$

The Guide of the Perplexed is a philosophical-religious treatise which presents its readers with a path to authentic divine worship, where intellectual knowledge leads to passionate desire: it ends on a magnificent allegory of the different human attitudes towards the truth and God. Maimonides's chosen mashal is a city with a royal palace at its center: people wander outside the city walls, or enter them but take a wrong turn, while still others stop in the entrance hall of the palace; only a few reach the king`s room and stand before him.

I say then: The ruler is in his palace, and all his subjects are partly within the city and partly outside the city. Of those within the city, some have turned their backs on the ruler's habitation, their faces being turned another way. Others seek to reach the ruler's habitation, turn towards it and desire to enter it and stand before him, but up to now they have not yet seen the wall of the habitation. ${ }^{3}$

The images Maimonides had in mind were probably of Jerusalem and the Temple, with their different degrees of holiness, from the Temple Mount, to the vestibule, the inner courtyards, and the Sanctuary (called heykhal, 'palace'), to the "dwelling place of the monarch," the Qodesh ha-qodashym or Sancta sanctorum, where the Tablets of the Covenant were kept and where the divine presence was most intense. 


\section{The Allegorical Sanctuaries of Mosheh of Rieti}

Encouraged by this prestigious precedent, Jewish authors placed the Temple of Jerusalem at the center of their allegory-making - in Hebrew, the making of allegories is called memashel meshalym, and is a quality ascribed to prophets. Like their Christian counterparts during the same period (such as Bonaventura of Bagnoregio, in his Itinerarium mentis ad Deum), they turned the city of Jerusalem into an allegory of perfection and bliss, marking the point of arrival for the faithful at the end of their voyage of initiation. One of them, Mosheh ben Yitzhaq of Rieti (1388-ca. 1465), an unconditional admirer of Maimonides, linked all of his intellectual productions to the image of the Temple. ${ }^{4}$

A physician, philosopher, and poet, Mosheh of Rieti is mostly known for his Miqdash me 'at ("The little Sanctuary"), a 4,800 verse poem in Hebrew meant to constitute the "Jewish response" to Dante Alighieri's Divine Comedy. ${ }^{5}$ Modeled on the Temple of Jerusalem, Rieti's poem is constituted of three parts: a vestibule, a palace, and the Sancta sanctorum. A level of sacred knowledge corresponds to each one of these three spaces, increasing the closer one gets to the center of the Sanctuary. But the Temple does not merely provide an external framework for an encyclopedia of knowledge, it also represents Paradise, the final destination of the poet's voyage of initiation, both a heavenly Sanctuary and the Yeshivah shel ma 'lah (celestial school), where the souls of the saints practice intellectual disputations, as they would in a Talmudic school, under the guidance of the divine Presence. Rieti confers additional meanings to the Sanctuary: not only does it allegorically represent Paradise, it also illustrates a divine emanation. He suggests a long prayer in which the poet entreats the Temple to forgive his sins, including the passage:

Temple of supplicants, $\mathrm{O}$ supreme aspiration,

To which we turn for mercy and forgiveness,

Life springs from thy blessed source. ${ }^{6}$

It is not surprising that the worshipper should address a prayer to the Temple, if we consider that we are not dealing with the historical Temple here but with a divine emanation (probably Hokhmah, "Wisdom") that allows him to access the divinity, the essence of which lies beyond his grasp. 
Mosheh of Rieti's Miqdash Me 'at is entirely allegorical. Its allegories can either be explicit, as in the chapter on "The City of God," in which each house represents a biblical book (hence the subsequent identification of the Temple or Sacred City and the scriptures ${ }^{7}$ ), or left to the reader to interpret, as is the case for example with the mashal in which some young girls draw water from the sea outside the City of God ("pure water, purity from above") in order to pour it into "the House of the Father."

In this poem, spatial representation does not seek to depict a tangible reality; instead, it provides a springboard for reflections that are conceptual in nature, a visual representation allowing the author to evoke abstract considerations which might otherwise be impossible to grasp.

In another, shorter and more difficult text in Hebrew, Ya 'ar ha-Levanon ("The Forest of Lebanon"), Rieti considers the Temple in a more traditional light, as an allegory of the different worlds: the sublunar world, the celestial spheres, and the separated intellects. The final part of this work consists of a series of answers to the question Ubi sunt? (loosely translated as, "what has become of the Temple and of its objects?"):

Where are the Cherubim? Where are the Ark and the Tables that were left there so that we may remember that the Torah is the very mystery of being and lies at the root of the life of every soul? [...] The Ark represents the part of the world which is comprised of a body sustained by the intellectual form surrounding it $[\ldots]$ the Cherubim are there in order to show that all beings in this world are separated, actual intellects .

The poet is not interested in the material Temple; what is at stake here, for him, is gaining access to another level of reality which the edifice, its accessories, and its rites point to.

The third of Rieti's texts we will examine, Filosofia naturale e fatti de Dio ("Natural philosophy and things concerning God") was written in Italian - in a central Italian dialect, more specifically - but transcribed into Hebrew characters. Intended for students, this work on physics and metaphysics includes some remarkable allegories, the most elaborate of which centers on the Temple. Associating an answer he received in a dream to a question that has been haunting him - is there a hierarchy between the various biblical books? - Rieti conceives the grandiose and complex image of 
a palace within which correspondences between the mashal (the figure, the allegory) and the nimshal (the figured meaning) abound: ${ }^{10}$

And I saw a magnificent edifice in the uppermost part of the world. It was the most sacred and remarkable thing I had ever seen, and it seemed to me that the heavens did not surround it at all. Its walls were of fine silver, and it was covered with shapes of pure gold which shone so clearly and brightly that at first glance they looked exactly like stars; upon a closer look, however, one could see that even though they were myriad, they all constituted variations on twenty-seven figures. Its roof was made of the same material, and propped up by forty-eight wonderful columns with the same filigree. One of them stood at the center while the others encircled it. The central column shone like a sun and those around it were like stars. And I saw seven others that mingled with them and had the sheen of pale moonshine. All together, I counted fifty-five.

Inside the temple I saw four small clouds of the finest crystal, woven into a completely ethereal covering. They indicated five precincts within the temple. It seemed to me impossible that gazing upon so much radiance and majesty combined should not trouble the eye and spirit of the onlooker.

Outside, I saw that there were sixty small rooms dotted around the temple and connected to it, each with a separate entry leading inside it. They all resembled the temple in their ornamentation, apart from those which never showed themselves; but they were as tall as a man.

Again and again, I counted six hundred and thirteen windows around the temple. But nothing I had ever seen equalled the luminosity of these splendid figures, combined with the serene atmosphere of the temple; and no balas or earthly ruby, any more than any ruby on Venus or Jupiter in the heavens, has ever had a similar color. There was a magnificent entrance on the eastern side.

And all around this hung a very precious and fine cloud, which was itself surrounded by another dreadful, heavy cloud, casting an impenetrable and deadly gloom all around.

Inside, the temple seemed almost completely filled with the most beautiful little birds I had ever seen. They fluttered tirelessly from one end of the temple to the other. They kept singing verses of great delicacy and sweetness, more joyful and jubilant than any human voice could express. Every now and then they perched somewhere, amusing themselves by 
listening to each other, and sometimes they seemed to me to be contemplating something nobler and higher than themselves.

[...] Take a close look at this entire splendid figure, because you may have never seen anything similar; it describes Paradise in terms of the Holy Scripture, that is, Torath Mosheh, the Torah of Moses, in the firm belief that the one corresponds to the other. ${ }^{11}$

In this image, the intrinsic correspondence ("intrinsic unity," in Rieti's words) between the Temple, the Scripture, and Paradise is made explicit.

Having depicted this vision, the author presents the "intention" (that is, the significance) of its every detail, before concluding with a general definition of allegorical representation: the more images the mind creates (to adorn the memory), the more pleasure the soul experiences, like a woman who is all the more beautiful and adulated for being decked in beautiful and enticing veils that have been finely pleated. The human psyche is seen as an empty space to be furnished ("to adorn the memory"), and allegorical images are both mnemonic tools and factors of pleasure (which, one might add, is aesthetic: "the soul experiences pleasure"). ${ }^{12}$

\section{The Temple as Encyclopedia: Avraham Portaleone}

Mosheh of Rieti was very popular with Italian Jews until the beginning of the seventeenth century. After that point, his memory was completely forgotten, probably because cultural changes made his works appear outdated.

It is precisely during this period that the Temple of Jerusalem stopped allegorically evoking another dimension and started to be studied for its own sake. Just as Galileo rejected the idea that there is a difference between the physics of the supra- and sub-lunar regions, the two versions of the Temple became one, and Jewish intellectuals began to focus on establishing its historical and architectural reality. Spinoza took a similar approach to biblical exegesis, vigorously denouncing allegorical interpretations as well as their major Jewish proponent, Maimonides. Instead, the Dutch philosopher insisted on the principle of sola scriptura, according to which texts are sufficient unto themselves and do not allude to other worlds of meaning.

Among Italian Jews, the most ambitious attempt at describing the actual reality of the Temple of Jerusalem and its rites came from a Mantuan author who was also a physician, and whose works we analyzed in the previous 
chapter: Avraham Portaleone (1542-1612). In reality, his project was, as discussed, the outcome of a more complex intellectual process, rooted in a religious imperative which dictated that all Jewish texts, however profane and whatever their discipline, had to have some sort of religious justification. The extensive body of scholarly works which Portaleone produced (to be read and quoted more often by Christians than by Jews) originated in his wish to expiate the sins of his youth, during which he had shown excessive interest in such profane disciplines as philosophy and science. Twenty-five years after producing a resolutely modern philosophical and scientific treatise in Latin advocating the experimental method, the brilliant physician repented, resorting to the rhetoric of the Catholic Counter-Reformation, while adhering to Jewish cultural coordinates, in his new Hebrew text Shiltey ha-Gibborym, which we have already discussed briefly, and which absolutely and unquestionably deferred to the elders, the masters of the Talmud.

Attempting to expiate the sin of "secularization" by giving his children the opportunity to study Jewish writings on sacrifice, Portaleone compiled an anthology of biblical and rabbinical texts to be read on different days of the week. $\mathrm{He}$ insists, however, on the fact that the exercise will be more productive if readers can picture themselves in the (Second) Temple of Jerusalem, the better to identify with the believers who took part in the rites; hence the need to reproduce the architecture and the rites of the Sanctuary "as they were":

When the children of Israel have all returned to God, they shall be able to pray throughout their Land and in the Temple they have built, turning towards the Western Wall [...] and they shall envision themselves inside the Sanctuary when they pray. ${ }^{13}$

Accordingly, Portaleone gives a rich and detailed account of the Temple, basing his descriptions on both Jewish and non-Jewish sources. The first part of his volume is devoted to this description, and constitutes a sort of preparation for the anthology that makes up its second part.

An almost mystical religious exigency presides over his work of historical reconstruction: the reader must be able to envision himself standing in the Temple. Portaleone's keen awareness of the temporal gap he has to overcome gives birth to a scientific quest. Ceasing to be an allegorical signifier, the Temple acquires a physical dimension, which can be envisioned in the imagination. 
Interestingly enough, whereas Portaleone turned away from allegories, his Christian contemporary Philippe d'Aquin - a converted Jew-continued to regard the Tabernacle as an allegory of the three worlds (divine, celestial, and earthly); ${ }^{14}$ similarly, for the Jesuit Juan Battista Villalpando, the Temple of Jerusalem was a blueprint for the perfect harmony between the different dimensions of the human being and the universe. ${ }^{15}$ This seems to suggest that, when it came to representations of the Temple, Jews - particularly members of the Italian Jewish community, which was probably the Jewish community in Europe most open to the non-Jewish world-were in some cases more "modern" than Christians. ${ }^{16}$

As in Rieti's poem, the Temple becomes the cornerstone of an encyclopedia of contemporary knowledge. Thus, an account of the musical accompaniments for the sacrifices leads the learned Portaleone to compose a treatise on polyphonic music; a discussion of frankincense offerings becomes a pretext for botanical reflections; an allusion to the salt sprinkled on victims leads to a disquisition on chemistry, and so on. The Temple becomes a kind of "theatre of memory," 17 but has no mystical connotations: these encyclopedic digressions have a very clear-cut framework, and are associated with extremely precise architectural descriptions, suggesting that the scientific empiricist remained unchanged by his "conversion." Portaleone walks his readers through the courtyards of the Sanctuary and makes them witness its rites. His descriptions are based on canonical rabbinical texts and - this is quite remarkable — on numerous non-Jewish sources. His Shiltey ha-Gibborym is thus a work born of an expiatory imperative which offers its Jewish readers a synopsis of contemporary knowledge and allows them to conjure a threedimensional image of the Temple of Jerusalem in their mind's eye by visually evoking its different sections, its ritual objects, and the life that unfolded within its sacred walls.

Of course, Portaleone was neither the first nor the most prominent Jewish author to give a detailed account of the Temple: there is a long tradition of such descriptions, from Hilkhoth Beyth ha-behyrah ("The Laws of the House of Election"), a treatise incorporated in Maimonides' code Mishneh Torah to the commentaries Maimonides and the sixteenth-century Italian scholar Ovadiyah of Bertinoro wrote on a treatise from the Mishnah entitled Middoth ("Measures"), and to other subsequent works. However, more than any other author, Portaleone emphasized the visuality of his descriptions. It can sometimes seem as though illustrations are all that is lacking from his 
book; indeed, when the Christian Blasio Ugolini, who published thirty-four volumes in folio on the rites and customs of the Jews between 1744 and 1769 , later translated a few chapters from Shiltey ha-Gibborym into Latin, he added illustrations. ${ }^{18}$ (See fig. 1)

\section{Scale Models of the Temple}

It was outside of Italy that the representation of the Temple would undergo another important change several decades later, most probably in 1641, when Jacob Judah Leon (1602? - 1675), a Dutch rabbi who would come to be known as "Templo,"19 took Portaleone's virtual evocation of the Temple one step further, producing a three-dimensional model. This scale model was exhibited to the public in several cities, including Amsterdam and London, conferring a degree of celebrity to its author. Jacob Judah also devoted an illustrated book to the Temple, Retrato del templo de Selomo (1642). Meant to explain his scale model, the book was translated into several languages and sold thousands of copies. (See fig. 2)

Jacob Judah's projects were spurred on by representatives of the Collegiants, a Dutch religious group with millenarian tendencies, which Spinoza would associate with after his excommunication from the Jewish community. Could there be a connection between the Millenarian current of thought and three-dimensional representations of the Temple? The historian Richard Popkin's careful investigation of this question suggests that the Millenarians were interested in realistic representations of the Temple because they were preparing for the advent of the Messianic era, when the Jews would return to their Land and the Temple would be reconstructed. ${ }^{20}$ If this is true, a religious motivation underlies Jacob Judah's and Portaleone's displacement of allegory with a three-dimensional space which is sufficient unto itself and does not allude to another sphere of reality. In other words, the "modern" overlap within a single space of the human and heavenly dimensions, the separation of which had long legitimated allegory, may have had religious roots. Let us not forget that this change in representation focused on the Temple, that privileged object of the Jewish imagery.

Although we left Italy when we turned to Jacob Judah Templo, a manuscript source suggests that as early as 1570 another Italian Jew had constructed a scale model of the Temple for his personal use: the dramatist Leone Sommo, who was, like Portaleone, from Mantua. ${ }^{21}$ 


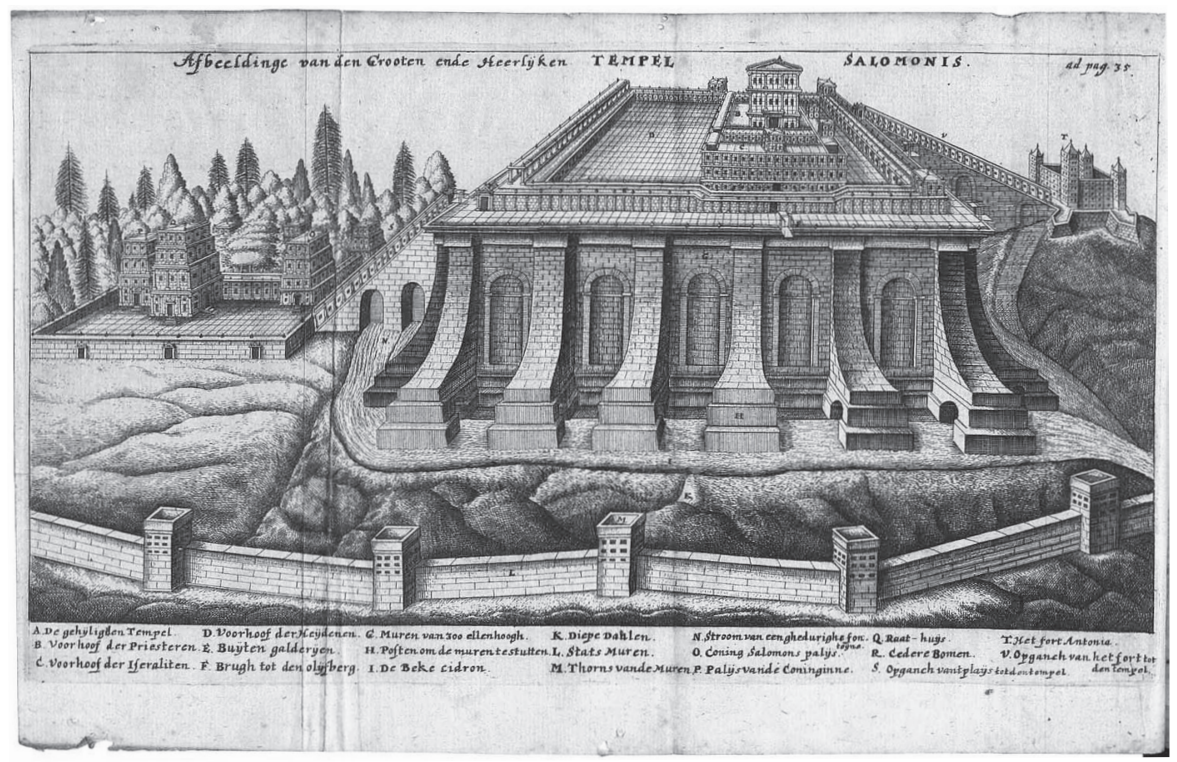

Fig. 1. Jacob Jéhuda Léon (called "Templo"), Retrato del templo de Selomo, Middelburg 1642

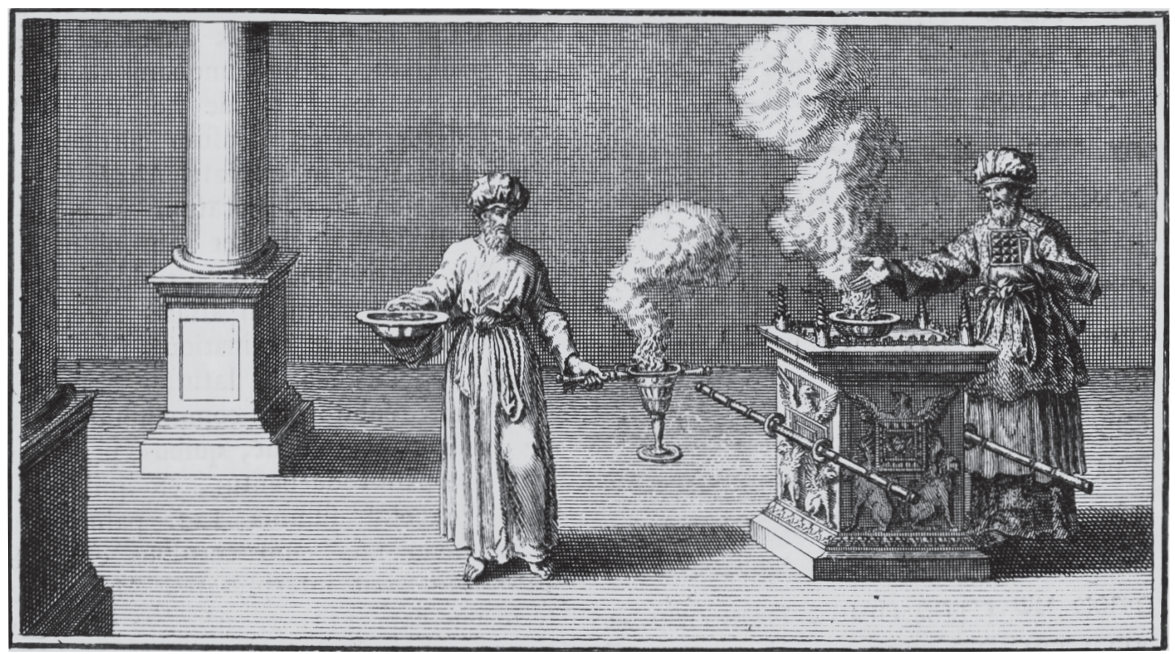

Fig. 2. The golden altar and the marble table. Illustration to the Latin translation of Avraham Portaleone's Shiltey ha-Gibborym (The Shields of the Brave), in Blasio Ugolini, Thesaurus Antiquitatum Sacrarum, vol. 9, Venice 1748, columns CCCXI-CCCXII. 
By the seventeenth and eighteenth centuries, realistic depictions of the Sanctuary proliferated in the works Italian Jewish authors, who sometimes used them for educational purposes, with or without resorting to scale models.

In 1696, Mosheh ben Gershom Hefetz (Gentili) published Hanukath ha-bayith ("The Inauguration of the House") in Venice. This remarkably learned and accurate work is exclusively based on Jewish sources: ${ }^{22}$ there are around twenty, ranging from the Mishnah to seventeenth-century authors (Maimonides is the author who is quoted most often). Interestingly, Hefetz rarely quotes Portaleone, probably because the latter referred so much to non-Jewish sources: "external" contributions were not looked on favorably during that period. Even though the argument of his book follows the logic of Talmudic commentaries, it nevertheless does occasionally resort to geometrical or physical demonstrations (especially optical experiments), some of which emphasize the tree-dimensional character of the descriptions. A very accurate three-dimensional drawing illustrates the text (fig. 3, fig.4.).

In spite of its strictly Talmudic approach, Hanukhath ha-bayith was in many ways merely a work of erudition devoid of any judicial impact: an antiquarian work of historical investigation based on Jewish sources only. The author underlines this aspect of his book when he explains that he wrote it in the spirit of "Darosh we-qabbel sakhar" ("Study, and get a reward"), a Talmudic formula which asserts the intrinsic value of scholarship, even in the absence of any judicial implications. ${ }^{23}$ Significantly, Azariyah de' Rossi, who probably initiated this antiquarian trend in the Jewish world and was its most prestigious representative, quoted the same formula in order to justify his own historical and philological investigations. ${ }^{24}$

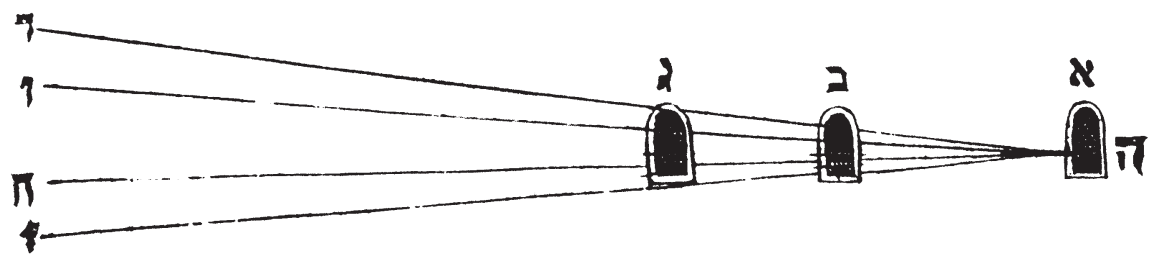

Fig. 3. Mosheh ben Gershom Hefetz (Gentili), Hanukath ha-bayith ("The Inauguration of the House") (Venice: 1696), fol. 3b: representation of the line of vision into the Sancta sanctorum, as seen from the entrance of the Temple courtyard. 
Chapter 3

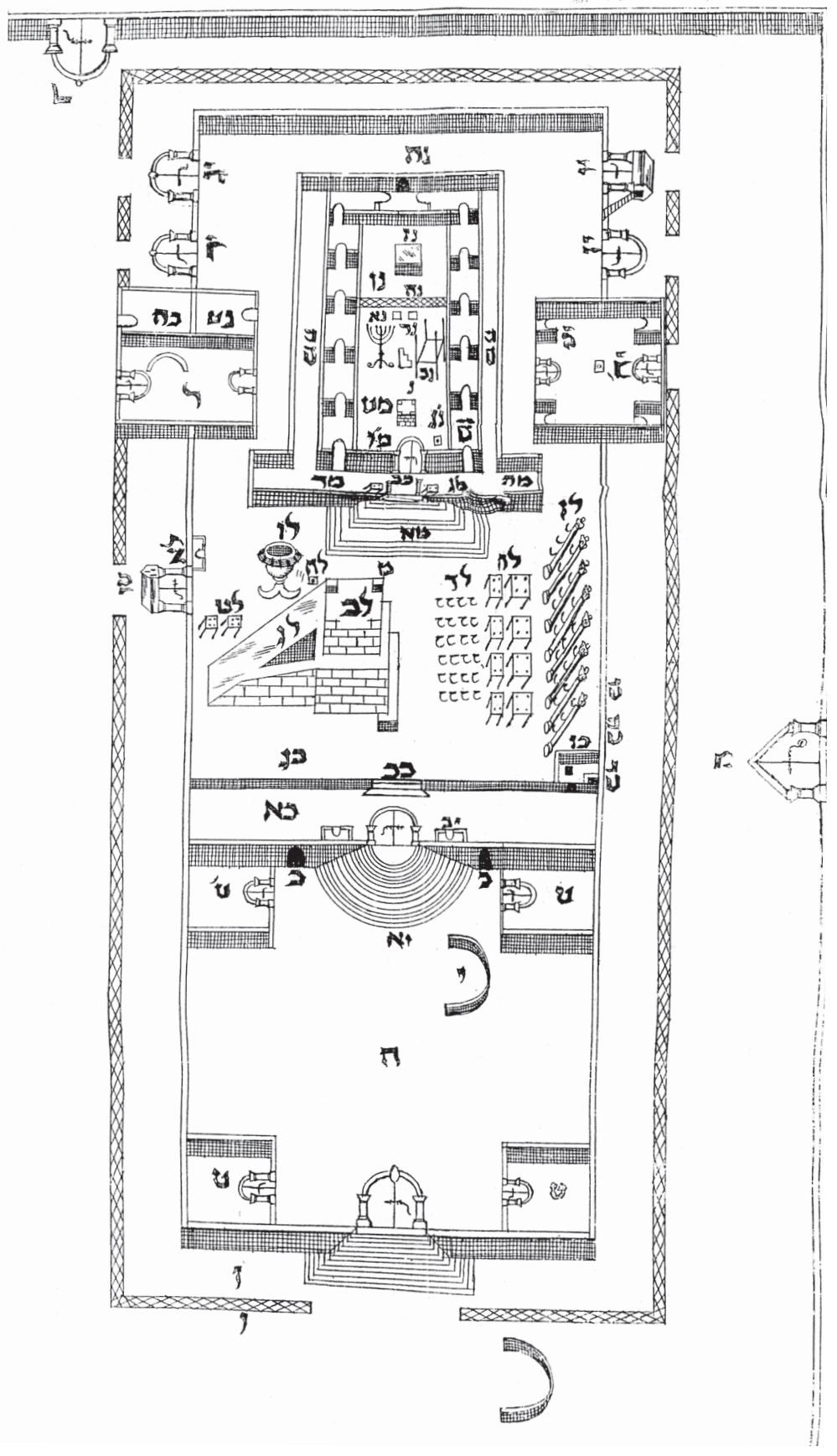

Fig. 4. Mosheh ben Gershom Hefetz (Gentili), Hanukath ha-bayith ("The Inauguration of the House") (Venice: 1696): a model of the Temple according to Talmudic sources and later Jewish authors. 
In turn, the kabbalist Immanuel ben Abraham Hay Ricchi's Ma'aseh Hoshev ("A Work of Thoughtfulness," published in Venice in 1716) does not focus on the Temple so much as on the Tabernacle. Like Hefetz's book, this work is exclusively based on Jewish sources, Talmudic and medieval, including a reference to the Zohar. In other words, it addresses Jewish readers well acquainted with the traditional concepts and methodology of their own religious culture. A major exponent of the Lurianic kabbalah, Ricchi showed no interest whatsoever in the wider culture of the non-Jewish world in his works, instead emphasizing Israel's special relationship with the divinity. Yet he explains in his introduction to Ma'aseh Hoshev that his book is based on a small cardboard scale model of the Tabernacle which he made for his young students. This suggests that even in a literary work exclusively focused on the Jewish religious heritage, which on the face of it seemed indifferent to realistic reconstructions, the author felt compelled to undertake historical researches on the Temple (or the Tabernacle) and represent it in three dimensions.

\section{Kabbalah and Bi-dimensional Representations of the Temple}

Although the transformation of spatial perception revealed by the evolution of the representations of the Temple followed a linear historical path, this did not stop the resurgence of an ancient intellectual and religious universe in a text entitled Mishkeney 'elyon ("The Tabernacles of the Most High"), by the kabbalist and poet of Padua Mosheh Hayyim Luzzatto (1707-1746). ${ }^{25}$ The object of this book is not so much the historical Temple as the Temple the prophet Ezekiel imagined in chapters $40-47$ of his eponymous book: that is, the third Temple, the most perfect one, which will come down from the heavens, heralding the final redemption. This Temple corresponds to the world of divine emanations, the sefyroth, according to the kabbalistic principle which posits the existence of correspondences between the lower and upper worlds: its physical structure is a perfect replica of the upper world, and each of its parts alludes to a particular aspect of the world of divine emanations. Its gates, for instance, are apertures in the walls created by the concentrated energy of the divine influx in order to sustain the inferior beings, while their proportions - described in great detail by Ezekiel and discussed by Luzzatto- have a very precise meaning, because they indicate God`s names and their numerical values. The world of divine lights is hierarchical: each one of its various 
parts must sustain a different category of beings with its energy - the souls of Israel, the different classes of angels, and the other creatures.

In this text, a two-dimensional image replaces the illusion of depth afforded by three-dimensional representation: we are a long way from the perception of space which made other writers imagine and describe threedimensional volumes before recreating them in scale models. As a matter of fact, the reader is under the impression that Luzzatto only conceived the map of Temple - which corresponds to the world of the sefyroth - in terms of two privileged sets of coordinates: up/down, right/left. Indeed, the author declares that his description of the Temple seeks to follow the downward movement of divine emanations, as they flow down from the upper to the lower realms. The text's modern editor rightly appended a bi-dimensional map representing the set of buildings and spaces which compose this ideal Temple in the kabbalist's account.

The kabbalist thus conceives of a two-dimensional image, as in allegories; yet it is not an allegory. Whereas in allegories one plane of reality evokes another on the basis of their external resemblances, kabbalistic images pretend to adhere to reality, insofar as the human mind can conceive of the reality of the divine world. Thus, according to the great thirteenth-century kabbalist Yosef Gikatilla, whenever the Biblical text mentions "the hand of God," this neither refers to the literal meaning of the word "hand" nor to some allegorical meaning: instead, it evokes the intrinsic likenesses ("an analogous sign") which link the divine entity and the physical hand. ${ }^{26}$ In Luzzatto's text, there is a correspondence between every detail, however small, of the image of the third Temple and the worlds of divine lights, which it allows us to visualize by deploying "analogous signs" while also visually prolonging these divine dimensions in the sensible world. According to Luzzatto, redemption consists of moving from the level of likeness which exists between the upper and lower Temples to sameness, as the heavenly Sanctuary extends all the way down to earth, becoming one with the terrestrial Sanctuary:

The two Sanctuaries, upper and lower, lean towards each other [...]. One day, the two Sanctuaries will not only be alike, but the upper Sanctuary will extend all the way down. The rabbis said that the third Temple is the work of God, because the celestial edifice shall not shift, but shall extend all the way down, at which point a physical structure shall be erected around it, for this world. The two structures shall then merge into one and shall never be set asunder. ${ }^{27}$ 
Luzzatto could hardly be described as a minor writer who was part of a marginal trend; quite on the contrary, his work was very influential, in the past in Europe and now in Israel. Moreover, his systematic approach to Kabbalah - reminiscent of the new Catholic scholasticism - was adopted by other major Italian Jewish authors. The prevalence in his works of features which might be termed medieval - particularly the image of a hierarchical bi-dimensional world - cautions us against sweepingly linear and progressive accounts of intellectual history, and Jewish intellectual history in particular: indeed, it would not be tenable to assert that this history evolved straightforwardly and linearly from allegorical to realistic representation.

The fact that the widespread popularity which Kabbalah enjoyed in Jewish communities in the modern period coexisted with the dissemination of a new vision of the world that was founded in scientific rationalism represents a conundrum for historians. In any case, focusing on the Temple, a privileged object of Jewish representation, whether allegorical, realistic, or symbolic, helped us trace some important changes in spatial representation. This is a solid testimony, we believe, for more general processes. 


\section{4 \\ The Myth of Politics \\ in the Jewish Communities of the Italian City-States}

In 1638, the Venetian rabbi Simone (Simhah) Luzzatto described the Jewish nation as "a nation incapable of any form of political governance while they are in their current state, [and] so preoccupied [...] with their particular predicament that they fail to take any interest in the universal." "A marginal group so completely removed from power and confined to a narrow range of economic activities could hardly concern itself with "the universal." At an intellectual level, this meant that the Jews had difficulty thinking of the political and social reality of their society as a whole-beyond the confines of the Jewish community - and analyzing these concepts. And yet, as we shall see, between the sixteenth and the first half of the seventeenth centuries, a few Italian Jews applied themselves to this task, producing interesting works which attempted to represent the universal from the perspective of the particular.

During that period, the Italian peninsula was a sort of experimental laboratory for new political ideas and practices. For centuries, its strong commercial, industrial, and financial performance, combined with its almost chronic institutional instability and the extreme political fragmentation of its territory, had laid the ground for major breakthroughs in political thought. In this country, Jews could not truly be said to be foreigners, as their presence predated the fall of the kingdom of Judea. Nonetheless, being well-established had not prevented them from remaining marginalized, as Italy had never had more than 50,000 Jews, and their involvement in its public sphere was very limited. Indeed, even during the period of integration, it was inconceivable that the Jews might actively participate in Italian politics.

\section{Yoḥanan Alemanno in Praise of Florence}

The first significant Jewish author to write on political issues was Yohanan Alemanno (ca. 1434-ca.1504). He spent years in the Florence of the Medici, at a time when Lorenzo the Magnificent was in power, taking part in the 
cultural life of the city. He was active in neo-Platonic circles and particularly close to Giovanni Pico della Mirandola. ${ }^{2}$

Yohanan Alemanno remains largely unpublished to this day. However, recent studies by Arthur M. Lesley, Abraham Melamed, Moshe Idel, and Fabrizio Lelli provide a good overview of his works. ${ }^{3}$ Alemanno elaborates on a sort of Jewish version of Florentine neo-Platonism. In his two great works, Hesheq Shelomo ("The Desire of Solomon") and Hay ha-olamym ("The Immortal," or "The Eternal"), he describes the rise of the human soul as it moves through different phases, from worldly concerns to a quasi-mystical fusion with the intellect agent. King Solomon, who excelled at all the sciences and was elevated by his love (or desire, hesheq) for Good-which coincided with intellectual contemplation-epitomizes this process, for Alemanno. However, he views Lorenzo de' Medici as the contemporary embodiment of the figure of the philosopher-king. He describes him as follows:

A man named Lorenzo de' Medici was extracted from the mountain of this land, and he was more precious than gold; with circumspection and a spiritual intelligence that lies beyond the ken of the people, he commands and rules over the surrounding areas to their outermost edges [...] and he does not position himself in the community as someone whose power is founded on force and ostentatious physical power, unlike the other kings, princes and rulers of the world. Rather he governs with discernment and great humility: this is the treasure (otzaro) from which he draws his strength. And everything he wishes for is in the spirit of the knowledge and fear of God. ${ }^{4}$

Alemanno then praises the qualities of the inhabitants of the city, naming seven of them. The impression this creates is of an industrious republic that is able to rule itself, favors the art of discourse over violence, and aspires to unity while overcoming ideological differences, and where one's true thoughts are concealed. But above all it seems to be a city where the practical approach-i.e., political action-is born of speculative knowledge. ${ }^{5}$ This characteristic combination of ideological control and enticement to philosophical speculation evokes Florence under Lorenzo de' Medici's enlightened government.

Alemanno ends his account of each virtue with a reference to his own selfimprovement: "I acquired this quality (...) I strove to adopt this behavior." 
In this respect, he seems to be part of the intellectual life of the city, which encouraged individual spiritual and speculative exploration, even as it hindered open debate and the elaboration of a political and social discourse based on observations of reality. On the other hand, Alemanno does not show interest in the Jewish community as a distinct social entity. King Solomon represents a sort of myth of origins for him, an ideal source of inspiration for the improvement of his Jewish readers and students. Although his works make space for politics in between rhetorical and metaphysical speculations, his thought does not allow for an examination of the role of force in political action. For lack of the conceptual tools that would allow him to understand the actual predicament of the Jews, Alemanno overlooks their marginal and precarious position. Yet, this precariousness was far from exceptional when Lorenzo de' Medici was in power, as Jews were not the only ones to depend on the good will of the republican Prince.

\section{The Project of a "Modern" Jewish Society in the Works of Avraham Portaleone}

A century later, the writings of the Mantuan Jewish physician Avraham Portaleone, outlined a dramatically new relationship to politics. His encyclopedic Shiltey ha-Gibborym (1612) devotes a few interesting pages to politics and the military arts.

Explaining the role priests and Levites played in the service of the Sanctuary, the author mentions the existence of a third group of people, the Israelites, and subdivides them into different classes. Proceeding to describe each one of these classes, Portaleone emphasizes the fact that he is drawing from personal experience:

I am not aware that any other author has described these classes in any detail, except for Maimonides who wrote something [...] about priests. This is why I have decided to provide readers with brief insights which are not drawn from books. ${ }^{6}$

Portaleone explains that there are two main types of Israelites: those who contribute to the well-being of society and those who teach men the ways of the Torah and Mitzwoth (the commandments). 
According to Portaleone, membership in this last subsection has seventeen degrees, ranging from respectable men who devote themselves to studying the sacred texts to prophets. This list is temporally and thematically consistent with the focus of his book on the Sanctuary. However, Portaleone's account of the first type of Israelites - those who represent civil society and the public sphere, whether on a military, administrative, or strictly political level - actually evokes a contemporary nation, and therefore strays from both a historical perspective and the Jewish context. Let us try to explain this anachronism.

When he lists the professions which make up civil society, Portaleone seems particularly drawn to occupations involving ceaseless movement and effort: manual work, but also intellectual labor. He gives a detailed description of the extraction and transformation of minerals and of field work. His evocation of merchants constrained to live peripatetic lives so as to provide for their families is clearly sympathetic. The work of those who deploy scientific knowledge and numerical skills in order to make physical labor more efficient prompts him to coin a phrase inspired from a Biblical saying, be-ze'ath af tevunatam (through the sweat of hard intellectual graft). These short descriptions cannot fail to recall the portrait of sixteenth- and seventeenth-century Italy which Piero Camporesi painted in The Beautiful Lands, which describes:

These cities full of craftsmen and workers, of workshops where resourceful men [...] alter, mold, and translate into the language of usefulness and beauty the stone and metals extracted from caves and mines through the sweat and blood of other laborers. ${ }^{?}$

Portaleone describes sedentary merchants spending their time at home, resting, or trading their goods for money or drafts, and does not even mention brokers and other financial occupations; as a result, he either does not account for the more specifically Jewish professions of the period or discredits them. As for those at the top of the social pyramid-landowners- he describes them in the following terms:

the man of high standing who dwells at his court, under the vine and figtree, partaking of the finest produce of the land with no need for work, he is noble and dignified. ${ }^{8}$ 
This implicit criticism of a particular medieval conception of society also tacitly questions the role it allocates to Jews. Portaleone's sympathy for the manual arts and all activities involving movement suggests that, despite his "conversion" and return to the intense devotion of his fathers' religion, he has not lost the modern sensibility that once led him to choose experience and scientific reasoning over auctoritates. ${ }^{9}$

It is probably worth reminding ourselves that Portaleone's classifications describe a non-existent, and purely imaginary, Jewish society. He takes an exclusivist stance, focusing only on the people of Israel and making everything else revolve around them. This stance may exhibit a wish for what one might call-borrowing from Zionist terminology—the "normalization" of the Jewish condition.

Portaleone's portrait of the military sphere and activities seems to confirm this hypothesis. Versed in science and technology, he was well-acquainted with this field and wished to impart his knowledge to his readers. But how could a digression on the military arts fit in to an essay on the Temple? Portaleone begins by resorting to a familiar strategy, which consists of asserting that the Jewish people and their legislators have a particular claim to this discipline.

Portaleone explains that many learned Gentiles have devoted their whole lives to studying what to do in times of war and peace. In contrast, the Torah effortlessly enlightens the Jews, teaching them "in a second" both what path to take in civilian life (be-darkhey ha- 'olam) and how to avoid evil, idolatrous peoples under the protection of divine Wisdom. One of the first lessons Revelation teaches the Jews is how to deploy troops. When the Romans followed the biblical battle plan, they became unbeatable, as the writings of both Sallust and Titus Livius show. Portaleone reiterates the notion of biblical precedence at the end of the chapter: as well as confirming its significance in his eyes, this leads him to argue that the Jews have a right to debate military matters:

One must remember that our Lord is majestic in holiness, dreadful in praises and works miracles: why couldn't we also debate military matters with justice, measure, and reason? Thus, all those who answer to the name of Israel must realize that God spoke unto us as well; and that we have no need of erudite books on these matters, which are against religious teachings. ${ }^{10}$ 
After a digression regarding the proper deployment of troops, Portaleone proceeds to describe a modern army. In order to place these remarks in a Jewish context, he imagines the priest in charge of a war making a speech which expands on a passage from Deuteronomy, chapter 20. Wavering between biblical and contemporary perspectives, he describes ruthless enemies armed in the modern and ancient fashions. ${ }^{11}$ The Jewish people must prepare for war, Portaleone suggests, because God wills it, even though he could have led the fight Himself. In his speech, the imaginary priest explains:

You too must do your part. Do not gaze at the sky like a dim-witted idler, like a fool counting the stars; so numerous that they cannot be counted [...]. It falls to you, $\mathrm{O}$ blessed by the Lord, to take up arms and kill those who hate you, Ismael, Moab and the converts, to vindicate yourselves from your enemies, who are rising to destroy you. ${ }^{12}$

One may wonder what provoked this rather belligerent tone. Did the predicament of Mantuan Jews - and of Italian Jews, more generally-justify such vindictive feelings? It would be tempting to attribute these pugnacious lines to the creation of the ghetto in Mantua in 1610 and 1611, at the same time as Shiltey ha-Gibborym ${ }^{13}$ was published. Yet Portaleone states that he wrote his book between 1606 and 1607. What is more, recent scholarship suggests that the impact of the creation of the ghettoes on Jewish communities was less severe than was once thought. Could Portaleone's bellicosity be attributed to the fact that Italian society was becoming more entrenched at the turn of the sixteenth century? Much as the Catholic Church redefined its religious and intellectual arenas in the wake of the Council of Trent, Jewish attempts to rethink their own identity led them close to a form of national exclusivism. But this did not keep society as a whole from moving toward a sort of proto-modernity, fostering tensions in religious quarters.

The priest's speech ends as it began, on a combination of modern insights and religious justifications. Envisioning a Jewish "ghost-army" focused almost exclusively on artillery, at the expense of cavalry, he goes so far as to state the number of firearms it should ideally own: 50 canons, 3,000 muskets, and 5,000 "Spanish" harquebuses. Discomforted by the foreign-sounding names of these weapons, Portaleone manages to link them to the biblical qesheth nehushah (the antique bronze ark mentioned in Psalms 18:36 and Job 20:24), which allows him to refer to the musket as qesheth. The extreme 
and almost ideal modernity of this army is obvious: in particular, the focus Portaleone places on its artillery defies contemporary notions on military strategy. Indeed, it anticipates future developments, even if strategists as talented as the Swedish King Gustav Adolph in fact still deployed one lancer for two musketeers twenty years later. ${ }^{14}$

Portaleone finds biblical references in support of his marked preference for artillery: Mosheh explicitly told the Jews (Deuteronomy 17:16) that the king should not multiply the number of his horses, while God reminded Joshua (Joshua 11:6) to burn the horses and chariots of the Cananeans. Thus the cavalry, which was a privileged part of medieval warfare, is rejected in favor of a modernity heralded by the Bible.

Portaleone's concern with biblical justification makes it impossible for him to assess military techniques dispassionately-i.e., solely in light of their usefulness. Instead, he feels compelled to expound on this issue, despite coming from a social background which leaves him completely unfamiliar with military drills. As well as evoking the penitent's characteristic tendency to consider everything in a religious light, this attempt to mark out such a secular sphere as sacred reveals the frustration of a talented man confined to the margins of society, as the following example will illustrate. The detailed account Portaleone gives his readers of the handling of weapons in the book corresponds exactly to an engraving by Jacob de Gheyn on the same question in Maniement d'armes, d'arquebuses, mousquetz et piques (Handling Weapons, Harquebuses, Muskets and Pikes), which was published in Amsterdam in 1608. Although the two authors give exactly the same account of providing individual soldiers with weapons, ${ }^{15}$ there are significant differences in the way they present this process. Portaleone describes it without resorting to illustrations, relying instead on a tale in which past and present overlap. Although he gives detailed descriptions to his readers, he evokes a fictional army and targets an audience which may or may not be familiar with the concepts of war. Moreover, he feels compelled to include in it a religious background which is both extraneous, as evidenced by his depiction of the Temple, and fictitious, as exemplified by the discourse of the Kohen mashuah, the priest who spurs the troops to war. The Dutch author had no such concerns. His illustrations needed no additional justifications: they were merely meant to instruct soldiers and officers in military drill. Moreover, the servicemen themselves and amateur students of weaponry were the expected readers for this type of book. For the same reason, it 
was natural that the Prince of Orange - a politician and military strategistshould back his work. In contrast, Portaleone composed his own Hebrew book with his children or students in mind.

In sum, Portaleone does not appear interested in questions of power; instead, his considerations on society and the military arts are characterized by:

1) a fundamentalist desire to integrate secular concerns into the religious sphere;

2) a tension between the social usefulness of the knowledge Portaleone imparts to his readers and the reality of Jewish social marginality;

3) a belief in the "normalcy" of the Jews, which borrows from the traditional motif of Jewish self-sufficiency and has aggressive undertones.

\section{The Praise of the Venetian Republic}

Among the Italian Jewish intellectuals and Jewish intellectuals who lived in Italy for parts of their lives and wrote about politics, one of the most notable is Yitzhaq Abravanel (1437-1508). This important figure, who was, within the limits of his condition as a Jew, personally invested in political issues as an advisor to princes and governors, transmitted his ideas on the best form of government not in a specific treatise, but in his comments in Hebrew on the Bible. The most "political" of the Jews of the late fifteenth century thus turned to a religious literary genre to express his thought. Furthermore, his ideas refer to biblical history and the Jewish precepts that inspired it, and therefore refer to the realm of the ideal, with little reference to the observation of reality.

The two passages of his commentary on the Torah that are most significant for political doctrine, Deuteronomy 17:8 (which refers to the Jews possibly having a king when they are established in the Promised Land ${ }^{16}$ ) and Exodus 18 (the advice given by Yitro to Moses on how to administer justice ${ }^{17}$ ), demonstrate a certain aversion to monarchical government, and certainly to absolute monarchy.

In Abravanel's view, the king of Israel - and it is on this figure that the Spanish author concentrates his analysis - is primarily subordinated to the Torah, which is the divine Law. Furthermore, his power is moderated by two types of advisers: the Sanhedrin and the courts (batey dyn). Thus, Abravanel sees the regime proposed by the Torah as a mixed system. Furthermore, 
establishing a monarchy is not seen as a mitzwah - a positive commandment—but simply as a possibility.

Abravanel wrote the commentary to Exodus when he was in Venice, acting as advisor to the Republic of San Marco. In the various Councils of the Republic among which power was distributed he identifies the intermediary bodies that Yitro recommended to Moses to alleviate the weight of justice. ${ }^{18}$ But this distribution, which for various authors represented the key to the solidity of the Venetian regime, is barely mentioned by the Jewish commentator. It is true that, with his citation, Abravanel implicitly attributes to Venetian institutions conformity with divine Law, but his citation is quick and scant - far from the genre of the direct apology.

In comparison, entirely and explicitly apologetic is the brief writing of another important author, David de' Pomi (Spoleto 1525-Venice 1593), who lived in central Italy - essentially in Umbria - and then moved to Venice. ${ }^{19}$ De Pomi, a member of a prestigious Italian Jewish family, was a well-regarded physician. As a writer, he intended nearly all of his work to familiarize Christian readers with aspects of Jewish culture, both biblical and rabbinic - we might speak of "civilization" - including showing them its moral elevation and closeness to Christianity. We are dealing, in his case, with work both informative and apologetic.

A brief piece in Italian by De Pomi, written between 1577 and 1587, 20 is political in character: Breve discorso nel quale si mostra la maestà divina haver particolar cura e custodia della repubblica Venetiana e che li oderni dì essa sono nel pubblico governo alle divine Mosaice constitutioni conformi (Brief discourse showing divine majesty having special care and protection of the Venetian Republic whose public governance is now in compliance with the divine Mosaic Constitutions). As indicated in the title, De Pomi wants to demonstrate that the Venetian Republic is constituted according to divine rule and that - as Abravanel wrote - its institutions, and in particular its advisors, corresponded to the Mosaic model. Furthermore, returning to one of his previous writings, De Pomi interprets some biblical passages (Isaiah 27:1-3 and Daniel 11:21-30) as prophesies of a Venetian victory over the Turkish fleet at the Battle of Lepanto and in subsequent years.

De Pomi not only uses a more explicitly laudatory tone toward Venice than Abravanel does, he also focuses on the ancient administration of justice according to Jewish rules — not only biblical, but also rabbinic: the monarchic 
institution, the Sanhedrin, and the much smaller courts. ${ }^{21}$ His many citations from the Mishneh Torah, the fundamental legal code of Maimonides, which was virtually unknown to the Christian public at that time, are characteristic of his work: De Pomi uses a text lauding the Republic of Venice to transmit some knowledge about Jewish civilization. Praising the Venetian constitution, he also indirectly lauds rabbinical law, which conforms to that constitution.

His designation of a mixed government as ideal, and the limits that he demonstrates are imposed on the power of the king, who must strictly comply with the rule of the Torah, show that De Pomi, like Abravanel before him, had a clear anti-monarchical orientation. He believed that Jewish decadence derived from the lack of respect for biblical and rabbinic institutions:

While this order was observed, the Jews happily dominated, but as the rules and laws started to be broken, their dominion began to decline, such that finally, because of our sins, the masters became the servants of all..$^{22}$

De Pomi suggests that the Jews' condition of weakness and servitude has a political-religious origin, which implicitly means that it does not result from the sin of not recognizing Jesus as Messiah, as argued by Christian theologians. This idea is confirmed in the trilingual Dittionario De Pomi wrote, where, in the definition of the word "king," he noted that the contemporary Jewish condition is the product of a lack of respect for the rules of the Torah with regard to the limits of monarchical power. Wanting to be "like all other peoples," and thus not recognizing the divine origins of their political and military successes, the Jews lost all of their strength. In other words, God left them because they did not recognize their special election, and not because - as Christian theology maintained - they did not accept that their special election had been transferred to the universal community of believers in Jesus:

Our fathers gained all their marvelous victories not through multitudes of people, nor the horses they purchased, but only through the infinitely triumphant divine power. When, therefore, they started to ally now with one, now with the other lord with earthly power, heaven started to turn its back on our princes, along with the people, and still we bear the penalty. ${ }^{23}$ 


\section{Simḥa Luzzatto's Apologia}

\section{as a Pattern of Universal Political Thought}

Simone Luzzatto (1583-1663) represents a third form of Jewish intellectual self-positioning in relation to politics. ${ }^{24}$ Luzzatto was Rosh Yeshyvah of the Venetian Jewish community-i.e. its leading rabbinical authority-at a time when it was one of the most prestigious Jewish communities in the world, while also being a meeting point for Jews from Northern Africa, the Ottoman Empire, and Northern Europe.

It is worth emphasizing that Luzzatto's most ambitious books-Discorso circa il stato de gl'hebrei and Socrate, ovvero dell'humano sapere ${ }^{25}$-were written in Italian: in other words, he chose to address the intellectual community at large, irrespective of religious differences. This open-minded stance contrasted with the ethnically and religiously exclusivist tendencies of contemporary Jewish Italian culture, which had led to a refusal to resort to any language other than Hebrew. Moreover, the popularity of theological and kabbalistic approaches had taken politics off the Jewish agenda. Luzzatto was perfectly aware of this, and on various occasions he brought attention to the pernicious widening of the gap which separated Jewish culture from the sciences. ${ }^{26}$

Published in Venice in 1638, Luzzatto's Discorso circa il stato de $\mathrm{gl}$ 'hebrei is an essay on the continued existence of the Jewish people in a big city, namely Venice. Demonstrating its author's understanding of political economy, this brilliant book describes the social identity, economic activities, and intellectual concerns of the Jewish community. This aspect of Luzzatto's work is strikingly realistic, and totally devoid of the exalted idealization which characterizes Portaleone's account of the Jews. Luzzatto's assertion that one would be hard pressed to define Jewish customs, exemplifies his position. Following a general introduction on the contradictions and paradoxes of the human soul and manmade society - by way of Anaxagoras, Plato, and Solomon, together with a few examples taken from Roman history-Luzzatto explains:

If [...] it is difficult to define the particular customs of an individual, how can one determine those of an entire Nation? [...] The soul of their Nation is so debased and weakened as to be incapable of any form of political governance while they are in their current state. So preoccupied are they with their particular predicament that they fail to take any interest in the 
universal and are parsimonious to the point of meanness. They are great admirers of ancient times but poor observers of current affairs [...] Whatever their faults may be, they nevertheless also exhibit many noteworthy qualities. They are steady and wonderfully unwavering in their belief in, and observance of, their Religion. [...] They are admirably constant—if not always in the presence of danger, then at least in the face of adversity.

The Jews are thus described as being devoid of any interest in the universal and incapable of political organization. In the context of Luzzatto's essay, these characteristics were to the advantage of the States which had taken them in, insofar as a scattered people with neither leaders nor political ambition would not pose a threat to their local institutions.

We saw Alemanno grant political qualities reflecting the ideal virtues of King Solomon to a contemporary city and person from outside the Jewish sphere, while Portaleone tried to integrate the political, social, and military realities of his time to the Jewish experience. Luzzatto adopts the perspective of an outsider, in a bid to avoid disguising the moral and political weaknesses of his co-religionists. His concern for realism is genuine, and he does not let Portaleone's national mysticism water it down. Wishing to elaborate upon a political theory of universal import, as his Socrate makes clear, he reflects on several questions and texts from outside the Jewish tradition. In that respect, his Discorso circa il stato degl'ebrei anticipates the completely objective perspective which Spinoza claimed to adopt in his Tractatus theologicopoliticus thirty-two years later. Yet, whereas the Dutch philosopher sided with Reason and aspired to rid himself of religious dogmas and partial visions, the Jewish Luzzatto could not be so independent: instead, he couched his observations in the partisan genre of the Apologia.

In an important article about Simone Luzzatto, ${ }^{27}$ Abraham Melamed shows that the Venetian rabbi reviews Tacitus' indictment of the Jews not only in order to dismiss the charges leveled at them by a number of contemporary Christian authors, ${ }^{28}$ but also in order to hint at his Machiavellian vision of history and politics. As Luzzatto could not openly mention an author as subversive as Machiavelli, he

like many other Italian thinkers of the period, solved his problem by turning to classical sources. When it was too dangerous to quote Machiavelli, he turned to Tacitus. ${ }^{29}$ 
But the Venetian rabbi is forced to resort to a more convoluted subterfuge than non-Jewish authors by integrating his general, "universal," ideas in an Apologia. Even as they articulate a defense of the Jews and Judaism, the arguments Luzzatto develops in his Discorso have more far-reaching implications. In other words, as a member of the minority under discussion, Luzzatto make the particular case of the Jews the focus of his universal thought.

This leads him to find surprising rationales for the most hermetic religious rites by ascribing political motivations to them. Thus, commenting on the ban on pork, Luzzatto quotes a passage from a classical author in order to introduce Machiavelli's notion that religion is an instrumentum regni: the most absurd rites, he writes, help monarchs to bend the minds of their subjects and test the limits of their obedience. ${ }^{30}$ Nevertheless, he covers himself by adding that "God's decrees exceed the scope of our investigations and defy human understanding." " ${ }^{11}$ Dismissing the charge of superstition Tacitus leveled at the Jews, Luzzatto declares - still quoting the Classics ${ }^{32}$ - that although superstition helps rulers to assert their power, it can be very harmful if it takes over their own minds. He develops this idea in an interesting comparison:

The world is akin to a big market; God apportions riches between us so we may purchase what is on display and for sale. The most widespread among these riches are prudence and strength, and they bear God's seal because He is science and strength. With these riches, we can cope with everything that depends on the will of man. Real religion belongs to those who ask God for this abundance of wealth (pecunia). ${ }^{33}$

As well as obviously referring to Machiavelli- prudence and strength are the Prince's virtues ${ }^{34}$ — this passage glorifies and consecrates capitalism and the market society with religious language. ${ }^{35}$

Throughout his essay, Luzzatto develops a political theory based on the observation of actual facts and the rejection of the principle of authority. ${ }^{36}$ At a time when Italian society is still dynamic and thriving, despite worrying signs of early decadence, he privileges active lives over contemplative existences, and realistic policies over utopias. ${ }^{37}$

Although his perspective is mystical and visionary, Portaleone shares this stance. The realistic point of view which these authors privilege leads them to turn away from theology when interpreting reality, and to give up on both the notion that the Jews are intrinsically different-as is preached by the 
kabbalists - and the idea that the people of Israel are chosen. Whether what spurs them on is the logic of scientific discourse - as in Portaleone's case- or Machiavelli's empirical approach to history - as in Luzzatto's - these Italian Jewish thinkers cannot conceive of the election of the people of Israel as formulated by Sephardic philosophers such as Yitzhaq Abravanel, Menasseh ben Israel, or Yitzhaq Cardoso. These Sephardic Jews shared in the Christian notion of the singularity of the Jewish people - whether God had chosen or cursed it — and had absorbed the Spanish notion of pure blood, ${ }^{38}$ applying it to the Jewish people in a process which evokes René Girard's "antagonistic mimesis." ${ }^{39}$

In contrast, even deeply pious thinkers such as Portaleone conceived of the Jewish nation independently of theological concerns, as a nation which ought to be on an equal footing with others and need not be considered superior. Indeed, as Spinoza remarks at the opening of his Tractatus theologicopoliticus,${ }^{40}$ only the imagination - as opposed to an accurate perception of factual reality - can validate the notion that one nation is intrinsically superior to others. 


\section{5 \\ A Link to Humanity: \\ Judaism as Nation and Universal Religion}

Scholars have long pondered the presence — or absence — of political ideas in Jewish thought in the Middle Ages and the Renaissance. On the one hand, some argue that Jewish thought essentially became disengaged from the political sphere during that period in both the Muslim and the Christian worlds, for the obvious reason that political reflections were irrelevant in the absence of either a state or an autonomous political life. On the other hand, many agree with Leo Strauss that, unlike Christian thought but like Muslim thought, Jewish thought is founded on a religious tradition that does not differentiate between the earthly and celestial spheres, but instead incorporates the political into the theological. Proponents of this second position assert that Jewish political thought is not to be found in specifically political texts - as it is in the Greco-Roman-Christian tradition - but lies scattered in other types of documents, such as legal or even theological texts.

Abraham Melamed sums up this approach in a well-documented and thought-provoking article, "Is there a Jewish Political Thought? The Medieval Case Reconsidered."1 Noting that there is no Jewish political thought in the traditional sense of the phrase, Melamed proposes to expand or alter the sphere of "political thought" in the Jewish tradition to other literary genres, such as judicial responsa or moral literature. In this sense, Jewish culture did produce political thought, although not by the standards of the GrecoRoman-Christian canons from which this intellectual discipline derives in the Western tradition.

Melamed's argument is broadly valid. And yet, even if we were to skip over well-known cases - such as that of Maimonides, who had a distinct influence over the Christian world ${ }^{2}$ - in order to focus on the so-called modern era, it would still be possible to find instances of political thought in the "traditional" sense of the phrase in several Jewish works.

Unsurprisingly, these writings are to be found in the textual production of the most intellectually advanced Jewish community of the sixteenth and seventeenth centuries: the Italian Jewish community, which had assimilated 
and had, through contact with the culture of the Italian Renaissance and post-Renaissance, developed disciplines that were neglected or completely unknown (and in some cases condemned) by Jews of other regions. These disciplines included rhetoric, historiography, philology, science, and profane poetry, which thrived with extraordinary intensity and continuity in that community.

Political expression flourished alongside these disciplines, although its development was sporadic rather than systematic. Instead of tackling themes typical of political thought, it consisted for the most part of observations on the highly "apolitical" condition of the Jews at the time. Although a few authors effectively turned to traditional political categories, they either adopted a negative stance, remarking on the present non-applicability of these categories to their existence, or focused on portents of change in the condition of the Jewish people, arguing that the Jews can and must reclaim their political identity, just like other peoples. This involved variants on familiar Jewish themes hinging on their relationship with others, and on the tension between exile and the prospect of reconstruction. Yet the rhetoric these authors deployed departs significantly from tradition: in their writings, they underlined the national character of the Jewish religion, to the detriment of its theological importance. In this way, these Italian Jewish authors made political expression in the traditional sense of the phrase ${ }^{3}$ possible for the Jews.

\section{"A nation incapable, in its present condition, of any political government": Simone Luzzatto's Discourse Concerning the Condition of the Jews}

As we saw in the previous chapter, in Discourse Concerning the Condition of the Jews, published in $1638,{ }^{4}$ the Venician Rabbi Simone Luzzatto gave what one might call an anthropologic, rather than apologetic, account of the condition of his coreligionists, ${ }^{5}$ adopting the perspective of an external observer. The result is a precise and at times impious description of the rites, beliefs, and behaviors of contemporary Jews, based on categories borrowed from external assessments of the Jewish tradition. Thus, the account Luzzatto gives of the Jewish intellectuals of his time is founded on notions drawn from Greco-Roman literary and philosophical culture. For instance, he resorts to the notions of the "particular" and the "universal" in order to 
evoke their political predicament. Although central to his argument, these notions have no equivalent in Hebrew, at least not in the sense Luzzatto intended.

Indeed, the very fact that this Discourse was written in Italian - rather than in Hebrew as was customary for Jewish writers - is noteworthy, because it induced him to use categories borrowed from the culture of the "Other." Although it is true that addressing the city authorities required him to write in Italian, Luzzatto nevertheless seems to have been completely at ease developing an "objective" argument in a language that was in a sense "extraneous" to the Jewish reality. As the Jewish rabbi's only other published text, the philosophical treatise Socrate ovvero dell'humano sapere (Venice, 1651), ${ }^{6}$ was also written in Italian, it seems that he participated in the general propensity of the Italian Jewish community of that period to adopt the Italian language. ${ }^{7}$

The following is the introduction Luzzatto gives in his Discourse to his account of the rites and customs of the Jews at the time, which was briefly discussed above:

If [...] it is difficult to define the particular customs of an individual, how can one determine those of an entire Nation? This is especially problematic in the case of the Jewish people, who are so dispersed all over the world that it is impossible to speak about them with any certainty or decisiveness. Across the universe, just as the waters of a river flowing through a village receive impressions from the many lands it runs through, the members of the Jewish people living in other nations have acquired a range of different customs. In the same way that those who live in Venice have very different ways than those from Constantinople, the latter diverge from those of Damascus and Cagliari, and all of them differ from the Germans and the Poles. Yet, if anyone wished to inquire after their universal customs, it might be said that the soul of their Nation is so debased and weakened as to be incapable of any form of political governance while they are in their current state. So preoccupied are they with their particular predicament that they fail to take any interest in the universal and are parsimonious to the point of meanness. They are great admirers of ancient times but poor observers of current affairs, and many of them are also bad-mannered and little versed in the doctrines and knowledge of languages. Others also say that they are dutiful, indeed 
scrupulous, in their observance of their Laws. Whatever their faults may be, they nevertheless also exhibit many noteworthy qualities. They are steady and wonderfully unwavering in their belief in, and observance of, their Religion. The dogmas of their Faith have remained uniform over the course of the 1,550 years they have been scattered all over the world. They are admirably constant-if not always in the presence of danger, then at least in the face of adversity. They have a unique understanding of the Sacred Writings and their interpretation. They show human charity and hospitality to all the members of their Nation, whether or not these are foreign to them: thus, the Persian Jew empathizes with the suffering of the Italian, and distance does not dissolve their bond, or affect the uniformity of their Religion.

The account Luzzatto gives of exile in this excerpt is significant. Describing the Jews journeying across different peoples and absorbing the various "customs" and "ways" of those with whom they come in contact, he almost entirely neglects to mention the suffering associated with exile, which is a commonplace in Jewish literature. Similarly, the essentially positive slant he gives to the image of the river flowing through different lands contrasts with the way that metaphor is usually deployed in Jewish Italian works. ${ }^{8}$

Although Luzzatto's remarks are based on objective observations, he also doubtless seeks to justify his thesis that his community is harmless when, a few pages later, he emphasizes the political passivity of the Jews of his time. ${ }^{9}$ Even under the most trying circumstances, as in 1492 Spain, they never dared rebel against authority:

... Since proselytizing is not a Jewish precept, they never had any thought of universally raising the issue of their People, and believed that everything that happened to them was caused by a superior cause rather than human action. In the time of King Ferdinand and Queen Isabel, as a great number of them - nearly half a million - resided in Castilia and other nearby realms, and were forced to convert or go into exile, 300,000 of them refused to convert to Christianity. Yet none of them dared to rise resolutely against that miserable banishment: instead, they scattered all over the world. This shows that contemporary Jewish customs incline them to subjection and obedience towards their princes. (P. 57) 
However, Luzzatto does not merely set out to make unflattering observations. True, the docility which makes the Jews easy to subjugate and prone to focus on their particular sphere, as opposed to the "universal"-wider wordly events - is the consequence of their fatalism; nonetheless passivity does not completely pervade their souls. Their focus on the "particular" does not entail isolation in petty egoism. Although the author proceeds to assert that it is true that Jews generally show little interest in the scientific and literary production of the wider culture, preferring to concentrate on studying their own texts, they nevertheless know how to be open to others. According to Luzzatto, this capacity to reach out is dictated by their very religion, which has universal dimensions that are not at odds with the particularity of the Law. According to their religion, men have a common origin because they share the same father, Adam. Indeed, the injunction to respect other religions (except those that preach appalling and unnatural behavior) prohibits offending their divinities. The "particular beliefs" of the Jews do not exempt them from having a "link to humanity" and entering into a "reciprocal friendship" with humankind, as there are "various degrees of connection between men"; therefore

... Together with those who are alien to their religion, the Jews belong and are bound to that human community which observes the precepts of natural morality and has some knowledge of a superior cause. (P. 52r)

At the time, it was widely believed that the humanity of Men resided in acknowledging the existence of a superior cause and sharing in the precepts of natural morality. Beyond that, according to the Venetian rabbi, everything is merely impiety and superstition, which Jewish Law has always tried to eradicate. Indeed, this is especially true of superstition, as this "abuse,... or excrement of the true Religion and legitimate cult of God" is particularly insidious and underhanded. In sum, for Luzzatto, at the heart of "Judaism" lies a desire

... to eradicate superstition, because the orderly succession of causes, and even the anatomy of the merest creature, are good reasons to believe, and refute Atheism. (p. 66r)

In other words, atheism is at odds with the proper deployment of reason and with the Jewish religion-inasmuch as proper religious behavior 
conforms to reason, is at odds with superstition and immorality (as demonstrated by regular biblical injunctions against idolatry and its rites) and is universal.

Luzzatto's position and ideological strategy are clear: turning to the Venetian authorities, he wishes to present the Jews as loyal subjects, too weakened to be capable of vain political ambitions, and, therefore, rebellion. At the same time, Luzzatto's account suggests that even though their culture is only concerned with essentially religious and apolitical matters the Jews are not exclusivist; instead, they consider that all those whose religion and ethics conform to reason (even when they are not rooted in it) share in the same humanity, whatever their rites. Even as he recognizes the material and political decadence of the Jews and their disinterest in the universal, he vindicates their religion, which sets out to uncover superstition. However, the qualities of this religion do not seem to reside in its exclusive election so much as in its universal dimension. The flip side of the inadequacy of the Jews in the realm of the political universal is their aptitude to achieve a religious universal.

Even though one must not forget that Luzzatto's Discourse is apologetic in nature, the sheer breadth and rigor of his argumentation, together with the fact that it echoes positions he adopted in other contexts, ${ }^{10}$ suggest that it expresses the Venetian rabbi's true position.

During the so-called first "period of the ghetto," during which Luzzatto writes, considerable progress had already been made to create common cultural ground between Jews and Christians, in order that they might understand each other. This common ground resided in a natural morality and a theistically-inspired religiosity which need not be confessional but were resolutely at odds with atheism; it was also founded in the beginning of their historiography ${ }^{11}$ and in an embryonic form of religious anthropology that shied away from theological polemics. The Venetian rabbi presents the Jews as a nation on historical-anthropological grounds: although decadence has made them "incapable in their present condition of any political state," they nevertheless constitute a nation. ${ }^{12}$ This nation owes its unity to the strong chains of religion: it deploys what little secular culture it has to religious ends, in order to achieve a better understanding of the scriptures. In the past, it excelled at the art of war, literature, and the sciences; but as a result of exile, not only have its members become weakened, but "every light of knowledge is almost extinguished in them and any splendor of erudition almost obscured" (p. 74a). 
Yet, "not every spark was extinguished" (75b) during its long exile, and one may speak of its "literary occupations" despite its limited engagement with the "human disciplines."

It may seem rather surprising that the preeminent rabbi of the prestigious Venetian Jewish community should present Jewish exilic culture as crippled and limited. Although this idea is not shocking in itself, as evocations of intellectual decadence were in fact typical of Jewish historical accounts, it is startling to come across it outside of a religious context bemoaning the collective sins of the Jews and lamenting their decreasing observation of religious rites and declining interest in studying the Torah. In this text, history is kept separate from theology, confirming - as Melamed has shown ${ }^{13}$ - that Luzzatto was well-acquainted with the writings of Machiavelli, which were well-known despite being banned.

In the Discourse Concerning the Condition of the Jews, Luzzatto does not offer a way to transcend these limits: however, in some of his rare texts in Hebrew he praises and encourages the Jews' receptivity to the sciences and contrasts it to "pious ignorance," probably referring to the kabbalists, whose popularity he denounced during those same years. ${ }^{14}$

The belief that Judaism could be loyal to its traditions while being invested in the general progress of the sciences, open to humanity and respectful of differences, actively engaged in the fight against superstition and keen to prove the vanity of atheism, and cherished by all rational ethical men who place their faith in a Supreme Being was held by the Venetian rabbi and formed a coherent scheme, which might be termed "modern." 15

The celebrated third chapter of Spinoza's Tractatus Theologico-politicus, published in 1670 (that is, thirty years after the Discourse) did not disagree, even if it adopted a different tone. Speaking on the "Vocation of the Hebrews," the Dutch philosopher insisted on the political character of this vocation, since "the Lord is not so nigh to any other nation as $\mathrm{He}$ is to the Jews [...] for in respect of intellect and virtue [...] God was [...] equally gracious to all." 16 Thus, according to Spinoza, the Jews did constitute a nation with an honorable political and military past which was currently cemented by established religious rites, although it lacked the particular qualities of prophecy, that is, a proximity to God and an understanding of his decrees. These traits led Spinoza to declare that one day the Jews would perhaps rebuild their state, "if the foundations of their religion have not emasculated their minds," 17 echoing Luzzatto's evocation of the "debased 
and weakened" soul of the Jews "in their current state"- that is, under the conditions of exile.

These aspects of Luzzatto's position-his notion that the Jews form a nation and that this has no theological implications for their election, together with his vision of the Jewish religion as neither closed nor exclusive, but on the contrary open to humanity - had, in truth, already been developed by other Jewish Italian thinkers before him.

We have already analyzed the "political" sections of Avraham Portaleone's Shiltey ha-Gibborym (1612), in which the Mantuan doctor imagines a Jewish nation "capable of having a universal dimension," to quote Luzzatto; that is, a nation possessing all the social strata of a "normal" society, from farmers to craftsmen and a civil elite, as well as its own army. ${ }^{18}$

As Luzzzatto would recall a few decades later, the call Portaleone made to the Jews - through the mouthpiece of a priest in charge of the war-to acquire a theoretical and practical knowledge of the art of war sounded like an attempt to bring them out of their passivity:

You too must do your part. Do not gaze at the sky like a dim-witted idler, like a fool counting the stars; so numerous that they cannot be counted [...]. It falls to you, O blessed by the Lord, it is up to you to take up arms and kill those who hate you, Ismael, Moab and the converts, to vindicate yourselves from your enemies, who are rising to destroy you. (36v)

These lines invite a few remarks. The first is that the Jewish author shows a very modern contempt for "idle contemplation," which itself evokes the way medieval science was perceived at the end of the Renaissance. In this sense, Portaleone belongs to a small group of resolutely "modern" Jewish Italian scientists, along with the likes of the mathematician and astronomer Yosef Shelomo Delmedigo (1591-1655) and Simone Luzzatto himself, who had a reputation as a good mathematician. ${ }^{19}$

Portaleone's helpless call to arms evokes Luzzatto's account of the weakened Jewish people. Indeed, although one of these accounts is utopian and the other objective, it is worth noting that even an author as tormented and as contradictory as Portaleone - he was at once an objective scientist and a devout follower of a traditional and partly kabbalistic pietas - voiced the idea that the Jews formed a nation: a nation that had lost touch with both the sciences and the habit of action, but could rediscover both. 


\section{Abraham, the Common Father: The Universalism of David de' Pomi.}

Simone Luzzatto's conception of Judaism - the notion that it is an open and universal religion - had also already been advanced fifty years earlier by another Jewish author, David de' Pomi, in a Latin text titled De medico hebraeo enarratio apologica (An Apologetic Discourse on the Jewish Doctor), published in Venice in 1588. De' Pomi's objective was to defend the probity of doctors in general, and of Jewish doctors in particular, as Christians were suspicious of them and reluctant to engage their services, fearing that they did not have their patients' best interests at heart. In 1584, Pope Gregory XIII had forbidden Jewish physicians to heal Christian patients. However, de' Pomi's book quickly moves from this question to the global relationship between Judaism and Christianity. Like any Jewish author wishing to enter into a dialogue with Christians without renouncing his own particularity, de' Pomi embraces a pluralistic vision and begins by acknowledging that men are naturally diverse "in religion, grade, and dignity." ${ }^{20} \mathrm{He}$ then follows a two-pronged strategy: first, he demonstrates the beauty and humanity of the Jewish religion, quoting a series of ancient Jewish maxims of universal import (taken from the mishnaic treatise Pirkey Avoth); and second, he attempts to show how religious diversity need not impede true friendship. Rather "audaciously," as he himself admits, ${ }^{21}$ the author brings to the fore the fundamental affinity between Judaism and Christianity, illustrating it by citing numerous passages from the Gospels and some carefully selected letters by St. Paul. ${ }^{22}$

De' Pomi describes the foundations of an Abrahamic religion encompassing the Jews, the Christians, and the Muslims (although he has some reservations about the latter, probably given the situation in Venice during the Turkish-Venetian war). Abraham, their common father,

possessed the necessary science to attain the greatest virtue: he was exemplary among men for his faith, temperance, honesty, innocence, and piety. ${ }^{23}$

Their real common enemies are the idolaters, those who deny the true cult of God; however, in Europe - in Christian countries, that is - this type of enemy does not exist, and has never existed. In sum, Christians and Jews are brothers,

but that is not enough, because all men are brothers, except those Nations rejected by God for one and only reason, their cult of idolatry. ${ }^{24}$ 
On the one hand, the Jewish doctor feels compelled to show that the Mosaic Law believes that the enemies of the Jews can be counted precisely and consist of those peoples who dissuaded the Jews from their divine cult and lived in the Jews' promised land, neither of which applies to the Christians. Indeed, if it is true - as Josephus Flavius asserts - that the Romans, who went on to become Christians, were descended from the Edomites, then the following verse from Deuteronomy (23:3) may apply to them: "Thou shalt not abhor an Edomite; for he is thy brother." ${ }^{25}$ On the other hand, de' Pomi lists several of the repeated references the New Testament makes to the Jewishness of Jesus and Paul, fully endorsing it. He concludes that not only are these two religions not at odds, but the chain of "carnal and spiritual"26 affinities linking them far outweighs their differences, which in the end are minimal. ${ }^{27}$ Jews and Christians are God's witnesses, and spread moral and religious virtues ${ }^{28}$ while also pursuing indulgence and charity. ${ }^{29}$

Thus, according to de' Pomi, there is a Judeo-Christian (and partially Muslim) civilization founded on the cult of a common God, which does not preclude particular attitudinal differences. Although one may object that this book is a work of apologetics, much like Luzzatto's Discourse, the Jewish doctor's previous works nevertheless seem to suggest that his ecumenism was heartfelt. In particular, his Discorso intorno a l'humana miseria, e sopra'l modo di fuggirla ${ }^{30}$ - a text on ethics published alongside an Italian version of the Ecclesiastes ${ }^{31}$ —is saturated with a non-confessional religiosity: exclusively basing himself on the Book of Ecclesiastes, which he considers to be a moral treatise the true meaning of which was as misunderstood by the Jews as it was by the Christians, de' Pomi warns his readers against pessimism, skepticism, and excess. In his later Enarratio apologica, de' Pomi includes a series of non-confessional rabbinic maxims of universal moral import in the Appendix ("Sciences of the Ancient Jews"), in order to confirm the Jews' capacity to rise to ethical universality.

Between the end of the sixteenth and the first half of the seventeenth centuries, Italian Jews thus variously began to conceive of themselves as forming a nation materially and intellectually weakened by exile: their constant references to their political and military past — as opposed to their religious election-reinforce this impression further. Although particular rituals and beliefs cemented this nation, its religion fundamentally encompassed humanity as a whole, since it considered Adam, or Abraham, the common father of all men, or believers, whatever their individual confessions. 
The Jews thus had the right to re-integrate into the community of nations, rediscovering the path to social - and perhaps even political-normalcy, and aspiring to the dignity owed to all those who shared basic moral and religious precepts.

Leone Modena naturally comes to mind in this context. Just like Luzzatto, Modena gave an objective account of "Jewish rites" in his Historia de' riti ebraici, ${ }^{32}$ later confirming the anthropological - indeed in some ways almost post-theological-vision he develops in other works. ${ }^{33}$ The Venetian rabbi encouraged the Jews to translate the Bible into literary Tuscan, rather than medieval Judeo-Italian, ${ }^{34}$ and also probably covertly tried to reform the Jewish religion by omitting some of its more "particularistic" rites and describing its characteristics in biblical, rather than rabbinic, terms. ${ }^{35}$

\section{The Return of Exclusivism}

This was only one strand of the Jewish Italian culture of the period. An entirely different current developed in parallel, reaching its peak at the beginning of the eighteenth century.

We have already evoked the significant chapter of Jewish intellectual history that corresponds to the spread of kabbalistic sensibility in the second half of the sixteenth century, in the wake of the works and teachings of figures such as Mosheh Cordovero and Yitzhaq Luria, in Safed and Galilea. As the study of Kabbalah took off, an esoteric doctrine which had been the preserve of a few initiates progressively became the shared heritage of all believers, including the most unsophisticated. ${ }^{36}$ Naturally, this new sensibility called for collections of the new interpretations of Kabbalah. Even as early as 1558 , the publication of the first print edition of the Zohar and other important kabbalistic writings was not opposed by anti-kabbalists so much as by those rabbis who, although they acknowledged Kabbalah as possessing supreme knowledge, feared that its dissemination would require reading rather unorthodox works, as well as making them vulnerable to a fresh outbreak of ecclesiastical censorship at a time when Italian Jews were still smarting from the burning of the Talmud decreed by the Church a few years previously. ${ }^{37}$

It is not possible to delineate the contrast between old and new intellectual attitudes here. Suffice it to say that Kabbalah brought to the fore the particularity and superiority of the Jewish people, grounding these attributes 
in the belief that they were the depository of the most profound truths about God and the world, which teachers had transmitted from one generation to the next, starting with Moses, who received them from God Himself.

Kabbalah opened a rift between the Jews - who were not only the depositories of these truths but also could act upon the divine world through the mediation of certain practices - and non-Jews; moreover, Kabbalah was at odds with philosophy and the sciences, as any revealed and true doctrine may be when dealing with human and uncertain knowledge.

Whether they were kabbalists or the proponents of a scientific, protonationalistic and universalistic spirit, Italian Jews were at the vanguard of the Jewish world: they were the first to understand and study the teachings of the masters of Galilee, which they also disseminated by printing them. In sum, Italy was where the Land of Israel met the rest of the Jewish worldboth Sephardi and Ashkenazi - which was itself rapidly conquered by this devotion and love for the study and practice of Kabbalah. Although the near hegemony of Kabbalah lasted for almost two centuries, it is difficult to explain how the doctrine was able to become so widespread so rapidly in so "modern" a state as Italy. The religious and epistemological crisis which made space for the Reform and for so-called "post-Tridentine" Catholicism in the Christian world of the late Renaissance probably generated a spiritual void in the Jewish sphere that modernists such as Simone Luzzatto were unable to fill. There are echoes of a futile resistance to Kabbalah - to "this" Kabbalah - from Luzzatto himself, as well as from other rabbis of the period, such as Leone Modena. ${ }^{38}$ However, despite not being in short supply, the opponents of Kabbalah could clearly not express themselves publicly: their interventions were anonymous, and they had difficulty publishing their works, which often remained in manuscript form. Indeed, they were sometimes even forced into voluntary exile from their native city, as happened to the poet Ya'aqov Francés in the wake of the outcry caused by his rationalist verse, even though he opposed Sabbateanism, rather than Kabbalah in general. ${ }^{39}$

The spread through Italy of a number of complex, suggestive, and totalizing doctrines bearing some formal resemblance to science but at odds with it and denouncing its futility - if not outright harmfulnesss - suggests that, despite the fact that the most modern Jewish culture was evolving in that region, it was also in a sense being "orientalized" by ideas coming from the Land of Israel. 
Italy had several great representatives of Kabbalah at the beginning of the eighteenth century, yet, so problematic was their relationship with science, philosophy, and the belief in Jewish exclusivity which marked their vision of the Other that they were on their way out. Their followers would essentially be confined to Eastern Europe, while in Italy Jews would reestablish contact with "the letters and the sciences" and start collaborating again with their Christian fellow citizens, allowing for the re-emergence of the rationalists' universalist stance. Although one may wonder to what extent this new-found harmony made them lose their particularity, as they merged with the common culture of so-called "modernity," what is certain is that the notion that Judaism constitutes a nation started to disappear as Italian Jews increasingly began to see themselves as the Jewish citizens of the Italian nation. 


\section{6 \\ The Italian and Latin Works of Lazzaro da Viterbo, Sixteenth-Century Jewish Humanist}

\section{Lazzaro da Viterbo: A Jewish Humanist}

In the second half of the 1500 s, the Jewish community in Rome passed through an extremely delicate period, the result of the intolerant attitude of the Catholic Church, which was engaged in the so-called Counter-Reformation. One of the responses of the community's intellectual elite was to advocate for the rights of Jews from within the traditional ecclesiastical legal framework, showing in some cases that the Jewish religion shared some fundamental notions with Christianity and that Jews corresponded to the model of religiosity sought by the Catholic Church at that time. To do this, they needed to express their own traditional notions in a language acceptable to their counteraprts - Latin or Italian — and with cultural references that were similarly acceptable - the classic philosophers and authors, the New Testament, the Church Fathers, and other more recent Christian writers. Thus this period gave rise to what can be considered a belated Jewish humanism, undoubtedly brought about by contingent necessities and defensive in nature, but rooted in an orientation that was in any case widespread among the members of the Jewish elite, and that would continue into subsequent years.

Judging from the work of Lazzaro da Viterbo, one of the most significant representatives of this trend, the level of such production was clearly elevated, demonstrating, in addition to a vast rabbinical culture, perfect control of the linguistic and cultural tools of the "other," in this case meaning Christians as a whole.

Lazzaro da Viterbo (Ely'ezer Matzliạ̣ ben Avraham ha-Kohen mi-Viterbo in Hebrew) is not unknown to scholars, though he has probably not yet received the attention he deserves. He was the author of at least three texts: a versed Italian version of $M e$ 'on ha-shoalym (a long chapter of the wellknown fourteenth-century Jewish poem Miqdash me 'at by Mosheh of Rieti); a work, written in Latin and dedicated to Cardinal Guglielmo Sirleto, ${ }^{1}$ on the validity of the Jewish textual tradition of the Bible; and the Tractatus de 
Anno Jubilaei, also in Latin, dedicated to Pope Gregory XIII, who had proclaimed 1575 a Holy Year. ${ }^{2}$ To this we can add a teshuvah, or legal response, expressed in his capacity as a member of the Roman rabbinate. ${ }^{3}$

If we exclude this last text, which is technical in nature, and the brief Hebrew dedication to the translation of Me 'on ha-shoalym, the work of this rabbi and Roman doctor ${ }^{4}$ is entirely in Italian and Latin. This quality aligns him with native central Italian contemporaries such as Mosè Allatino ${ }^{5}$ and David de' Pomi (who married Lazzaro's sister), ${ }^{6}$ or to Northern Italian (more specifically Mantuan) authors like the playwright Yehudah Sommo $^{7}$ and, in part, Azariyah de' Rossi ${ }^{8}$ and Avraham Portaleone. ${ }^{9}$ It also makes him a member of a limited group of Jewish Italian intellectuals who connected, or at least tried to connect, with the Christian world. We can justifiably grant these writers a denomination little-used in classical Renaissance historiography: humanist Jews (or Jewish humanists): writers or scholars who were perfectly at ease in the Hebrew language and its literature, which they knew deeply and even intimately, but who wrote part or all of their works in Italian and Latin. In 1895, David Kaufmann wrote: "The history of the 'humanistic' movement among the Jews of Italy has yet to be written," ${ }^{\prime 10}$ and this still applies today, with regard not to special research, but to the phenomenon as a whole. ${ }^{11}$

\section{The Italian Translation of Me'on ha-shoalym}

The poem Miqdash me 'at (Little Sanctuary) by Mosheh ben Yitzhaq of Rieti (1388-c.1465) was written in terza rima and conceived as a Jewish version of Dante's ${ }^{12}$ Divina Commedia. It found considerable popularity among Italian Jews from the late fifteenth century to the beginning of the seventeenth century. ${ }^{13}$ One of its parts was particularly successful, copied separately by scribes from various regions and translated into Italian many times, always retaining the poetic meter of the original (the Dantesque tercet); at least three of these translations were made by Roman authors within a relatively brief period, in 1585, 1602, and 1609. This part was called Me'on ha-shoalym (The Residence of the Beggars), with reference to the first words, made up of 115 tercets and constituting the second chapter of the second section of the Miqdash me 'at. This chapter is concentrated on the Temple itself, after the first section, which is dedicated to the "outer courtyard," or the profane sciences. The Me 'on ha-shoalym follows the majestic vision of Paradise described in the first chapter, expresses the moral and intellectual insufficiency 
experienced by the poet, who had just been made the receptacle of a revelation; and precedes the allegory of the "City of God," formulated when the author was still "blinded" by this vision.

Apart from its position in the narrative fabric of the poem, this long chapter can stand alone as an independent text, and this is how it was interpreted by its translators ${ }^{14}$ and by numerous copyists. ${ }^{15}$ It is a prayer in three roughly delimited parts, intended for the day of Kippur (explicitly recalled in the finale; also evoked is the yom teru ' $a$ h, the day of the sounding of the shofar). ${ }^{16}$

The first part (around fifty verses) is made up of the confession of sins (widduy); the second (around thirty verses) is, according to the intellectualist vein represented by Rieti, a form of purification consisting of the enunciation of a series of truths about God and the heavenly and earthly realms; the third part, also composed of about thirty tercets, is the selyhah, or request for God's forgiveness.

In Me 'on ha-shoalym, biblical language (with some expressions that are Talmudic or taken from the philosophic and scientific lexicon) is adapted, without forcing, to the prosody of the original Italian (tercets of hendecasyllables) in a fluid succession that makes this chapter one of the most important in Italian Jewish literature and in all Jewish religious literature of the late Medieval period.

The first printed translation was done by Lazzaro da Viterbo. The translator preceded his work with two dedications, one in Hebrew and one in Italian, both to Donna Corcos, the daughter and sister of important Sephardic leaders in the Roman community. In the Hebrew text, the dedicatee is assigned the laudatory attributes typical of Italian Jewish literature of the Renaissance: beautiful, good, generous, and modest, and above all intelligent. The poet hopes that Donna Corcos will recite this version "with her lovely voice" on the day of Kippur, and that this will help him to expiate his sins. The Italian dedication, of equal length (one and a half pages) reveals that Lazzaro wrote this translation "more for [his] amusement than to give it out," i.e., to publish it, and that being "asked by certain of my loving young people to give them a copy," he had decided to dedicate it to Donna Corcos. In this case as well, he noted regarding the dedicatee (described more piously than in the parallel Hebrew text: "full of spirit, clothed in piety, adorned with holiness, and devotion, and divine religion") that, "When the time comes [...] he would like to hear her sing some verse."

The translation is fluid and extremely faithful to the original, as can be observed by comparing it to the Hebrew text, which is reproduced in the 
appendix. Some of his renderings are poetically remarkable. It is obvious, as Lazzaro observes in the Italian dedication, that "all the words will not correspond point by point to their original; being an extremely difficult thing, perhaps impossible, that verses in rhyme, transferred from one language to another, although in verse and in rhyme, should completely balance out." In any case, despite the inevitable approximations in correspondence between individual words, the Italian text shows no particular awkwardness; its meter is perfect and it is easy to comprehend. In sum, Lazzaro is gifted with a true literary talent, though this manifests itself in a translation rather than an original work, as he himself reminds us in the same dedication: "As I myself am unable (like a dry font) to give you something of my own, I will give you something from another." 17

His reasons for doing this translation, like those of others who translated this or other Jewish texts, must have been essentially personal. The Italian text was not actually intended for liturgical purposes, but neither could it be viewed as a useable translation, like versions of the Bible intended for use by women and schoolchildren. Thus his intention should be read as the desire to produce, in the language of daily communication (which in those years had actually assumed a literary dignity as well), a text perceived as an exemplar of his own "national" cultural tradition, and of Jewish poetry tout court. At the same time, this text-of a penitential and wisdom-sharing nature, like the others translated in these decades - had to appear consonant with the Catholic religious sensibility of the time, which, as we can see, was shared by Jews living in the same region. Thus this translation can indeed be considered, in its own right, an example of "spiritual rhymes," a form widespread within Italian Catholic literature in those years.

\section{The Search for a Common Religious Space between Christians and Jews: The Tractatus de Anno Jubilaei}

The Tractatus de Anno Jubilaei is a 46-page opera di circostanza (a work written for a specific occasion), dedicated and addressed to Pope Gregory XIII (1572-1585). It is undated but surely written before the 1575 Jubilee proclaimed by that Pontiff. The purpose of the Tractatus is to plead the case for the readmission of the Jews into the Papal States after their expulsion by decree in 1569 (with the exceptions of Rome and Ancona, which had not been concerned by the expulsion). 
Only in the final pages does the reader discover that the text was written for contingent purposes; indeed, the Tractatus is presented as a description of the Jewish roots of the institution of Jubilee, including an explanation of the meaning of the word kadosh (in connection to the Holy Year) and the meaning of shemyttah (remission), as well as the allegorical interpretation of the menorah (seven-armed candelabrum) and the exegesis of Psalm 67, all topics connected to the Jubilee.

Lazzaro goes beyond a simple erudite description: all of these topics come to support a textual exegesis that culminates in a very intense religious vision in which the elements of intellectual contemplation and mystical union with the divine are repeated and emphasized. This intellectual and spiritual level is made possible, the author insists, by a "conversion" in which liberation from the slavery of the senses (reflecting the freeing of the slaves instituted by the biblical Jubilee) is fundamental. Lazzaro returns often to this intellectual-ascetic vision of humanity, citing the psalms, ${ }^{18}$ the Talmud, ${ }^{19}$ and Christian authors like Lucius Caecilius Firmianus Lactantius (third-fourth century), ${ }^{20}$ but above all autonomously developing the idea that sanctification is preparation for the intellectual conjoining with God, and that the Judaic Law is a means to attain this conjunction.

Man, who is a temple of God and is formed in his image, must elevate his mind - through his own works - to the deepest secrets of God, so that the soul is elevated to the most sublime heights and is shaped by divine thoughts as if he were in God, and God in him. For this reason, the Holy Law commands many things, which allow humanity to arrive at speculation on divine topics. ${ }^{21}$

Spinoza would have liked Lazzaro's interpretation of the Jewish Sabbath: by abstaining from any servile labor on that day, he states humanity dedicated itself to the intellectual contemplation of God, which led to tranquility of the soul:

But by considering the works of God, meditating on the celestial ones and keeping the works of God in the highest veneration, let us truly rest in Him, and this means not to venture outside of our place. Because this place is the justice of the soul, it is truth and sanctification, the quiet and calm of the spirit: this is the true Sabbath. ${ }^{22}$ 
The profound sense of freedom of Jubilee — considered a "Sabatum maximum"- is the liberation from every sensual desire, ${ }^{23}$ and knowledge is the path humanity must take to rejoin with God and receive his wisdom, an experience that was fully granted only to Moses:

Knowledge is the means that allows us to join with God himself. ${ }^{24}$

This concept of the conversion that leads to the intellectual contemplation of God, closely related to the Neo-Platonic sensibility of the Renaissance, could have an autonomous source within the Jewish tradition in the doctrine of Maimonides, described in The Guide of the Perplexed. It is interesting to note that in this case, the focus of consideration was not the Aristotelian inspiration of the philosopher of Cordoba, but the mystical upshot of his work. ${ }^{25}$

Maimonides, the author cited and used by Thomas Aquinas, could easily appear in a text addressed to a Pontiff. ${ }^{26}$ The other explicit citations from Jewish literature are from the Bible or from authors accepted by the Christian tradition of thought and historiography, such as Philo and Josephus. ${ }^{27}$ Rabbis' statements were often accompanied by citations of Christian authors, with the clear goal of showing the proximity of Jewish and Christian doctrine. Firmianus Lactantius, for example, is used to support Rav Catina's statement in the Talmud Bavly Sanhedrin (f. 97a) about the world that will last for six thousand years, and the Sabbath, with its eternal repose of the seventh millennium, was treated as a notion derived from both Jewish teachers and Augustine. ${ }^{28}$ With regard to the value of children praying for their deceased father, and the soul's passage from Purgatory before being received into the grace of God, ${ }^{29}$ although the first idea at least (again attributed to "Jewish teachers") is certainly part of Jewish theory and practice, we can assume that both concepts are mentioned insofar as they perfectly correspond to the orientation of the Catholic Church during that period. ${ }^{30}$ Finally, the benediction that humanity must address to God for both good and evil received, a notion discussed in a famous passage from the Talmud Bavly Berakhoth (f. 60b), is preceded by a citation of "the Divine Augustine" with a similar meaning: "Omnia a voluntate Dei proveniebant, et ideo in omnibus laudandus est Deo." 31

Lazzaro's most frequently cited author is Augustine (eleven times, from six different works), ${ }^{32}$ and this is perhaps not by chance: a number of statements on the will of God as the sole origin of human success (which is therefore independent of both human behavior ["industria"] and the nature of 
materiality) and on the divine aid necessary for humanity to do good ("Ipse enim facit ut velimus bonum"), ${ }^{33}$ together with the aspiration to intellectual contemplation, seem to represent a characteristic element of Lazzaro da Viterbo's religious orientation.

The Tractatus de anno Jubilaei explicitly designates an intellectual space common to Jews and Christians. Not only were the cited Jewish authors chosen from among those recognized by Christian tradition, and the rabbis of the Talmud flanked by the authority of their tradition to validate their statements, but Lazzaro da Viterbo also developed, however briefly, some kabbalistic notions drawn from Yosef Gikatilla's Sefer Yetzyrah and Sha 'arey orah (known in the Latin translation respectively as "Liber creationis" and "Portae lucis"), which were well known to Christian kabbalists. ${ }^{34}$ Furthermore, a detailed exegesis of Psalm 67 was accompanied by a drawing of the seven verses of the psalm arranged like the arms of the Menorah - which was common enough in Jewish prayer books, but was accompanied in this case by the same drawing for the Latin version as well. ${ }^{35}$

The Roman rabbi goes even further in the suggesting a commonality of Jewish and Christian religious notions, indicating some possible parallelisms between a series of passages from the Old and New Testaments. ${ }^{36}$

Given the conclusion of the text - the request for readmission of the Jews into the areas from which they had been expelled - it is difficult to believe that this proposal of common space was not a tactic to gain the favorable regard of the Pope and his entourage. The Tractatus suggested that Jews and Christians shared the same ethical (ascetic) and religious (mystic and contemplative) values, and of course the same foundational texts, the books of the Bible. The only stubbornness ("obstinacy") that Lazzaro dwells on is not that of the Jews who refuse the truth of Christ but that of human nature, which is therefore universal and not denominational: the refusal to abandon servitude to worldly things ("saeculum") and achieve true freedom, which is service to God. ${ }^{37}$

Lazzaro found himself in an extremely delicate position. He had to defend the Jews without claiming that they were the possessors of religious truth, and without placing them in an inferior position, and he had to do all of this in a potentially hostile environment, where the pressure to convert was strong. To get an idea of the difficulty of his task, we need only recall the dedicatees of the three works in non-Hebraic languages that we have seen. Donna Corcos, the dedicatee of the poetic translation, was the daughter of one of the most prestigious representatives of the Roman Jewish community, 
an influential member (hashuv zaken, Parnas) of the Castilian "Scola"38 who, however, converted during the pontificate of Gregory XIII. ${ }^{39}$ Cardinal Guglielmo Sirleto, dedicatee of the writings on the Jewish textual tradition, had since 1568 been patron of the "House of Catechumens," where new converts to Catholicism were hosted and instructed. He also oversaw the application of both the papal bull "Cum nimis absurdum," which ordered a series of restrictions on the Jews, and Church decrees against Hebrew books. ${ }^{40}$ As for Pope Gregory XIII, his name is associated with the papal bull of 1584, which obligated Jews to attend a Christian sermon once a week, and the confirmation of the ban on Jewish doctors treating Christian patients.

While taking into account the intended character of the text as a whole, we must note that its author moved with a certain ease through the classics of the Christian tradition, not only the books of the New Testament but also those of the Church Fathers (Firmianus Lactantius, Augustine, Gregory the Great) and the great thinkers and popes of the Medieval and Renaissance periods (Isidore, Boniface VIII, Nicholas V). Thus, by the end of the 1500s, these sources would become part of the library of an educated Jew, by choice or by necessity. ${ }^{41}$ Throughout this brief treatise, as with other writings by contemporaneous Jewish authors, we are faced with a phenomenon similar to that of Christian scholars of Judaism, which has not been sufficiently featured in historical research: not only were there Christian scholars interested in Jewish literature, but there were also a good number of erudite Jews who demonstrated a knowledge of not just the classical philosophical tradition, but also Christian doctrine.

We must also remember the language of the text: a rich and fluid Latin with Ciceroan influences, which must have surprised the readers of the Roman Curia - that was likely also part of the purpose of the Tractatus.

\section{A Defensive Strategy: \\ The Defense of Jewish Scriptural Tradition}

On an unspecified date, as previously mentioned, "Lazarus hebreus Viterbienses" wrote a brief essay, in Latin and dedicated to Cardinal Sirleto, on the reliability of the transmission of the biblical text by the Jews, responding to attacks from Christians who accused them of having changed passages announcing the coming of the Messiah, Jesus Christ. This was an ancient accusation by the Christians, originating in the second century and appearing in the Dialogue with Trypho by Justin Martyr, for example. 
Lazzaro states that his co-religionists - who had always recognized Hebrew as a holy language, ${ }^{42}$ designating the biblical texts written in it as "most holy" because they were the work of God - did not even minimally alter those texts. On the contrary, they had carefully preserved them according to their laws, which they believed must be followed to ensure eternal life; a sacrilege as impious as altering the word of God was therefore unthinkable. To this religious justification he added an empirical one: the identicalness of the biblical texts possessed by Jews throughout the world, whether "itali iudei, galli, hispani, alemani, greci, africani, et tandem qui trans Eufratem habitant." We can see in this passage, incidentally, Lazzaro's awareness of the different areas of the Jewish diaspora. A similar awareness will be demonstrated nearly a half-century later, in 1638, in another text by an Italian rabbi intended for non-Jewish readers, Discourse on the Condition of the Jews by Simone Luzzatto.

As he did in the Tractatus de anno Jubilaei, Lazzaro takes recourse to notions shared with his interlocutors, supporting his thesis with citations from Christian authors. To a defender of Catholic reform like Sirleto, it certainly seemed acceptable to say that the psalms were more stylistically rich and "mellifluous" than any speech or heroic poem; these were the years of Catholic suspicion of profane literature. The Jews were described in this text as believers, respectful of the Divine Law, and aspirants to eternal happiness. For Lazzaro - and, by implication, for his Christian interlocutor - the fact that they did not chase after the pleasures of worldly life, riches, honors, and power is evidence that this statement did not need to be proven. ${ }^{43}$ In sum, this description portrayed the Jew as the ideal type of religious person, one that fits the model envisioned by the guiding forces of Catholic reform. So strong was the Roman rabbi's desire to present his illustrious recipient with an acceptable reading from the point of view of the Catholic tradition that he was even willing to admit (if hypothetically) that it was the Jews' own fault that they had been dispersed and persecuted. ${ }^{44}$ However, this fault of the Jews was left undefined: it could be putting the Messiah to death, but it is more likely the sins enumerated by the Talmud Bavly. ${ }^{45}$

With regard to Jewish faithfulness in the protection and transmission of the biblical text, prestigious witnesses in its favor include Thomas Aquinas, who considered the Jews "a cabinet [that protects] the Sacred Scriptures," and Agostino Giustiniani, Bishop of Nebbio, who in his Psalterium nebiense (Genoa 1516, the first polyglot edition of a book of the Bible) agrees with 
the Jewish reading of the verse of Psalm 22:17 (21:17 in the Christian tradition), interpreted traditionally by Christians from the Vulgate on as a prophecy of the crucifixion of Jesus. ${ }^{47}$ Addressing another controversial passage, ${ }^{48}$ Lazzaro insists on the correctness of the Jewish version, which, he adds, is perfectly adapted for both Christian and Jewish exegesis.

For Lazzaro, the important thing was to exonerate the Jews from the ignominious accusation of corrupting the scriptures in order to eliminate justifications for Christianity's truth. The Roman rabbi insisted at length on the enormous care that had been taken with the text, preserving it from possible corruptions through a series of measures such as the counting of not only verses but also words, and even the letters of each individual book of the Bible. The Hebrew words were then, he recounted, given attributes of mnemonic symbols, based on a correspondence between letters and numbers. The Jewish scholars also counted the various ways in which the words were written: the number of occurrences with vowel points ("scriptio plena") and without ("scriptio defectiva") and the occurrences with different vowelizations.

According to the author, this enormous task of protecting the sacred text, called mesara (a wording used by Lazzaro instead of the more common masor ${ }^{49}$ ) was the work of Ezra and his Academy (the Keneseth ha-ghedola, "Great Assembly") upon his return from Babylonian exile. The oral tradition, handed down through the generations both through vowels and through accents (going back to Moses, who had received it as revelation), could easily have been corrupted during the years of exile, and so the textual intercession of Ezra and his colleagues was urgent and necessary:

That great academy, and Ezra the first in it, knew that the Hebrew language and the sacred scripture were full of so many minutiae, points and nuances that the details could be corrupted by some means, Thus they devised a way to preserve it intact at all times, and to be able to restore to it final completeness and clarity, should the need arise. Those excellent people then began to create a sort of conduit for the memory that would be handed down through the generations: they called it Masera, or tradition, and left in writing all the signs and rules that had preserved the sacred page in its originality and purity. ${ }^{50}$

Lazzaro takes a decidedly partisan stance toward the dating of the vowelization and accentuation of the biblical text of the time of Ezra, completely ignoring the "discoveries" of the great grammarian Elia Levita, 
already published in 1538 in the introductions to his Masoreth ha-masoreth (Tradition of the Tradition). ${ }^{51}$

Levita had contested the attribution to Ezra and his Academy, with regard to both the indispensable graphic aids to the correct reading of the Scriptures and the masora, the well-known apparatus intended to protect the text from corruption. With rapid and dense argumentation, the German grammarian attributed the editing of the first scriptures to the Masters of Tiberias, who lived in a post-Talmudic era. If the masora had started during those years in Tiberias, he added, many other scholars over the generations made useful contributions. Although he insisted on the conformity of these theses with the statements of the Talmudic teachers, Levita was aware of his novelty: with a typically "humanistic" attitude, he criticizes previous authors and declares that "the truth is recognizable [in itself]." 52 Of course, even Levita did not believe that the authors of Tiberias had innovated in the reading of the Bible; he argued that they limited themselves to inventing a system of symbols that would preserve the oral tradition, which arose from the Sinai tradition. But dating the invention of these symbols to a relatively late era was a delicate gesture in itself in that it removed every aura of holiness from this apparatus, taken in its "materiality."

In a text like Lazzaro's, explicit in its apologetic nature, there was likely no space for a critical attitude that — even in limited amounts - reduced the antiquity, and therefore the authority, of traditional scriptural Judaism. This attitude later found a prestigious foe in Azariyah de' Rossi (who was nevertheless, on other topics, one of the most exacting critics of the rabbinic tradition among Jewish authors $)^{53}$ and, some decades later, created difficulties in the Protestant camp as well. ${ }^{54}$

From the brief presentation of his writings, Lazzaro da Viterbo appears to be a man gifted with an intense mystical-intellectual faith: a talented rabbi and doctor, skilled translator of poetry from Hebrew into Italian, and lucid writer in Latin, he testifies to the intellectual level of the Roman Jewish elite in the late $1500 \mathrm{~s}$. Although the culture of that community was heavily conditioned by the presence of the Catholic curia, it nevertheless succeeded in expressing its autonomy and originality. It is interesting to note how an author like Lazzaro expressed his deep knowledge of the Jewish tradition essentially in Italian and Latin. This appropriation of the tools and content of the culture of the "other" can perhaps be interpreted as a sign of modernity, even if, in this case, it was a forced modernity, imposed by the particular situation of the Jews of Rome. 


\section{APPENDIX: TRANSLATION OF ME'ON HA-SHOALYM}

\section{Paraphrases of the Hebrew Text}

The poet begins by addressing the "Place of the supplicants, supreme end of those who ask for mercy, whose source of benediction spreads life," an allusion to the Third Temple announced by the prophet Ezekiel, or the Celestial Temple, identified with an emanation or manifestation of God.

The supplicant starts with the declaration of his inadequacy ("my spring is like a drop of water in the Ganges compared to the river of the Ancients") and the fear that arises from both the Highness of the Divine Name-indeed, the author merely "draws near to the door of the evocation of God"and the paucity of his own value ("dust that blows in the darkness, without direction").

The soul and body must not fight each other, but must recall how precarious life is, and that punishment could come to both. Here begins a loving prayer to his own soul, in twelve tercets and characterized by an anaphora that is repeated five times: "My soul" (nafshy). The author exhorts the soul to flee from the ruined field in which it wanders: "your oars are deceit and falsehood" (using an aquatic metaphor frequently used in all Rieti's works), "and you cross a sea of bitter waters" (note the alliteration in w-ma 'avarekh ba-yam hem mey marym). The soul is a prisoner of the material body, descended from above to serve God and "drink His water." When the cup is full, to vanish from that ephemeral shade that is earthly life, it must return to its origins.

This exhortation to the soul concludes with a call to action, so that "the already drawn-in wings of my desire [hishqy, a Platonically-inspired term that characterizes Rieti's religious thought ${ }^{55}$ do not exert themselves in vain, and their feathers are not torn by enemy spirits." Indeed, a corrupt life is followed by the fire that burns the human soul, and the passage of the soul from a sacred place to a profane one. And so the final appeal is heard, recognizing he who created the root of existence. This hearing reawakens the soul, which has passed through a period of darkness and vanity in the human body.

The inadequacies of the author are innumerable: he is directed toward the good, but unable to achieve it; he listens to the word of God, but then forgets it; he rebels like a student with his teacher; he evades reproaches, values his own instinct, and has a heart within him that burns like fire. 
A list of sins in poetic form follows, in six tercets, the liturgical formula, in which the failings of humanity are enunciated in alphabetical order (Elohay hen eda' ky ashamty / bagadty gazalty wa-adabber / dofy we-gam harea' hare' oty etc.).

Sin is now so well-rooted as to become a habit that prevents the perception of desecrations, and thus the thoughts depart from God. For this reason, the author once again addresses his own soul, calling on it to present itself before the Lord of the world, at the moment of judgment, as a penitent virgin. So, to save itself, the soul will have to manifest the same energy it has already employed to cast off its treasures and sacrifice to demons, which are only shadows: virginal breasts, adds the poet, were led to a place of menstruation and impurity.

But the root, or essence, of the supplicant was undermined by his folly, enough to prevent his beholding the light and finding the path taught by God: he thus turns to God to redeem his soul, according to the ancient promise, and "the water of mercy spills" onto the sinner.

At this point begins what could be considered the second part of the text - the evocation of a series of behaviors proposed by the author to expiate his own sins (four tercets with the anaphora we-im, "and if"): ${ }^{56}$ if forgiveness is granted through tears, the poet will go off into a secret place and cry, lamenting as if for the loss of a loved one; if prayer is enough, he will offer a sacrifice of words on his altar; if pain is what is required, his heart will dissolve at the enunciation of sins; if penitence is necessary, the author is ready to publicly repent, lamenting, clapping his hands (a sign of pain and grief from the biblical age), and tearing his hair.

He who knocks on the door of divine mercy shall perhaps obtain grace; perhaps God will guide his soul back onto the path and cease to remain concealed, but show again the light of his presence. "Forgive me, o Lord, pardon me," erupts the poet, "I didn't mean to irritate you, it is my heart that perverted me!"

If $\sin$ is essentially related to thoughts, the author has prepared a text (sefer) to serve as a sacrifice of expiation. This text consists of the enunciation of fundamental religious principles (inspired in part by Maimonides) whose function is clearly to purify perverted thoughts. The first principle is the necessary existence of God, followed by his singularity, immutability, eternality (absence of beginning), simplicity (absence of parts), and 
incorporeality (absence of perceivable body). It continues on, saying that the attributes of God add nothing to his essence and that the world was created by Him, through wisdom, from nothing. In this world, the first place is occupied by the angels, saints that are pure and made of incorruptible substance. They are arranged in ten degrees, singing the praises of God and enjoying his intellectual contemplation, some of them being charged with the judgment of earthly things. Since he who was, is, and shall be can only be feared, one cannot help but be amazed and thank him for the beauty and pleasingness of that heightened world.

The angels are followed by a dense crowd of souls, which are returned in flight to the place of their origin and, based on their actions, meet either the fullness of life or darkness and absence of pleasure.

Then come the celestial bodies of impressive majesty, made of a pure material, spherical in form, united as they are to the separate intellects: their movements tell of the extraordinary acts of God. In their great diversity they are - miraculously — directed toward a single goal. Their sizes are frightening; astronomical movements like epicycles and eccentrics must be the subject of grand science. Above them are the fixed stars, with their properties and their astrological aspects, while the sun and the moon are tasked with indicating the weather.

Matter follows, ready to receive its four forms from the last sphere (an allusion to the Aristotelian causes) and the qualities (a possible reference to the categories): here, therefore, are the elements and the corruptible creatures, composed and with a temperament, and subdivided into mineral, vegetable, animal, and rational beings, each with its internal constituent proportion. Only the species persist, while the assembled individuals are destined to die, after the universe deviated off its course (Rieti probably alludes here to the mortality of the human race after the sin of Adam).

"Given all this," continues the author, speaking to God, "we cannot deny Your infinite science. You have rendered the body a receptacle of the soul, made of a simple and intellectual substance, which leads me to know Your ways; because it is not possible to give any definition of You (dimyon mashweh; literally "equivalent image"), and yet this is not even the beginning of the praises of God."

After this "purification" of thoughts through the description of the fundamental elements of the celestial and the material worlds, we return to the 
declaration of sins and the pleas for forgiveness which represent the third and last part of the text. Recalled here is "the day of sounding" (yom teru 'ah), an explicit allusion to the sound of the shofar and therefore to Kippur, which culminates the period of penitence.

The poet prays for God to turn his golden scepter toward him and protect him in the shade of his hand, because his banner is Love: he is repentant, and his heart has been replenished with Grace. God can make blessings come down from heaven and send the Redeemer, who will gather up the people within our lifetime and put an end to their suffering. He can sustain the penitent just as he led the children of Israel when he gifted them with the faith of the elect.

This prayer to the Lord continues with the request to provide the soul with new instruments to serve Him and, above all, to avoid leading the speaker into temptation; that his poor words may be welcomed; that his progeny as well - whom the poet hopes to see up to the fourth generation - may not be lacking in the fundamental needs: food, housing, and science (hokhmah we'iyun, literally, "science and rational investigation"-a formulation typical of an author like Rieti, who attributes an existential value to knowledge). If the merit of his children was not sufficient, could God consider the merit of his Fathers? In any case, the real enemy is still instinct, which he compares to a swollen river or a bear waiting in ambush. So the poet prays to God to save his soul on the day that he offers Him his gift. Here Rieti uses some sophisticated alliteration: kishut kosht nikhsaf ly mi-kesef / emunah omen emeth amarym (a well-adorned offer, more coveted than silver / true faith, words of truth).

The final verses present an anaphora of the word yom (day) in reference to the day of judgment for which this text is intended: it is a day of affliction (an allusion to the biblical command in Leviticus 23:27 related to the day of Kippur, "Afflict your souls"), but also a day of expiation (yom kippur) in which God will accept the prayers offered as a sacrifice, and a day of faith (bitahon) in which God will rebuild the destroyed homeland of Israel, and finally, a day in which the penitent will rediscover God, who will allow him to drink from the gushing fountain of his dwelling place. The circle of invocation of the divine water, dispenser of grace and mercy, begun in the first verses, closes at the penultimate verse, before the ultimate appeal to give peace to his soul and the solemn declaration of love for the Law, which is "more precious than gold and diamonds." 


\section{Italian Text}

IL TEMPIO di M. Moise di Riete, trasportato in vulgare Italiano, da M. Lazaro da Viterbo

Tempio d'ogni Orator fin'e desio

Di chi pietà ricerca, e gratie tante,

Fonte di vita benedetto, e pio.

Vengo hoggi humil col cor, dentro tremante, Sò che'l mio rivo, è breve stilla al Gange, Al gran fiume di quei che furo avante.

Con viso chino, il corpo steso piange, Senza vigor, e'l cor dirotto in tutto.

Forse perdoni Iddio, si strugge et ange?

Contrito, afflitto, macro, e in viso asciutto, Alto tremando, et ho sicuro molto, Fronte impudica, e di Can viso brutto.

Surgomi con preghier, povero e stolto, Ma per doppia cagion, l'alma diffida In arido deserto, ov'io son colto.

Pe'l santo alto tuo nome, ò luce fida, E per lo basso mio stato di terra, Ch'in tenebre ne và, senz'altra guida.

Scrivo in carta, e nel cor, che chiude e serra, Di molte colpe mie, picciola parte, E l'alti lodi tue, spiega e disserra.

Ma con timor m'appresso à ricordarte, E qual cera il mio cor si sface e strugge Ché l'error mio, non ha termin'in parte.
Hebrew Text

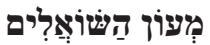

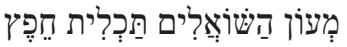

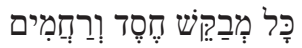

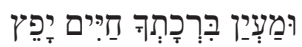

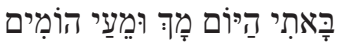

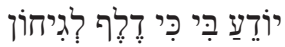

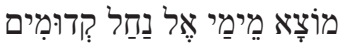

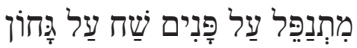

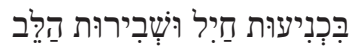

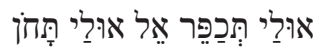

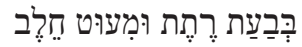

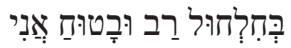

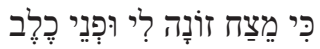

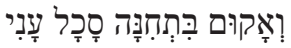

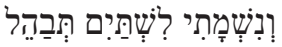


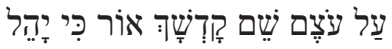

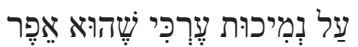

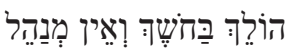

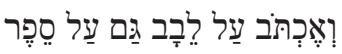

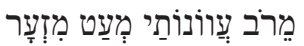

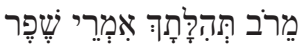

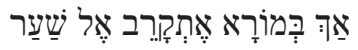

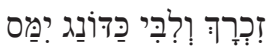

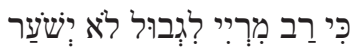


Ah trist'alma, ch'a torto grida, e rugge

Del corpo, et ei con lei và combattendo

Nel gran giudicio, ch'ambedue distrugge

Non pensor prima mai, che non volendo

Ch'al fin la vita, ver me sia con lai,

Sotto tempo, fortuna, e caso horrendo.

Anima inpria che'l mal ne giunga, e guai, Torna pentita, e scampa fuor dal suolo Misero dove ancor'errando stai.

Anima i remi tuoi, son fraude e duolo

E varchi un mar, d'amara acqua, e d'orgoglio,

E l'Angelo di Dio, sententia il nolo.

Alma se post'hai nido in alto scoglio, Qual Capria corri in van segue le peste, Qual chi tramonti, chiama il suo cordoglio.

Se preda sei da luogo alto, e celeste, E son com'ombra i tuoi fugaci giorni, Perché t'affondi in la corporea veste?

Sei peregrina in terra, acciò t'adorni, Tuo velo à server Dio, e ber sue acque, Con l'urna piena, dunque a'lui si torni.

Sia grande, e vivi l'uomo, e da che nacque, Appo'l gran Creator del tutto un'ombra, E tutti con pietà, nutrir gli piacque.

Alma, fin che'l Cortil di fuor s'ingombra, A che ammantata, in le sue stanze entrare, Non speri per viltà, che'l cor t'adombra.

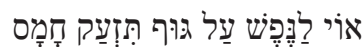

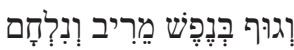

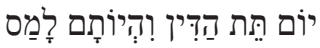

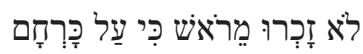

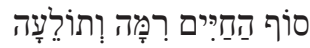

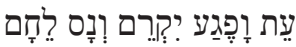

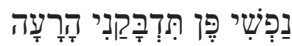

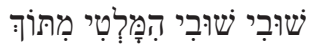

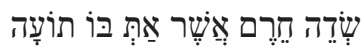

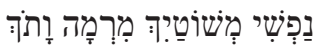

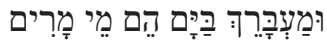

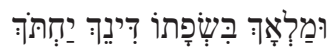

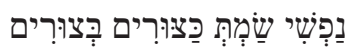

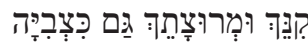

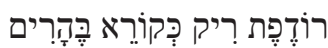

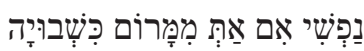

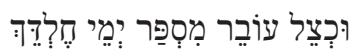

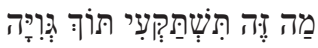

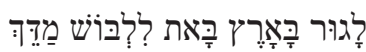

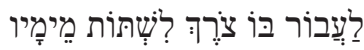

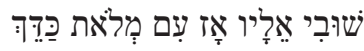

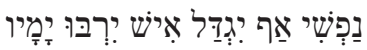

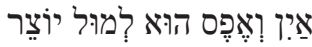

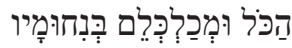

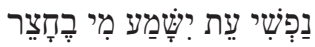

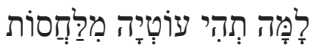

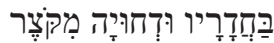


Anima eleva il cor, tempo è di fare,

Ché non sudin in vano i moti varij,

L'ale del mio desir sparse à volare.

O furie, ò spirti amari, lor contrarij,

Faransi incontra, ò sterperan lor vanni,

Corrompendole ancor, come avversarij.

Alma non sai, com'arder con affanni, Fan l'alma umana, in pene, in ira, in foco, E sospinta in profan, da sacri scanni.

Pensa a l'ultimo segno, anima un poco, Sappi chi à l'esser tuo, principio ha dato, Ciò più ti sveglia, che chiamar non roco.

Ché pensando io ch'i giorni del tuo stato Meco, passan in nebbie, e vane schieggie, Corrotto ho le mie vie, da te guidate.

Io mi vergogno, et à chi il tutto regge, Dico mia colpa, e dal dritto sentiero, Torcendo l'error mio, mai si corregge.

Il pregar mio Signor, com'è sincero, Sì grave è l'error mio a perdonarsi,

Ch'al cor l'ho litigat'oggi, ancora intiero.

L'opre del van desir mio, che gonfiarsi, Con l'onde sue, pur lodo, e mi compiaccio, Disegno il bene, e per me non può farsi.

L'aborrito da te, stringo et abbraccio

E quel che vieti in licito contesto, Le tue parole intendo, e da me scaccio.

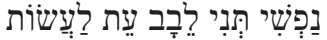

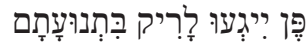

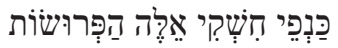

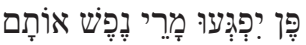

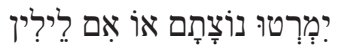

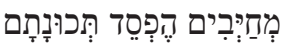

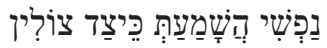

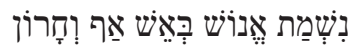

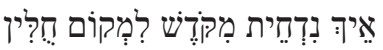

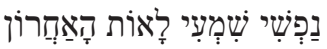

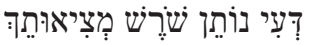

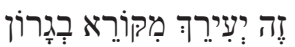

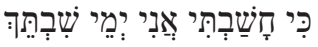

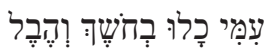

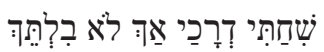

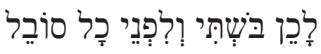

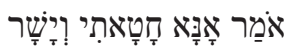

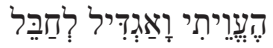

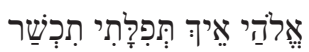

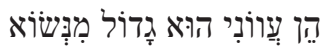

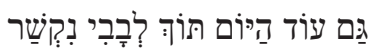

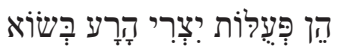

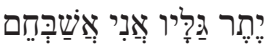

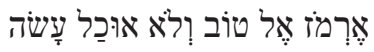

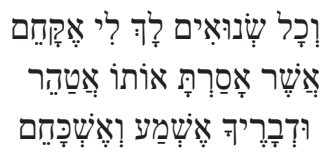

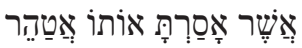

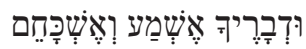


E ne precetti tuoi non son già presto, Ma qual Scolar, contra al Dottor audace,

Corre il mio piede al mal veloce, e desto.

Chi mi riprende, fuggo, e mi dispiace, In aspro il viso mio come dur sasso, Il cor dentro arde come ardente face.

Io sò Signor mia colpa, e mai son lasso

Di mentir, di rubbar, di parlar male,

E fò ch'ognun vien dietro al mio mal passo.

Il dir dei Correttor, fo rotto e frale,

Son empio, adulator, pien di lussuria,

Et à peccati l'accompagno eguale.

Sempre erro, e son immondo, e con gran furia,

A carra il Genio rio, m'empie il cor tutto,

Et ogni mia parola è falsa e spuria.

Ribellar, e schernir son bene instrutto,

E consume il mio ben, falso giurando,

Grand'e'l debito mio, senz'alcun frutto.

Come inimico in infinito errando,

Tort'ho le strade mie, dur'in cervice,

E com'empio à disfar vò pur cercando.

Son d'immonditia già vaso infelice, Lasciando i tuoi precetti, nome e regno, Com'huom che l'alma sua rapir gli lice.

E per uso opro il mal, nel popul degno, E non m'accorgo lasso, s'io profano, Tua legge, ò rompa di tua vigna il segno.

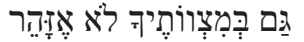

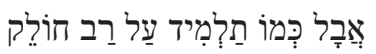

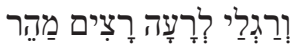

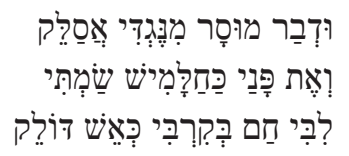

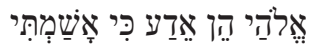

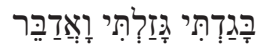

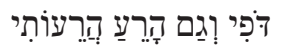

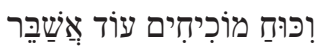

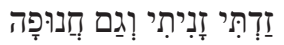

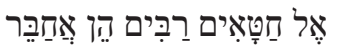

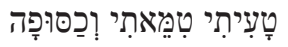

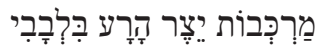

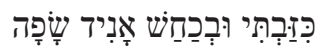

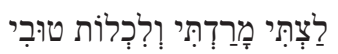

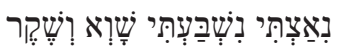

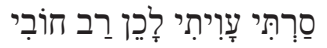

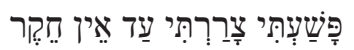

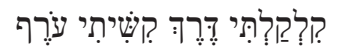

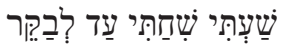

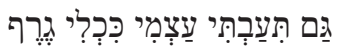

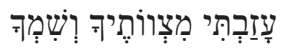

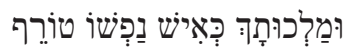

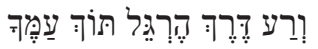

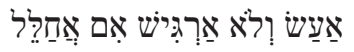

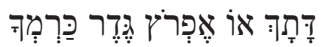


L'occasion per tutto cerco insano,

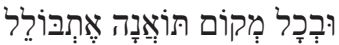

E la tentation sveglio al peccato,

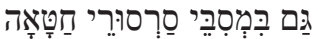
Notte, e dì seco e'l cor, l'occhio, e la mano.

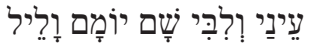

Il cor mio pensa ogni tempo onorato

Disunir me, da la tua faccia vera,

Con diversi pensier, dal dritto stato.

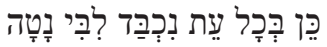

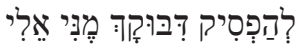

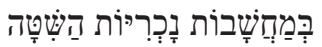

Dura isola, alma mia, mattina e sera

E monti erti gridando, ascendi, e monta, Vergine sconsolata, in vesta nera.

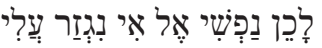

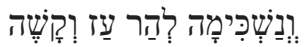

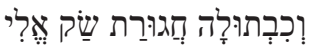

Che'il mio censor qual'usuraro ponta,

De la mia pueritia, i giorni gai,

$\mathrm{E}$ di mia gioventù numera $\mathrm{e}$ conta.

Deh trista anima mia, quando verrai Al Signor in giuditio à tal trascorso, Che dirai tu? o che avantaggio harai?

Ché strugge l'ira sua, la carne e'l dorso, Deh dimmi s'havrai ingegno a fuggir quella Qual fù à celar il mal oprare incorso?

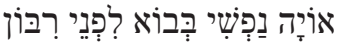

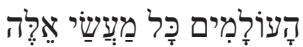

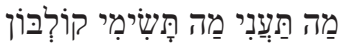

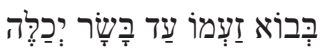

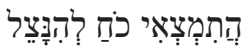

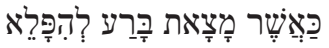

Quando a privarti d'ogni cosa bella, E d'ogni ornato, tue virtù s'unirno

Per imolar à i demoni, ombra fella. ${ }^{57}$

E le cose più care in te perirno

A luoco immondo, trascinate l'hanno, Quì le lor caste mamme espresse girno.

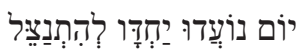

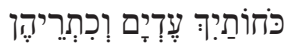

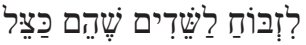

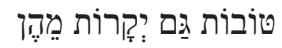

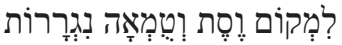

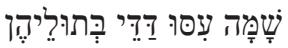

Signor li miei travagli, pien d'affanno, Han girato, e coperto, il capo mio.

E qual ecclisse, l'occhi ombrato m'hanno.

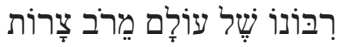

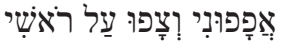

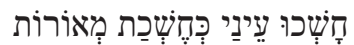


E per pazzia del mio principio rio,

Tornare à quella via non hò saputo,

Che dignaste mostrarne, ò Santo IDDIO.

Ingenocchion dimando il tuo aiuto,

A liberar quest'alma stanca, e satia,

Com'hai promesso, al dì magno, e temuto.

Manda hor Michel, ch'in me, l'acque di gratia Sparga, e torn'io à veder tua dolce essenza, Lasso, se'l penso men, me n'empij e satia.

Se per pianger, perdoni, et hai clemenza, Ecco ch'io piango in loco occulto, e cavo, Com'huom per huom, si duol senza prudenza.

Se per pregar io nel pregar m'aggravo,

Parando ${ }^{58}$ il sacrificio del mio dire,

Su l'ara e del peccato temo, e pavo.

Se cor contrito ottien, ecco perire

Lo spirto, e'l cor gia liquefatto e lento

Mentre conta l'iniquo suo fallire.

Se penitentia vale, ecco io mi pento,

Gridando ohime, con batter palma à palma,

E pelarme per doglia, il capo, e'l mento.

Torno e confesso la mia grande salma, Chiedo alle porte di pietà perdono

Con tutto il cor, gratia impetrando all'alma.

Aiutami da chi sviato sono,

E drizza l'alma mia à solco dritto,

Sempre qual arator perfetto, e bono.

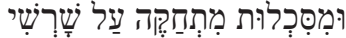

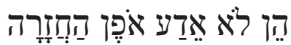

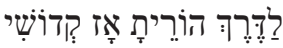

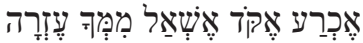

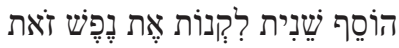

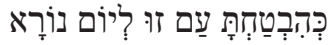

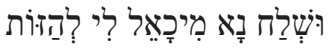

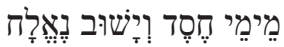

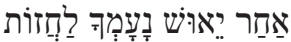

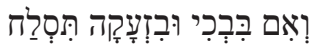

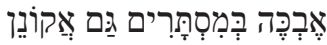

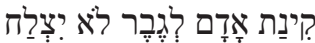

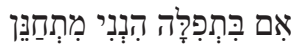

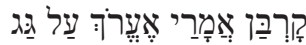

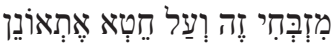

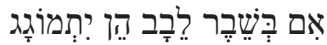

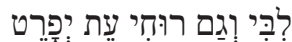

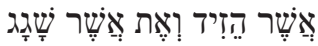

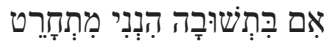

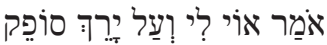

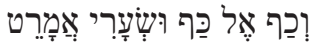

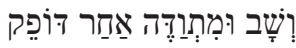

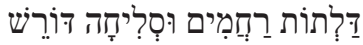

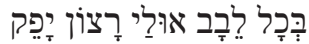

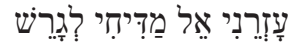

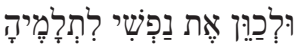

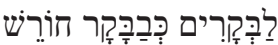


L'alto tuo lume, non li sia interditto,

Né più celato, e sgrava ogni suo peso,

Dacci pene infernal, del gran conflitto.

Perdon perdon, per quell ch'io t'abbi offeso, Deh $^{59}$ santo di Iacob, ch'io son sommerso, E serva anco'l tuo servo, al ben difeso

Ch'alletto stato son da cor perverso, Non per spiacerti, ma l'aspide occulto, Opra l'inganno suo torto, e traverso.

Per l'error ch'in pensier Signor ho sculto, Ho preparato in carta, et in parola Vittime sacre, al tuo sacrato culto.

Dal nome di tua essenza, unica e sola, Comincio, ordino et orno il mio poema, Né tua necessità, si nega ò invola.

Da quella intendo, e pigli il mio gran thema, Ché lei semplice e sol, né in te si trova Principio, ò senso, ò parte alcuna estrema.

Né l'epiteto in te, cos'altra innova, E con l'alto saper tuo senza pari, Creasti il mondo, et ogni cosa nova.

L'angeli eccelsi tuoi familiari

Con santa lode, tuo nome essaltando, Nell'alto regno tuo, son primi e chiari.

Compresi in dieci gradi, e ben pensando, Altro non son, che semplice intelletto Eterni sempre, senz'andar mancando.

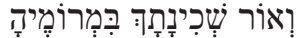

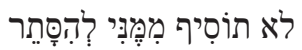

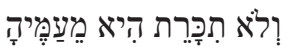

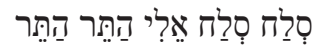

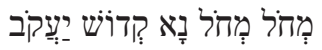

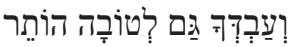

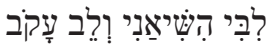

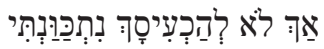

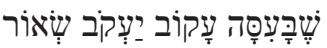

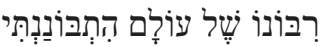

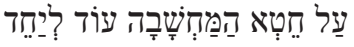

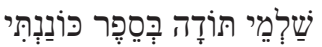

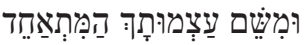

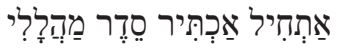

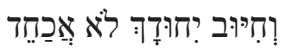

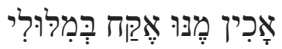

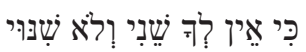

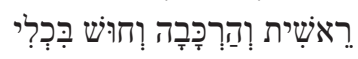

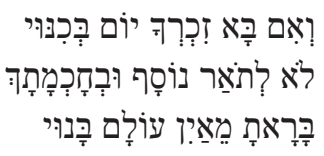

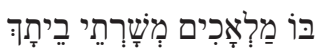

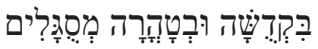

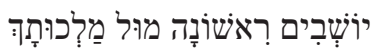

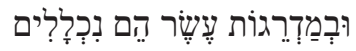

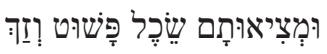

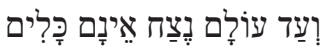


L'ammirande tue lodi, al tuo conspetto,

Cantan mai sempre, e te veder lor luce,

Dal mental'occhio, e san'esser tuo effetto.

Di quei per giudicar mandi alto duce, Il mondo tutto, et ogni tuo creato,

Chi ben, chi mal, tuo detto al fin conduce.

Di te che sempre sei, sarai, sei stato, Chi non harà timor? $\mathrm{e}$ in ogni passo, Con gran stupor d'ognun, sarai lodato.

Di bellezza, di fausto e dolce spasso Empien tuoi servi, e luce son gradita, E nutrimento al cor'afflitto e lasso.

Questi seguita poi turba infinita D'humani spirti, e di là volan tutti, Ivi tornan'a'sorte alla partita.

A l'opre lor, quì troveran per frutti, Tesor di vita, e salute, e sovente Cumuli oscuri di ben privi e brutti.

L'alti corpi celesti, nostra mente Empien con lor grandezza di stupore Di corpo e di sostanza trasparente.

Figura han circolar, e co'l splendore Dell'alma san tua Gloria, e con gl'effetti, Haranno l'opre del tuo gran valore.

In varie spetie, et uniti intelletti, Seguita ognun sua via, con gran prudenza, Dal dolce amato lor tratti, et alletti.

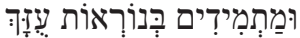

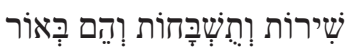

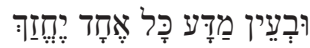

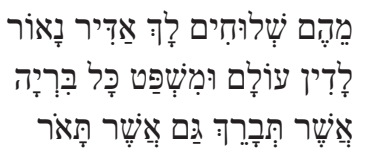

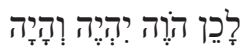

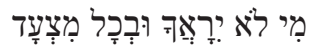

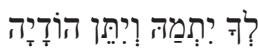

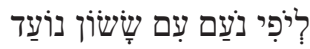

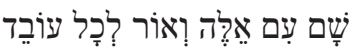

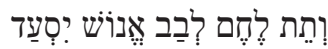

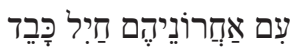

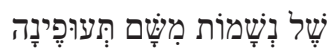

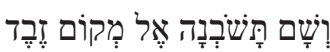

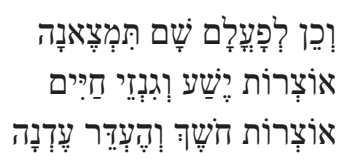

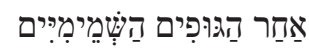

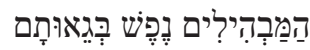

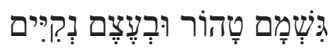

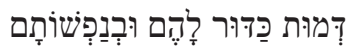

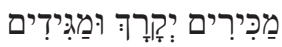

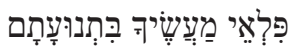

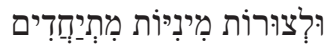

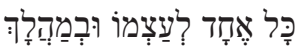

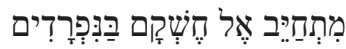


L'infinit'arte e tua gran providenza,

Chi potrà dir Signor, quand'à un fin solo, Accordi ogni lor moto, e differenza.

La lor proportion unisce a volo

Co'l diametro longo il corpo magno, Ove spaventa di Geometri il stolo.

L'epiciclo à l'eccentrico compagno

I varij Poli, e l'altre cose belle

D'alta scienza, e non opra da ragno.

In questi fissi le lucenti stelle

Con lor proprietà stati, et aspetti,

E la reflession de lor fiammelle.

Ecco il Sole, e la Luna in via esperti A girar sempre sopra ogni sapere, $\mathrm{Al}$ variar de tempi segni certi.

Poi la materia, il ciel con suo piacere Fa ch'a ricever quella atta diventi Le quattro forme, e sue qualità vere.

Queste son prime forme, et elementi Di ciò che nasce, ò more sotto il cielo Uniti, e misti co'temperamenti.

Forma lor quantitate giust'a pelo Inanimato pianta animal'huomo, Ma terminati ben tra'l caldo e'l gelo.

E per che ogni composto è frale, e domo, E l'individuo per se poco dura Ciascun passando qual caduco pomo

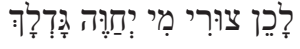

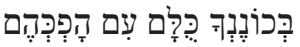

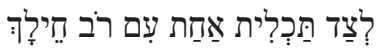

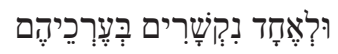

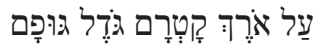

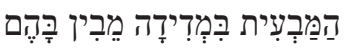

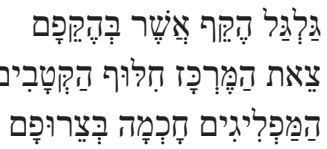

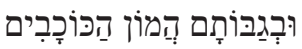

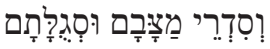

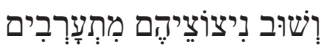

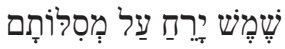

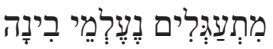

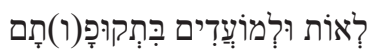

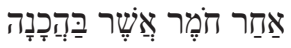

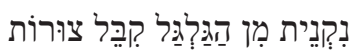

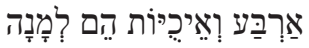

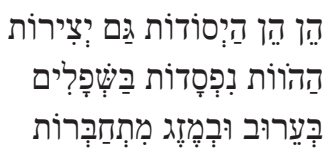

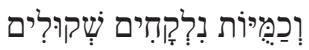

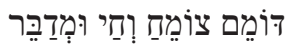

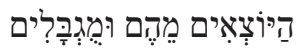

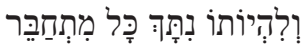

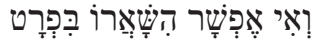

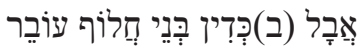


Quinci ben provedeo l'alma natura

Succedendo in le specie restorarlo

Poi ch'a durar la via, non fù sicura.

Il saper tuo Signor, chì mai negarlo

Potrà ch'à darli termine non lice,

O l'esser tuo santissimo occultarlo?

Fatt'hai nostra materia suscitrice

D'anima rationale, e d'intelletto

Imisto, ma di lui albergatrice.

Da lui vien quella luce, che fà retto

Mio piede alle tue vie attento, e bono:

Dunque simil non hai Signor perfetto.

Quest'è giorno cor mio d'horribil suono

Cor mio, ah figliuol vano, ah figliuol tristo

Che dà d'infamia pena, e non perdono.

E si d'honor disprezzi il vero acquisto

Per il velen di neghittosa vita,

Scrivi à tuo libro pur ch'ancor sia visto.

E questa mia dottrina così ordita,

Principio è de sue lodi, né potrete

Dir l'alta gloria sua haver finita.

Signor del mondo à te drizzo con sete

Lo spirto, e l'alma, e pien d'affetto il core

Ligato quasi un bù con fune, ò rete.

E si t'è grato, e piace alto Signore

Tua verga d'or mi porgi con baldanza

Co'l nome tuo mio bon procuratore?

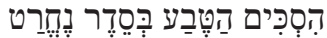

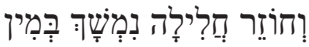

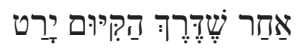

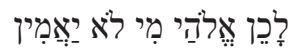

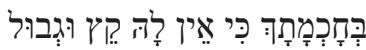

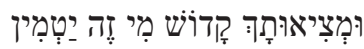

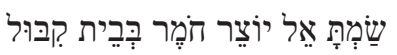

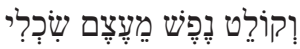

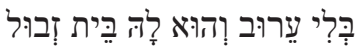

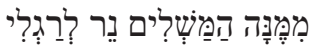

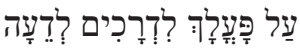

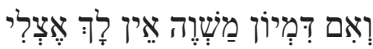

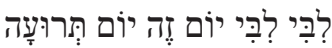

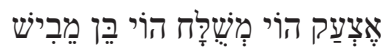

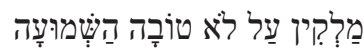

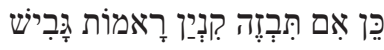

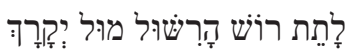

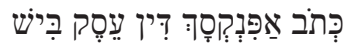

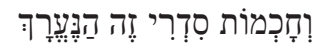

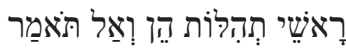

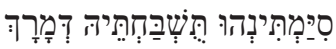

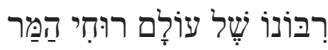

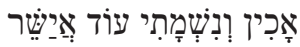

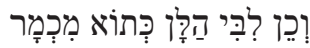

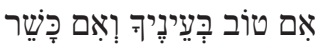

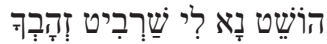

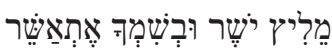


E come servo in te post'hò speranza

A te l'occhio alzo sempre, e'l vero santo

Canto, riponi in Dio la tua fidanza.

L'ombra della tua man per ogni canto

Sia mia custodia, e'l suo vessillo amore,

E l'opra tua favor m'è gratia, e manto.

Trahe di travaglio fuor la pien d'errore

Anima mia pentita, trista, e satia

Di mia stoltitia ingrata al suo fattore.

Ché per pietà'l cor mio pien hai di gratia E di me vede, ma qual prima in volto Appar né più né men con sua disgratia.

Deh Signor fà che successo da stolto Non succeda al tuo servo, e vogli amarlo, $\mathrm{E}$ da grande sentenza sia assolto.

E l'opre mie non le rodi mai tarlo,

E gratia piova giù d'ogni pianeta

D'ogni Ciel, d'ogni segno à consolarlo.

E manda al Popul tuo quel gran Profeta Predichi a'i figli, il Redentor ne viene A congregarli, e farli gente lieta.

Né me macchi mai stil de peccatori, $E$ di chi è morto per santificarte

Le cenere ricorda, e lor arene.

E come ci portaste in quella parte Con l'ali tue à darci ${ }^{60}$ eletta fede Aiutan'hoggi in strada d'adorarte.

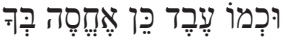

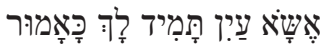

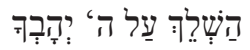

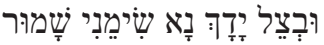

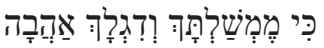

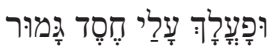

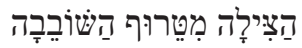

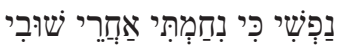

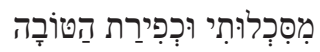

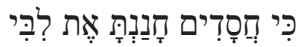

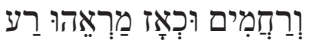

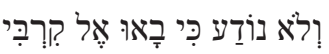

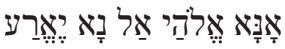

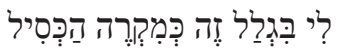

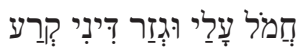

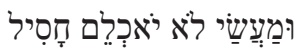

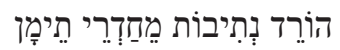

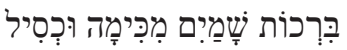

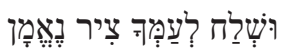

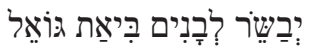

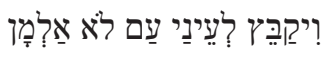

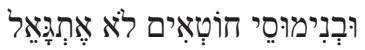

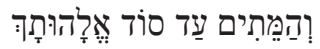

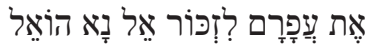

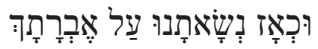

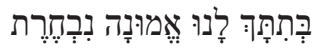

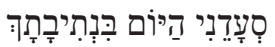


Novi instromenti l'alma mia richiede

Acciò ti servi, e torni à te pentita

Nascosa al mal si ${ }^{61}$ sia per tua mercede.

Creasti me per tua gratia infinita,

E manco al dover mio qual huon mendico

L'arte è assai longa, e breve è nostra vita.

Deh salva me da vergognoso intrico

Nella breve mia vita vana e stanca,

Non mi tentar Signor, ch'io te'l supplico.

Ben che'l domandi [e sia $]^{62}$ di scienza manca

Quest'alma mia con l'occhi pien di pianto

Lava la macchia mia, e'l rosso imbianca.

Mentre il mio don mi passa innanzi alquanto,

E la mia oration da terra s'ode,

Con pietà, con perdon, piglia'l mio canto.

Nella tua legge di mirabil lode,

Ré mio sia'l mio consiglio, e di bon core

Il seme mio ti serva, e senza frode.

Né mai li manchi ò vivo Pastore,

Vitto, e vestito, e sapere, e scienza,

Et abbracci io'l mio quarto successore.

Per Israel che piange à penitenza

Empite di pietade, e basti hormai

Tua casa empin d'offerte in tua presenza.

E si'l merto de figli poco fai,

Unisci seco i meriti paterni,

Che'l nome tuo potente aperto l'hai.

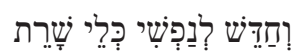

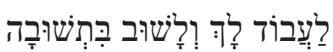

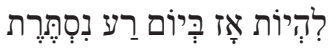

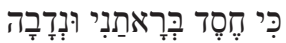

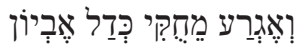

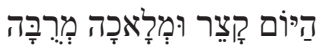

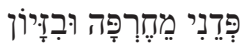

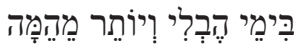

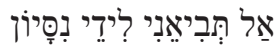

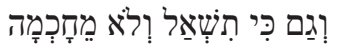

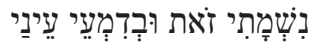

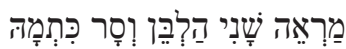

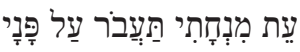

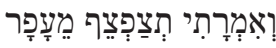

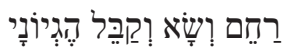

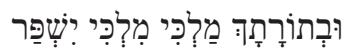

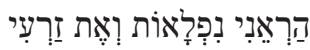

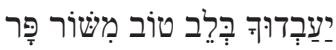

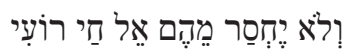

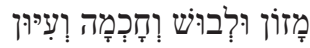

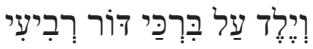

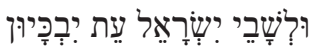

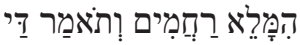

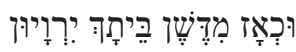

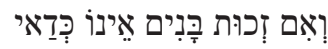

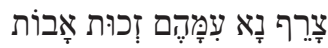

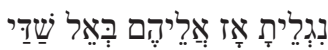


E così tutti i cuori, e membri interni

Te crederanno da l'Orto à l'Occaso,

Gratioso Signor de beni eterni.

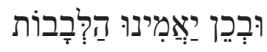

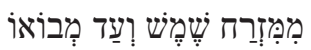

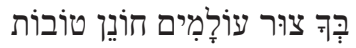

Dell'error suo ciascun ben persuaso,

Che torni à te Signor pietoso aspetta,

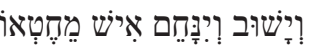

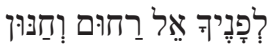

Che vedi il cuor d'ogni huom dentro al suo vaso.

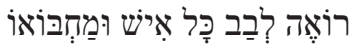

Qual vengo hoggi io con mille canti in fretta

Chiedendo à te perdon vivo, e leale,

Temendo l'ira tua più che saetta.

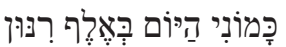

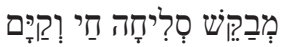

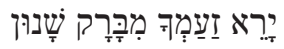

Temo questo mio genio che m'assale

Come torrente turbido, e sonante,

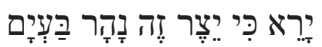

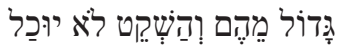
Né può chetarsi, e'l mio pregar non vale.

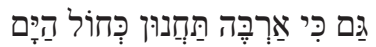

M'ha consumato in fin'à l'alma avante,

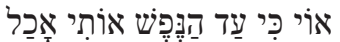
E sta qual'Orsa al guado ascosa, et erta $\mathrm{E}$ tutti miei pensier misura inante.

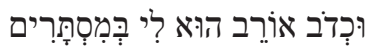

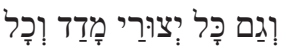

Salva hoggi l'alma mia mentre l'offerta Ornata, e vera, e più cara ch'argento

Con vera fede io t'offerisco, e certa.

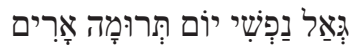

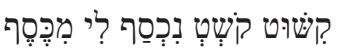

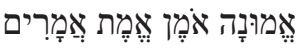

Dì d'afflizion di cuor, né mai più spento Il mio sol sia, e la mia luna asperghi

Sette volte il suo lume in augumento.

Dì di perdon è sempre in ${ }^{63}$ me alberghi

Mentre l'offerta pur conduco a fine

Di quest'orar, e come incenso emerghi.

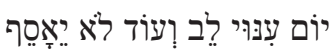

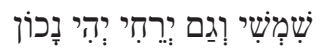

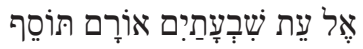

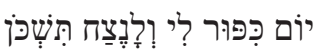

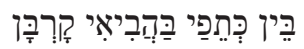

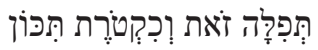

Dì di speranza à murar le ruine

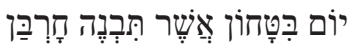

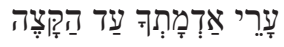
Et Israel ritorni al suo confine.

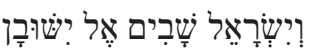


Dì che sete ho di te grande, et asciutta, E fa ch'io veda, e bevi se ti piace

L'aqua del fonte in casa tua condutta.

Grida anco à l'alma mia pace pace,

E tua legge intenda io ché più che gemme, E più che l'oro è cara alta, e verace

Com’ognun canta per Gierusalemme.

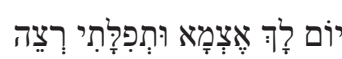

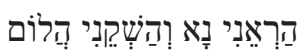

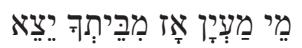

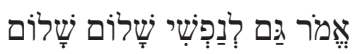

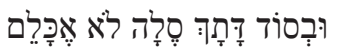

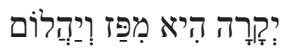

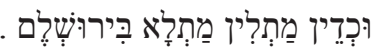




\section{7 \\ Leone Modena's Magen we-herev as an Anti-Catholic Apologia}

The Venetian rabbi Leone (Yehudah Ariyeh) Modena's anti-Catholic Magen we-herev (The Shield and the Sword) has usually been read as an exemplarpossibly the last - of a religious polemical genre that developed in the Middle Ages. By stressing how the work fits into a long tradition, such a reading highlights the ways it both differs from and resembles the texts that preceded it. ${ }^{1}$ In this article I wish to concentrate on the work's Jewish and Christian cultural context, the guiding idea behind this analysis being that terms and concepts which belong within an established tradition can at times take on new meanings when reapplied in a different context. There is no lack of originality in Magen we-herev, but it is also possible to read in a new light those elements that, on first reading, would seem to be no more than repetitions of familiar devices. Leone Modena wrote this work, an anti-Christian apologia, in 1643, five years before his death. ${ }^{2}$ Two centuries later, Abraham Geiger described the work - still in manuscript form - in a marginal comment in his edition of another of Modena's works, Magen we-tzinnah (The Shield and the Target); ${ }^{3}$ it was not until 1960 that an edition was produced by Shlomo Simonsohn. ${ }^{4}$

Magen we-herev is divided into five sections (mahanoth, or camps, as the author called them, using the language of polemical jousting), themselves divided into chapters (ma arakhoth, or "battle orders") on original sin, the Trinity, the Incarnation, the virginity of Mary, and the Messiah. According to the initial plan, which Modena was unable to complete, there should have been three more sections, on the death and resurrection of Jesus, ${ }^{5}$ the eternity of the Torah, ${ }^{6}$ and miracles. ${ }^{7}$

In the introduction to his edition, Shlomo Simonsohn asserts that the author does not depart from the traditional framework of medieval JudeoChristian polemic. He does, however, remind the reader that Modena proposed avoiding as far as possible a scripturalist approach, i. e., an analysis of biblical verses contesting their Christian interpretations, favouring instead a purely logical approach. ${ }^{8}$ The following study attempts to demonstrate that, when compared with the Jewish polemical tradition, Modena's method is, in 
fact, innovative, and thus in tune with the profound changes then sweeping across the intellectual scene in Europe. Moreover, some aspects of the work are innovative even within this context. It is true that its originality is not immediately apparent: the arguments propounded appear to be drawn from a familiar arsenal, and at first glance the logic followed would seem to be within the philosophical tradition of Aristotle and Maimonides. The work's modernity would seem to lie purely on the stylistic level, for Modena's Hebrew, though dependent on rabbinical Hebrew for both vocabulary and phrasing, is remarkably vivacious and supple, rendering with clarity the author's thoughts, both in discussing theoretical questions and in passages that are closer to the language of everyday speech.

It is also true that Modena's avowed intention was not to innovate: ${ }^{9}$ if novelty there was, it depended in part on the nature of the work it was preparing to criticize. His work was in fact an answer to the most recent and comprehensive anti-Jewish text, Pietro Colonna Galatino's De arcanis catholicae veritatis, published a hundred and thirty years earlier and reprinted several times. ${ }^{10}$ We do not know whether there were particular circumstances that drove Modena to write a major text like this at such an advanced age, and can only guess at his intended readership. The only theory advanced to date has come from Howard Adelman, who suggests that Modena's true aim was to oppose Christian missionaries' use of Kabbalah for conversion purposes. ${ }^{11}$

Magen we-herev is in many ways, however, a modern and original work, its originality residing in its sustained rational method, the consistent use of which results in a historical vision being applied to fields hitherto not subject to this kind of examination and a type of analysis that could be described as pre-anthropological.

\section{Asynchronous Criticism}

The polemical target of Magen we-herev was thus Pietro Galatino's De arcanis catholicae veritatis, a choice dictated by the importance of that work. According to Modena, refuting the arguments in Galatino's book would refute all the anti-Jewish arguments before and after it, for

he alone, among the numerous authors who have written religious polemics against the Jews, said and wrote all that was possible by their method. He took into consideration everything in the Bible, our commentators 
and the texts of the Talmudic scholars; he overlooked nothing, from the smallest to the greatest point, which could have supported our position. [... ] Every other work written against the Jews by Christian authors on these subjects - and I know almost all of them-plagiarised this book, without adding anything. And, as the principal author in the field, he was first among the liars and forgers. ${ }^{12}$

In reality Magen we-herev follows Galatino's book only in part, sporadically; Modena's logical progression is his alone and, moreover, places his argument on an entirely different level. The different cultural contexts of the two authors easily explain the differing tone of their works.

De arcanis catholicae veritatis was written in support of the "Christian Kabbalist" Johannes Reuchlin (1485-1527) in his struggle against the Dominicans, especially Jakob Hoogstraten. The text is presented as a dialogue in which Reuchlin (Capnius) and Hoogstraten (Hogostratus) put questions to Galatino. The work's central premise is that the Christian truths are to be found within traditional Hebrew texts, not only the Bible but also the Talmud and Kabbalist literature, if they are read correctly. Obviously, these truths are generally expressed in veiled terms, which is why the only possible interpretation of the texts - considered, moreover, by Talmudic scholars and medieval Jewish authorities such as Maimonides to be the truest and most profound one - is of a spiritual or mystical nature. To the question of "whether the Talmud should be accepted by Christians,"13 Galatino answers decisively that it should, as a reading which takes account of the Talmud's enigmatic language would reveal "arcane" truths of Christianity. Contemporary Jewish sages ("nostri tempori"; "universus recentiorum magistrorum et iuniorum Talmudistarum coetus") understood only the outer crust of the scriptures, their literal and historical meaning; they could rightfully be considered blind, almost devoid of intellectual insight. ${ }^{14}$ De arcanis catholicae veritatis thus aimed to use the Jews' own arms - their texts - to force them to recognise their errors. ${ }^{15}$ Recourse to hebraica veritas, or Jewish texts in their original language, thus served as an instrument of religious polemic, but also re-established the meaning of the scriptures, which had become corrupted in their Latin and Greek versions,${ }^{16}$ the philological insistence that characterises humanism, albeit used for apologetic purposes, was obviously present in Galatino.

In his other works, most particularly De vera theologia and De sacra scriptura recte interpretanda, ${ }^{17}$ Galatino accentuated the tendency to mystical 
interpretation, adding to it an elitist aspect: the sacred mysteries could not be made available to all, which is why God revealed the correct method of exegesis to the Elect, allowing them to lift the veils enfolding the secret knowledge. ${ }^{18}$

The Kabbalah forms part of the classical Jewish corpus that, according to Galatino, contained Christian truths. De arcanis in effect presented a number of explanations inspired by the Jewish esoteric tradition. Moreover, he considered himself a "Christian Kabbalist," the latest in a line that began with Giovanni Pico della Mirandola and culminated in Egidio da Viterbo. ${ }^{19}$ Galatino did not, however, need to resort to Kabbalah to show that Jewish texts announced Christianity, for in his opinion the Talmud itself-which is considered an esoteric corpus - expressed these truths, and it is effectively upon the Talmud (and the midrash) that he principally drew. One is therefore forced to moderate quite extensively (in spite of his self-definition) the historiographical assessment that classifies Galatino as among the Christian Kabbalists, ${ }^{20}$ and which probably influenced Adelman's judgement regarding Magen we-Herev's intended readership.

Modena worked in a context that differed significantly from Galatino's. Mystical or spiritual interpretation was no longer the order of the day among Catholics, the Protestant "heresies" had become established confessions, and knowledge of Hebrew was no longer rare among Christians. The Venetian rabbi's approach was therefore informed by other criteria: he almost completely abandoned the scriptural examination so central to Judeo-Christian polemic and cited the Talmudic scholars only where their affirmations seemed to him to be rational, or at least to be reasonable opinions (sevara). ${ }^{21}$ For Modena, then, the primary criterion for examining religious thinking must be reason: recourse to auctoritas had virtually no place in his argument, other than in correcting the mystical reading of the Bible by certain Christians. Even then the authority is that of good sense, which forces an understanding of the text according to its obvious meaning.

\section{A Model for Rational Religion}

Between apologia - defence of the Jewish religion - and polemicscriticism of Christianity — or, in other words, between the "shield" and the "sword" of Magen we-herev, the second is certainly uppermost. If that is explained by the nature of the work, proposing as it does to deny Christianity any legitimacy by refuting Christian claims to biblical roots, it is, on the 
other hand, interesting to note that Modena constructs a positive model for religion through his criticism of Christianity, through negation. This religion of his is largely suffused with the spirit of rationalism: it is a Judaism based on reason, or at least on the reasonable, avoiding everything contrary to the laws of understanding and good sense. In the rational Judaism that is gradually taking shape in the text, the attribute (rational) at times appears to have more weight than the substantive (Judaism), for it is the responsibility of the intellect to judge what is a just belief; the correspondence between Jewish religion and reason noted by Modena is thus immediately subjected to a condition, no less so because of its hypothetical character:

If we were to find in the Torah something that clashed with reason, we would adapt the Torah to fit with reason, rather than adapt reason to the Torah. ${ }^{22}$

In talking about "adapting" the Torah to reason, Modena built on the rationalist position of Averroes and Maimonides, who, in the event that reason and scripture diverged, expected the latter to be "interpreted" until the necessary consonance was found. Modena could not fall back on interpretation - especially allegorical interpretation - to reestablish the rational meaning of the scriptures, as it was on exactly this kind of reading that the Christian apologists based the arguments they used to justify their dogma. Christianity's weakness lay in its systematic recourse to irrational beliefs. Contrasting at all levels with the rules of logic, these beliefs corresponded neither to sensible knowledge nor to intellectual understanding, whatever its degree of formal rigour. How, for instance, was it possible to claim that Jesus saved all mankind and by his death banished idolatry, when

Christians do not make up one percent of the world's population $[. . .]^{23}$ We can see that the majority of men do not accept the cult [of Jesus] and would thus be condemned to the perdition of their souls. ${ }^{24}$

Christians might well claim that with the coming of the Messiah mankind had been freed from curse, wrote Modena: good sense denied the claim, for "our senses affirm that men die, that they toil to nourish themselves with the fruit of the land, that women bring forth children in pain." We might "deny our condition: it is nonetheless visible enough." ${ }^{25}$ 
On a higher level than sensible understanding, though based upon it, intellectual understanding also attested to the impossibility-or, expressed more clearly, the inconceivableness - of certain Christian beliefs, according to Modena. For him, Christian theology did not follow the usual order of intellectual understanding, whereby the understood is preceded by an intelligible abstract (muskalym mufshatym mi-homer), placing, in other words, the imagined object in a coherent, non-contradictory context of the conceivable. It followed the opposite strategy of the imagination (tziyyur vedimiyon ${ }^{26}$ ), which conceives of an object at will and justifies it a posteriori. The Christians imagined Jesus to be God, which led them to construct increasingly incomprehensible dogmas to justify his human nature and death. The difficulties inherent in conceiving of the Trinity-three persons simultaneously equal and different with all the subtle differentiations between the modes and essences of the three persons - naturally gave rise to numerous heresies. ${ }^{27}$ The Christians framed the facts to fit the theory or, as Modena stated it more popularly, "[the Christians] cut off the toes to fit into their shoes." In other words, they built a dogmatic structure from false premises, and were thus forced to draw a series of irrational and absurd conclusions.

Drawing on Maimonides (The Guide of the Perplexed, I:50) and Yosef Albo (Sefer ha- 'Iqqarym, 1:22 and 3:25), Modena spelled out his plausibility criterion for a belief:

Belief is not something that is spoken only in words, but something conceived of in the soul, in the belief that the thing exists outside of the mind contemplating it. It can refer to an order of things not found in nature (like the transformation of Moses's staff into a snake), but not one that goes against the intellect (as would be the case-for example - with simultaneous being and not-being). [ ... ] In the Torah of Moses, the founder of the first among religions, ail the commandments concerned sensible or thinkable truths. ${ }^{28}$

The principle applied above all to the concept of original sin, the notion that Modena considered to be the basis of the Christian belief system. The idea that the first man committed a sin that stained and diminished his soul, a degeneration that was then passed down into the souls of every man, was a false, even an absurd, idea. The sacrifice of Jesus, man, and God necessitated by such an extreme notion, was but a flatus vocis unacceptable to 
the intellect; the union of the human and divine natures of Jesus and the transmission of the sacrifice from the one to the other "is nothing more than words, of which we cannot really conceive." 29

Another conclusion that follows inevitably from the basic assumptions (original sin inherited by souls, the incarnation of God the Redeemer), and one the Christians did not fail to draw, was that the souls of the just who died before Jesus must be consigned forever to limbo, a region of hell from whence they are freed by Christ. But heaven and hell, argued Modena, were merely imagined by man to represent in his mind the rewards and punishments for acts committed on earth; if the idea of reward and punishment was therefore a logical necessity, its precise nature-rejoicing in the divine presence or suffering spiritual and bodily torment, by fire for instance-was the pure fruit of the imagination, as were the terms gan 'eden, heaven, and gehinnom, hell. Limbo was a case of pure invention (hamtzaah 'al hamtzaah, beduta 'al beduta), designed to justify the absurd idea ("that cannot be contained in thought" ${ }^{\prime 30}$ ) of the punishment of the pre-Christian just. Because of the notion of original sin affecting all souls from the very first man, and that of the consequent coming of Jesus the Redeemer and his death, the position of the just who had served God constituted a problem, concluded Modena. Thus the new invention, limbo, became a necessity. ${ }^{31}$

\section{The Stumbling Block of Original Sin}

Modena's refutation of Christianity operates according to a logical structure. From the beginning it attacks original sin, the idea it takes as central, to show it up as inconsistent: the rest of the argument follows seamlessly.

Placing himself within a well-established Jewish interpretive tradition, ${ }^{32}$ Modena diminished the extent of the first man's sin compared to the Christian notion ${ }^{33}$ by criticising the very notion of its being "original" or "radical." The consequence of Adam's sin was physical and not spiritual. Individual souls come directly from God rather than the bodily parents: they are thus pure and are rewarded or punished according to their behaviour in earthly life. There is no original stain and therefore no need for a redeemer of souls. ${ }^{34}$

In comparison with his predecessors, Modena distinguishes himself by the precision with which he develops his argument and by his frequent use of Christian sources, not only the Gospels - for which there were precedentsbut also such a theological authority as Thomas Aquinas. ${ }^{35}$ 
Modena quotes and summarises the chapters of the Summa Theologica that deal with original sin; these texts seem to suggest that at the beginning of his study, as a free thinker untrammelled by prejudice taking a purely rational approach, Thomas came to conclusions identical to those reached in the Jewish tradition. ${ }^{36}$ At the end, he introduced by main force (dahaq et 'atzmo) a conclusion that conformed to Christian dogma, breaking his line of reasoning. Having developed the idea that the son does not bear the consequences of the father's sin, for only the physical, bodily element ("not as a leper begets a leper through some defect in his sperm") and not the soul are influenced by inheritance, Thomas concluded that all men could be considered a single man, insofar as they all inherit from their first parent. ${ }^{37}$

But if, according to Modena, sin had consequences for the body, what might they be? Somewhat surprisingly, it is his polemical target, Pietro Galatino - the author of the anti-Jewish work which provoked the writing of Magen we-herev - that he chooses to quote on the subject. He is "in total agreement" ${ }^{38}$ with the affirmations of De arcanis catholicae veritatis, which he mentions and then proceeds to develop. Galatino had defined original sin itself as being an absence of original justice - in other words, as the rupture of internal harmony, based on the subjugation of the will and lesser psychological faculties to reason-and its effects as "fomes peccati, scilicet concupiscentia," impulsion to sin, following Augustine. He confirmed the latter definition in his identification of sin for the Jews: using a number of genuine and false midrashym, Galatino identified it with the yetzer ha-ra', which he interprets as "plasma, sive figmentum malum," an evil conformation (from yatzar, to form) manifested in a disposition towards sexual corruption. ${ }^{39}$

The sin of the first man therefore led to a weakening of the flesh, which expressed itself through disproportionate sexual proclivities, and the purification announced by the prophets dealt with this sullying of the flesh. As Modena wrote to a Catholic correspondent, apparently some years before he wrote Magen we-herev, this belief had been denied by "some Jewish schismatic sects like the Sadducees and the Samaritans" but adopted by "the true Jews, which is to say the scribes and the Pharisees, whose doctrine was also followed by Your Lord in his articles of faith," as demonstrated by the Gospel according to Matthew, chapter 23, verses 2-3: "The scribes and the Pharisees sit in Moses' seat: All therefore whatsoever they bid you observe, that observe and do." ${ }^{40}$ Modena finds support for these affirmations 
in other, more recent, Christian authors: he mentions briefly, but without naming them, a number of "important sages" (hakhamym gedolym) whose theses ("quite the equal of our own"41) he had read in "The History of the Council of Trent."

\section{Coincidence Between Jewish and Protestant Theses}

The Istoria del concilio tridentino, written by the Servetian friar Paolo Sarpi, a contemporary and fellow-citizen of Modena who held the influential position of state theologian in the Venetian Republic, is a major piece of critical historiography on the official positions of the Church of Rome, detailing the discussion on original sin which took place in Trent in May/ June of $1546 .^{42}$

In the course of the discussion, the Dominican Ambrosio Catarino declared that original sin, the punishment meted out to the first man and all mankind, consisted in concupiscence and the forfeiting of justice (harmony between the various faculties), and denied that this sin was passed down in a hereditary, physical, manner. This position was rejected. As for the extreme version of this idea, which laid aside the fault of the soul to stress the identification between sin and physical inclination - the version supported by Modena - it was seen as a Protestant proposition and was correspondingly condemned.

Sarpi wrote that the discussion became so complicated that "the bishops, of whom very few had a theological understanding [...] were confused by the scholastic and complex manner in which the subject was handled." One of the condemned propositions was referred to by Sarpi in the following terms:

Original sin is an inclination to evil in nature corrupting children, in such wise that when reason begins to manifest itself, it provokes a horror of the divine and an immersion in the worldly. ${ }^{43}$

Whether Modena's reference to Sarpi's work, which was not specific, was deliberately allusive or not, the parallels between the Jewish position and that condemned as Protestant is interesting. ${ }^{44}$ It allows for the possibility of a partial but significant dogmatic convergence between the two religions, for whatever reason. The interest that certain aspects of the Jewish religion held for the Protestants, including the central position afforded 
reading of the Bible and the Old Testament in particular, was perhaps the principal attraction; or the Jews' hope that the new religion, by fracturing Christian unity, would perhaps inaugurate a more peaceful era. ${ }^{45}$ In reality, for this objective convergence to be understood the term Protestant must be qualified. If there is a closeness between Modena's position and that of some Christians, the Christians in question are members of minority heretical movements such as the anti-Trinitarians, rather than the Lutherans or the Calvinists.

The proximity expressed itself above all in a rational approach to scriptural interpretation and regarding Christian dogmas, which Modena shared with both "avowed" and potential anti-Trinitarians. Criticism of the Trinity inevitably follows this approach. ${ }^{46}$

Modena was disposed to admit ab extra multiplicity, or attributes, aspects, or manifestations of God. The philosophers (Modena was thinking of Maimonides ${ }^{47}$ ) expressed them through the distinction between the intellect, the intelligence, and the intelligible, specifying that to God, who is knowledge made manifest, these three different things are one; the kabbalists called them sefyroth, as Menahem Recanati wrote in his commentary on the Torah; Plato spoke of "ideas." ${ }^{48}$ But if we assume an essential identity between unity and multiplicity ( $a b$ infra multiplicity), we are forced into a series of insurmountable contradictions that infringe upon the thinkableness criterion and limit the notion to a purely verbal expression stripped of significance. ${ }^{49}$ Having exposed the rational difficulties inherent in belief in the Trinity, Modena examined the "common places" of the scriptures, which according to the Christians justified such a belief, criticized them by using the obvious sense method and concluded by stating the following principle:

If a thing as profound as the unity and trinity of God that does not imply His multiplicity was a cornerstone of belief, it would have been stated by Moses as a fundamental principle, explicitly and not with allusions, in an extremely clear way, so that everyone from the sage to the common man could understand it; for the one, just as much as the other, aspires to happiness. Moses explained the commandments in the richest detail, and beliefs a fortiori. The deeper they are, the more they need elucidating. ${ }^{50}$

This was precisely the position expounded by the Venetian anti-Trinitarian Niccolò Paruta in De Uno Vero Deo Iehova ${ }^{51}$ a major work already 
referred to by the Karaite Isaac Troki in his apologia for Judaism. ${ }^{52}$ On reading the Bible, Paruta wrote:

All we need to know of God in this mortal life and which contributes to our felicity is clear and lucid in the divine texts to render unnecessary the toil of interpretation and deduction. In this way God wished not only to provide the simple explanation but also to give all of us a healthy and solid understanding of Himself: we know that faith is founded not upon human explanations but on His clear and explicit word. ${ }^{53}$

Such an important principle (tantae rei ${ }^{54}$ ) should have been expressed clearly and without ambiguity; this is the only way to show the path to salvation, and the faithful would then have had no trouble accepting it.

The Trinity was thus conceded by Paruta, but stripped of its essential character. God-Iehova - is One, the Father, which is how he was understood by Jesus, Paul, the apostles, and the evangelists. If the Old and New Testaments are read correctly, there is not the faintest allusion to the division of the divinity into three persons, whereas a distinction is made between "the existent God, the Father, from whom all things come (ex quo omnia), the Lord Jesus-Christ, Son of God, through whom all things come (per quem omnia) and the Holy Spirit, who dispenses all good things (donorum omnium distributore)." ${ }^{55}$

Jesus, according to Paruta, was a man and at the same time he was the son of God: Jesus said so himself, while never claiming to be God. ${ }^{56}$ Despite his rejection of the incarnation, Paruta remained a Christian. ${ }^{57}$ While the antiTrinitarians insisted on the exceptional nature of Jesus, man and superman, they did not break through the barrier of his radical humanization: that was to be the contribution of Modena, a rabbi who made no secret of his sympathy for the historical Jesus.

\section{Modena, Historian of Religions, and the Historical Jesus}

Modena pointed out a number of times the erroneous interpretation of the Gospels by the earliest Christian theologians, who forced them doctrinally; on this point, he was in complete agreement with the anti-Trinitarians. ${ }^{58}$ Pursuing the analysis involving the definition of original sin as a desire for the pleasures of the flesh and its punishment as the weakening of the body, making it more 
vulnerable to temptation, Modena attempted to understand Jesus as an ascetic wanting to free man from this sin, trying to expiate the sin through his own increasingly modest behaviour and self-chastisement, intended to mortify evil instincts. His disciples were encouraged to act likewise. This might have influenced the divine decision to institute the messianic age, characterized, in Modena's interpretation, by man's return to his original state of purity: ${ }^{59}$

God could have accomplished through him [Jesus] what he reserved for the messianic age. ${ }^{60}$

This, however, was not the result, as was plain to all: sin and all its poisonous consequences still held sway in the world. That is why, "we hope that God's promise will be redeemed in our age and that He will send the true Messiah through whom He will save us." ${ }^{\prime 61}$

Jesus was therefore, in Modena's opinion, a man of profound morality, even messianic potential. This led him to continue enquiring into the man called Jesus - a historical Jesus. His reconstruction began with the categorical rejection of the Toledoth Yeshu, the Jewish accounts of the life of Jesus, which tended to belittle him, as being "lies written by someone who was prejudiced against him and wanted to cast shame on him. And every Jew who believes those lies is as deserving of that shame." ${ }^{\prime 2}$

Modena's historical work relied on Christian and Jewish sources ${ }^{63}$ both ancient and modern, particularly Carlo Sigonio's De Republica hebraeorum libri VII, published in Bologna in 1582, which he surpassed in historical contextualisation concerning the life and character of Jesus. Sigonio's historical analysis stopped short of the figure of Christ, who was for him the end-point of Jewish history, to whom all the laws, prophesies, and acts of the Children of Israel mysteriously referred. ${ }^{64}$ Unimpeded by such finality, Modena reached conclusions that he announced with solemnity (perhaps conscious of the novelty of the undertaking) and obvious satisfaction:

I came to conclusions which seem to me truthful and sound, as though I had lived in his times, alongside him. ${ }^{65}$

His affirmation gives a glimpse of a "modern" historical conscience, relying on psychological transfer into a past stripped of mystical aspects and completely secularised. Historical access to the most sacred arena-the 
character and life of Jesus - to which European historiography would come only much later represents Modena's not insignificant contribution to the secularisation of the social sciences.

According to Modena, Jesus not only adhered totally to the teachings of the Pharisees, which is to say that he believed in not only the written but also the oral Torah, excepting the minor detail of the ritual washing of the hands, the divine origin of which he denied. ${ }^{66}$ Disturbed by something that could constitute the beginnings of a rebellion against their authority in a period already destabilised by a plethora of sects, the Pharisees embarked on the persecution of a young troublemaker, who was, moreover, from a humble background. Jesus reacted by becoming more extreme in his positions and declaring himself to the small group of disciples he had gathered around him to be the "son of God." He could not claim to be God, as the pharaohs and Alexander the Great had done, for while they were in a position to hide their human failings from the public gaze, he would have been considered a madman by the scholars and men in the street alike, and would have risked being lynched by a mob before he could ever be brought to trial. Identification of God with the mortal individual, Modena reminded his readers, belonged to the sophistry of later theologians.

Wishing nonetheless to claim a position of superiority, Jesus could still call himself "son" (ben) of God, a title considered superior to that of "slave" ('eved) of God, which was reserved for the prophets, or "servant" (mesharet), which referred to the angels. Modena cited a number of passages from the Gospels - which he translated into Hebrew, something remarkable in itself - to recall the fact that Jesus always spoke in terms of a divine mission and knowledge of God, but never of filiation in a strict sense and certainly not of identification with the divinity. Jesus achieved his ends all the same, concluded Modena, insofar as he was considered the being closest to God, and so his authority was indisputable.

Curiously enough, Modena attributes this hierarchy of "slave," "servant," and "son" to popular belief (ha-hamon we-ha- 'am) ${ }^{67}$, initially making no mention of the source text in the midrash. He cites that text later (p. 64) to contest Christian usage of the text, but ignores it when discussing Jesus. In the Midrash Tanhuma, ${ }^{68}$ in the interpretation of Isaiah 52: 13, reference is made to a being superior to Abraham, Moses, and the very angels: the Messiah. Modena's silence on this topic is somewhat strange, his reasons hard to understand. ${ }^{69}$ 
This midrash had been at the centre of a dispute between Nahmanides and Pablo Christiani, in $1263 .^{70}$ The Jewish author interpreted it in an apocalyptic way: the Messiah is superior to Abraham, Moses, and the angels because he will do more than them for redemption, ordering the Pope and every king to leave the Jewish people free to serve God and live without fear in Rome until its destruction. Modena's historical perspective and more moderate attitude are pointed up more clearly in comparison with the text of the fourteenthcentury Catalan rabbi. ${ }^{71}$ The historical perspective of the Venetian rabbi has already been noted, ${ }^{72}$ and we will return later to his moderation, contrasted with the apocalyptic mentality.

To grasp the modernity of Modena's analysis, it must be remembered that unconditional humanization of the Christ figure would seem to be a step too far for the Christians. Paruta made him a mediator between God and the world, a sort of intermediary being, somewhere between the creator and the created. Faust Socin, a dogmatic essential for the anti-Trinitarians, insisted that Christ was a man - a key point of his "heretical" doctrine - and that he had not existed for all eternity. He did add, however, that he ascended to heaven after his birth, summoned by God, receiving from God the possibility of resurrection, and hence immortality, to which those who believe in him may aspire. ${ }^{73}$

For the Italian historian Luigi Salvatorelli, ${ }^{74}$ historical inquiry into the origins of Christianity began with the English Deists, who were philosophers rather than historians, for "Christian Europe could not be expected to submit for criticism its sacred texts, the facts pertaining to the salvation and the divine person of the Redeemer out of mere historical curiosity." John Locke was representative of the new school of thought that displaced both Catholic and Protestant dogma, publishing his Essay for the Understanding of St. Paul's Epistle, by Consulting St. Paul Himself between 1705 and 1707. Later, according to Salvatorelli, Voltaire occupied a central role, with his description in the Histoire de l'établissement du christianisme (1777) of Judea in the time of Jesus. Voltaire denied in this work that Jesus ever intended to found a religion and - like Modena - provided his own explanation for the title "son of God."

Albert Schweitzer, author of a "history of histories" of the life of Jesus, offered a later date for the first attempts at biography, suggesting that they appeared in the late eighteenth or early nineteenth centuries. The German authors, followers of an enlightened religion, wrote, according to Schweitzer, with a clear desire to depict a rationalist Jesus, and drew largely on novelistic technique..$^{75}$ 
What the Christians came to only very late and with much hesitation was relatively easy for a believer in the only non-Christian religion extant in premodern Europe; all the more so for a Jewish rationalist like Modena, who was critical of Christianity without being hostile to it.

\section{History and Anthropology: The Beginnings of National Consciousness}

Having sketched his historical depiction of the life of Jesus and his contemporaries, Modena attempted to explain the reasons for the great success of Christianity, a religion lacking, in his opinion, any real internal coherence. Here Modena became a historian of religious mentalities.

It is not astonishing that the Nations, called Gentiles, accepted the Christian faith as time went on. For the fundamental idea on which all the rest depend, that the Holy Spirit entered a virgin womb and engendered a god, held nothing new or difficult ( $r a h o q$ ) for them. They already believed that Apollo, Mars, and the other gods desired and needed mortal women, that they engendered the children of the gods and of men, and that they could suffer violent death. Differences in quantity and method in the links between the human and the divine were no obstacle to their belief, all the more so as the new religion was shot through with some of the truths of the Torah, which tempered the absurdities of their divinities. Over time, Christian propaganda towards the Gentiles intensified; by continually inventing and altering elements of their belief they gradually distanced themselves from both the Jewish faith and the intentions of Jesus, coming to resemble the pagans ever more closely. They finally managed to impose their religion under the Emperor Constantine. As for the Children of Israel, the people close to the blessed God, in whom He and Moses, his faithful servant, had inculcated the understanding that God is utterly non-corporeal, being far above all terrestrial baseness, no hammer or axe or iron instrument could make them accept such absurdities: that God entered the womb of a woman, virgin or otherwise, and was born of her like any base and ephemeral creature, in short, like an ordinary man. Let His name be praised and glorified, for He has given us understanding, intelligence and wisdom; may his Holy Name, blessed-is-He, be exalted, magnified, and praised. ${ }^{76}$ 
In this remarkable passage, in which Modena tries to account for the reason Christianity penetrated among the pagans, we should note his explanation of how the message of Jesus is assimilated into that of the Jews, from which Christianity distanced itself; the Jewish insistence on the noncorporeal nature of God, proudly asserted in the face of violence and torture (a phrase that could have been uttered by an Iberian crypto-Jew or a heretical Christian); and finally his definition of the Jewish people as the "people of God," since they were gifted with intelligence and, one could add, rationality.

Reducing the range of original sin, Modena sketched a religion without drama; he wanted it to be in keeping with reason, denying as he did the logical possibility of the Trinity, and steering clear of the paradoxes and extreme beliefs that the birth of God from the womb of a woman and the incarnation represented to him; this religious attitude is, finally, a stranger to eschatology. As we have seen, the Messiah was only a human redeemer and redemption in itself was a matter of the body rather than the spirit; eschatological calculations based on the midrash had no authority in his eyes, and belief in the Messiah's coming was not a dogma as it was for the Christians, but a simple emunah nekhonah, or just belief. ${ }^{77}$ Emphasising the secondary nature of the messianic belief for the Jews, Modena wrote that

[ ... ] We could even accept their idea that the Messiah has come, but we still would not be one and the same with them, for we share neither the same doctrine nor the same rules, as well as all the other differences that separate us. ${ }^{78}$

The relatively secondary nature of messianic belief had already been expressed by Hasday Crescas (Or Adonai, 3, 8, 3) and Yosef Albo (Sefer ha-'Iqqarym, 4, 42); according to them, whoever did not accept this belief broke a commandment and was considered a heretic, but did not cast doubt on the Torah in general. Modena, however, emphasised what we could call an "anthropological" concept. For him, the Jewish people was defined by certain behaviour-and beliefs were in a sense forms of behaviour. In other words, religion represented the culture of a people, and believing in the precepts of another religion in no way prejudiced what we might call a sense of "national" identity. The Historia de riti ebraici" could be understood in the same spirit, as the aim of this work, which was written in Italian and 
enjoyed considerable popularity with Christian readers all over Europe, was to propagate among non-Jews an understanding of the religious and social practices of the Jews, satisfying a curiosity that was more ethnographic than theologico-religious in the strict sense of the term. The people-belief correlation, which only works in this direction (according to this perspective, beliefs spring from belonging to a people, whereas the opposite-national identity arising out of a belief-is untrue) would seem to be supported by the affirmation that follows in Magen we-herev:

I often say that I believe in the coming of the Messiah because I am a Jew, but not that I am a Jew because I believe in the coming of the Messiah. ${ }^{80}$

The concept of the nation implicit in Modena's work excluded the political level. The Messiah would not serve as the people's guide, assembling the lost tribes of Israel and rebuilding the Temple in Jerusalem, as was understood by Maimonides, ${ }^{81}$ nor would he subjugate the Pope and the nations of the world, as Nahmanides claimed; he would be the man who allowed mankind to return to a state of physical purity, lost through original sin. This messianism, confined to the moral sphere, retained a universal appeal since it concerned all mankind, without special relevance to the Jews. The Jewish nation was a concept more ethnological than political. ${ }^{82}$

Modena's moderate stance constituted a step toward a Jewish acceptance of actual history. Magen we-herev was a plea for a realistic religious position and was as free from ill-considered eschatology as it was free of the theological absurdities rejected by good sense (sekhel yashar, sevara ${ }^{83}$ ). It could be envisaged as the Jewish counterpart to the search for decorum and socially acceptable manners that fuelled certain anti-Jewish positions.

\section{Good Sense and Good Manners}

At the 1632 Geneva trial of Nicolas Antoine, a Protestant pastor accused of Judaising, the judges declared themselves astonished that the defendant could be attracted to the rites of the Jews, for as they put it,

[They] have delivered themselves up to a spirit of blindness, their synagogues are purest confusion, with neither reverence nor devotion, strange cries and screams and all manner of lewd gestures. ${ }^{84}$ 
Antoine had tried to convert to Judaism in Venice, but the city's rabbis refused his application, surely for opportunistic reasons. ${ }^{85}$ The Geneva judges may well have been thinking of the services conducted in Italian synagogues when they expressed their "aesthetic" scorn for Jewish rites; Modena provided indirect testimony on the conduct of such services, in a ritual responsum composed between 1604 and 1606 on the legitimacy of singing in synagogue according to the rules of musical science. Modena's response was categorical:

[ ... ] If these gifted people want to improve themselves according to the rules of the art, for the greater glory of God, are they guilty? God forbid! Should we impose cantors who bray like donkeys without the slightest modulation of their voices, in application of the verse it crieth out against me (Jeremiah 12:8)? And should we, who in ancient times employed the art of music in our praises and prayers, become the object of the scorn of Nations, seeing us deprived of our former knowledge, reduced to baying at the God of our Fathers like dogs or cawing at Him like ravens? ${ }^{86}$

A famous Jewish convert to Christianity who professed to be a pupil of Modena, Giulio Morosini (previously Samuel Nahmias), also stressed the lack of order in Jewish prayers. He described the qiddush, the sanctification of the Shabbat, in the following terms:

When the head of the house sings or calls, all the others shout with him, doing just as he does: and the number, variety, and lack of harmony between the voices generates great confusion. ${ }^{87}$

Aesthetics appeared to be a significant factor in the repugnance to Judaism which incited Nahmias, the grandson of a Castillian New Christian who had reverted to the ancestral religion, to convert to Catholicism. In his work La via della fede mostrata agli ebrei he emphasised the superstitious and physically unattractive rites of his former coreligionists, in short their lack of "civilization." "Superstition" is a key term in his argument, applied by Morosini to the religious-scriptural domain (superstition meant any belief or rite that did not correspond to the true religion as taught in the Bible), but also to the realm of good sense and, to a certain degree, good manners: "You 
celebrate numerous rites which are manifestly superstitions, in the basic sense of the word (nel senso che ognuno le piglia)." $"{ }^{9}$

Morosini was not a theologian; his criticism of Judaism was essentially based on its ritual aspect. If, however, the term "superstition" is taken in not only the context of practice but also that of belief (a sickness of the soul "capable of extinguishing natural light," "a religious cult counter to reason and the sane idea one should have of the supreme being," as the Encyclopédie ${ }^{90}$ was to define it a hundred years later), parallels can be found, somewhat paradoxical, but nevertheless significant, between the positions of Modena, the orthodox rabbi, ${ }^{11}$ and Morosini, the apostate with a horror of Judaism. Both aspired to a kind of reasonable and socially acceptable religiosity, in which conceptual absurdities (found in Christianity, according to Modena) and attitudes neither civilised nor in accordance with the scriptures (the province, according to Morosini, of Judaism) had no place . Modena's apologia can be read as being either against Christianity or in favour of a rational religion, a requirement similar, though differently expressed, to that made by a number of his Christian contemporaries. 


\section{8 \\ The Immortality of the Soul and Opening Up to the Christian World}

\section{The Immortality of the Soul as a Philosophical and Religious Subject}

Inherited from a medieval debate and continuing well into the early modern period, the question of the immortality of the soul was one of the main issues in the philosophical and theological literature of the Renaissance. Both Platonism and Christian thought had developed the idea of separation between the body and the soul, and - as something of a correlate - the idea of the corruptible nature of the former and the incorruptible nature of the latter. The body was made of matter, and was thus destined to decomposition and death; the soul had a divine essence, and therefore lived forever in a celestial world after departing from its earthly residence. To deny this idea meant to share a thoroughly materialistic vision of the world and, therefore, a disbelief in the partially divine nature of man, who was - according to the Bible - created in God's image and resemblance. God had breathed the soul into Adam's nostrils; as far as his body was concerned, then, man was subject to the natural laws of reproduction, whereas the soul was created anew by God for every man.

Besides, the materialistic vision was problematic on ethical ground. According to the Christian doctrine, man-or, to put it better, his spiritual component - had to receive rewards or punishments for his behaviour during his life; since it was clear that this absolute, divine justice was not always implemented in this world, one had to assume that there was another world, in which all human, blatant injustices would be corrected, once and forever.

An epistemological dimension was added to this issue by the Aristotelian theory of knowledge. In his very detailed analysis of the process of knowledge in De Anima and in other books, Aristotle did not come to a clear conclusion as to the capacity of the intellective soul—supposedly able to formulate universal concepts devoid of material ground - to act independently 
of the body. The different interpretations of some controversial passages of the Stagirite philosopher, generally read in European medieval universities through the commentary of Averroes, served as a basis for opposite conceptions, one spiritualistic and the other materialistic (the so-called Alexandrist position, after Alexander of Aphrodisias). ${ }^{1}$ Furthermore, the Arabic reading of Aristotle's theory of knowledge had led to the necessity of imagining an agent of divine nature, or an active mind independent from the man, one which enabled the process of cognition by bringing forth the universal notions that lay in potentiality within the human, or passive, intellect. But if knowledge consisted of the union between the individual human intellect and the unique active intellect, then every formulation of universal notions entailed that man must join with this active and unique intellect; through the act of understanding man himself became intellect and therefore lost his individuality. As an intellectual soul in action, man had to be united with other men who had developed the same, disembodied ideas.

This concept, however, was the opposite of the Christian doctrine of punishment and reward, which identified the individuality of man's soul as a condition for his moral responsibility. The issue provoked a bitter theological and philosophical debate among Christians, leading to the dogmatic formulations that defined the orthodox position. ${ }^{2}$

As Paul Richard Blum put it in his chapter on the immortality of the soul in The Cambridge Companion to Renaissance Philosophy, we have here a multi-faceted question: the exegetic issue - the interpretation of Aristotle, with his indisputable philosophical authority-implied the epistemological one; this, in turn, led to the religious-ethical issue, which also implied a cosmological dimension: the place of the human soul in a well defined universe made of corruptible and incorruptible beings. ${ }^{3}$

The answers given to these questions produced effects that went well beyond the walls of the university. The danger for the official Christian doctrine did not result only from the possibility of a materialistic view-which was, after all, quite rare-but also, and maybe more hazardously, from the separation of the rational and the religious sphere: a view identified as "Averroistic." As a result of his reading of Aristotle's texts, a philosopher could very well support the idea of mortality of the soul from a mere philosophical point of view, yet reaffirm his belief in immortality because that was 
the truth affirmed by the divine revelation and by the Fathers of the Church. The question became so sensitive that in the Fifth Lateran Council, in 1513, an authoritative declaration was issued on the immortality and individuality of the soul, imposing not only upon theologians but also upon university philosophers the task of proving rationally those truths.

This is not the place to expand on the history of this issue in the Christian intellectual world. Let us remark only upon two major works: Theologia platonica de immortalitate animorum by the Florentine humanist Marsilio Ficino (1469-74) and Tractatus de immortalitate animae by the university teacher Pietro Pomponazzi (1516).

The first book is a true "summa," the main reference for the Neo-Platonic scheme that saw the human soul as being in an intermediate position, or the "third essence," between the superior level of God and the angels and the inferior one of matter and its qualities, and thus representing the link between those two levels: aspiring to the divinity, while at the same time filling the corruptible matter of the body. The immortality of the soul was demonstrated by Ficino in many ways, following the method of Aristotelian logic but assuming the Neo-Platonic idea, which became a central notion of the Renaissance, accompanied by and founding another important notion, that of the dignity of man.

Pomponazzi's Tractatus was of a completely different nature, not only because it was the output of a typical representative of Aristotelian philosophy as taught at the university (Pomponazzi, who was a professor at Padua, was the most prestigious lecturer of his time), but also because it radically criticized the intellectual scheme followed by Thomas Aquinas. Thomas' method was held long after him (lasting until our days) as the official position of the Roman Church regarding the substantial agreement between the truths of reason and the truths of faith. According to Pomponazzi, one had to believe in the immortality of the soul because such was the teaching of the Church, depositary of the divine revelation; but philosophy could not reach the same conclusion, and nor did Aristotle. This was the conclusion of the Paduan philosopher. Pomponazzi's book was burned, but as it was preceded by some other, less radical works, which opened the way for it, so it was followed by a great number of texts reacting to it, all adhering to the official Catholic position, and trying to use reason to prove the immortality of the soul. 
After the decline of Aristotelian epistemology, the issue of the immortality of the soul continued to be discussed: the first edition of Descartes' Meditationes de prima philosophia (1641) bore the subtitle in qua existentia et animae immortalitatis demonstrantur. Moreover, besides the strictly philosophical analysis, both the immortality of the soul and its purity and longing for God in the afterlife were at the centre of the Christian devotion in the so-called Baroque period.

What was the Jewish position on this issue? Did the Jews take part in the controversy? As far as the Renaissance and early modern periods are concerned, the subject has yet to be studied globally. Two cases, however, have been the object of several researches: firstly the controversy in Amsterdam, during the first two decades of the seventeenth century, fuelled by the anti-rabbinic position of Uriel da Costa, and secondly the debate between the Jewish poet Sara Copio Sullam and the Catholic priest Baldassare Bonifaccio, which took place in Venice in the same years and which can be placed in relation to the Amsterdam controversy. Even though these cases have already been deeply investigated, they still deserve a brief comment in light of our concern with the issues of Jewish-Christian relations and of the growing secularization of European culture. Besides, they will be better understood if they are placed in continuity with the texts of other Jewish intellectuals of the Renaissance, specifically in Italy, who dealt with the same issue.

It is difficult to find a common line of thought in these Jewish authors; there were Neo-Platonists-who referred themselves to Plato either directly or indirectly, through, for instance, references to the Kabbalah; and there were Aristotelians - who followed the Arab-Jewish tradition that encompassed Averroes, Maimonides, and Gersonides. This intellectual tradition had concerns and methodologies similar but not identical to those of Christian scholasticism. Nobody made the immortality of the soul a central issue of their work, or more exactly, as we shall see, of their Hebrew work. In other words, the "sub-genre" of demonstrations concerning the immortality of the soul, so common in the Christian theology and philosophy of the period, seems not to have been a Jewish-Hebrew genre.

Among the Neo-Platonic authors we can count Mosheh of Rieti (1388ca. 1465) and Yehudah Moscato (c. 1530 - c. 1593); according to both, the immortality of the soul was a fact, upon which a poet-philosopher like the 
first or an exegete-rhetorician like the second could elaborate, sometimes in a lyrical manner; but they never tried to prove it in an argumentative way. The writings of Yitzhaq Abravanel (1437-1508), the exiled Spaniard who lived his last years in Italy, must also be examined. In Renaissance Italy, Abravanel wrote extensively on that matter, and his position is clearly NeoPlatonic; his Jewish references, on the other side, probably belong more to the Spanish than to the Italian tradition. As for an "orthodox" Aristotelian position, the main representative was doubtlessly Eliyah Del Medigo (ca. 1458 - 1493), whose assertions on the matter of the soul's immortality were, to say the least, ambiguous, and deserve therefore a special attention.

In order to understand the positions of these authors, we should bear in mind what, at different levels, the most influential Jewish philosophers, Maimonides, Nahmanides, Hasdai Crescas, and Yosef Albo, wrote on this issue.

\section{The Discussion among Jewish Thinkers of the Middle Ages}

Maimonides - as the philosopher and author of the Guide of the Perplexed, not in his capacities as a jurist or as the author of a list of dogmas-admitted the difficulty of proving rationally the immortality of the soul: a notion even more difficult to prove than that of the creation of the world. ${ }^{4}$ In this context, he did not explicitly confront the issue, stopping at merely indicating that the Torah prepares for the perfection of the body and the soul, and that the later leads to a condition of eternal happiness. ${ }^{5}$ The soul, which separates itself from the body, is the form of that body (in Aristotelian sense), that is, it is the intellect that has reached true knowledge of God (according to its limits) and can thus avoid death. ${ }^{6}$ This is the true objective (takhlyth aharon) of the Torah.

As for his dogmatic affirmations, those that appear in his other, non-philosophical works, Maimonides writes more extensively, holding a position resolutely spiritual: the souls of the righteous will live in the world to come ('olam ha-ba), rejoicing in the spiritual and intellectual contemplation of the divine presence. The resurrection of the dead is but an intermediate stage: the resurrected people will indeed end up dying again, according to Maimonides, and eternity will be reached only in the world to come, when souls will no 
longer be bound to bodies. Even when he writes as a jurist, Maimonides emphasizes the intellectual aspect of human behaviour. The merits of the soul are essentially intellectual, and consequently the highest reward in the afterlife consists of pure intellectual contemplation of the divine, without the burden of the body and the duties of earthly life:

The soul will continue to exist for eternity, just like God, who was its cause, having perceived it, as has been explained by the first philosophy. This constitutes the greatest good to which no other good could be compared, since how could one compare eternity without end to something ephemeral? ${ }^{7}$

The Catalan Nahmanides (Mosheh ben Nahman or Ghirondi, in Catalan Bonastruc ça Porta, 1194-1270), for his part, is fond of the description of man's destiny after death as recounted by the Jewish tradition, which he considers of divine origin, and as such superior to human philosophy; he is not, therefore, interested in the rational foundation of the notion of immortality. Referring to the teachings of the rabbis (Hazal) in the Talmud and the Midrash that he is often compelled to interpret, the Catalan author provides a very precise description of the rewards and punishments of souls in the afterlife, their characteristics, and their duration in the various sections of what can be called hell and heaven. As for the relationship between the resurrection and eternal life, he objected to Maimonides' assertion that in the future world the souls of the righteous, after living in the celestial paradise (gan 'eden), would be reunited forever with their bodies.

What need did he [Maimonides] have to try and prove that in that world there are not bodies but only souls? Even a Jewish schoolchild knows that the soul of a just man who dies remains in the good, that is, the good of the superior world in which there is no matter and no body. ${ }^{8}$

Nahmanides concludes that Maimonides wanted to draw attention to the fact that, even after the reconnection of souls with bodies at the time of resurrection, people (including the Messiah) will die anew and will obtain their reward in the spiritual world of the soul. For Nahmanides, however, after the resurrection, the risen people will live for eternity, with a body of angelic characteristics and separated from corruptible matter. 
Besides, commenting on the book of Job, Nahmanides makes allusions to the kabbalistic theory of the transmigration of the souls, though, following his custom, he doesn't insist on its importance. ${ }^{9}$

The position of Gersonides (Levy ben Gershom, Provence 1288-1344), expressed in the famous and controversial treatise Milhamoth Adonay (The Wars of the Lord, 1st ed. Riva di Trento, 1560) can be considered a clarification and accentuation of the rationalistic position of Maimonides. In fact, in the first part of this work, the Provençal philosopher and scientist offers a long and complex demonstration of the necessity of the immortality of the "acquired intellect," that is, the material (human) intellect that is appropriated by the eternal intelligibles, present in the "Agent Intellect."10 "The acquired intellect," writes Gersonides, "is immortal; for what it apprehends of these objects of knowledge is itself an intellect in the Agent Intellect." He proceeds with a syllogism: "The acquired intellect is immaterial, and an immaterial substance does not have the conditions requisite for corruption; and whatever lacks these conditions is incorruptible." 11 Immortality is therefore a function of learning and concerns the intellectual soul.

For the Catalan philosopher Hasday Crescas (ca. 1340-1410/11), discussion on the immortality of the soul is within a more ample reflection on the perfection required by the Torah: this reflection leads to a sum condemnation of the intellectualistic school of Maimonides, and to a shifting of emphasis from intellectual perfection to love of the faithful toward God. That the intellect augments its capacity until it reaches immortality thanks to the intellection of the universals; that the intensity of its beatitude in the afterlife depends on the loftiness of its intellections: these are two typical affirmations of Maimonides' intellectualism that, according to Crescas, are in complete opposition to the Torah and tradition, as well as absurd from a rational point of view.

The conflict of intellectualism with the Torah and the tradition is rather simple to demonstrate. The texts, Crescas writes, show abundantly that action, not intellection, and especially execution of the mitzwoth, leads to a reward in this world and the next. Demonstrating the rational absurdity of the intellectualistic optics is more complicated; it relies on a great number of dialectic proofs based on Aristotelian premises and articulated in syllogisms. 
What Crescas aims to prove, above all, is that not the intellect but rather the soul in its entirety-which also possesses intellectual faculties-is immortal, as a substance separate from matter that survives material corruption. ${ }^{12}$ The soul is, therefore, immortal by nature — even if it can be destroyed by some evils - and remains individual after it abandons the material body. The idea of one universal intellect resulting from the union of single "Passive Intellects" (human) with the "Agent Intellect" (divine), which had stirred many polemical storms in the Christian world of the thirteenth century, is therefore discarded by Crescas as impious and absurd. ${ }^{13}$

Having developed the idea that action is superior to intellection, Crescas then arrives at the notion of love for God as man's authentic objective. The soul that loves God, pursuing its true objective, perfects itself, and in this way obtains eternal immortality and happiness.

It is therefore clear that the perfection required by the Torah is to obey [God] with the greatest zeal, observing His commandments and being careful not to violate His prohibitions; with joy and light heart, which are the secret to service and true love. This is apparent in many rabbinic texts. Since this is the perfection required by the Torah, it necessarily results in eternal happiness and immortality [for the soul]. ${ }^{14}$

The causal bond between love for God and immortality is argued by Crescas rationally as well. If the soul's perfection lies in loving the Good, love for the Summum Bonum, which is God, leads to the maximum perfection of the soul. Moreover-and here Crescas refers to the thought of Empedocles ${ }^{15}$ - if, in nature, love is a cause of unity among the elements, the same must be true for the spiritual realm: the more intense the love (ahavah) for God (until it becomes passion; the Hebrew word hesheq will enter the discussion further ahead) the stronger the union (devequth) of the soul with God will be. Perfection and bond with God have a worth equal to that of immortality and beatitude. ${ }^{16}$

The shifting of emphasis in respect to Maimonides and Gersonides is evident. After Crescas - with rare exceptions such as in the work of Eliyah Del Medigo - the immortality of the soul will be treated in the devotional religious sphere, even if - occasional-demonstrations are conducted in accordance with the scholastic dialectic. The intellectualistic concern, which 
linked immortality to intellectual knowledge, will be definitively abandoned. Love for God, religious zeal and fear of sin, not intellectual comprehension of the divine (even if it eventually flows into love) become then the most diffused religious values within the Jewish world, including the Italian one.

As for the author of the best known list of Jewish articles of faith, Yosef Albo (1380-1412), he is not concerned with finding a rational justification for the idea of immortality. His preoccupation is exclusively dogmatic. In Sefer ha- 'Iqqarym ${ }^{17}$ (IV, 29-30), Albo states four possible opinions on the remuneration of human actions from which can be extracted his conclusions regarding the nature of the soul. The first postulate (inspired by Aristotle) negates the existence of remuneration; the soul is, in effect, a function of the body and dies along with it. The second (inspired by Alexander of Aphrodisias's reading of Aristotle) admits to a material remuneration; the soul is a function of the body - and consequently vanishes with its death — but thanks to the intellectual faculty it can enter into contact with God, who rewards man in the course of his life. The third (which is Maimonides') maintains a uniquely spiritual remuneration in the world to come on the basis of intellectual results achieved during life on earth; according to this conception, the soul is separate and immortal and its most noble part is the intellectual one. Albo objects that, noting that embracing this extremely elitist conception would exclude from immortality people who are not particularly gifted intellectually but who have merits on the basis of their religious devotion. The fourth postulate, which is Albo's and, according to him, also the authentic position of the Torah and the rabbis, contemplates a material remuneration during the earthly life, as well as a spiritual remuneration destined for the soul after the death of the body. The texts of the Torah and the masters of the Talmud, according to Albo, speak explicitly to that end. ${ }^{18}$

These, then, were the theological suppositions reflected upon by the Italian Jewish thinkers. None of them, until the spread of the Kabbalah of Safed in the seventeenth century, concerned themselves with the description of the destiny of the soul after death, the pleasures of paradise and the torments of hell. ${ }^{19}$ There were various attitudes, but for the most part the immortality of the soul was taken by them an indubious belief that sustains and justifies religious devotion. This belief, in time, becomes one of the hinges of their faith, which allows the opening of - or at least the will to open-a religious dialogue with the Christians. 


\section{Neo-Platonists and Aristotelians}

\section{The Soul: A Protagonist in Mosheh of Rieti's Poetry}

Mosheh ben Yitzhaq of Rieti (1388-ca. 1465) was an extremely prominent poet, philosopher, and medic among the Italian Jews in the fifteenth century, well known until the end of the sixteenth century. He was later forgotten, and while he was rediscovered in the nineteenth century, the full extent of the value and originality of his work, in verse as well as in prose, is still to be fully appreciated. In almost all of his writings the soul plays an important role. It is probably the protagonist of Ya 'ar ha-Levanon (Forest of Lebanon), ${ }^{20}$ a difficult and interesting text, written in rhymed prose, in which a female character, No'ah (whose name could be translated as "Wandering"), identified as the "daughter of the King," laments being separated from her father and compelled to roam a hostile land. The allusion to the separation of the soul from its celestial source is rather clear; this female character, however, also possesses typical traits of the spiritual projection of the people of Israel, the Shekhynah, also in exile, awaiting redemption, which will restore her affectionate closeness to the divine father. The inspiration behind the lyrical narration of this double exile is clearly Neo-Platonic and Kabbalistic.

Without a doubt, Mosheh of Rieti believed in the immortality of the soul; a position in itself evident for a rabbi, but one that would have been true for any observant Jewish person as well. As Nahmanides had noted, even a Jewish schoolchild knew that after death the soul separates itself from the body and returns to its celestial sphere. What is interesting here is to find out the use of this belief, whether leaning to the Aristotelian-Maimonidean perspective oriented toward intellectualism or to a more "pietistic," devotional attitude.

His most ambitious writing, Miqdash me 'at (Little Sanctuary), a "Jewish response" to the Divine Comedy by Dante Alighieri, ${ }^{21}$ consists, for the most part, of a journey to the afterlife, or more precisely to the Jewish paradise, where the author encounters the souls of saintly Jews: prophets, teachers, martyrs, and children who have died innocent. His guide on this celestial journey is his father, who had died when Mosheh was a young boy. It is apparent that such an imagined journey implied the idea of the immortality of the souls, or at least of the just ones.

An entire chapter of the poem consists of a direct discourse between the author and his soul, until the latter becomes cognizant of its sins in view of divine justice. Rieti calls it nefesh, even if the philosophers used to call 
the intellectual soul neshamah, probably writing under the influence of the Psalms, especially 103 and 104, in which the poet holds a dialogue with his own interiority. The soul is described as "celestial prisoner," "a fleeing shadow that stays behind in a cadaver" but will rise up again when its chalice becomes full of earthly water. It must assume consciousness of how man's neshamah, corresponding here to the vegetative soul, can be punished after death, burning in fire and pushed far away from the world of Sanctity.

My soul (nafshy), be careful that the stretched out wings of passion (hesheq) will not grow tired in their motion

And bitter spirits do not encounter it

To tear its feathers; or demons

Who will corrupt its qualities

My soul, haven't you heard how the soul (neshamah) burns in the fire of wrath

And is thrown out of the holy place to a profane one? ${ }^{22}$

In a previous chapter of the poem, in the context of a eulogy of Aristotle, Mosheh of Rieti had sharply settled scores with the thought of Alexander of Aphrodisias, which constituted a dangerous deviation from the thought of the Stagirite: "In one part of the sciences, there is a root that gives off poison: it's Alexander. / Even the Guide [an allusion to the Guide of the Perplexed by Maimonides] brings back the arguments." ${ }^{23}$ The reference is certainly made to the idea, attributed to Alexander, that the soul is nothing but a disposition of the body and therefore dies with it.

Mosheh returns to the question of the survival of the soul post-mortem in an elegy composed on the occasion of the death of his wife. ${ }^{24}$ The questions that are posed in this case are existential, not theoretical, in nature. They arise from suffering, and are posed in a direct way, in an urgent and anxious tone: will the souls of the two lovers find each other in the afterlife? Will the actions taken during the earthly life attain for them different destinies? Philosophy and dogma do not come to the author's rescue here: his questions remain without an answer. It is necessary to note that the author does not cast a doubt on the immortality of the soul but on the forms of this immortality, the way in which the soul will live in the dimension beyond the earthly life. ${ }^{25}$ 
Mosheh of Rieti had received a traditional philosophical education, founded upon Arab and Jewish Aristotelianism, whose most prominent figures were Aristotle, Porphyry (the author of Isagoge), Al-Ghazali, Averroes, naturally Maimonides, and finally Mosheh Narboni and Gersonides (with whom he is in partial disagreement on some nonspecified points). ${ }^{26}$ For him, philosophy and religion are not in conflict, but are rather complementary: the first is not "impure" but instead constitutes a neutral instrument, necessary to ascend the ladder of knowledge that culminates in the Torah. Mosheh associates the conceptual instruments that Aristotelianism offers him with a dimension that is clearly Neo-Platonic, in accordance with his lyrical propensity. On this subject, besides the importance he attributed to the subject of the soul and its exile in the body, one must also remember the insistence on the notion of hesheq, or desire, eros, the stimulus placed in man that aspires to lift itself toward the superior spheres of knowledge and being. ${ }^{27}$ Two successive Italian Jewish thinkers, Yohanan Alemanno (ca.1435-ca.1504)28 and Yehudah Moscato, both with Neo-Platonic inclinations, will also insist on the importance of the hesheq, which dates back to Plato (particularly in the Phaedo and the Symposium) and which was taken up again in Italy and developed poetically by Dante (the model of Mosheh of Rieti). ${ }^{29}$ Another important Jewish philosopher, originally from Iberia but active in Italy, Yehudah Abravanel ("Leone Ebreo," son of the famous Yitzhaq) makes such a notion the subject of the famous Dialogues of Love (published for the first time in their entirety in Rome in 1535).

Oftentimes the Neo-Platonic sensitivity of the Jewish thinkers is expressed through a Kabbalistic language, and Mosheh of Rieti-as we have seen-is not an exception. In his writings, the references to the wide-spread kabbalistic literature in Italy of his time-such as the Sefer Yetzyrah, perceived as kabbalistic text, the Sefer ha-Bahir, the Castilian Kabbalah, among which the Sefer ha-Zohar and the works of Nahmanides - are associated, in a harmonious way, with Neo-Platonic notions: here can be found the beginnings of a synthesis that is destined to unfold among both Jewish and Christian thinkers in the following period of the so-called Renaissance. It should be noted that this complementarity between Aristotelian philosophy, Platonic subjects, and Kabbalah will subside between the end of the sixteenth century and the beginning of the eighteenth, when the Jewish kabbalists would proclaim themselves enemies irreducible to philosophy. ${ }^{30}$ 
To summarize, for a philosopher-poet such as Mosheh of Rieti, the subject of the soul and its relation to the body and the divine is central, but it is treated in a more lyrical than argumentative manner. This approach would be appreciated in a later period, when the emphasis would be placed on an internalized and spiritualized religious devotion. The pages from Miqdash me'at cited above, in which the poet addresses his own soul, are the only ones that have survived the oblivion of his work; they were copied as a model of Jewish poetry ${ }^{31}$ and translated into Italian in four different versions by Jewish authors, who evidently considered them an example of "spiritual poetry" 32 befitting the Baroque sensitivity of the time.

\section{Yitzhaq Abravanel: \\ The Conciliation between Kabbalah and Philosophy}

Yitzhaq Abravanel was one of the most prominent figures of the Spanish community before and immediately after the expulsion of the Jews from that country in 1492. This "philosopher and man of the State"33 is considered one of the Jewish thinkers most open to non-Jewish cultures, in particular the cultures of Hellenistic and classical Greece and Christian theology from the patristic to the medieval period. The culture of the Renaissance certainly had an important influence on Abravanel, who lived the last years of his life exiled in Italy. At the same time, he was an heir to the Spanish Jewish culture in which the Kabbalah, considered a traditional revealed teaching, occupies a central place.

It is exactly by going back to the Kabbalah that Abravanel affirms the idea of the transmigration of souls (gilgul ha-nefashoth), that circulate within their celestial world and reincarnate themselves in different human bodies-perhaps even in animals - in accordance with their merits and faults. A further elaboration of this conception concerns the reincarnation of the souls at the beginning of each new cosmic cycle. ${ }^{34}$ At the end of each cycle of 4900 years, in fact, in the next millennium or cosmic jubilee, as matter becomes annihilated, the souls lose their individuality in order to become reabsorbed into the divine world. Everything begins anew — back to being materialized and the descent of the souls into bodies assigned to them - at the start of the next cycle.

Despite attributing these doctrines to the Jewish tradition as revealed by God to the prophets, Abravanel feels compelled to justify them according to philosophical criteria. As has been noted, ${ }^{35}$ his sources are more 
Renaissance-Platonic than kabbalistic in the true sense: his continuous references to prisca theologia, to Hermes Trismegistus (whom he identifies with Hanokh), to the "divine" Socrates and to Plato, render him a very likely reader of Marsilio Ficino.

Abravanel's doctrine on the soul, therefore, belongs to a Renaissance thinker par excellence. Nevertheless, it does not seem that Italian Jewish thinkers of that period, or of successive periods, at least until the seventeenth century, were formulating such precise and articulate conceptions of the soul's destiny in the afterlife, nor that they were embracing in such an explicit way the theory of transmigration, which, in the Jewish sphere, was only maintained by the kabbalists.

Before the spread of Lurianic Kabbalah and the teaching of influential figures such as Mosheh Zacuto (ca. 1610-1697), there are no comprehensive visions in Italy of the afterlife that are directly inspired by the Kabbalah. ${ }^{36}$ As a Jewish thinker, Yitzhaq Abravanel, although engaged in the philosophical culture of the Renaissance, which was essentially Italian in origin, nevertheless should be considered as fully belonging to the Spanish philosophicalkabbalistic tradition. ${ }^{37}$

\section{Eliyah Del Medigo (ca. 1458-1493): \\ The Ambiguity of a Late Aristotelian}

It is not surprising that Eliyah Del Medigo, who can be defined as one of the last Jewish philosophers entirely faithful to the Aristotelian perspective, ${ }^{38}$ treats the subject of the immortality of the soul in an entirely different way. Del Medigo, originally of Crete, lived in Padua, teaching at the prestigious university, a bastion of Aristotelianism, where the most significant debates on the question of the soul took place. At the same time, he was heir to a Jewish philosophical tradition that read Aristotle through Averroes' commentaries and shared a great part of the positions of the Cordovan philosopher. ${ }^{39}$

Del Medigo expressed his thoughts on the question of the soul at the invitation of Giovanni Pico della Mirandola, writing two treatises in Latin which he then himself translated into Hebrew as the "Questions on the soul."

As a good Aristotelian philosopher, Del Medigo assimilates the question of the soul into that of the intellect, bringing the subject of the immortality back to a gnoseological level. The questions that he poses are the same that occupied the Christian theologians: is the acquired intellect, a product of the 
union between the passive and active intellect, unique for all individuals, or should only individuals who reach that condition be counted? In other words, do single intellects lose their individuality when they conceive of universal notions? The question was implicitly linked to that of the individual immortality of the soul - for Del Medigo does not note it — which would be inconceivable if the intellects united themselves in a universal intellect. The response of the Cretan philosopher is inspired by the "moderate" position of Averroes: the acquired intellect is unique, but the paths to attaining the intelligible are numerous. It seems the reader is left to draw his own conclusions from this as to the immortality of the soul.

One interesting aspect of these writings is the ambiguity with which the relationship between philosophy and religion is formulated. On the one hand, Del Medigo criticizes the Christian theologians, as well as the Jewish and Muslim ones, for mixing religion and philosophy: the idea that God has miraculously created individual and eternal souls, for example, could be, according to him, exactly what the Torah requires of every Jew to believe, but is unsubstantiated from a philosophical point of view. It is not surprising that the masses embrace such beliefs, argues Del Medigo, but the theologians should abstain from seeking rational justifications. Philosophy and religion, to which we can respectively apply reason and faith (emunah), should remain separate. On the other hand, having praised Aristotle and Averroes on their position vis-à-vis the intellect and the soul, Del Medigo denies that theirs is also his position. His belief, he states, is that of the Torah, and philosophy may contain elements that are contrary to it.

This position must be compared with the one put forward later in Behynath ha-dath (Examination of Religion, composed in Candia in 1490 and published for the first time in Basel in 1629 in a book written by his descendant Joseph Del Medigo). Behynath ha-dath is a book of small dimensions but remarkable historical significance, such that it was considered by various scholars to be the swan song of medieval Jewish rationalism and the attempt to harmonize Reason and Revelation. ${ }^{41}$ In this work, Del Medigo analyzes the claim that the method to apply to notions revealed prophetically (at least to the principal ones) is different from the method applied in philosophical research..$^{42}$ This is not a question of theorizing a "double path" that leads to the same results: revealed religion and philosophy can in effect lead to different conclusions, and the attempts of rationalistic theologians (including Maimonides) to achieve a harmonization between the two ways are criticized for being neither truly 
religious nor truly philosophical. ${ }^{43}$ In case of contradiction between the two dispositions, the Jew must adhere to the Torah, which is certain, while philosophy - especially in the final phase of its research - has uncertain boundaries. The preference for religion, however, is valid as long as it does not oblige one to believe conceptual absurdities or to negate reasonable evidence, as is the case with Christianity: that irrational religion must be refuted.

The fundamental notions of the Jewish religion, according to Del Medigo, even if they cannot — and should not - be demonstrated by a rational way, do not enter into opposition with the "first intelligibles," which are naturally present in the human intellect. ${ }^{44}$ It is evident, he continues, that the ideas of the Jewish religion (including those concerning the soul) do not contradict those fundamental laws of the working of human thought: "Our holy Torah does not oblige us at all to believe in contradictory principles, nor to refute the first intelligibles, or to believe in concepts like to those first ones, or in reasonable experience", ${ }^{45}$ an affirmation which seems in partial contradiction with that of his Latin works on the soul, and which casts some doubt on Del Medigo's actual position.

\section{Rhetoric and Religion:}

\section{Yehudah Moscato (1532/33 - 1590)}

The spiritual fervor of Mosheh of Rieti, who makes use of both NeoPlatonic and kabbalistic elements, and builds upon an Aristotelian base, can be found a hundred years later in the work of one of the most refined intellectuals of sixteenth-century Jewish Italy, the Mantuan Yehudah Moscato. ${ }^{46}$ Moscato's name is connected with two important works: the Qol Yehudah (The Voice of Yehuda, Venice, 1594), a classic commentary on the Kuzary by Yehudah ha-Levy, and the collection of sermons Nefutzoth Yehudah (The Dispersion of Yehudah, Venice, 1589). The issue of the soul is confronted directly in the second sermon of the collection. Here, one can find the same references as in Rieti, first of all to the desire (teshuqah $)^{47}$ that God has placed in man so that he can rise up from material objects to their first form and cause, God; then to the soul, also called in this text "daughter of the King," ${ }^{48}$ which has to be brought back to its celestial seat, but with care taken that it not sink into the material abyss; and finally to the intellectual character of this perfection, which corresponds to the eternal happiness described by the "medieval" philosophers, osher we-hatzlahah nitzhyth. ${ }^{49}$ 
The tzaddyq, the just man, is the one who knows how to contemplate the divine truth in the correct way, "without distortion or confusion." The contemplation that Moscato alludes to is probably not a simple knowledge of the argumentative type but a disposition of the soul, which focuses on the eternal object of knowledge:

Derekh tzaddyqym la 'ad, the path of the just is eternal. [...] The just contemplate the firmament of the knowledge of His truth, which is blessed, without distortions or confusion, in such a way that their very direction (derekh) is the permanent and eternal intelligible. Their way of searching thus reaches a just and true knowledge of God. ${ }^{50}$

This contemplative outcome of knowledge, inspired by Maimonides but also by Plato, does not exclude, or devalue, matter. On the contrary, for Moscato, only through an "internal alchemy" capable of transforming elements without value into gold, or in other words elevating the lower components of the soul, man "will be united with his Creator in an eternal beatitude," ${ }^{11}$ saved by the stormy ocean of the earthly world (zeman). ${ }^{52}$ If he does not practice this elevation of the material components of the soul, a reversal will occur and "its gold will become dull." The elevation of the body, rather than its refusal, can be seen as a typical feature of the Humanistic sensitivity, which disconnects itself from the ascetic disposition of medieval culture, be it Christian or Jewish.

The immortality of the soul is not, in the work of Moscato, the result of rational argumentation typical of scholasticism but rather the fundamental nucleus of a complex exegetical and rhetorical discourse. ${ }^{53}$ This is in agreement with the typology of these writings - which are sermons, not lessonsand is, on the other hand, in harmony with the Platonic inspiration of a good part of the Christian literature of his time, known as "Humanistic."

\section{The Attempted Dialogue with Christians}

\section{David de Pomi (1525-1593): Judaism as a Religion Based in Ethics}

The second half of the sixteenth century and the seventeenth century, in Europe, are not only marked by the birth of a new science and a new 
rationality: there is also a period of a new devotion based on an interior vision, an exploration of the landscape of the soul. The transient nature of life, as a valley of deception, corruption, and sin, together with the longing for another, purer dimension, not subject to the ravaging of time, were also commonplaces of the religious literature of the time.

The Italian Jews shared this sensitivity with the Christians; or at least, this was the face that they showed to the Christians when they wrote in Italian or translated into Italian some of their religious poetry. Indeed, many of the poetic translations made by Italian Jews from the end of the sixteenth century to the first half of the seventeenth century had the soul as their subject or protagonist. ${ }^{54}$

The biblical translations and commentaries followed the same token. In 1572, the physician and lexicographer David de Pomi published a book in Venice entitled Discorso intorno a l'humana miseria, e sopr'al modo di fuggirla (Discourse on Human Misery, and on the Way of Escaping from It), which accompanied his Italian translation and commentary on the book of Ecclesiastes. The book of Ecclesiastes was seen (quite curiously, considering its plain meaning) as a text warning men against skepticism, pessimism, and over-indulgence in worldly pleasures. In his Discorso, De Pomi writes about the physical misery of man, from birth to old age, on man's more common sins - particularly sexual ones - and on the behaviour of the righteous. The first part of the book "shows that human happiness is in the future, not in this transient and frail life." ${ }^{55}$

The commentary of Ecclesiastes itself is replete with references to the true happiness of the afterlife. The verse 10:15, "The labour of the foolish wearieth every one of them, because he knoweth not how to go to the city" has, for example, this commentary:

As it occurs to the peasant, who, not aware of the refined pleasure of the town, does not want to leave the freedom of the farm, in spite of the efforts it demands, it happens to the stupid man: he does not understand the delights of Paradise and therefore devotes himself to earthly pleasures. At the end of the day, he will receive eternal suffering. ${ }^{56}$

In this commentary, de Pomi, as Ficino and all the spiritualist thinkers had, takes Epicurus and his materialist followers as the main adversaries; because, de Pomi writes, they affirmed that the soul perished with the body, 
and followed the concupiscent desires because they did not believe in the eternal good. ${ }^{57}$

De Pomi was a Jew who wrote in Italian and addressed a Christian-Italian audience. Interestingly enough, he chose a philosophical-moral text from his own Jewish tradition in order to illustrate a universal moral discourse. $\mathrm{He}$ probably assumed - as was more explicitly demonstrated in his Latin work De medico haebreo enarratio apologica (Apologetic discourse on the Jewish physician, Venice, 1588) - that fundamental religious and moral values were shared by Christians and Jews: especially the condemnation of the flesh and the exaltation of the immortal spirit, and that these values were rooted in the Jewish tradition. In De Pomi's work as a whole, some clear hints to a common religious outlook can be found, going back to the biblical figure of Abraham; Islam is not excluded from this "universal" attitude, although its inclusion does have some reservations. ${ }^{58}$

\section{Sara Copio Sullam: The Immortality of the Soul as Shared Value of Jews and Christians}

One of the more interesting examples of a common ground based on the belief of the immortality of the soul is the debate that took place in Venice in $1621 .{ }^{59}$ In that year, a young Jewish woman, Sara Copio Sullam, published a Manifesto in which she publicly defended herself against accusations of denying the immortality of the soul. ${ }^{60}$ Renowned for her literary skills, and for presiding over a salon littéraire, Sara Copio was herself a poet, writing in Italian. Her well-known correspondence with the poet Ansaldo Cebà, started by Sara, who had read and admired his poem Ester, is an eloquent example of Baroque literature and illustrates how Christians were not ready to accept the idea that a talented Jew could participate in the world of general culture while remaining a Jew: Cebà tried in almost every letter to convince the "beautiful Jewess" to convert to Christianity, but with no success. ${ }^{61}$

But let us go back to the debate that took place in 1621 .

The Christian intellectual Baldassare Bonifaccio, who would later become Bishop of Capo d'Istria, began a religious-philosophical exchange with Sara Copio on the questions of the immortality of the soul and original $\sin$. The Venetian addressed him in a letter in which she denied the hereditary character of Adam's sin. A soul, she argued, is not passed on to the next 
generation, and furthermore the stain of the original sin is not transmitted. In addition to these arguments, most probably inspired by the Venetian Rabbi Leon of Modena - a close acquaintance ${ }^{62}$ of hers - she added some further hypotheses concerning the eternal nature of matter, which elicited in turn a strong reply from Bonifaccio.

In his reply, the Discorso sull'immortalità dell'anima, a work trying to synthesize the traditional demonstrations of the theological-philosophical tradition, Bonifaccio denounced publicly the heterodoxy of such ideas. ${ }^{63} \mathrm{He}$ stated that, by denying the immortality of the soul, Sara Copio chose to accept the authority of Aristotle and the plague-ridden doctrine of Epicurus over the "oracles of the prophets." Bonifaccio added that these doctrines were clearly affirmed in the scriptures, and that by denying them Copio separated herself from her own people.

Even though Bonifaccio was adamant that Copio should convert if she wanted her soul to become immortal, one nevertheless notes that the controversy was based much more upon a difference of ideas than it was upon religious affiliation. As a matter of fact, argued the Christian Bonifaccio, by not accepting the immortality of the soul, Copio was renouncing to a doctrine of her own religion, a doctrine that her fellow Jews subscribed to. The controversy had thus implicitly, and notwithstanding the declarations of the Christian side, crossed the boundaries of religions.

Copio replied with her Manifesto, in which she vigorously denied that she was questioning the immortality of the soul. In the context of her argument, the inter-religious character of this religious idea is stressed. Sara Copio places this emphasis in strategic parts of her text, both at the beginning and at the end. In her address "To the reader," she announces that the controversy is vain, because no one, Jewish or Christian, can contradict the immortality of the soul. The text itself starts with a series of vigorous affirmations:

The soul of man, Mr. Baldassare, is incorruptible, immortal, and divine. It is innate, a creation of God in our bodies at the very moment when our organized being is ready, in the maternal womb, to receive it. This truth is as certain and infallible for me as it is - I believe-for every Jew and every Christian [...] so much so that I have asked myself what good it serves to present such a treatise now, and especially here in Venice, what purpose does it serve to publish such things among Christians? ${ }^{64}$ 
As a conclusion, Sara wrote: "Live happily and hope that the immortality that you preach will be yours if you indeed live by following your Christian law, just as I declare to follow my Jewish law." ${ }^{65}$

Sara Copio thus defended the legitimacy of her own religion while simultaneously expressing her respect for an equally legitimate Christianity. Incidentally, in another passage of her Manifesto, she referred to Jesus as the "Christ," that is as the Messiah, and she praised him for his response to the Sadduceans, who themselves denied the immortality of the soul. (These were the same Sadduceans who aroused the sympathy of Uriel da Costa, as shall be discussed.) At the same time, Sara Copio demonstrated her fidelity to Judaism, writing that devotion to Jewish Law prevented her from attacking Baldassare too vigorously. Let us note here the moral aspect of this remark, which a Christian reader could perfectly understand. In other words, she suggested that Judaism, no less than Christianity, was a religion of humility and of authentic devotion.

Copio explicitly refused to engage in a religious controversy with Baldassare, as she did in correspondence with Cebà. ${ }^{66}$ The only religious values she was ready to share with her Christian correspondents were devotion and the immortality of the soul.

This moral and devotional aspect of Judaism, which would have confused Christians who regarded Judaism as a lower form of religion — or the Jews as a sort of sub-species in the Homo-religious category - is illustrated by some of the sonnets that Sara Copio composed for other occasions. One of the sonnets begins with an invocation to God:

O Lord, You who observe the perpetual burning

Of my heart for You as an holocaust;

You who know that a desire other than a fragile honour

Pushes me to implore You, shedding tears. ${ }^{67}$

In another sonnet she addresses the soul:

O you, divine form of the mortal life

And sublime goal of God's work. ${ }^{68}$

She ends with a reminder of the impossibility of human reasoning comprehending the ephemeral and divine worlds. 
In this common-ground dialogue (the sonnets make no mention of sectarian affiliation), and within the context of those Italian and European intellectual and religious scenes that departed progressively from scholasticism, Jewish religious spirit is described as being as intense as Christianity, and thus fully comprehensible to Christians. A dividing line was increasingly drawn less between different religions and more between believers and non-believers, between religious men and atheists. Concerning the question of the immortality of the soul, Jews and Christians could fully concur with each other, together differentiating themselves from Materialists.

\section{The Tragic Consequences of the Issue: The Case of Uriel da Costa}

The dramatic episode of the converso Uriel da Costa is the only case of a public controversy on the immortality of the soul that took place within the Jewish world. This happened in the Sephardic community of Amsterdam, whose social and intellectual composition was very peculiar. Uriel Da Costa believed that the soul was not at all a separate substance but that it resided in the blood, and therefore was mortal. This position stood in total contradiction with the rabbinic teaching. Materialism-if not atheism-penetrated into Judaism via the former Iberian conversos. ${ }^{69}$ Rather than enter into details of this process here, we need only remark that the intense polemic was carried out primarily in Portuguese: both da Costa's Exame das tradições phariseas (1624) and the related Samuel da Silva's Tratado da immortalitade da alma (1623) were written in this language. ${ }^{70}$ So were the texts on the same issue authored by Moses Raphael $\mathrm{d}^{\prime}$ Aguilar ${ }^{71}$ and Isaac Cardoso. ${ }^{72}$ Menasheh ben Israel wrote in Spanish and Latin. ${ }^{73}$ In 1568, Daniel Arón Afia had already published the Spanish Las Opiniones sacadas de los más auténticos y antigos philósofos que sobre la alma escrivieron y sus definiciones (The Opinions of the Most Authentic and Ancient Philosophers Who Wrote About the Soul, and Their Definitions).$^{74}$

To sum up, when the Jews devoted specific texts to the immortality of the soul, emphasizing either the ethical and devotional aspect of the topic or its problematic side, they did so in Latin or in their various vernacular languages-Italian, Portuguese, and Spanish — but not in Hebrew. Exceptions 
are the books written in Hebrew by the three main rabbis of Amsterdam, Saul Levi Morteira, Isaac Aboab de Fonseca, ${ }^{75}$ and Menasheh ben Israel. However, Levi Mortera's text was never published and is now lost; ${ }^{76}$ and as for Menasheh ben Israel's Hebrew text Nishmath hayym (Living Soul), ${ }^{77}$ it was apparently more successful among the Christians than among the Jews. ${ }^{78}$

We can thus speak of a common Italian Jewish-Christian view on the immortality of the soul, and an internal Jewish controversy in Amsterdam, which ended with the opening of a dialogue with the Christians. We can consider these two historical events as manifestations of the same phenomenon: a growing commonality of religious interests among Jews and Christians, focused on that issue. After all, the Jewish reaction in Amsterdam against the materialistic positions of Da Costa was in unison with the Christian position, and indeed was possibly determined by it, as Steven Nadler convincingly argues, with regard to the partially similar case of Spinoza, in his Spinoza's Heresy. ${ }^{79}$

Another possible conclusion is that the Jews did not consider the immortality of the soul to be a problematic issue within their own religious and philosophical thought. They rarely wrote specific texts on it, nor did they engage in any controversy on the topic, and when they did, they wrote for non-Jewish readers-like Pico della Mirandola - or for Jewish readers with a Christian education, as many Jews possessed in Amsterdam. After all, Menasheh ben Israel was turning towards the Christians in order to create, along with them, a common front against those who denied the immortality of the soul. The same was happening in Venice at the same time-albeit in a less direct way-in the polemic between Sara Copio and Baldassare Bonifaccio. $^{80}$

The Jews generally believed in the immortality of the soul, and quite naturally shared this conviction with the Christians. Both were concerned about the dangers of materialism and atheism, to such an extent that they were able to make it the basis of a common intellectual ground. They did not share the experience described by Uriel da Costa when he wrote about his "Christian years" in Portugal:

In truth, the most distressful and wretched time in my life was when I believed that eternal bliss or misery awaited man and that according to his works he would earn that bliss or that misery. ${ }^{81}$ 


\section{Salomone Fiorentino (1743-1815): Jewish Ideas in Italian Poetry}

Salomone Fiorentino lived in a later period than the one generally taken into consideration for the purposes of this book. Nevertheless, this poet, who despite his excellent knowledge of Hebrew wrote exclusively in Italian, can be seen in a line of continuity with the other authors considered thus far. At the same time, he represents, in a certain sense, the point at which Italian Jews arrived at modernism.

Fiorentino was, culturally and politically, a Francophile and anti-Materialist, an admirer of scientific progress, and a man of profoundly religious spirit. ${ }^{82}$ The histories of Italian literature, though not neglecting him completely, reserve a very limited space for him and do not sufficiently explicate the contribution he made to Italian literature by his use of some typically Jewish subjects. At the same time, histories of Jewish culture - which pass him by almost completely_might profit by seeing him as someone who, having stripping himself of the language of his own religious tradition and avoiding explicit references to it, nevertheless presented its values in a Western language, translating them linguistically and conceptually.

Jewish subjects are already present in Fiorentino's youthful sonnets. In fact, it was not common, at the end of the eighteenth century, to describe in verse such subjects as the universal flood, Elijah's ascent to Heaven, a "Comparison between Jefte and Abraham," or to respond poetically to the question: "One searches for the reason why the Mosaic law instills the duties of the son towards the father and silences the duties of the father towards the son." ${ }^{\prime 3}$ We should not let ourselves be misled by these themes: despite their didactic-moralistic character, the fluidity of the expression and the sincerity of the author render these compositions perfectly appreciable even for a modern reader.

The relative fame of Fiorentino, however, has to do with the Elegie (Elegies), written on the occasion of the death of his wife, especially the first three of the six he composed, which are known as "The Disease," "The Death," and "The Vision." 84 With utmost sincerity, without hesitating to capture his most painful emotions, which in some cases were contradictory, Fiorentino runs through the stages of an event fundamental to his existence and his philosophical-religious conceptions. 
The Elegie are a cathartic journey which attempts to make sense of an incurable injury. In effect, even after receiving a nocturnal vision of his wife, who reveals to him how unjustified it is to suffer for an earthly loss, the author still finds no peace: "But sighing, I still search for comfort." 85

Written in hendecasyllabic tercets - the meter of the Divine Comedythese Elegie are rich in references to Dante and Petrarch. In her posthumous apparition, the wife exhibits many characteristics of Dante's Beatrice: the poet does not see her as she was at her death but "In that amorous state, and that countenance / that would transform men into gods." $" 86$ This donna angelicata, who transforms men into divine beings, is seen glowing with celestial light, while remaining at the same time humble and noble:

The face seemed lovingly humble:

And from the damp eyes a certain ray

Superhuman, it rained, noble. ${ }^{87}$

This eighteenth-century Beatrice, however, was also reminiscent of Petrarch's Laura (interestingly, Fiorentino's wife was in fact called Laura Gallico): "Her dress was white and scattered in the aura" 88 and the poet, prey to his unsatisfied desire to find his wife again, "pushes like mad, the wandering and empty foot." 89

In these Elegie, the reference to God is both discrete and evident at the same time, for despite the pain, the author worships with devout thoughts and words a God who is "arcanely just," $" 90$ the power and will of God that like to separate the two halves of one whole. ${ }^{91}$ There is not a single reference that is explicitly Jewish in these verses; a Christian could easily have written the Jewish Fiorentino's declarations of intense religiosity-even if, at that time, the non-confessional religiosity was being expressed, above all, in a deistic form.

It is the social references of his poetry that render Fiorentino an explicitly Jewish author. The loved woman in this Elegie is not a young and beautiful lover to whom the author is linked with a consuming passion, but a wife who passes away at the age of forty-five. The spectators to the author's pain are his children: reunited around the dinner table, they bring their father, who is dreamily seeking in their manners something of his dead wife, back to reality — and his responsibility. The theatre and witness of his excruciating 
solitude is the nuptial bed; a "disturbing pity" pushes the poet to rediscover what by now is "a field devoid of love." 92

It can be noted that these are the elements of a bourgeois poetry, in which there is nothing typically Jewish. Nonetheless, it is exactly these elements that betray a mandatory choice, dependent upon the social situation and the cultural tradition of the Italian Jews. Like Jews in other countries, Italian Jews saw in the family the initial — and fundamental - nucleus of society, without possible deviations. The Jewish community, it should be noted, was a micro-society, founded upon religion, which admitted a bond, even if it is only a sentimental one, between man and woman only within the limits of marriage.

Only the comic literature of medieval Spain and that of Immanuel of Rome (ca. 1261-after 1328) alluded to extra-marital love, usually in the form of erotic adventures. Stories of amorous passions are, therefore, almost entirely absent in the Jewish literary corpus, and no inspirational muses exist for this genre. On the other hand, one cannot find in the history of Jewish culture - again, apart from medieval Spain and the brief period in which Immanuel of Rome wrote - an autonomous artistic sphere. The Jews did not have circles, academies, literary currents and clubs, or patrons. ${ }^{93}$ Moreover, the artist, as such, did not have his own legitimacy: in order to write poetry, he first had to demonstrate that he had been engaged in the study of the Talmud and religious law. Literature was a hobby, not a profession, and was allowed only if religious duties had been fulfilled.

The absence of a cultural and artistic autonomy in the socio-religious sphere, which was founded upon the family and the community, leads to the superimposition of the two spheres: art is expressed in religious terms, not artistic ones. The inspiration behind poetic verses could then be a wife; the drama and the events that are the subjects of the poetry would be those of the family or community life, such as a wedding or the death of an eminent rabbi or the wife herself.

Being inspired to write poetry by the death of one's wife is an extremely rare circumstance, almost non-existent, in the history of Italian literature. ${ }^{94}$ Salomone Fiorentino, however, has an illustrious precedent in the history of Italian Jewish literature, the poet and philosopher Mosheh of Rieti, whom we have already mentioned. Mosheh's elegy, composed upon the death of his wife and cited above, is a text interwoven, as was customary, with biblical 
and talmudic references, but written in original meter and, above all, expressing a strong and sincere emotion. This poem, just like Fiorentino's, presents different stages of the process of the loss of a loved one: the announcement of death, the pain of the bereaved, and the lengthy elaboration of the bereavement. A celestial vision of his wife, which contains not Dantesque but Kabbalistic references, is present as well.

Fiorentino's wife passed away at the age of forty-five, and her husband felt it necessary to justify the composition of a poem in memory of a mature wife. ${ }^{95}$ In Rieti's case, his wife was actually seventy. This, however, did not diminish the intensity of the surviving husband's emotions. In this fifteenthcentury elegy, the wife is also described in a familiar context, as a wise educator of her children. Here too, the drama of the insane and useless search of the widower for the deceased spouse is domestic. It is his own house that admonishes him: "I look for her, agitated, as a madman, all over the house, saying to myself: 'My sister, ${ }^{96}$ perhaps I will find you, I have been accustomed to your image in this place, for more than fifty years.' But at the fall of night, a stone screams from the wall: 'What are you looking for? The superior forces have won, they have imprisoned her in a coffin, stretched out."'97

As mentioned above, the wife of Salomone Fiorentino appears before the husband in a nocturnal vision. In her visit she announces a consoling truth: the earthly life is not the true one, and therefore mourning the death of a loved one is unjustifiable:

Life is this one that Time does not measure

The one whose face is the Always, and its reverse is the Never While it runs blessed and goes secure. ${ }^{98}$

In this life without time, the immortal souls of the husband and wife will reunite in happiness.

In a fourth elegy, entitled "La rimembranza" ("Remembrance"), the poet returns to his mistake, which was a result of the senses, in considering a divine favor an injury. Instead of suffering over the death of his wife, he should have been happy about the passing of her soul to eternal life. The fifth and sixth elegies are entirely dedicated to a reflection on Time and Eternity.

The subject of the immortality of the soul is present in Fiorentino's other writings: a lengthy composition entitled "The Spirituality and Immortality 
of the Soul"99 and an intervention in a polemic on the subject with several Italian rabbis. ${ }^{100}$ In none of these texts does the author refer to the sources of the Jewish tradition — biblical or rabbinic — as authoritative. The arguments are always either rational or religious, but never confessional. Eighteenthcentury rationalism no longer ran in parallel to revealed religion, as had been the case in medieval theology, but was completely disinterested in revelation as a source of truth, even when it evidently took on a religious tone. Mendelssohn's Phaedon is the best example of a work on the immortality of the soul, founded on rational arguments while permeated with religious spirit. At the time, the Athenian setting of the dialogue obviously (and intentionally) impedes any recourse to the texts and traditions of the European religions, Christianity and Judaism.

One of these texts by Fiorentino has, in actuality, an explicit religious content. In order to write on a noble subject such as the immortality of the soul, the poet evokes God in a way that is reminiscent of Maimonides' conception: "Of each cause first Cause / being necessary and infinite" (p. 7). Criticizing several Materialist conceptions, the poet insists on the idea that "beyond the tomb / life can be found." One of the most significant arguments used to sustain this idea is based on the claim that in nature nothing is destroyed, but everything is transformed; life and death are not as disjointed as they appear to the senses, but exist in reality in a relationship of continuity. If this is true for matter, why should it not be true for the soul as well? ${ }^{101}$

What happens to the soul after death, however, remains a mystery, as is its connection to the body; the only thing that can be affirmed is its immortality. All the ways of the Lord are likewise mysterious - here we are reminded of the "arcanely just" God of the first elegy. A century and a half after Sara Copio, Fiorentino insists on this aspect of divinity: his laws and his designs are "arcane" and incomprehensible to the limited knowledge of humans. This, however, can be confirmed of God with certainty: that he is absolutely just and infinitely good. A good and just God, wrapped nevertheless in mystery as his essence (which does not hinder rendering him as a possible subject of a fervent cult), an immortal soul: these seem to be the religious notions that the Italian Jews bring with them when, stripped of explicit references to Judaism but undoubtedly nourished by its conceptions, they turn toward a non-Jewish audience. ${ }^{102}$ 


\section{Modern Ideas in Biblical Hebrew: Shemuel Romanelli}

The religious language of the Italian Jews, from the end of the eighteenth century onwards, should likely not have differed depending on whether the words spoken were addressed to community members or others. The Mantuan poet, translator, and "anthropologist" Shemuel Romanelli (17571814), an intellectual in the modern sense, is an eloquent example of this orientation. He published in Berlin in 1792 a Hebrew poem of thirty sestinas, entitled Ruah nakhon (A Just Spirit), dedicated to a protagonist of the Berliner Haskalah, David Friedländer. ${ }^{103}$

In this composition, Romanelli took on the religio-philosophical subject of the immortality of the soul or, more precisely, the existence of an entity called soul that transcends matter. He did so in a sophisticated biblical Hebrew-so carefully researched that he felt compelled to clarify his own verses with annotations - with evident references to the Jewish tradition. His form of argumentation, however, has nothing confessional. Just like Fiorentino, Romanelli does not present biblical texts or rabbinic affirmations as sources of authority; his argumentation is based on logic and observation. This method does not, however, succeed in arriving at exact and certain results. If the enemies are indeed the Materialists, who maintain that soul and thought are one unique whole, and are tightly connected to the body, the response of the author, beyond indicating that he visualizes an admired vision of the Universe in which all elements are connected among themselves in a beautiful harmony, cannot go beyond the proclamation of the mystery:

But what is this link, and what is the soul?

And matter, what is it? Who could say, who would know it all and could explain it? ...

Everything has a force (an invisible hand operates in it with its law) which maintains it: this is its soul, its life, without which there would be chaos. ${ }^{104}$

Every being, therefore, has a soul, and the Universe is described as a hierarchy of beings equipped with forces, that is, of increasingly noble souls that little by little ascend in the hierarchy. This is as far as human knowledge can reach; whoever is pushed by arrogance to explore beyond these limits runs the risk of being intellectually affected, affirms Romanelli, in an 
idea reminiscent of another Mantuan poet of the previous century, Ya'aqov Francès. ${ }^{105}$

Having once affirmed - without having explained - the existence of the soul, Romanelli asks himself if it is indeed immortal. Even here, the author is not capable of furnishing real demonstrations, apart from noting that in merely wondering whether they have souls, men distinguish themselves from animals. His argument comes down to a version of the famous wager of Pascal:

What do you lose, if you believe? What do you not lose, if you do not believe? You could not, however, understand, even if you give it your best. ${ }^{106}$

\section{Jewish Religiosity: A Neglected Heritage}

Quite paradoxically, Romanelli's religiosity, though expressed in Hebrew, is not directly inspired by Jewish sources, while Fiorentino's was. The Tuscan poet, who wrote exclusively in Italian, was no doubt a religious man. While his religious fervour went beyond the boundaries of one religion, it was nevertheless grounded in Judaism. The exchange of sonnets between the female poet Corilla Olympica, who presided over a literary academy, and Fiorentino, who had just been admitted into it, is revealing. Olympica is surprised by the personality of the poet:

Destiny has looked kindly on my wish

It has allowed me to finally meet you

And to discover that in your poems there is a God

Who inspires you with strange and unknown grace

$\cdots$

If I were to gaze upon you with surprise

What would then occur if by the same path

I was to rediscover the truth? ${ }^{107}$

The God that is described here could well have been Apollo, who allowed Fiorentino to compose new poetical forms. It is possible, however, to read "the strange and unknown grace" as referring to poetry that is surprisingly both familiar and unexpected, poetry written by a Jew expressing himself 
in Italian with his faith grounded in Judaism. It is a "strange" culture that is nevertheless perfectly understood by a Christian.

Fiorentino's response reveals just how important the religious element in his work was. Instead of thanking or even flattering his distinguished correspondent, he elaborates on the final lines of Olympica's sonnet, in which she sees the possibility of understanding the truth. In the sonnet he composed as a response to hers, he speaks of only one topic - how the acts of God seem unfathomable for humans. He concludes by describing the limits of poetry, which, while it may have certain brilliance, is nevertheless unable to pierce through the secrets of the divine.

Arcane, impenetrable, profound

Are the ways of the one who gave the being to nothing

And to his justice and his goodness correspond

What he did, and wanted, and accepted.

...

You may be able to follow these brilliant poems

But you will see that a veil which is covering over many truths

Has written on it the words: Adore and keep silent. ${ }^{108}$

What we have here is an image of the Jew very different from the one to which we are accustomed in Christian literature: the Jew as blind and obstinate, refusing to see the light; the unhappy Jew bearing the burden imposed by God the legislator. We can therefore well appreciate how the poet Olympica was surprised by the fact that she could receive religious instruction from a Jew.

Fiorentino's other intervention on the subject of immortality occurs-not in poetry but in philosophical-scientific prose - in the context of an exchange of opinions among rabbis of central Italy on the subject of the resurrection. The debate, as David Malkiel notes, takes place against a scientific backdrop despite the fact that the interventions refer to religious concepts (in this case Kabbalistic ones). ${ }^{109}$ His point of departure was the book of the English theologian Thomas Burnet (ca. 1635-1717) De statu mortuorum et resurgentium, published in 1723. Burnet's works were characterized by an attempt to reconcile modern post-Christian science with the Bible; the fact that some representatives of Orthodox Judaism in Italy were freely referring to these subjects and texts, originating in the Protestant world, is quite remarkable. 
Finally, it is important to note that a profoundly religious person such as Salomone Fiorentino, who actively participated in the life of the Jewish community, ${ }^{110}$ wrote a poem in praise of Galileo Galilei at a time when the Church condemned his theories. ${ }^{111}$ The same Fiorentino adamantly criticized religious fanaticism, without outlining its origin and characteristics.

The fanaticism of the black crest

Polishes the iron with the cloth it wears

Blooded by religion. ${ }^{112}$

An intense faith, a mentality decisively open to scientific progress and religious and cultural tolerance - these are the characteristics that these men and women of Jewish culture brought forth as their contributions to nineteenthcentury Italy, in the years just before the gates of the ghettoes were opened. 


\section{9 \\ Kabbalah and Rationalism in the Works of Mosheh Hayyim Luzzatto and some Kabbalists of his time}

Ranging from poetry to mysticism and from logic to morality, Mosheh Hayyim Luzzatto's works are so wide-ranging that finding their unifying elements can be difficult. This diversity challenges attempts at classifying him historically: is Luzzatto a modern author heralding a new age in Hebrew literature? ${ }^{1}$ Or does he represent the final manifestation of a kabbalistic sensibility on the wane in Western Europe? The history of the reception of his works is equally problematic: Eastern European communities of different orientations ${ }^{2}$ hailed him almost immediately as a master worthy of veneration, and this fervor continues to this day in religious Israeli circles, inspiring a rich variety of studies and publications. ${ }^{3}$ The Paduan author's works were recently rediscovered in Israel, where many understand them to articulate a New Age sensibility: an authentic religious experience expressed in modern terms. Poet and mystic, modern man and kabbalist, Luzzatto lends himself well to this kind of research. Indeed, the persecution he suffered at the hands of the rabbinic establishment gives him the aura of a victim of intolerance. ${ }^{4}$

Yet, in the West, he has been forgotten for almost a century. His memory was not helped when a few nineteenth-century Italian scholars, adhering closely to the critical method, reread him unsympathetically, complaining about his fascination with Kabbalah, which they considered an obscurantist discipline. Their lack of enthusiasm for kabbalistic studies was nevertheless tempered with admiration for his great theological and poetic talent. His well-known descendant, Samuel David Luzzatto (Shadal), clearly took this position:

R. Moses Chajim Luzzatto [...] a great genius, but unfortunately born in times too infelicitous and dark [...] devised a system which was all his own and founded upon the most abstruse questions of Theologyquestions which are beyond human investigation. He had a talent for 
interpreting all the mysterious doctrines of the modern kabbalistic school according to this system, and in so doing made his own hypotheses appear like the simple development and explanation of Kabbalah. ${ }^{5}$

According to Shadal, Mosheh Hayyim Luzzatto develops personal theological concepts but presents them in kabbalistic terms, ill-serving his theological genius. This was also the view of Samuel David Luzzatto's contemporary, Yosef Almanzi, whose early — and excellent-biographical account of the Paduan kabbalist and poet at once praised and criticized him. ${ }^{6}$

Simon Ginzburg gave a more nuanced assessment of the kabbalist in The Life and Works of Moses Hayyim Luzzatto (Philadelphia, 1931). Despite its Romanticism, this work constitutes the most important biographical monograph on the kabbalist and poet. Ginzburg understands Kabbalah as a dynamic force, especially in periods of isolation, as was the case during the period of the ghetto, when legalism tended to fossilize Jewish life. Ginzburg felt that Luzzatto's poetic talent rivaled the literary gifts of Yehudah ha-Levy, and restored beauty to the stagnant Hebrew language. Luzzatto's kabbalistic works were, for Ginzburg, a product of their age, and he read them as a form of resistance against legalism animated by a messianic spirit and argued that they testified thus to the vitality of Jewish life. ${ }^{7}$ Ginzburg nevertheless bemoaned the fact that:

a splendid combination of poetic emotion and mythological material, which Luzzatto, like Milton, could have embodied into a national epic, was turned into fruitless kabbalistic speculation. ${ }^{8}$

To this he added:

Had Moses Hayyim Luzzatto lived at an earlier date- he would no doubt have become a great religious leader, had he lived later-he would have become a great poet of the modern school. But living in a transition period as he did, tragedy was knocking at his door the first day he was ushered into this world. ${ }^{9}$

More recent critical appraisals of Luzzatto's works have been equally mixed. Although there have been a few analyses of his poetic works, ${ }^{10}$ as well as a biography based on a new examination of his correspondence, ${ }^{11}$ most of these studies have concentrated on the messianic aspects of Luzzatto's 
thought, both from a theoretical point of view (including an exploration of the Sabbatean question) and from an experiential perspective (focusing on the revelations which a celestial voice or maggid $^{12}$ made to Luzzatto). Other studies have concentrated on the question of the feminine dimension of the sefyroth..$^{13}$ Finally, an important monograph has examined, among other things, the links between the Paduan author's rhetoric and his kabbalistic thought. ${ }^{14}$ Some of the points discussed in this last work deserve further examination, in particular its exploration of the relationship of Luzzatto's works with both the Lurianic kabbalistic tradition and the philosophical-scientific thought of the age in which they were written. ${ }^{15}$ Among other things, such an investigation needs to meet the demands of Jewish intellectual historiography by contextualizing the Jewish experience. This means starting from the premise that, in a single period and place, Jews and non-Jews must have had analogous behaviors and perceptions of reality; different religious cultures merely expressed similar contents differently, because the society that lived within the walls of the Ghetto was not completely cut off from the outside world. Indeed, Luzzatto's own works are almost explicitly in conversation with ideas coming from outside the ghetto.

Luzzatto wrote solely in Hebrew. His kabbalistic, logical/rhetorical, ${ }^{16}$ ethi$\mathrm{cal}$, and poetic works all fit within the Jewish tradition. A theoretician, rather than an encyclopedic writer, Luzzatto did not often cite other works or authors; among his rare quotations, there are no references to any non-Jewish texts. The sources of his brief logical/rhetorical treatises are evident, and he never sought to dissimulate them, even if he did not mention any names and titles. Yet, there is an even deeper consonance between his thought and the philosophical-scientific ideas of his time. The texts that provide evidence for this are considered to have been exclusively intended for Jews, because the doctrine they articulate was developed within the confines of the religious intellectual "sanctuary" of Kabbalah. This is not to say that Luzzatto alludes, however implicitly, to this or that non-Jewish author. Instead, it is the general tonality of some of his important kabbalistic works which makes him an author of his time, even if only up to a point (we will address these reservations later): a writer who lived at a time when one could not ignore the new demands that rationality and scientific developments placed even on religious thought.

In other words, it seems appropriate to situate Luzzatto's works within the framework of early eighteenth-century European religious thought, when Cartesianism deeply influenced the way problems were approached and 
methods developed. Clearly sensitive to the concerns of his time, the Paduan kabbalist responded to them in his own way, by attempting to offer a new reading of a doctrinal corpus which was a priori indifferent to such modern demands, and which constituted the shared heritage of all Jewish communities, in every region of the Jewish Diaspora. There is a rationalistic slant in the reading Luzzatto proposed, so much so that one might risk describing him as a rational theologian. In this sense, his descendant, Samuel David, who was struck by the power of his theological reflections, appraised him correctly.

Mosheh Hayyim Luzzatto may well have sought to accentuate the rationalistic character of his thought following the well-known events that obliged him to alter the nature of his writings from 1730 onward. From then on, he was no longer permitted to base his works on the revelations of celestial voices, and was ordered to stop publishing on kabbalistic material. ${ }^{17}$ Yet, the peremptory character of his rationalistic statements, as well as their importance in his eyes and the urgency of his tone, suggest a genuine exigency rather than a literary strategy. ${ }^{18}$

Of course, the rationalistic aspects of Luzzatto's thought do not preclude the fact that the young Paduan was also a mystic, the recipient of celestial revelations and the organizer of a group which aspired to perform tiqqunym (the restoration of the divine world). He believed in gilgulym (the reincarnation of souls), and believed he was the reincarnation of great personalities of the past. He was at one and the same time a mystic and a rationalist, and saw no contradiction in this. He adhered to a mystical form of religiosity which found collective expression during the years of belief in Shabbetay Tzevy, and survived discreetly in Italy at least until the beginning of the nineteenth century, if not beyond that. ${ }^{19} \mathrm{He}$ nevertheless also embodied the intellectual elite's need to confront the most dynamic aspects of European culture. In other words, Luzzatto defended Kabbalah from the charges its rationalist critics leveled at it, even as he at least partly accepted the criteria on which they based their attacks. In order to situate this aspect of his work, one must retrace the history of the criticisms Kabbalah received in Italy before the era of Luzzatto.

\section{Covert Critiques of Kabbalah}

In 1558, the year of the polemics surrounding the first printed edition of the Zohar and other important kabbalistic texts, hostility to Kabbalah on doctrinal grounds was confined to a brief, anonymous text. We deduce the 
existence of this critical pamphlet from the responses which it provoked from its adversaries. Drawing on observations found in Eliyah Delmedigo's book, Behynath ha-dath (An Examination of Religion, composed in 1490 and published in 1629), the anonymous author of the anti-kabbalist pamphlet questions the antiquity of the Zohar and voices reservations about the doctrine of the sefyroth, which he considers potentially heretical. Additionally, he reasons that the search for concealed and secret meanings within the divine commandments may potentially have an adverse impact on healthy religious behavior, which should be based on the study of Talmud and on basic obedience to the divine laws. ${ }^{20}$

In the following years, and particularly throughout the seventeenth century, Kabbalah was the cornerstone of the dominant culture of Italian Jews. It determined the theoretical orientation of the elite, spread through the dissemination of its ritual behaviors, and played an important role in shaping mentalities. Any opposition to Kabbalah manifested itself in resistance to a tendency that pervaded all aspects of Jewish life and affected the population at all levels. Significant yet sporadic, this resistance was censored by the rabbinic authorities and in some cases was not made public: it is in large part thanks to its censors and virulent attackers that we know about it today.

It is possible to reconstruct the main criticisms leveled at Kabbalah, particularly Lurianic Kabbalah, which associated the doctrine of Yitzhaq Luria - as transmitted by his disciple Hayyim Vital Calabrese - to the doctrines of the Zohar and earlier kabbalists such as Nahmanides. It is also possible to trace the intellectual model which the critics of Kabbalah proposed as an alternative.

The major accusation directed against the kabbalists concerned the fact that they considered the Kabbalah to be "the true wisdom"- the hokhmath ha-emeth - but had neither verified the historical authenticity of its teachings nor produced a theoretical justification of their truthfulness. The Venecian rabbi Yehudah Ariyeh Modena (1571-1648) stringently raises both of these points in Ary nohem (A Lion Roars), which, significantly, remained unedited until $1840 .{ }^{21}$ For Modena, Kabbalah is neither a true tradition nor a true science. It is not a tradition because the great rabbis of the past-from the Talmudic era onward - never mention it. Additionally, it seems evident to him that the major kabbalistic texts-particularly those collected in the Zohar, which have an aura of holiness and are attributed to the master of the Mishnah, Shim'on bar Yohai-are in reality apocryphal writings which 
were edited many centuries later. According to Modena, the kabbalists imitated ancient philosophers and manufactured their texts out of apocrypha in the style of Jewish writings. It was not easy to make such assertions, and Modena fully expected those who believed in the texts to rebut him stiffly: "And I know that I must fortify myself with shield and armor, in order to protect myself against their violent verbal arrows." 22

For Modena, Kabbalah is not an authentic tradition, but neither is it a science. Shifting to a theoretical argument, he presents a detailed epistemological analysis grounded in a definition of science (hokhmah). The Venetian rabbi argues that in order to be considered a science, a discipline must insist on reaching the truth (understood as the coincidence of a mental representation with reality) in its particular field through rational argumentation. In this sense, physics and mathematics are clearly sciences, as they follow a line of reasoning in order to reach rapid and authoritative conclusions. Similarly, astronomy is a science, as are, in a certain sense, rational theology (as long as it adheres to the proper rules of demonstration) and logic (the instrument for grasping the truth) ${ }^{23}$ Developing this line of argument, Modena cites Nahmanides, Meyr ibn Gabbay and Mosheh Cordovero in order to show that the kabbalists not only refused to investigate questions pertaining to the science of truth through rational argumentation, or sevara, but actually denounce such investigations as irreverent. The only proofs they produce are based on authority: they quote other quotations, and write books referencing other books. As the kabbalists do not think it apposite to extricate themselves from this circle of self-justification, their discipline is not a science. It is precisely sevara which leads Yehudah Ariyeh Modena to castigate the esoteric doctrine and its supporters. ${ }^{24}$

The criteria which Modena invokes in his critique of Kabbalah are analogous to those he made in a previous work in order to criticize Catholic theology; ${ }^{25}$ there, his discussion of Catholicism focused both on the historical reality of Jesus' ideas and on the rationality of Catholic doctrine. Modena's evaluation of Catholicism was negative on both counts: one the one hand, the "historical Jesus" differed significantly from the Catholic Jesus, and on the other, Catholic theology was based on hypotheses that were unacceptable to reason. However, his critique of Kabbalah is even harsher. The saying "tiqqun ha-regel la-na 'al" ("to correct the foot to suit the shoe") applies to both doctrines: both forge a series of notions with no historical or theoretical precedent, and are constrained to distort the biblical text as they adapt it to them, giving it non-literal interpretations. However, whereas Catholic 
theology leaves a certain amount of room for rational discussion, the only possible strategy for the kabbalists is unquestioning assent.

Modena's positive alternative to Kabbalah is implicit in his critique: a religion open to moderate rationalism, and in particular to the rational justification of fundamental beliefs such as the unity of God, the creation of the world, and providence. Considered as a whole, the Venetian rabbi's complete works define a "cultural project" which was soon destined for failure, at least as far as mainstream Jewish thought was concerned. Modena wanted Jews to know and appreciate the sciences, be versed in the Latin classics, and engage with Hebrew literature, but also to engage with the most modern productions of the Italian language and literature (he explicitly uses the term "modern"). ${ }^{26}$ He also thought they should be familiar with Christianity, without accepting or denigrating its dogmas. He probably wished for a Jewish religion more solidly based on the Bible than was the Judaism of his day, and trimmed of some of the exclusive practices and beliefs that impeded its diffusion. ${ }^{27}$

Seventeenth-century kabbalists departed significantly from this model. They turned to the East - in particular to Safed — for the light of truth. ${ }^{28}$ They generally did not bother to justify Luria's complex doctrines on divinity, and when they did they invoked the notion of the ruah ha-qodesh, the Holy Spirit (a degree of prophecy) that descended upon the Master of Galilee. Rhetorically, their writings took the form of a series of assertions, often opening with a magisterial injunction such as "Know," or "You must know that..."; from a systemic point of view, their teachings did not conform to the traditional categories of rational theology — which in Jewish thought developed from the tenth-century Sa'adiyah Gaon to the fifteenth-century Yosef Albo - but instead followed a peculiar course inspired by Yitzhaq Luria's emanationism. When, as sometimes happened, exegetical logic did prevail, their ideas took the form of peculiar biblical commentaries. Moreover, theirs was a theoretically and culturally exclusive doctrine: they presented the Jews as repositories of the science of truth and protagonists for the restoration of the divine world, and were suspicious of, or even hostile toward, anything that was not Jewish or not expressed in Hebrew. ${ }^{29}$

A few years after Modena, Ya'aqov Francés (1615-1667) of Mantua, who was probably the best Hebrew poet of his generation, launched another critique of Kabbalah. In a controversial poem, ${ }^{30}$ Francés denounces Kabbalah, not on the grounds of its doctrine - which he held in high esteem - but because its dissemination is detrimental to what should constitute the canonical 
knowledge of a learned Jew. Francés complains that the kabbalists of his age neglect the study of traditional Jewish texts - such as the Talmud - let alone philosophy and science, and thus aim to scale the peaks of divine wisdom without proper preparation. He considers silence to be the only authentic discourse on the divine, but instead:

Today, whoever does not speak of the Creator Is not considered a creature. ${ }^{31}$ [...]

The Kabbalah is talked about in the marketplaces: It is tossed about in everyone's heads. ${ }^{32}$

In these lines, he evokes the complex and detailed account Kabbalah makes of the divine world, contradicting the notion of absolute transcendence proposed by classical Jewish philosophy, in particular that of Maimonides..$^{33}$

Commenting on the kabbalists' ignorance of science and pretensions to perfect knowledge of the celestial worlds, Francés asks: "How can a man who is ignorant of the laws of nature (derekh ha teva) and the creatures of the earth and sky ("he does not know the course of the raptor / that every eagle discerns"34), how can he scan the face of the firmament with his speculations?"

Francés also denounces the kabbalists' methodology, which he considers fraudulent: characteristically introduced by the term "certainly" (wadday), the truths which they claim to utter are none other than the fruit of their imaginations (badday); the truth cannot grow in this arid soil. ${ }^{35}$ While this denunciation echoes Modena's main criticism of the kabbalists, Francés also condemns them on moral grounds: he who practices Kabbalah is guilty, because

he searches for secrets, only because they don't have to be proven. ${ }^{36}$

Even if Francés targeted the inexpert kabbalists of his day rather than the doctrine of Kabbalah per se, the ideal program of studies which he proposes at the end of his poem nevertheless does not seem to leave much scope for Kabbalah. ${ }^{37}$ The man the poet envisions will only come to know divine secrets after a slow and lengthy process (as instructed by philosophers, from Sa'adiyah to Maimonides). Avoiding great leaps forward "like the marten," he will "call the divine Torah his sister / and philosophy his friend." 38 
Francés' poem, which was published in 1660 or 1661, was censored by the leaders of the Mantuan community, who forbade its reading and probably ordered its destruction. Francés wrote many other poems with violent undertones against those he considered to be his persecutors, but they remained in manuscript form until the nineteenth century. It is possibly as a result of these events that Ya' aqov had to leave Mantua for Florence. ${ }^{39}$

In 1704, Francés' text was reprinted by the rabbi of Ancona, Shimshon Morpurgo, in the appendix of a book he published anonymously, 'Etz hada' ath (The Tree of Wisdom). This book was a commentary of Behynath olam (Examination of the World) by Yeda'yiah Bedersi, who had defended philosophical enquiry in a famous fourteenth-century polemic. ${ }^{40}$ Needless to say, reprinting Francés' poem in such a context was not a neutral act. Morpurgo does not deny endorsing a moderate rationalism, in which scientific and philosophical research accompany, clarify, and support religion rather than being at odds with it. For Morpurgo, philosophy should not be condemned because a few philosophers deviated from the straight path of religion; in fact, the kabbalists too could lose their way, as Francés' poetic testimony pointed out. Morpurgo's decision to publish his book anonymously and print a controversial poem condemned by the rabbis point to his desire to pursue a concealed polemic against the hegemony of kabbalistic culture, while also suggesting that he may have feared the reactions this new book could provoke. ${ }^{41}$

Morpurgo's book was criticized by the kabbalist rabbi of Mantua, Avi'ad Sar Shalom Basilea (1680-1743) in a text entitled Emunath hakhamym (Belief of the Wise). ${ }^{42}$ Basilea did not launch a direct attack against the author of 'Etz ha-da'ath; despite having identified him, he did not call him by name and maintained a respectful stance towards him, limiting himself to a few observations on the contents of the book. However, the Mantuan kabbalist adopted a much more virulent stance against Francés's poetry which Morpurgo had reprinted.

In a lengthy passage, Basilea declares Francés to be impure (mezoham) and devoid of any rabbinic qualifications. ${ }^{43}$ Rejecting the notion that there is a link between adhering to Kabbalah and being ignorant of the Jewish sciences, he seeks to disprove this idea by listing the many contemporary Italian rabbis who were distinguished scholars in both Kabbalah and Talmud. As for the exact sciences, his own interests in mathematics, geometry, optics, and astronomy implicitly demonstrated that one could be both a kabbalist and a scientist. Basilea also responds to Francés' and Modena's criticisms of the 
kabbalists' diregard for the logic of rational proof by appealing to the truthfulness of authentic tradition. In his view, the tradition of Kabbalah is even more faithful to the revealed sources than Talmud is; moreover, he proposes that this does not prevent it from being a true science, either in terms of its content, which is true, or its method: just as is the case with the human sciences one cannot study Kabbalah without respecting its particular order and progression (ba-seder ha-rauy we-ha-nakhon) ${ }^{44}$ In essence, then, Kabbalah is a tradition which is true in content and scientific in method..$^{45}$

Basilea seems to have oscillated between a completely anti-philosophical stance and the acceptance of rational discussion:

I will enter into discussion [with the opponents of Kabbalah] in order to know the truth, according to the instructions of the intellect and of our great teachers $[\ldots]$ on the condition that the opponents of Kabbalah listen to me in order to understand, not in order to object, and that they accept the conclusions of this discussion according to the rules of philosophical debate. ${ }^{46}$

Invoking his teacher, the great kabbalist Mosheh Zacuto, Basilea asserts that philosophy is for goyyim, as its deductions can prove erroneous. Jews have no need for it, he argues, because they arrive at knowledge through tradition: "One learns the hokhmah [the true, received science] from a teacher, while one learns the bynah [deductive science] by oneself." ${ }^{47}$

The polemical tone adopted by Basilea in much of his book is itself clear evidence of infighting in the Jewish world. A close examination of the references Basilea makes to the rationalists of his time brings out these tensions: he speaks of contemporary Jews who not only deny the secrets of the Torah but lack respect for the Talmudic rabbis, presuming to "separate the wheat from the chaff" in their teachings. ${ }^{48}$ Moreover, he writes, Christian authors are comparatively less radical in their rationalist critique of the Bible than these Jews, ${ }^{49}$ as they appeal less to Jewish religious texts than to the profane writings of non-Jews, ${ }^{50}$ and they pay more credit to these works than nonJewish readers. ${ }^{51}$ According to him, the mere fact that a text has non-Jewish origins increases its prestige in their eyes. He notes that they teach the commentaries of the rationalist Avraham Ibn Ezra in schools, convincing their students of the falsity of certain traditional beliefs although they are manifestly true, for example the belief in the existence of demons. ${ }^{52}$ Basilea even admits having to expend more effort correcting the erroneous tendencies of 
his coreligionists than entering into discussions with representatives of the Christian religion. ${ }^{53}$ Indeed, quoting Pietro Galatino, he asserts that Christians reproach the Jews for not respecting their own laws. ${ }^{54}$ Evidently, the medieval genre of the disputatio between different religions was in decline, and religious apologies were progressively taking over: aimed at skeptical unbelievers and rationalists of all confessions, these rallied the proponents of different faiths to a common front.

In order to address the criticisms of his contemporaries, the Mantuan rabbi devised a strategy involving the introduction of elements pertaining to the human sciences into his account of Kabbalah: we will examine these elements in greater detail further along. This is the context in which Luzzatto should be situated: between loyalty to Kabbalah and adherence to a certain scientific model, which could evidently no longer be refuted solely on the basis of authority.

Often considered Italy's most esoterically inclined Italian community, Livorno was the site of additional indirect resistance to Kabbalah. Yosef Ergas, its most prestigious representative between the late seventeenth- and early eighteenth-centuries, recounted in the first teshuvah (legal response) of his important collection, Divrey Yosef, that in 1710:

A certain person became agitated, and began to publicly defame the science of truth [i.e. Kabbalah], and those that study it, railing in particular against the holy Yitzhaq Luria. Some people of no value, who thought of themselves as wise, but who were actually worthless, rallied around this person, and began to criticize the wise and devoted men who were better than they and their fathers. ${ }^{55}$

Although the question at stake was relatively trivial (whether to omit two words from the prayers said during the Days of Penitence), Ergas' response gives us an insight into tensions that were not manifested more directly. It seems likely that his reference to people "who thought of themselves as wise" alludes to the advocates of a certain type of critical-rational culture: the same individuals that Basilea criticized.

Another case of resistance to Kabbalah, which was also censored by the authorities of the Jewish community, was recorded by a Christian source. In his famous Bibliotheca Rabbinica (1675), Giulio Bartolocci speaks of "a voluminous book against Kabbalah and the sefyroth," written by the Venetian 
rabbi Mordehay Corcos. Objecting to this work, however, the rabbis from Corcos' city appealed to the public authorities in order to halt its publication and were apparently successful. ${ }^{56}$

\section{Against Obscurantism: The Strategy of Dialogue}

The works of Yosef Ergas and Mosheh Hayyim Luzzatto- the leading early eighteenth-century theoreticians of Kabbalah — should be read in light of these criticisms. Each of them chose to compose a dialogue between a kabbalist and a rationalist ${ }^{57}$ in which the latter led the kabbalist to justify Kabbalah from a historical, and above all theoretical, perspective. Although these dialogues were not voluminous, their authors considered them fairly important. In both dialogues, the kabbalists are seen through the eyes of the rationalists and seem to be devout ignoramuses, whose ideas are obscure and confused, and who do not follow the ways of reason, instead relying solely on the principle of authority.

Shomer emunym (Guardian of Faith) is a dialogue by Yosef Ergas, published posthumously in Amsterdam in 1735 or 1736. According to the author, it constitutes a simply written introduction to Yitzhaq Luria's Kabbalah, or, more precisely, an attempt to "correctly elucidate the writings of Ha'Ary [the acrostic of Ashkenazy Rabby Yitzhaq, i.e. Luria]." ${ }^{58}$ Ergas begins with a historical justification of Kabbalah, indirectly answering Leone Modena's criticisms, then proceeds to introduce the principal tenets of the doctrine, giving them a philosophical explanation and, in some cases, justification: this is evidently what Ergas meant by "elucidating" Lurianic Kabbalah. In doing so, he seeks to circumvent two problems of Jewish religious studies: a decreasing interest in the "science of the truth," and-for those who still believe in and practice it - an engagement with the Lurianic doctrine that is excessively cursory and precludes the study of previous kabbalistic texts. ${ }^{59}$

According to Shealtiel — who is the rationalist interrogator in Ergas's dialogue and represents those who approach Judaism literally, ignoring its esoteric dimension - any discussion with the kabbalists is superfluous, because:

All of their discourses are founded on their faith in their teachers [...], and one cannot refute them with intellect (sekhel), or reason (sevara), or true opinion, because they would not listen: the arguments would not enter into their ears. I therefore do not see the usefulness of talking with them. 
The kabbalist Yehoyada" (whose name translates to "God knows") concedes that Kabbalah is founded on traditional teachings, but reminds his interlocutor that it leaves space for discussion:

We do not refrain from researching, investigating, and questioning the discourses of the kabbalists and the foundations on which their premises rest. On the contrary, it is our habit to discuss (lefalpel) their meanings, just as we discuss the halakhah, i.e. legal matters. ${ }^{60}$

The "rationalist" agrees to converse, even if there is scant space for free discussion: the legal pilpul operates within precise limits, which are set before each debate.

Granted the last word, the kabbalist ends by warning against an a priori refusal of kabbalistic ideas in the absence of counter-arguments, if research proves that they are close to the literal sense of the rabbinic statements in Talmud. In other words, although not entirely justified (let alone founded) on rational grounds, the doctrine the kabbalist proposes at least does not run contrary to reason. Furthermore, he implicitly reverses Modena's argument against Kabbalah's distorted, non-literal interpretation of texts ("the adaptation of the foot to the shoe") by defending kabbalistic exegesis for being closest to the literal sense- at least regarding the teachings of the Talmudic masters, if not the Bible. Throughout the successive arguments he goes on to develop, Ergas maintains that Talmudic discussions cannot really be understood without reference to Kabbalah. ${ }^{61}$

Shomer emunym bears the mark of rationalism, despite a few dogmatic and authoritarian statements, such as when it asserts that anyone who knowingly denies the theory of the sefyroth is a heretic, or that one must believe the rabbis even if one does not fully understand them. ${ }^{62}$ Although the kabbalist's interlocutor objects that Kabbalah contains several abstruse (zarym) and irrational elements which are not acceptable (mityashevym) ${ }^{63}$ to a learned person (hakham), the kabbalist explains that these difficulties derive from a methodologically flawed approach to its study. He argues that, like any other human science, Kabbalah has a particular order (seder rauy we-nakhon): one must respect this order in order to understand the works of the kabbalists and grasp their correct meaning (kawwanah) ${ }^{64}$ The notion-which Basilea also formulates - that Kabbalah is a discipline with its own particular order places it on a par with the sciences, at least from a methodological point of 
view. However, the idea that the doctrine has to be explained in order to become intelligible is perhaps even more important. From Menahem Azariyah to Mosheh Zacuto, the major seventeenth-century kabbalists set forth the doctrine of Kabbalah without resorting to this second, explicative level, instead following the descriptive, exegetical rhetoric of Yitzhaq Luria. In contrast, Ergas - and with him Luzzatto - felt compelled to clarify Kabbalah, which led them to articulate a series of ideas drawn from the sphere of reason. Hoping, as they explained, that this would bring Jewish scholars back to Kabbalah, they also recognized that founding a doctrine on tradition, no matter how prestigious, was no longer enough in their day and age. Naturally, we must ask if this decision was born of genuine conviction, or if it was merely a defensive strategy. In other words, was their determination to resort to rational explanation the result of an a posteriori concession to making Kabbalah comprehensible for the uninitiated, or did these important eighteenth-century thinkers believe that kabbalistic notions should be based on intellectual-philosophical constructions (although these in fact constituted two separate categories for Ergas and Luzzatto, as we will see)?

Whatever the case may be, what is clear is that one had to be something of a rationalist theologian in order to be a kabbalist in the eighteenth century. In other words, the criticisms Modena and Francés leveled at the kabbalists did not hold completely. As Ergas' anti-kabbalist interlocutor, Shealtiel, declares (touching on the fundamental question of the existence of the sefyroth):

I must speak the truth: I never thought that the kabbalists analyzed this subtle material in order to explain it or make it acceptably elegant or rational (le-ha- 'amydam w-le-yashevam be-tuv ta'am u-sevara). I effectively acknowledge that everything you say would be acceptable for any thinking person (nekhohym la-mevyn), and gives sufficient grounds for declaring rationally necessary your tradition of the existence of the sefyroth and the superior worlds. ${ }^{65}$

In a dialogue between a philosopher and a kabbalist which later editors entitled Hoqer w-mequbbal (A Philosopher and a Kabbalist) ${ }^{66}$ Luzzatto also felt compelled to enter the realm of reason in order to discuss Kabbalah. ${ }^{67}$

In a dense introduction to his dialogue, Luzzatto denounces the decadent state of true knowledge, the prophetic knowledge which was revealed and transmitted to Israel alone, and which a long exile has overshadowed. 
Whereas non-Jews, who arrived at their sciences rationally, were not subjected to this profound crisis, Jews now found themselves in possession of limited knowledge, and were reduced to simple, literal statements about the Scriptures. This lost prophetic knowledge of the intimate meaning of the Torah, for Luzzatto, was intellectual: a position which brings him very close to Maimonides. The soul, which Luzzatto identifies with the intellect (sekhel), was created in order to grasp (le-haskil) the light of divinity. Indeed, the content of Luzzatto's introduction is rather similar to, and possibly inspired by, Maimonides' well-known introduction to the Mishneh Torah. ${ }^{68}$ Even so, for Luzzatto this understanding will come from kabbalistic knowledge, which is exclusively the prerogative of Israel. ${ }^{69}$ Although it is true that the teachings of Luria and his disciples reintroduced prophecy after the long "sleep of exile," their doctrine has in fact become obscure and difficult, and requires much additional study; in contrast, as we will see, clarity is an important part of Luzzatto's own works. ${ }^{70}$

Luzzatto goes on to say that it is hardly surprising if the scholars of his time consider the "true science" to be constituted of empty formulas, or even if they judge these formulas clumsy and unacceptable, and doubt if the Zohar may be attributed to the great teacher Shim'on bar Yohay. Whereas scholars are in search of clear (meyusheveth) and in-depth knowledge, according to Luzzatto, in its current state, Kabbalah presents itself to them as an obscure book (sefer hatum), where one definition follows upon the other-the sefyroth and the partzufym, the various worlds and their dynamics - forming a series of statements unsupported by the merest attempt at intelligibility (zikhron shel ghirsa, akh belo sevara). ${ }^{71}$

The task Luzzatto assigns himself, then, is to recover the lost meaning of the true knowledge: he seeks to clarify the obscure notions - that is, the notions that have become obscure - of the true science, Kabbalah. In order to accomplish this and convince those endowed with a clear intellect that Kabbalah not only is not a nonsensical doctrine, but is the truest and most complete of the sciences, Luzzatto deems it necessary to couch this science in the language of rational philosophy, or, to be more precise, rational theology.

The hoqer - the philosopher interlocutor in Luzzatto's dialogue - begins by expressing his reservations. Even though persons of unquestionable piety (hasydym) follow Kabbalah, their arguments appear abstruse (zarym), and in some instances absolutely vain and empty (devarym shel mah bekhakh), as in the case of the discourse on the sefyroth. This leads him to request 
elucidations which, if they cannot reach the level of logical necessity, will at least not be at odds with straightforward reasoning (ha-sekhel ha-yashar).

Naturally, the philosopher is rapidly won over by the kabbalist's disquisitions, and especially by his style of argumentation, which is worthy of true science in its rigor and clarity. Thanks to the explanations of the kabbalist - Luzzatto's alter-ego - nonsense metamorphoses into knowledge of the highest order. The text emphasizes the purposefully "historical" character of Luzzatto's elucidations, demonstrating his ambition to see Kabbalah recover its true status in his own times. The rationalist concludes:

I could not stand the things I heard about this knowledge. I judged them foolish and banal, and could not find anything in them that could be called science. Yet, in this generation, I affirm that we are confronted with an extraordinary science, and it is good that every intelligent person should abandon all the other intellectual pursuits in the world in order to follow this great and holy science. In comparison, all other intellectual pursuits have no value. ${ }^{72}$

The idea of engaging in a rational discussion with Kabbalah's detractors is also present in Basilea's text. Significantly, the Mantuan kabbalist calls for a public debate on the crucial subject of the antiquity of the Zohar and of Kabbalah in general, in which reason and the conclusions of indisputably authoritative teachers will be the only decisive criteria. In fact, he warns his (Jewish) rationalist opponents against the prejudices they might show by rejecting evidence merely in order to deny prestige to the ancient traditions of their own culture. ${ }^{73}$ Evidently, in the early eighteenth century, the public space where one debated one's opinions was just as much of a concrete reality as was the attraction that many Jews felt for rationalist critique.

Although Basilea did not write a dialogue between a kabbalist and a rationalist, his Emunath hakhamym makes an interesting reference to debates that actually took place. ${ }^{74}$ In this book, the Mantuan rabbi mentions having assiduously studied philosophical and scientific texts in his youth before going on to read Kabbalah — as developed by Mosheh Cordovero — which he found in no way at odds with rational inquiry: "and I showed [these ideas] to several philosophers of our people, believers who asked me many questions on difficult topics touching on the science of the secrets of the Torah." He then repeated this experiment at the age of forty-four, reading Lurianic 
Kabbalah with Shemuel Norzi. Basilea mentions proving the truth of the notion of tzimtzum - the contraction of the Divinity - to various Jewish philosophers solely on the basis of philosophical proofs, before publicly repeating his demonstration and only making reference to topics pertaining to the natural sciences.

Basilea thus invites his reader into a discussion guided by a single imperative: rationality, on the grounds that "the truth will emerge only through debate, and we will both profit." Nevertheless, the authority of the Torah and the Talmudic masters also carry weight as proof, because their truths are as evident as tangible experience. ${ }^{75}$

\section{Rational Reductions of Kabbalah}

In their different ways, two Italian kabbalist-philosophers who lived four centuries apart, Yohanan Alemanno (1434-post-1504) and Eliyahu Benamozegh (1823-1900), observed similarities between certain kabbalistic notions and some aspects of the philosophical thought of their own time. Alemanno, who lived in the Florence of Lorenzo de' Medici and Pico della Mirandola, identifies the sefyroth with "spiritual numbers" of PythagoreanPlatonic origin. ${ }^{76}$ Contemporary with Positivism and Post-Hegelian Idealism, Benamozegh devotes himself to finding equivalents for various kabbalistic concepts in the terminology used in those schools of philosophical thought. ${ }^{77}$ Rather than merely assessing the relative merits of Jewish and non-Jewish doctrines, both Alemanno and Benamozegh focus on understanding and elucidating their own conceptual tradition in light of the intellectual coordinates of the culture surrounding them.

It is difficult to ascertain whether eighteenth-century Italian kabbalists shared the same motivations. Certainly they explicitly regarded Kabbalah as the true doctrine; for them, it was as superior to philosophy as divine revelation was to human thought. However, this did not imply a coherently elaborated opposition between Kabbalah and philosophy. Their audience was essentially, or exclusively, Jewish. They aimed their partially philosophical readings at those educated "modern" Jews who had grown increasingly wary of the "mythical" language and dogmatic tone of Lurianic Kabbalah and were distancing themselves from it, lured away by post-Cartesian rationalism.

As the kabbalist Avi'ad Sar Shalom Basilea is more of a scientist that a theologian, his calling does not lead him to elaborate a logical-rational 
reduction of Kabbalah. Instead, he seeks scientific and empirical confirmations for various kabbalistic notions, such as the gilgul (the transmigration of souls), the effectual value of the pronunciation of the names of God, ${ }^{78}$ and the existence of spirits. He suggests there is a striking harmony between rabbinical affirmations and the conclusions of modern science: he maintains that the Talmudic rabbis - who are infinitely wiser than his own contemporaries - already declared that the Earth was spherical in form, ${ }^{79}$ and that their astronomical observations anticipated those of contemporary scientists, as well as his own. ${ }^{80}$ Furthermore, the configuration of the highest sefyroth is confirmed by the science of anatomy, which has identified the tripartite structure of the brain. ${ }^{81}$

The theoretical framework of Basilea's magnum opus, Emunath hakhamym, is especially interesting, because it attempts to justify compulsory belief in the affirmations of the masters of the Jewish tradition, the Talmudists and the kabbalists. According to Basilea, both philosophy and science are founded solely on hypotheses, which are neither empirically certain nor logically necessary. If these hypotheses change, so do the entire constructions they support. Although Aristotelian physics and metaphysics had long constituted the peak of human knowledge for philosophers-including many Jewish thinkers, especially Maimonides - they had recently been displaced by Cartesianism. Notions which for centuries had been accepted as true, and which generations of philosophers had toiled over-prima materia, form and matter, substance and accident, the active intellect and separated intellects, etc. - - had been discarded as though suddenly irrelevant. Moreover, if past theories could prove to have been vain, it was clear that this could eventually happen to current theories. It was a small step that separated this realization from the belief the only true certainty lay in tradition (Talmudickabbalistic). ${ }^{82}$ Basilea's expertise in contemporary science is thus associated with an extreme traditionalism, founded on the notion of the weakness of the human intellect, which has produced dreams and madness and mistaken them for the truth. The Mantuan rabbi condems medieval philosophy for not being Jewish enough, and turns instead to the emunath hakhamym (faith in the masters of the tradition), in the belief that there is no other solid ground to stand on in that period of epistemological transition. The Jewish tradition is just as true as sensitive perception, even though our inability to find a true explanation means that we must sometimes content ourselves with mere awareness, as in the case of magnetism and the tides. ${ }^{83}$ 
As for Yosef Ergas, the Livornese rabbi admits that there are some points of contact between philosophy and Kabbalah, particularly in ideas of unity, incorporeity, and the immutability of God, although, quoting the fourteenth-century Menahem Recanati, he specifies that the only philosophy he takes into account predates Aristotle - which we may easily infer means Pythagoras and Plato. ${ }^{84}$ In effect, his Shomer emunym essentially attempts to explain the major notions of Lurianic Kabbalah according to standard philosophical categories. Although Ergas considers Pythagoras and Plato to be close to Kabbalah, he nevertheless constantly (although obviously only implicitly) evokes neo-Platonic ideas, especially in his accounts of the emanations which exist between the eyn sof and the sefyroth; moreover, his account of the cosmological system of the spheres ${ }^{85}$ - which is tied to the theory of the four physical elements ${ }^{86}$ - has Aristotelian roots, as do the principle of causality and the idea of rational necessity. In other words, Ergas's conceptual frame of reference is entirely medieval.

Ergas feels obliged to "explain" Lurianic Kabbalah in order to save it from accusations of irrationality, ${ }^{87}$ but attempts this rescue operation by turning to categories that were already considered irrelevant by intellectuals who kept abreast of contemporary epistemological shifts. This included Jewish scholars, even religious ones such as Basilea.

Nevertheless, Ergas' explanations and clarifications are noteworthy. He considers the existence of the sefyroth - which is central to kabbalistic doctrine - to be a logical necessity in order to explain the transition from unity to multiplicity, and from perfection to imperfection; that is, from God to the world (or worlds). Implicitly alluding to Platonic ideas, Ergas describes the sefyroth (divine emanations) as the "model" and the "ideal type" (defus) of being. ${ }^{88}$

This relationship may also be considered from the perspective of the relationship between living beings and the divinity. Intermediate entities existing between the created worlds (the material one included) and the absolutely transcendent eyn sof, the sefyroth justify and enable the existence of commandment, prayer, sacrifice, and the Torah itself, all of which reside in the world of multiplicity but are directed toward the unreachable eminence of God. In effect, humans cannot address themselves directly to God, who lies beyond the reach of representation, and therefore their prayers state what they are capable of knowing: his attributes, the actions of which correspond to the sefyroth, another important philosophical "reduction." Man might, for 
example, evoke the divine attribute (which is to say, the sefyrah) of greatness, while always keeping in mind (this is kawwanah, or intention) his aspiration to elevate himself to the eyn sof. In other words, it is through the sefyroth that humans attempt to reach the unknowable and ineffable when they pray, keep the commandments, perform sacrifices, study the Torah, and engage in all acts of religious value. ${ }^{89}$ There can be no relationship between humankind and God without the sefyroth, given the absolute transcendence of the divine:

For us, the recipients of the Torah, philosophical notions [of the unity, incorporeity and immutability of God] are not sufficient. In order to comprehend the Torah and its commandments we must know the secrets of existence and of the production of intermediate causes - i.e. the sefyrothby the eyn sof, blessed be His name. Most elements of the divine cult depend on the knowledge of their existence, the order of their connections, and their unification through the commandments of the Torah. No one can serve God perfectly without knowing the characteristics of this science. ${ }^{90}$

Ergas insists on this necessity, presenting it as though it logically confirms the existence of the sefyroth. However, he specifies that this is only an a posteriori justification demonstrating the non-irreconcilability of Kabbalah and Reason, because the existence of the sefyroth is a fact, decided by God, and communicated to the Jews through the prophets: "kabbalistic notions have no need of proof." ${ }^{\prime \prime}$

The imaginative and mysterious definitions proposed by Yitzhaq Luria and his disciple, Hayyim Vital, thus become clear and intellectually satisfying (devarym nekhohym la-mevyn), even though they are the product of revelations rather than human reasoning. ${ }^{92}$ Ergas describes the kabbalistic notion of ziwwug (union) as the union between an emanating (mashpia) and an emanated body (mushpa), and defines 'ibbur (pregnancy) as the passage from a thin and invisible existence to a thick and visible one. ${ }^{93} \mathrm{He}$ gives an intellectual and neo-Platonic account of the hithlabbeshuth (garment), explaining it according to a system wherein intermediate entities know and contemplate each other:

The garment and the enfolding (hithkaleluth) of one sefyrah by another have the meaning ('inyiano) of knowledge; an entity knows another entity, and enfolds and clothes it with its comprehension. ${ }^{94}$ 
In more complex passages, Ergas deploys the notions of mashal (allegory) and sod (esoteric interpretation, which seems to be equivalent with mashal $)^{95}$ in order to explain the more material and anthropomorphic images of Lurianic Kabbalah: shi 'ur qomah (measurement of the dimensions of the world of the sefyroth), and tzimtzum (contraction of the divine to permit the creation of the worlds). In order to understand shi ur qomah, it is necessary to think of an intermediate entity, or sefyrah, being enfolded by another, just as the body clothes the soul. The compound formed by these two divine entities, in which each directs a lower one according to precise and measurable relations, may be represented by the image of man, his dimensions being the object of measurement.

The notion of tzimtzum being more difficult to explain, Ergas is compelled to refer at length to Mosheh Cordovero's ${ }^{96}$ and Menahem 'Azariyah Fano's differences of opinion on the meaning of the divine will — ratzon (a notion which is central to Luzzatto's elaboration) - in order to conclude that tzimtzum does refer to the Divinity so much as to divine energy. Ergas describes tzimtzum as the image (mashal) of an act which is hard to grasp: God reducing his own infinite energy in order to create space for the creation of the worlds. Aware of having provided a personal explanation, Ergas develops a purely logical reflection, based on the categories of the finite and the infinite. ${ }^{97}$

The "theological" dimension of Ergas' work is clearer still in two other important stances he adopts. The first is his enunciation of the principles of faith as they appear in kabbalistic writings (particularly in the Zohar), although he formulates them with a clarity that leaves no room for doubt, in order to respond to his rationalist interlocutor. The second is a description of the various types of divine providence (hashgahah). In both cases, Kabbalah becomes theology, because Ergas invokes the particular terminology and problems of this discipline.

We shall limit ourselves to listing Ergas' principles of faith ( 'iqqarey haemunah), although it is worth noting at the outset that this kind of treatment had fallen out of favor two centuries earlier, after Yitzhaq Abrabanel had modified the principles set down by Maimonides, Hasday Crescas, and Yosef Albo. ${ }^{98}$ Ergas' 'Iqqarym — which have not yet been studied by specialists of Jewish dogma ${ }^{99}$ - are important both because they are founded exclusively on kabbalistic sources and because they demonstrate that in the eighteenth century, even a kabbalist felt the need to proceed systematically. As we shall see, Luzzatto will go on to develop a similarly systematic stance and declare 
it one of the fundamental requisites of all knowledge, and in particular of the supreme knowledge, Kabbalah. According to Ergas, there are six kabbalistic-theological dogmas which all the Masters of Israel have received, and which carry an obligation for all the faithful: "whoever accepts the celestial yoke must believe in them [the principles]; he who rejects them has no share in the God of Israel and in His Torah." 100

These principles a as follows: 1) God fills the world, there is no place devoid of his power; 2) God supports the world, attends to it, and directs it; 3) God is alone in his world; 4) God does not receive influence or benefit from any other being; 5) He is not a body, nor energy in a body, and does not mix with nor associate with any body; 6) He is not knowable; the only thing we know about him is that he exists, and that his existence is necessary. ${ }^{101}$

The other section of Ergas' work worth mentioning here is a passage on providence ${ }^{102}$ which responds to the same classificatory imperative as his profession of the dogmas, and is not founded on theoretical kabbalistic sources. In the first part of a series of ten affirmations, Ergas analyzes the general or individual manifestations of divine providence on various earthly beings based on his own theological deductions. In the second part, he explores the causes of suffering and premature death with reference to kabbalistic beliefs, such as the reincarnation ( $g i \lg u l)$, the defense against demoniac accusers (mekatregym), and the evil eye ('ayin ha-ra).

Ergas' theses on providence were criticized by several important Hassidic masters for being too "philosophical," even though they did on the whole commend Shomer emunym. ${ }^{103}$ Although he did not acknowledge it, Ergas based his ideas on Maimonides, ${ }^{104}$ who in turn referred back to Aristotle, in order to argue that whereas providence applies to humans on an individual basis, its impact on minerals, plants, and animals is only general - in other words, collective, common to an entire species. He links whatever happens individually to these lower beings to chance, an idea which is at odds with the principle that every event, from the greatest to the most infinitesimal, from "the horn of the unicorn to the eggs of lice," is dependent on the direct will of God.

Whereas in the first part of his analysis of providence Ergas' arguments could be considered too rationalist-Maimonidean for a religious thinker, in the second part the reader is reminded that Kabbalah contains practices and beliefs that have little to do with rational theology. Ergas clearly notes that philosophy and Kabbalah diverge on questions relating to the belief in the 
efficacy of amulets, the performative power of pronouncing the names of the divine, demonology, the nature of the soul, and the punishments inflicted upon it. There is a limit to how much Kabbalah may be rationalized, and its practices overstep this limit.

Although something of a pre-Enlightenment wind, as the writings of Yosef Attias testify, ${ }^{105}$ blew on the Jewish community of Leghorn, where Ergas resided, the city also later hailed kabbalists such as Hayyim Yosef David Azulay (Jerusalem 1724 - Leghorn 1806), an immensely erudite man with partially "modern" tendencies who nevertheless also supported himself by writing amulets. ${ }^{106}$

In Padua, a city with a prestigious university, the young Moses Hayyim Luzzatto displayed a propensity for rationality from his first writings, while also receiving the celestial revelations of a maggid. Similarly, although the passion for and competence in the sciences of Avi'ad Sar Shalom Basilea of Mantua is well-established, ${ }^{107}$ the following passage from his Emunath hakhamym provides a fairly balanced perspective on the whole spectrum of ideas and beliefs held by eighteenth-century Italian kabbalists:

A great philosopher of our people, who lived in an earlier age than ours, though not too long ago, completely rejected the existence of demons. A house was shown to him in Venice, in which the noises of spirits were heard at night, in particular from a window that faced a narrow alley, as is common in that city. The demon would knock at night, and when the house was opened there was no one to be found inside, nor could there have been anyone inside. [...] Yet [that philosopher] asserted: "I see all this, and nevertheless, I do not believe it." ${ }^{108}$

Like Ergas, Luzzatto proposes a reduction of Kabbalah grounded in rational theology, starting from Hoqer w-meqqubal, a dialogue illustrating several fundamental principles of Kabbalah with exemplary clarity. Indeed, clarity is what Luzzatto seeks to achieve in this and other works which could be described as attempting to divulge Kabbalah. Luzzatto feels that the written transmission of meaning imposes limits on clarity, because the transmission will be incomplete if the reader does not strive to understand the author's intentions. Yet he believes that it is just as impossible to find explanations that will be clear and satisfying for every reader as it is to find spectacles suitable for every eye. ${ }^{109}$ 
Although Luzzatto touches on many topics in his dialogue, we will focus on his definition of Kabbalah and its field of application, as it is obviously central to the kabbalist's conversation with his rationalist interlocutor, who thinks according to different categories. Luzzatto writes that the object of that doctrine cannot be God, who lies beyond any possible thought or discussion. Instead, what is at stake is the way God directs the world. Kabbalah is nothing other than

the explanation of the procedure of He whose name is blessed, the order of the rules of direction (hanhagah) through which the Holy One, blessed is $\mathrm{He}$, directs and articulates all the events occurring in His world with great wisdom. ${ }^{110}$

As for the sefyroth, they make the divine will tangible, and he creates and directs the world through them: the world depends entirely on these entities. ${ }^{111}$

Luzzatto grounds the fields of application of Kabbalah in categories reminiscent of traditional philosophical classifications: God, humankind, soul, world. The parallel between these systems of classification nevertheless stops there, as they differ radically in their content. The topic of God, as developed in Kabbalah, focuses on - and is limited to - knowledge of the diffusion (hithpashetuth) of his supreme light, the only thing that we may know of him. As for humankind, it is not conceived on its own terms but relative to the bonds which it has with the divine worlds and can act on: the human body is considered to represent these worlds in operation, while the soul is conceived of in relation to the divine service it performs, conditioning worldly events until the final redemption. This includes the theory of the reincarnation of souls (gilgul). Finally, the world is not studied according to philosophical or scientific methods, which are not only superficial but erroneous; instead, under the influence (hashpa 'ah) of the sefyroth, an esoteric reading of the world effectively leads to knowledge of the functioning of the worlds and the sefyroth themselves, in parallel with events in the inferior world. ${ }^{112}$

None of this is proven rationally. Instead, it is revealed by God. Nevertheless, "the intellect may experience pleasure and may be enriched in its natural need to know and understand." 113 All the explanations given by the kabbalist conform to rational imperatives, even though they are not rational in origin: Kabbalah is not portrayed as a doctrine blindly adopted by simple intellects incapable of reflection, but as true hokhmah, that is to say a 
praiseworthy and coherent knowledge which has the merit of explaining the totality of the created world in both its being and its becoming.

Throughout his works, Luzzatto praises straight reason (sekhel yashar), which is one of the criteria for evaluation in Kabbalah. ${ }^{114}$ On close examination, the Paduan kabbalist is reminiscent of medieval Jewish philosophers: like the great Jewish rationalist Sa'adiyah Gaon, ${ }^{115}$ he considers knowledge and understanding to be religious obligations-mitzwoth. Nevertheless, for Luzzatto, this commandment does not imply the rational comprehension of the Torah, but concerns the precise knowledge of the entire system of the divine guidance of the world. ${ }^{116}$ Luzzatto writes that humans were created for the purpose of knowledge, and more precisely, "the knowledge [hassagah] of the glory of the Creator [...] for which they were given cognizance and abundant knowledge." 117 This closely echoes Maimonides: "true praise of God is the comprehension [hassagah] of His greatness [...] and only humankind praises him with words that indicate that which he has understood with his intellect." 118

The true, life-giving light comes from cognizance and knowledge, writes Luzzatto; ${ }^{119}$ this is not the light born of the act of comprehension in itself, but the divine light that descends into the world as a consequence of human understanding. Luzzatto's brand of intellectualism fits within a kabbalistic context, wherein each human action corresponds to a divine action (and vice versa); again, this evokes medieval philosophers, including Maimonides, for whom the act of comprehension unites the passive intellect with the active - divine - intellect. ${ }^{120}$

For Luzzatto, human history is a history of intellectual decadence. Whereas the ancients were closer to true intellectual knowledge, more recent generations have become distracted from their true purpose, and pursue their activities while being immersed in materialism. ${ }^{121}$ Redemption (tiqqun) will therefore be a return to full knowledge. Once the unity of God is revealed, humankind wil be able "to bask in the splendor of His holiness, and completely and permanently understand deeper things than before, without limits." 122

\section{A Theology That Implies Kabbalah}

The rational reduction of Kabbalah is particularly in evidence in Luzzatto's other dialogue, Da 'ath tevunoth, which may be translated as "Knowledge of Clear Things" or "Knowledge of Comprehensible Things." 123 
This dialogue does not pit a rationalist against a kabbalist. Instead, its interlocutors are the soul and the intellect: it dramatizes the soul turning to the intellect in order to understand principles of faith which it believes in, but is unable to justify rationally - providence, reward, the Messiah, and the resurrection of the dead. The soul's position is clear: it requests havanah (comprehension), yedi'ah (knowledge), and sevara (rational thought) for principles in which it has a simple faith.

Throughout this book, Luzzatto behaves like a rational theologian and refers to traditional theological categories. The questions he addresses are: the origin of evil, and consequently original sin and free will; the necessary existence of God and the contingency of beings; God's attributes; humankind as final cause of creation; and, finally, redemption. However, the content of this theology is more or less obviously supported by kabbalistic notions, and this certainly bestows a certain originality on Luzzatto's rational construction. In other words, Da 'ath tevunoth is not, like Ergas' Shomer emunym, an attempt at reading Kabbalah in light of philosophical categories. Instead, it is a theological treatise constructed according to a rational model, which implies Kabbalah without alluding to it explicitly. ${ }^{124}$ Luzzatto's only kabbalistic references are to sections of the Zohar, which he conveniently calls midrash. ${ }^{125}$ Even a reader completely unfamiliar with kabbalistic notions would be perfectly capable of understanding the dialogue.

It certainly seems possible to think this was part of a "strategy": although he did not dissimulate his kabbalistic activities during that difficult period, the Paduan author nevertheless tended to emphasize the absolutely orthodox character of his thought, couching it in the language of traditional theology without recourse to Kabbalah.Yet, a few months after completing Da'ath tevunoth, Luzzatto wrote Kelalym rishonym (First Principles): although more or less parallel in content to Da'ath tevunoth, this series of propositions resorts to the terminology of Lurianic Kabbalah. ${ }^{126}$ One might therefore suggest that the philosophical-theological tendency of Luzzatto's kabbalistic thought allowed him to move seamlessly between different disciplinary languages. Indeed, one might even ask whether the philosophical-theological character of Luzzatto's thought in fact shaped his understanding of kabbalistic categories from the outset, rather than intervening a posteriori in the form of explanation or comment. In other words, did the categories of rational theology frame his conceptual grasp of the Lurianic Kabbalah? 
In Da 'ath tevunoth, Luzzatto understands the originally kabbalistic notion of tiqqun (repair) in terms of the traditional category of redemption, which is absolutely central to his thought. Indeed, one might equate tiqqun with the geulah (redemption) of which the prophets and the Talmudic masters speak: it is the progressive and inevitable revelation of the unity of God, which will dispel ideas of merit or guilt and therefore free will. It corresponds to a time when there will no longer be space for guilt, and good will replace evil. In this definitive phase of tiqqun the divine light (hearath panym) will reveal his concealed face (hester panym), leading to perfection. The absence of unity, the alternation of good and evil, and the material shadow prevail during the phases that come before this culmination.

Luzzatto's kabbalistic influences are most evident in his account of these phases. The divine decision to make visible the various forces presiding over the operation of the world is a case in point. As the attributes (middoth) - analogous to the sefyroth, which are significantly not mentioned - of Judgment and Kindness take turns directing the world, they produce light and darkness in varying proportions, more or less disclosing and concealing the divinity. This is illustrated and made visible in man through the soul and the body: whereas the soul is the image (tziyur) of the law, or the direction (hanhagah) of disclosure, the body represents concealment. In other words, the soul is one, like the unified perfection that will manifest itself through the total disclosure of divine unity, but the body is constituted of various parts, because it represents the world in the intermediate stage of reward and punishment, when God is concealed, not wanting to make manifest his perfection. In this phase, just as his ways of directing are multiple, so too he has wanted the created body to have many parts and various members, in order that it may truly correspond (maqbylym) to the laws that govern the world.This, according to Luzzatto, is the true sense of the verse, "Let us make Man in Our image after Our likeness." "27 Similarly, the individual parts of the human body correspond to different aspects of divine direction: thus, the right and left sides of the body are, respectively, images of severe and benevolent governance.

Luzzatto's approach to the same questions is radically different in his treatise Kelalym rishonym. Written after Da'ath tevunoth, this brief text engages with the same topics — creation, the existence of evil, the overcoming of evil-but in kabbalistic terms. In keeping with the program he set himself at the beginning of his dialogue Hoqer w-mequbbal (Philosopher and Kabbalist), the Paduan kabbalist strove to elucidate the notions of Kabbalah, 
in particular Lurianic Kabbalah. ${ }^{128}$ Nevertheless, he cannot entirely help resorting to technical jargon, which only readers at least partly familiar with the doctrine can understand. For example, Luzzatto compares the mixture of good and evil typical of the phase that comes before tiqqun —or redemption - to the relationship of the reshymu (the remainder of the divine light in the world) and the qaw (the ray of divine light that crosses the created worlds). Whereas the former is synonymous with exteriority (hitzoniyuth), the latter evokes interiority (penimiyuth): in other words, the two together conjure the concealment and disclosure of the divine face. These ideas presuppose the fundamental notion of shevyrath ha-kelym (rupture of the receptacles or instruments), which caused the divine light formerly contained within the receptacles to instead coalesce with those receptacles. Together these two dimensions - good and evil, spirituality and materiality - constitute the hanhagah: that is, the law regulating the combination and succession of good and evil as the worlds operate. The image of the hanhagah in its fullness is primordial man (adam qadmon), and the individual events taking place in the various worlds are the branches ('anafym) of this primordial man. At the end of the process of repair and redemption, illumination will overwhelm the shadow of matter, disseminating knowledge throughout the community of Israel, the ray ( $q a w$ ) will reabsorb the remainder of the light (reshymu), and the operation of the world will be characterized by unity. ${ }^{129}$

This brief treatise becomes yet more complicated when Luzzatto turns to more specific notions, in particular the different parts of primordial man, the roots and the individualization - i.e. the coming into existence — of events in the various worlds, and the split between inferior and superior sefyroth in the four worlds of the divinity. His treatment of these notions makes it clear that Kelalym rishonym was intended for a very different audience than Da'ath tevunoth.

Kelalym rishonym also offers some interesting new insights into another question, already evoked in Da'ath tevunoth: how the human image makes the operation of the worlds visible. Instead of merely presenting that idea, Luzzatto now contextualizes it within the dynamics of the sefyroth. In other words, he now explains where - and to a certain extent how - the visualization of the divine laws governing all the worlds and their concrete application in history (hanhagah) is possible. At the same time, he deploys kabbalistic notions in order to clarify the possibility of prophecy. According to Luzzatto, this is all thanks to the last sefyrah, the malkhuth (kingship) of the last divine 
world, the world of action ('asiyah). This sefyrah is the door, or passage, leading from the world of divine action to the world of human visualization:

Malkhuth is called "the image of God," because it is the root of the images of all created beings, which are the branches of the superior attributes. The Lord, blessed be He, wanted to reproduce (leha 'atiq) the mode of operation of His attributes, including all the details connected with them, according to the images of the created beings. The root of these images, according to the law of such a reproduction, is the malkhuth. Prophets perceive the upper lights according to their reproduction in images. Therefore, they perceive only the malkhuth, thanks to what the upper lights understand and conceive. This is explained several times in the Zohar and the Tiqqunym, through the esoteric meaning of the verses: "But let him that glorieth glory in this" (Jeremiah 9:23), and "This is the gate of the Lord" (Psalms 118:20). ${ }^{130}$

The rational reduction of Kabbalah by two nearly contemporary authors, Ergas and Luzzatto, is no coincidence. It clearly constitutes their response to what they perceived to be an intellectual necessity at a time when philosophical-scientific rationalism was spreading through Europe.

However, the two authors probably had different intellectual frames of reference. Unlike his Livornese counterpart, the Paduan kabbalist does not appeal to medieval, Aristotelian, or Platonic categories of thought. Luzzatto cannot do without the kabbalistic notion of hashpa'ah (emanation), which defines both the relation between the worlds created by the divine will-in a descending order of spirituality - and the divine will's constant direction (hanhagah) of the worlds. In order to clarify the concept of hashpa 'ah, he turns to "the great teacher," Maimonides, in a rare textual reference: 131 "All that is produced and exists among beings is produced or exists insofar as it is emanated from Him, blessed be He." ${ }^{132}$ Yet, the reader quickly realizes that Luzzatto does not explain what he means by "emanation." He only speaks generically of "that which originates from the Creator and is destined to his creatures," which is not otherwise definable because humans cannot know how God really operates, and are limited to ascertaining the effects of his actions. In other words, this category is left open, and represents nothing more than a simple name.

Luzzatto also deploys another notion which seems to pertain to an Aristotelian worldview: finalism. His conception of redemption is marked by 
a strong and basically optimistic finalism: good will ultimately triumph. The final causes of Aristotelian physics are not in play here, however. Instead, what we find is a philosophy of history which seems fairly consistent with the optimistic conceptions of seventeenth- and eighteenth-century Europe (including the Jewish haskalah). Spinoza's radical critique notwithstanding, finalism would still find fertile ground in European thought for many years to come.

Whatever their formal similarities, Ergas and Luzzato's intellectual reference points differ significantly. Luzzatto departs in three important ways from Ergas, who thinks according to the medieval categories of metaphysics, physics, and cosmology (the four elements of the sub-lunar sphere, the celestial spheres). ${ }^{133}$ First, Luzzatto's thought is more dynamic, centering as it does on a philosophy of history that leads to the total and definitive revelation of divine Unity. Second, it is more systematic, as it emphasizes the importance of conceptual coherence and distinguishing between concepts. Third, it is less openly neo-Platonic: instead, it was inspired by a scientific, post-Cartesian model, as we will try to show. ${ }^{134}$

Between 1736 and 1743, when Luzzatto lived in Amsterdam and was neither writing nor teaching on kabbalistic matters, he devoted himself to writing brief but edifying treatises on logic and religious works intended for a larger public than the works of his Italian period. They included a treatise on ethics, Mesyllath yesharym (The Path of the Just, published in Amsterdam in 1740), which remains his best-known work to this day, and Derekh ha-Shem (The Way of the Lord, published in Amsterdam in 1896), which synthesized the principles of Jewish faith and practice. Luzzatto composed these works in order that the reader might "gather from them an intellectually correct and sufficient representation, free from inaccuracies and confusion." 135

Derekh ha-Shem is a small manual intended for good believers and observers. It is meant as a starting point for religious study and consists of four sections on the following topics: 1) the existence of God and the created worlds; 2) providence; 3) prophecy; and 4) worship. Even then, the Kabbalah implicitly makes its presence felt right from the first section, where the author establishes that

one of the great principles that we possess is that to each body of the inferior world there corresponds separate forces on high, from which inferior beings and that which happens to them [literally: their accidents, miqreyhem] emerge, according to a concatenation willed by divine Wisdom. 
The superior forces are the roots, the inferior beings are the branches and the derivatives; and they are linked one to another, like the rings of a chain. ${ }^{136}$

The sefyroth, which Luzzatto explains with the philosophical term middoth (attributes) in Da'ath tevunoth, simply becomes kohoth (forces) in Derekh ha-Shem. As for providence, it is now called by its traditional name, hashgahah, instead of hanhagah, the typical term of his earlier works. After reading Kabbalah through the lens of rational theology, Luzzatto makes it the subject of a popular catechism in Derekh ha-Shem, emphasizing the importance of the devotion of the faithful and of terrestrial and celestial rewards. Furthermore, a range of topics which he hardly, if at all, touched upon in prior works make their appearances in this book, in particular the influence of the stars, ${ }^{137}$ the effects of the evocation of the divine names and of magical acts (kyshuf), ${ }^{138}$ and the presence of impure forces during the nighttime hours. ${ }^{139}$ The daily prayers are explained according to the kabbalistic kawwanah, but in a language comprehensible to people not familiar with the esoteric doctrine. A work of divulgation, Derekh ha-Shem nevertheless also seeks to "translate" Kabbalah, although at a different level than the works of Luzzatto's Italian period.

Even at this popular level, Luzzatto insists on the need for precision. In his presentation of the Derekh ha-Shem, he asks the reader to give each term due consideration, without forgoing exactitude, so as not to miss any necessary argument, because his exposition follows principles of order and progression.

Luzzatto's reaffirmation of the centrality of intellectual knowledge echoes Maimonides' aforementioned treatment of providence, which is one of the most controversial points of the Andalusian philosopher's intellectualism. Maimonides asserts in The Guide of the Perplexed that divine providence follows the divine emanation (shefa) of intelligence. In other words, for Maimonides "providence depends on intelligence," and the most intelligent people (the prophets, in particular) enjoy special celestial attention. ${ }^{140}$ Picking up on this notion, Luzzatto applies it to the kabbalistic notion of human action, suggesting that it attracts the emanation (hashpa ' $a$ h): the more elevated the action, the higher the level of emanation, or influence. Studying the Torah according to the right criteria (higayon) thus not only means reaching the highest level of comprehension (haskalah), but also enjoying the 
most elevated influence (which can be parallel to Maimonidean providence), since the two are linked. Luzzatto's position on providence confirms his intellectualist orientation, even though he sets it out in the context of practical Kabbalah, where knowledge is seen as a religious action corresponding to a reaction in the divine world. ${ }^{141}$

The proximity between the intellectualism of the medieval philosophers and that of the eighteenth-century kabbalist is further demonstrated by Luzzatto's assertion that there are two paths to the fundamental truths (such as the unity of God): the prophetic path and the rational path. Claiming that he does not wish to linger on rational demonstrations, Luzzatto prefers to focus on prophetic notions - that is to say, kabbalistic notions, even though he doesn't make it explicit in this context—which demand rigorous exposition:

[God's perfection, revealed at Sinai and transmitted by tradition] can also be confirmed by rational study and theoretical demonstrations, when necessary, according to physics, geometry, astronomy, and other sciences, from which one can draw true premises that clarify these true notions. But we shall not dwell on this approach here; instead, we will formulate true premises, putting things in their proper order, according to the tradition that is ours and to ideas that are well-known throughout our Nation. ${ }^{142}$

\section{Kabbalah as System: A Jewish “Neo-Scholasticism"?}

Luzzatto's approach in one of his most ambitious texts, Qelah pithhey hokhmah (One Hundred Thirty-Eight Doors to Wisdom) may surprise one who thinks of the rhetoric of the kabbalists a century before. In this work, the author states a principle (a "door") and proceeds to explain it in detail by subdividing it into two parts. This constitutes the apex of systematic formalism in kabbalistic exposition and departs markedly from the assertive rhetoric and narrative-exegetical form that Kabbalah assumes in the works of important seventeenth-century authors such as Mosheh Zacuto. In some ways, the expository style of Qelah pithhey hokhmah echoes contemporary manuals of Catholic scholastic theology based on Aquinas' Summa theologica. ${ }^{143}$ Indeed, one might even speak of neo-scholasticism in relation to this text, as with those of contemporary Catholic authors. The uniqueness of this Jewish form of "neo-scholasticism" lies in the fact that its content derives 
from Lurianic Kabbalah rather than from Jewish medieval philosophers, to continue our parallel with Catholic thought.

The attempts of eighteenth-century authors, and Luzzatto in particular, at systematizing Kabbalah and couching it in rational terms took place at a time when philosophical production had stalled, according to historians of Jewish thought. Traditionally, Jewish philosophical thought is said to have gone through a period of stasis between the end of Jewish Aristotelianismbetween the late fifteenth and the sixteenth centuries (especially after Eliyah Del Medigo's Behynath ha-dath, and Ovadiyah Sforno's Or 'ammym) - and the "rebirth" of the eighteenth and nineteenth centuries, with the authors of the Haskalah. ${ }^{144}$ It is in this "void" that Kabbalah developed, until it assumed the formal character of a theology toward the end of this period in Italy.

Spelling out the name of God in an acrostic as it lays out its first principle, the beginning of Qelah pithhey hokhmah is explicitly inspired by Sefer ha-mada', Maimonides' philosophical introduction to Mishneh Torah. As in Maimonides' text, Luzzatto highlights the unity of God only to set out the object of Kabbalah directly afterwards, the object being to develop knowledge of the creation and the functioning of all beings on the basis of the direction (hanhagah) of the divine will.

The principle of faith and the foundation of knowledge is the unity of the Highest, blessed be He; and it is therefore this that must be explained at the beginning, because all the knowledge of the truth is nothing other than a knowledge that demonstrates the truth of faith; so that one understands how everything that is created or that happens in the world comes from the will of the Highest, and how everything is directed in the world as suits the one God, blessed be He, and how everything develops in order to reach perfection in the end. ${ }^{145}$

The unitary direction of all wordly things is the fundamental principle of this treatise, and Luzzatto repeates it many times. All created beings and events are linked to one another by a unitary intention — expressing a unitary will— and Kabbalah is the revealed doctrine allowing us to know this, down to the smallest detail. ${ }^{146}$ Reiterated several times in other works as well, Luzzatto's definition exhibits the totalizing ambition of the doctrine which grants us knowledge of all of the worlds. This ambition finds an echo in science, although its field of application is rather different. We will see further along 
that analogies may be drawn between science and Luzzatto's understanding of Kabbalah.

As the object of this study is to explicate the formal aspects of Luzzatto's work, we shall refrain from giving a detailed account of the Paduan kabbalist's systematic treatment of the 138 principles of Lurianic Kabbalah, which he enumerates, explains, and fits into a general conceptual framework. This framework is essentially optimistic in nature: all the negative aspects of creation and history are seen as necessary steps toward the final revelation of divine unity. Evil exists for the benefit of good. ${ }^{147}$ Nevertheless, this rich exposition addresses two complex questions which deserve to be examined, both for their "philosophical" content and for Luzzatto's attempt to engage with them at a conceptual level. These are 1) the relationship between the sefyroth and the eyn sof; and 2) the relationship between infinity and finitude, God and creation.

1) The sefyroth: these emanations from God (hem mah she-ha-elohuth mithpashet) are not created, since they are divine. It is their revelation that is created. As for the eyn sof, it calls for the principles of negative theology, because there is no word that can speak of him, nor any thought that can conceive of him. Yet, knowledge of the sefyroth is possible. They are qualities or aspects (middoth) of the eyn sof, forces (kohoth) which are not separate from him, knowable manifestations of his will; they are the ways in which the divine will directs the world. The sefyroth and worldly beings have different origins: whereas the creation of the sefyroth is nothing other than their manifestation, since they are divine, and therefore eternal, the very existence of wordly beings is created. The fact that the aspects of the eyn sof have been made manifest and can subsequently be known implies a limitation, because the divine in itself is not knowable: this justifies their name, sefyroth, from the verb safar (to count, or to measure). Their created limitation allows them to be known.

All of God's aspects are originally infinite in themselves, and so too is their number. However, although God's aspects are infinite in number, only those through which the world was created and is directed have been made manifest. The manifestation/limitation of the sefyroth corresponds to a divine providential design within which humankind plays a decisive role. ${ }^{148}$

At first glance, these notions recall Spinoza's conception of the attributes of substance as defined in his Ethics. Luzzatto's myddoth echo Spinoza's definition of "attribute": "what the intellect perceives of substance, as 
constituting its essence," and which is infinite in itself and in number. ${ }^{149}$ Similarly, Luzzatto's account of the kabbalistic partzufym (faces) as "the particularization of the modes of acting of each of these forces," 150 recalls Spinoza's definition of "mode": "the affections of a substance, or that which is in another through which it is also conceived." 151 In spite of such affinities, there are many fundamental differences between the concepts Spinoza and Luzzatto deploy. In particular, they refer to very different systems. As the kabbalist's account of creation and the divine direction of the world suggests, his conceptual universe is religious. The philosopher, on the other hand, deploys non-religious Cartesian concepts, such as thought and extension: "Thought" and "extension" are two of "God's infinite attributes." 152

2) The relationship between infinity and finitude: this is extremely difficult to conceive, let alone describe. In order to account for the passage from infinite divinity to finite materiality, Luzzatto turns to the Lurianic concept of tzimtzum. Although the eyn sof possesses an infinite number of aspects-or forces - according to him, the human intellect can only conceive of those that played a role in the origin of the world and in directing it. As the force which produces the world undergoes a reduction, or contraction (tzimtzum), it renounces its infinity. This benefits humankind, because it allows humans to play a role in perfecting (tiqqun) the world and returning it to perfection. How was the move from infinity to finitude possible? Luzzatto asserts that infinity already contains finitude - limits are already present within limitlessness - and the divine will decided to make these limits manifest. It is through the passage into existence of limits that the unknowable divine will becomes knowable, or - in kabbalist parlance — visible. The limitation of the divine force leading to the material world is therefore not a non-being in the neo-Platonic sense, but rather a being (qiyum we-lo he 'der) that is already present within the infinite. Although there is no space within the infinite, this reduction allows the creation of a space (halal) in which the root of justice $(d y n)$ is manifested, altering the initial perfection. Infinite light made visible thanks to the reduction of divine force is called reshymu: that is, the impression (roshem) of infinite light. ${ }^{153}$ As limits are uncovered, the worlds gradually begin to come into being according to a hierarchy defined by their levels of spirituality, and imperfection starts to manifest itself.

Beyond its attempt to conceptualize the Lurianic doctrine, Luzzatto's text describes the transition from infinity to finitude in terms of a very optimistic philosophy of history. The divine will sets the whole process into motion in 
order to allow humankind to recognize that even evil is the work of the will of God, who will eventually eliminate it. On the other hand, Man is responsible for the final revelation of divine unity, since he can contribute to the perfection of the world, at least at its lower levels. ${ }^{154}$ However, the divine will complete the process by imposing perfection onto the world even if humankind fails to contribute adequately to this apotheosis.

Although Qelah pithey hokhmah gives a detailed account of the relative roles that human and divine action will play in the advent of the future world, this question becomes problematic in Da'ath tevunoth. Indeed, there seems to be an unresolved contradiction in Luzzatto's thought: if redemption is certain, what is the point of human activity? If the divine will is going to manifest itself "in any case," 155 why try to draw the divine closer by keeping the mitzwoth? The "Soul" is fully conscious of these problems in this dialogue: bewildered by the possible consequences of determinism, which could both make human efforts futile and doom to irrelevance the notion that imperfection allows Man greater merit as he strives to achieve perfection, the "Soul" asks the "intellect" to clarify. His interlocutor's response is simply to quote biblical verses demonstrating beyond any shadow of a doubt that divine redemption is independent of human behavior - a rather disappointing answer in light of the exacting arguments presented in the dialogue. ${ }^{156}$

\section{The Scientific Method:}

\section{The Importance of Making Distinctions}

Like any rigorous scholarly text, Kabbalah must be set out according to precise criteria in order to be understood clearly. The "modern" kabbalists never tired of repeating this. Luzzatto's kabbalistic works all introduce methodological criteria designed to foster a formal association between esoteric knowledge and science. ${ }^{157}$

The first of these criteria is a solid foundation: as the rationalist in Luzzatto's dialogue explains to the kabbalist, the doctrine must be built on an unquestionable assertion:

Had I found at least one stable principle on which to build all these notions, perhaps their details would also have become comprehensible. But without this principle it is useless to strain over the details, seeing as the whole is problematic. ${ }^{158}$ 
Supplying his interlocutor with this stable principle, the kabbalist simultaneously defines the object of Kabbalah. As he explains that the unity of God is this principle (yesod), and that the object ('iniyan) of the doctrine is to explain how God directs the world, ${ }^{159}$ Kabbalah ceases to be a disordered mass of complex, obscure, and unnecessary notions.

This principle supplied, the next criterion is to establish distinctions (havhanah) between terms: definitions must be very precise because "comprehension depends on distinction." 160 It is important to start by naming concepts $^{161}$ before one can proceed in an orderly and progressive fashion. The rationalist interlocutor is adamant that disorderly progress leaves the intellect dissatisfied, bewildered, and confused (navokh w-mevulbal). One must therefore proceed step by step, examining the various parts of the construction one by one. ${ }^{162}$ Incremental progression is key to knowledge: it is necessary to start from general premises before one can move toward a satisfying global vision. ${ }^{163}$

Whereas disorderly progress fosters doubt by jumping from one topic to the next, an orderly disquisition will allow for a correct understanding of Kabbalah. Proceeding in an orderly fashion will grant rational coherence to Kabbalah, will explain the doctrine, and will make it perfectly acceptable to the intellect, which accepts the idea of God but is not satisfied by obscure formulas that do not belong to a rigorous system. Without elucidating the meaning of each concept and the connections between them, one cannot pretend to know Kabbalah. To omit this step is to confine oneself to stating abstruse terms which mean nothing in and of themselves, such as "faces" (partzufym), "situations" (matzavym), and "ascents and descents" (aliyoth we-yeridoth). These examples taken from Lurianic Kabbalah were the most embarassing to a rational mind, ${ }^{164}$ and it was no coincidence that Luzzatto invoked them.

In case of doubt, the criterion of order would help to justify one conclusion relative to another, because notions are validated by their logical connections. Whereas logical relationships generate knowledge, their absence produces confusion (mevokhah). ${ }^{165}$ In other words, form can sometimes be a criterion for evaluating content.

Proceeding logically also has pragmatic consequences, because a correctly and rigorously ordered argument makes it possible to concentrate on general principles, instead of lingering on details, ${ }^{166}$ while also sparing the 
intellect useless effort. ${ }^{167}$ Less is often more: economy is one of the guiding principles of argumentation. ${ }^{168}$

Luzzatto's tendency towards conceptual rigor goes beyond his kabbalistic works. Written and published in Amsterdam in 1742-i.e., at a time when he was not officially working on Kabbalah-Luzzatto's study of Talmud, Derekh tevunoth (The Way of Understanding) ${ }^{169}$ is essentially a treatise on logic. According to him, the principles governing Talmudic discussions correspond to innate intellectual notions, which the Talmud simply elucidates:

If one investigates correctly, one will find that all the questions (qushiyoth) and answers (terutzym), like every part of Talmudic reasoning (pilpul), lean on principles and notions that are innate to intellectual comprehension, imposing themselves spontaneously and necessarily on the human intellect without having to be learned. ${ }^{170}$

It is the scholar's task to order these principles correctly in order to make them operational. Studying complex arguments is made easier by reducing them to a few brief, simple rules. ${ }^{171}$

The rules Luzzatto sets out for the study of Talmud are not based on traditional rules of Talmudic hermeneutics, such as the thirteen rules of Rabbi Ishma'el. Instead, they are grounded in the principles of formal logic, which draw on and develop Aristotelian logic. Thus, Luzzatto devotes a chapter of Derekh tevunoth to the different types of argument, distinguising between sensitive, conventional, ${ }^{172}$ and logical demonstrations. ${ }^{173}$ Whereas the havhanoth discriminate between terms and content in kabbalistic texts, in Derekh tevunoth they become criteria of definition analogous in function to Aristotelian categories, only more numerous (twenty-four instead of ten).

In that same year-1742 - Luzzatto wrote the Sefer ha-higayon ("Treatise on Logic"), ${ }^{174}$ which was mostly inspired by non-Jewish works. ${ }^{175}$ In this brief text, he confirms that the correct use of the intellect depends on rigorous classification. He ends his first chapter by stating that "distinction is the necessary foundation of intellectual operations in the quest for knowledge, ${ }^{\prime 176}$ and declares that Jewish readers would find a treatise on logic useful. For Luzzatto, disseminating such a work amounts to a religious task: just as farming perfects nature by increasing its beauty and usefulness, ${ }^{177}$ so too does logic allow each person to achieve a correct knowledge, free from confusion; both complete the work of God. ${ }^{178}$ 
This short work stands out not for its originality but for its translation of the traditional terms of logic into Hebrew. Even then, this "Hebraization" of logic was redundant because Italian Jews likely to be interested in this material could easily access it in Italian and Latin texts. The significance of this attempt is essentially historical: it demonstrates that efforts to assimilate external cultural products into Jewish cultural coordinates were still being made in the first decades of the eighteenth century. Although there were many such endeavors in the history of Jewish culture, this was one of the last in the history of Italian Jews, who were to confront non-Jewish works directly in the coming decades, no longer needing to "Hebraize" them.

Luzzatto's apologia of order and distinctions reached its apex in the introduction to his religious manual, Derekh ha-Shem, where he deployed the neoclassical metaphor of the Italian garden to describe how intelligent human action imposed order on nature:

The advantage of having knowledge of things according to their subdivisions and the order of their relationships, as opposed to knowledge without distinctions, corresponds to the vision of a garden with well maintained hedges, and adorned with narrow paths and lines of trees, compared with a bush of reeds or a wood that grows in a disordered manner. For the intellect that desires to know, the representation of multiple parts which ignores their relationships and proper position in the construction of the whole is a tiresome and pleasureless operation. ${ }^{179}$

\section{Kabbalah: A Science of the Knowable}

For Luzzatto, however, the parallels between Kabbalah and science are not merely methodological. Just as physical science - and the sciences connected to it - establishes the laws governing natural events, the object of Kabbalah is to know the causes of these events, which constitute the divine direction (hanhagah) when united with the totality of physical and human events. While physics attempts to describe the laws governing events that are merely effects, Kabbalah states the laws presiding over physical and human causal events. Yet, even though the origins of physics are human and those of Kabbalah divine, both disciplines nevertheless seek to give an ordered, precise, and exhaustive account of their object. Luzzatto's descriptions of the divine worlds sometimes appear to borrow from the terminology of physics: 
it is not a coincidence that he refers to the sefyroth as "forces" (kohoth). Indeed, the kabbalistic term hokhmah may be understood as meaning "science": it is the supreme science, a meta-science (or "metaphysics") which goes beyond what other human sciences can do by establishing the connections between the superior and the inferior worlds. Yet this hokhmah shares the demonstrative rigor of the human sciences as well as their mechanistic outlook and ambition to achieve total knowledge of their object.

Kabbalah touches on the "roots" of beings and the rules governing them. On the one hand, it seeks to know the primary source of all beings, but on the other it ignores the natural laws inscribed in the sefyroth, which are the concern of human science. ${ }^{180}$

Luzzatto writes in a post-Cartesian context, at a time when mechanics are the model for all the sciences and when all that is really left of the categories of Aristotelian physics and metaphysics are terms largely stripped of their meaning. The world of the sefyroth is a very ordered world, which Luzzatto describes with the metaphor of a clock: it is built like a mechanism and its elements are connected to each other and the inferior world like a series of gears. Luzzatto is so bent on a mechanical model that he sees Man and the material world as proto-robots covered with skin, or a material membrane reverberating up to the divinity through their motions before returning down to humankind. ${ }^{181}$ Human acts are at the origin of the motion of the totality and depend on the soul, which is located in the body.

The following account may be read as a religious transposition of Cartesian dualism, with the soul taking the place of Cartesian thought, and the global mechanism put at the service of God and the final proclamation of his unity. The various worlds are regulated by precise laws of operation (huqqym) and a system governing the interaction ('arakhym) of different forces $^{182}$ in a dynamic combination responding to a unitary principle:

The totality is a fabric of many forces coming from different orders, each of which acts solely in its designated time and manner. This is called "the diffusion of the forces" (hithpashtuth ha-kohoth), that is, the diffusion of the forces in different ways and according to different well-defined and established rules. [...] This order is not dispersed and divided into parts that do not report to a single principle; rather, there is one general order governing the expansion of every force in the ways which pertain to it. Everything is calibrated with an eye to a final direction. ${ }^{183}$ 
If the object of Kabbalah is to explain how this dynamic works both at the time of creation (at the origin) and over the course of time (in history) according to a unitary principle, ${ }^{184}$ then the kabbalist should give a detailed account of the existence and present and future behavior of all beings. In other words, although Kabbalah is a science of divine origin, its object is the functioning of the worlds (hanhagah), which Man can-and should - understand.

Creation has come about by divine design: in his extraction of limitsand renunciation of his infinity - God wanted to perform an act of mercy. The final tiqqun, the moment of redemption when his unity will definitively manifest itself, will come after a lengthy period when good and evil will be intermixed beyond the grasp of human knowledge. Tiqqun demands human intervention in a world that Man is able to know despite his limits. Thus God operates not according to his capacities, but according to Man's: God wants Man to understand his ways, however limited that knowledge will be. Humans live in a comprehensible world because God wishes it to be so, subordinating his infinite action to the laws of causality and temporality. ${ }^{185}$

Human understanding cannot conceive of God's essence, since, as Maimonides stated, the only thing we can affirm is the necessary existence of God. His actions, too, are thus only partly conceivable. Since everythinggood and evil, imperfection and perfection - is created by God, humans do not know what anything means for the divine will, i.e., in itself. Instead, what we know and understand corresponds to our way of knowing:

That which is inside Him is unreachable for any intelligence; we can understand only that which is within us creatures." 186

In other words, humans cannot know God's works per se, only their effects. ${ }^{187}$ Strictly speaking, central notions such as emanation (shefa ), potential, or action lie beyond our grasp: we cannot understand them from the agent's point of view, only from our perspective as recipients. ${ }^{188}$

Luzzatto's gnoseology is a theory of the limits of knowledge (rather like the philosophy of Kant), which nevertheless is optimistic about the possibility of achieving knowledge within those limits. God wants us to achieve knowledge according to our capabilities. The content of this knowledge constitutes the object of the science of Kabbalah, and lies within the grasp of Man despite its divine origins. In the age of redemption, things will not 
change fundamentally: our understanding of the divine remaining within the limits of our abilities, we will grasp "a drop compared to the ocean."189

The entire science of truth consists of this: distinguishing between the forces God used to create the world, their intensity, their measure, and the relationships between forces and created beings. In effect, we are capable of knowing these forces only after they have been limited, and chosen between all the others. God created the world according to a single intention (kawwanah), and this intention implied limiting and ordering the forces that He wanted to introduce, and establishing their order and relationshisps. Man can understand this, if this knowledge is given to him, because it is not unlimited and does not lie beyond the abilities of the human intellect. The totality of this order constitutes this science. And therefore we assess the measure of those forces according to a hierarchy; we understand how things exist in a reciprocal relationship, and how created beings are connected together. It is essential to understand that everything pertaining to created beings has its root in these forces, that everything happens according to a hierarchy and an order, that all these beings are connected one to another and oriented toward a single aim (kawwanah). ${ }^{190}$

It is the scientific character of Kabbalah that Luzzatto posits in these lines, by linking it formally to physics on several levels. He fosters a mechanistic vision by evoking "forces," speaks of the human capacity to know this totality, and founds the successful operations of this knowledge on a methodology based on order and distinctions.

Venerated to this day in Orthodox Jewish circles and rediscovered by a generation in search of a new spirituality, the young Paduan mystic who never wrote a word in any language other than Hebrew straddled two worlds: the old and ever-enduring world of kabbalistic thought and devotion and the eighteenth-century world of rationalism, marked by the scientific method and an optimistic understanding of human destiny. 


\section{Notes}

\section{Introduction}

\section{Pages 8-11}

${ }^{1}$ The writings of these two authors, the second in particular, are cited throughout the book. For an analogous review in the broader field of Jewish history of Europe, the foundational works are Jonathan Israel, European Jewry in the Age of Mercantilism 1550-1750 (London: Littman Library, 1998), and David Ruderman, Early Modern Jewry: A New Cultural History (Princeton: Princeton University Press, 2010).

${ }^{2}$ Yosef Kaplan, An Alternative Path to Modernity: The Sephardi Diaspora in Western Europe (Leiden: Brill, 2000).

${ }^{3}$ Moritz Steinschneider, Die Italienische Literatur der Juden (Frankfurt: J. Kauffmann, 1901).

\section{1: From Philosophy to Kabbalah:}

\section{Yehiyel Nissim of Pisa and the Critique of Aristotelianism}

\section{Pages 12-29}

1 D. Kaufmann, "La famille de Yehiel de Pise," Revue des études juives 26 (1893): 83-110; D. Kaufmann, "Notes sur l'histoire de la famille 'De Pise'," Revue des études juives 29 (1894): 142-147; D. Kaufmann, "La famille De Pise," Revue des études juives 31 (1895): 62-73; D. Kaufmann, "Abraham b. Isaac De Pise," Revue des études juives 32 (1896): 130-134; D. Kaufmann, "Eliézer et Hanania de Volterra," Revue des études Juives 34 (1897): 309-311. U. Cassuto, in Rivista Israelitica 5 (1908): 227-238; U. Cassuto, "Sulla Famiglia da Pisa," Rivista Israelitica VII (1910): 9-19; 72-86; 146-150; U. Cassuto, in Rivista Israelitica X (1913): 48-59. M. Luzzati, La casa dell' ebreo (Pisa, 1985), passim.

2 The text was published by Kaufmann in Berlin in 1898 and was reprinted in Jerusalem in 1970.

3 The Discourse on the Righteous Man and the Purpose of the World (Hebrew) was published by S. G. Rosenthal in Kovetz 'al yad 8 (1975): 451-478. Discourse on the Ten Sefirot (Hebrew), has not yet been edited. Moshe Idel published several extracts from this work in his article "The Three Versions of the Letter of Yitzchaq Da Pisa" (Hebrew), Kovetz 'al yad 10 (1982): 161-214 (hereafter Versions). For a description of the manuscripts, conserved in the library of the Jewish Theological Seminary in New York, see U. Cassuto, "Sulla Famiglia da Pisa," 48.

${ }^{4}$ The text, dated 1559, was published in translation by S. G. Rosenthal as Banking and Finance among Jews in Renaissance Italy (New York: Bloch, 1962), and is accompanied by an English translation and introduction. S. Schwarzfuchs published four responsa of Yehiyel's in "La valeur de la Kethubah en Italie au XVIe siècle," Revue des études juives n.s. 18 (1958): 116-123. 
${ }^{5}$ R. Bonfil, Rabbis and Jewish Communities in Renaissance Italy, trans. J. Chipman (Oxford: Littman Library, 1990; new ed. 1993) (hereafter Rabbis). See also Ha-rabbannuth be-Ytaliyah bi-tkufath ha-Renessans (Jerusalem, 1979), where Yehiyel Nissim of Pisa's work is considered on pp. 43, 188, 253, 255, 284289, 292-293, and 312.

${ }^{6}$ See the Discourse on the Righteous Man and the Purpose of the World (hereafter The Righteous Man), 478. As to the Minhath Kenaoth (hereafter Minhath), the generally didactic tone of the work and its address to a potentially vast public ("And here I repeated myself because the matter is not considered elsewhere ... and here I reiterated to facilitate the reading") make it appear destined for publication. See also p. 90: "I have dwelled on the subject of the soul because since the time of Hillel of Verona [1220-1295] there has not been any complete review of the philosophical positions on this matter."

${ }^{7}$ Bedersi's apologetic writing was published in 1539, the same year of the redaction of the Minhath, as a premise to Shemuel ben Adret's Responsa, This may not have been a coincidence. Yehiyel may have felt the need to react to the publication of Bedersi's Iggeret.

8 Yehiyel, Minhath, 7.

9 Yehiyel, Minhath, 9.

10 Yehiyel, Minhath, 11.

${ }^{11}$ Yehiyelh;., Minhath, 12.

12 Yehiyel h;. Minhath, 9, 13.

13 Yehiyel, Minhath, 38, 39. Cf. Yehudah ha-Levy, Kuzary V:20; II:57.

14 See A. Marx, "Glimpses of the Life of an Italian Rabbi of the First Half of the Sixteenth Century," Hebrew Union College Annual (1924): 617. This article considers the alternating teaching of the two works in the Community of Naples. Cf. Bonfil, Rabbis, 148.

15 Eliyah Hayyim Ben Binyamin mi-Genazzano, Iggereth Hamudoth (The Letter of Delights), ed. A. W. Greenup (London, 1912), 7. New edition with an Italian translation, La lettera preziosa (Iggeret hamudot), ed. Fabrizio Lelli (Florence: Nimes, 2002).

16 "Because we live in terms of what His mouth says." Yehiyel, Minhath, 16. At issue here is the transmission of the name of God. At this point Yehiyel cites Nahmanides' elliptic interpretation of Exodus 3:12 sub fine, maintaining its extremely prudent tone:

17 Yehiyel, Minhath, 113, 48, 89. Cf. Nahmanides, Introduction to the Commentary on the Torah (Hebrew), ed. Ch. D. Shavel (Jerusalem, 1969); Nahmanides, Introduction to the Commentary on Job (Hebrew) (here Nahmanides has very harsh words for the philosophers who deny divine knowledge and providence: "May God erase the memory of them"). Cf. also Nahmanides, Commentary on Genesis, 38:8. 
18 Yehiyel, Minhath, 21 (on the movement of skies), 41 (on prophecy), 45 (the polemic with the philosopher Gersonides), 100 (on creation ex nihilo).

19 Yehiyel, Minhath, 45. See Gersonides, Commentary on Genesis 18:21.

${ }^{20}$ On Yohanan Alemanno, whose writings remain for the most part unpublished, see U. Cassuto, Gli ebrei a Firenze durante il Rinascimento (Florence, 1918), 301316. Cf. also M. Idel, "The Curriculum of Yohanan Alemanno" (Hebrew), Tarbiz 48 (1980): 303-331; M. Idel, "The Magical and Neoplatonic Interpretations of the Kabbalah in the Renaissance," in Jewish Thought in the Sixteenth Century, ed. B. D. Cooperman (Cambridge, MA: Harvard University Press, 1983), 186-242 (hereafter Magical); M. Idel, "Vases and Sefiroth: Substantiality and Hypersubstantial Infinity in the Kabbalist Theories of the Renaissance" (Hebrew), Italia 3 (1982): 89-111 (hereafter Infinity); C. Mopsik, Les Grands Textes de la Cabale (Paris: Verdier, 1993), 305-312. Fabrizio Lelli published Alemanno's Hay ha- 'Olamin (L'immortale) pt. I: Rhetoric (Florence: Olschki, 1995) with a translation, accurate commentary, and comprehensive bibliography, followed by "L'educazione ebraica nella seconda metà del '400. Poetica e scienza naturali nel Hay ha-‘Olamim di Yohanan Alemanno,” Rinascimento 36 (1996): 75-136. In "Il ritorno agli antichi nella cultura ebraica tra Quattro e Cinquecento," Storia d'Italia, ed. C. Vivanti (Turin: Einaudi, 1996), pt. 1 (Annali, 11), 387-409, Arthur Lesley contextualizes Alemanno's work within the period's rhetoric and education. See his “'The Song of Solomon's Ascents' by Yohanan Alemanno: Love and Human Perfection according to a Jewish Colleague of Giovanni Pico della Mirandola" (Ph.D. dissertation, University of California, 1976); "Giving Birth to the Hebrew Author: Two Compositions by Johanan Alemanno," in The Jewish Body: Corporeality, Society, and Identity in the Renaissance and Early Modern Period, ed. Maria Demling and Giuseppe Veltri (Leiden: Brill, 2009), 273-299; see also Klaus Herrmann, "The Reception of Hekhalot-Literature in Yohanan Alemanno's Autograph MS Paris 849," in Studies in Jewish Manuscripts (Tübingen: Mohr, 1999), 19-88.

${ }^{21}$ Menahem Recanati, Commentary on the Torah (Venice, 1545), f. 65a (Section Wa-yishlakh). For an outline of Recanati's importance in Italy, see A. Diena, Responsa, ed. Y. Boksembaum (Tel Aviv, 1977), vol. 1, p. 133. On this author, see M. Idel, R. Menahem Recanati ha-mequbbal (Hebrew) (Jerusalem: Schocken, 1998) and Menahem Recanati, Commentary on the Daily Prayers: Flavius Mithridates'Latin Translation, the Hebrew Text, and an English Version, edited with introduction and notes by Giacomo Corazzol (Turin: Nino Aragno, 2008).

22 Other than Idel's "Versions," "Infinity," and "Magical," see also Idel, "Major Currents in Italian Kabbalah between 1560 and 1660," in Italia Judaica 2: Gli Ebrei in Italia tra Rinascimento ed età Barocca (Rome: Ministero per i beni culturali e ambientali, Ufficio centrale per I beni archivistici, 1986), reprinted in Essential Papers on Jewish Culture in Renaissance and Baroque Italy, ed. D. Rudermann (New York: New York University Press, 1992), 345-368. 
${ }^{23}$ Y. Nadav, "A Letter of the Kabbalist R. Itzhaq Mar Hayyim on the Doctrine of the Superior Lights" (Hebrew), Tarbitz 26 (1957): 440-458; A. W. Greenup, "A Kabbalistic Epistle by Isaac b. Hayyim Sepharadi," Jewish Quarterly Review 21 (1931): 365-375.

${ }^{24}$ Yehiyel, Minhath, 23: "The first three sefyroth belong to the essence, the remaining seven are called 'attributes' because they refer to His world ... and they are as instruments in the hands of an artisan." Genazzano explicitly upholds Recanati's theory. See Genazzano, Iggereth Hamudoth, 34.

${ }^{25}$ Yehiyel, Minhath, 24; Yehiyel, The Righteous Man, 470.

${ }^{26}$ Y. Alemanno, Hesheq Shelomoh (The Desire of Solomon), quoted in Idel, "Versions," 179. In the second half of the sixteenth century, this "hierarchizing" of the worlds was an established fact in the culture of Italian Jewish schools (yeshivoth). Shlomoh di Monte dell'Olmo, a student in Siena, describes it in twenty Hebrew tercets conserved in an Oxford Bodlean manuscript, 1989/2, ff. 172-3, which will be the object of a future publication.

${ }^{27}$ Nadav, A Letter, 456; Greenup, A Kabbalistic, 370.

${ }^{28}$ Yehiyel, Discourse on Eternal Life, 12-16.

${ }^{29}$ Yehiyel, Minhath, Introduction, IX.

${ }^{30}$ Yehiyel, Minhath, 33, 72.

${ }^{31}$ R. Bonfil, Rabbis, 286. See also Kaufmann, in Revue des études Juives 26 (1893): 93: "Parfois le critique se montre, dans son ouvrage, juge et connaisseur plus compétent que le panégiriste."

32 A convincing analysis of the theoretical relationship between philosophy and Kabbalah is found in Charles Mopsik, "Philosophie et souci philosophique. Les deux grands courants de la pensée juive," La storia della filosofia ebraica, ed. Irene Kajon (Milan: Biblioteca dell' "Archivio di Filosofia," 1993), 247-254. Reprinted in Charles Mopsik, Chemins de la cabale: Vingt-cinq études sur la mystique juive, (Paris: Editions de l'éclat, 13-22).

${ }_{33}$ Yehiyel, Minhath, 15, 23, 25.

${ }^{34}$ Yehiyel, Minhath, 21, 23.

35 Yehiyel, The Righteous Man, 641; Maimonides, Guide of the Perplexed I:58 and 72; Aristotle, De Coelo I:3.

${ }^{36}$ Yehiyel, Minhath, 39. The Mantuan Yehudah Moscato (1532/33-1590), perhaps the best-known exponent of Renaissance Platonism among Italian Jews, briefly mentions this idea, citing another famous Platonic Jew, Avraham ibn Ezra (10921167). Cf. Judah Moscato, Sermons, vol. 1, ed. Gianfranco Miletto and Giuseppe Veltri (Leiden: Brill, 2011), sermon 9/166, p. 94 of the Hebrew section. The original edition of the sermons was published in Venice in 1589, under the title Nefutzoth Yehudah.

${ }^{37}$ Yehiyel, The Righteous Man, 465. See also Yehiyel, The Righteous Man, 469-470.

${ }^{38}$ See Idel, "Magical," 211, 237, and M. Shulvass, The Jews in the World of the Renaissance (Leiden: Brill, 1973), 328-332. Yehiyel lists proofs of the reality of 
magic and of the existence of demons, which he takes from the Torah and from experience. See Yehiyel, Minhath, 48 and following.

${ }^{39}$ Heptaplus, V exposition, ch. 7, ed. Garin (Florence: Vallecchi, 1942), 304; see E. Garin, La cultura filosofica del Rinascimento italiano (Florence: Sansoni, 1961); E. Garin, Ermetismo del Rinascimento (Rome: Editori Riuniti, 1988), in particular p. 18 on the "miracles of Pico through natural magic and kabbalistic doctrine," and p. 49 for the quotation from Pico "magiam operari non est aliud quam maritari mundum." On Ficino and the union of the male and female parts of God, see p. 67. For these questions in general, see F. A. Yates, Giordano Bruno and the Hermetic Tradition (Chicago: University of Chicago Press, 1964); F. A. Yates, Cabala and Occult Philosophy in the Elizabethan Age (London: Routledge, 1979). The author's wish for a vast comparative study of the Jewish and Christian Kabbalah is still to be fulfilled. Hayyim Wirszubski's studies, now collected in Bein ha-Shyttim (Jerusalem: Magnes, 1996), constitute a first and fundamental step in this direction.

40 Yehiyel, The Righteous Man, 464. See Zohar III: 244b-245a; Yehudah ha-Levy, Kuzary III: 26.

${ }^{41}$ Idel, Magical, 198.

42 Yehiyel, Minhath, 108.

43 Yehiyel, The Righteous Man, 477. Thus does Yehiyel continue his reasoning: "And to the question that can be asked: what is the end of our existence in this state of perfection? We could answer: because thus has God willed. And to investigate his will would be the equivalent of investigating his essence, in that one and the other are the same." This passage is a literal citation of Maimonides, Guide of the Perplexed III:13, and it proves how strong Maimonides' prestige was, even among the opponents of Jewish Aristotelianism. In Yehiyel, the centrality of man in the universe touches on the theurgic perspective. A few decades later, with the diffusion of the Lurianic Kabbalah, human activity will be seen to directly condition the life of God himself, in accordance with the saying "My Torah is in your hand, and your soul is in my hand." Cf. Avraham Portaleone, Shiltey ha-Gibborym (The Shields of the Braves) (Mantua, 1612), Introduction (here, chapter 2). Regarding the limited usage among the Italian kabbalists of the Zoharic doctrines on the harmony between the Sefyroth, see Idel, "Versions", 198, 248.

${ }^{4}$ See Maimonides, Guide of the Perplexed II:6 and III:13, and Y. Tishby, The Teachings of the Zohar (Hebrew) (Jerusalem, 1957), vol. 1, pp. 386-387 and 447. Eliyah Del Medigo (1458-1493), the last representative of the AristotelianMaimonidean orthodoxy, will decidedly oppose the idea that there is any possibility for humans to modify the course of the universe. See Behynath ha-dath (The Religion Exam), ed. J. J. Ross (Tel Aviv: Tel Aviv University Press, 1984), 99-100.

45 Yehiyel, The Righteous Man, 460-469. 
${ }^{46}$ We are naturally thinking of Pico della Mirandola's oration De hominis dignitate, ed. Garin (Florence: Vallechi, 1942), 110: "If we will so desire, we will not in any way be inferior to the angels." Yehudah Moscato devoted an entire sermon, no. 9 (see above, note 36), to the idea of man as microcosm. Moscato's work undoubtedly possesses similarities to that of Yehiyel, but in this sermon the intellectual aspect is much more pronounced than in the ideas of the rabbi from Pisa. For Moscato, humanity is a microcosm, capable above all of universal understanding; the history of humanity is the history of a fall from the state of initial intellectual perfection, of rising up again, and of new tumbles downward, up to the point of final redemption, which will lead to eternal intellectual plenitude. Similarly (sermon 10/363, p. 125, Hebrew section), Moscato accepts the idea that an extraordinary man may be superior to the angels, but this superiority — which only Moses possessed — is of an intellectual nature. Moreover, it is no coincidence that Moscato often cited the biblical commentaries of Ovadiyah Sforno, who has a decidedly rationalist attitude.

${ }^{47}$ Bonfil, Rabbis, 290-291. To understand this issue in the Italian rabbinical context, see Bonfil, "Expressions of the Uniqueness of the Jewish People in Italy during the Renaissance" (Hebrew), Sinai 86 (1975): 34-46.

${ }^{48}$ Yehiyel, The Righteous Man, 471. Yehiyel picks up on Yehudah ha-Levy's famous analogy in the Kuzary (II:36: "Israel is among the nations as the heart among the members of the body: it is the part most sensitive to sickness, as well as the most robust"), but he attributes to the heart only vitality and not delicacy or fragility, as in the original text. One can interpret this small but significant omission keeping in mind the difficult situation in which the Italian Jews found themselves at the moment of the writing of this text in 1559: the Talmud had just been prohibited six years earlier, and ghettoes were starting to be built in the various cities. It was therefore appropriate to insist on the formula of encouragement. The similitude is instead quoted in its entirety in Minhath, 85, written in 1539 and therefore before these events. For a development of the similitude, see Zohar III:221b.

49 Yehiyel, Minḥath, 38; see Yehudah ha-Levi, Kuzary V:20, fourth premise.

${ }^{50}$ Yehiyel, Minhath , 47.

${ }_{51}^{51}$ Maimonides, Guide of the Perplexed III:7, 18.

${ }^{52}$ See Bonfil, "Expressions of the Uniqueness," 36-46.

${ }^{53}$ Yehiyel, The Righteous Man, 471-472. Yehiyel modifies and explains in philosophic fashion the interpretation of the Song of Songs, II:2 "Like a rose among thorns" given by Wa-yiqra Rabba 23:3. At issue is how to save the orchard invaded by brambles to rescue to the one perfumed rose therein. That rose is the Torah.

${ }^{54}$ Quoted in C. B. Schmitt, Gianfrancesco Pico della Mirandola (1469-1533) and His Critique of Aristotle (The Hague: Martinus Nijhoff, 1967), 48. 
55 For a more extensive discussion of some of the subjects of Sforno's philosophy, see R. Bonfil, "The Doctrine of the Soul and of Sanctity in the Thought of 'Ovadiah Sforno" (Hebrew), Eshel Beer Sheva' 1 (1976): 200-257.

56 O. Sforno, Or 'ammym, new ed. in Ketavym (Jerusalem, 1985), 495.

57 Yehiyel, Minhath, 11.

58 Yehiyel, Minhath, 45-6. Yehiyel does not present in this case the usual review of philosophical opinions, but he refers to Hasdai Crescas, Or Adonai (The Light of God), pt. II rule 5. Yehiyel naturally does not follow Crescas in his semi-deterministic conclusions. On this subject see the Talmudic source, Talmud Bavly, Nidda 16b: "Everything is in the hands of God, except for the fear of God."

59 See L. Cristiani, “L'Eglise à l'époque du Concile de Trente," L'Histoire de l'Eglise 17 (1948): 233; Enciclopedia Cattolica (Vatican City: Enciclopedia Cattolica, 1951), sub voce "Giustificazione."

${ }^{60}$ For the consideration of Maimonides in Jewish Italy in this period, see M. Schulvass, "The Italian Jewish Study of the Torah during the Renaissance" (Hebrew) Horev 10 (1948): 105-128, and Bonfil, Rabbis, 251-272.

${ }^{61}$ See, for example, Yehudah ha-Levy, Kuzary V:14.

${ }^{62}$ Yehiyel, Minhath, 117-118; see also pp. 9 and 82 there and Yehiyel, The Righteous Man, 460.

${ }^{63}$ Augustini Niphi Suessani Philosophi in Aristotelis Libros Posteriorum Analyticorum Subtilissima Commentaria (Venice, 1558), 43.1 and 61.4. F. Cf. Aristotle, Physics 184 A 16.

${ }^{64}$ Yehiyel, Minhath, 88. In this context, the contrast between the Torah and philosophy is forcefully expressed: "To compare the two forms of knowledge means subverting true judgment, because their relationship is that of reciprocal aversion [ki hem tzaroth zo le-zo]."

65 See P. Pomponazzi, De fato 709, quoted in Garin, Storia della filosofia italiana (Turin: Einaudi 1966), 509: "Ita sunt quae me insomnem et insanum reddunt, ut vera sit interpretatio fabulae Promethei (...) Prometheus vero est Philosophus qui dum vult scire Dei arcana, perpetuis curis et cogitationibus roditur." See also T. Gregory, in Grande Antologia Filosofica VI (Milan: Marzorati, 1964), 625.

${ }^{66}$ See E. Garin, Storia della Filosofia Italiana, 536, regarding Nifo's early adhesion to the transmigration theory.

67 "Whoever wants to persevere in it [philosophy] shall always move in uncertainty and vagueness [...]. Those who proceed along the way of faith remain strong and sure": "De immortalitate animae," Grande Antologia Filosofica, 717. But also "Oportet in Philosophia haereticum esse qui veritatem invenire cupit" (in Garin, Storia della filosofia italiana, 511).

68 Sforno, Or 'ammym, 418.

${ }^{69}$ Ibid., 414-415. 
${ }^{70}$ See R. Bonfil, "The Commentary of Mosheh Provenzalo on the Twenty-five Axioms of Maimonides" (Hebrew), Qiryat Sefer 50 (1974-1975): 157-176.

${ }^{71}$ See E. Garin, La cultura filosofica del Rinascimento italiano (Florence: Sansoni, 1979), 118.

72 Examen veritatis doctrinae gentium et veritatis disciplinae Christianae V, 2. Quoted in Garin, Storia della Filosofia Italiana, 593.

73 Yehiyel, Minhath, 48-50. In "Talmudists, Philosophers, Kabbalists: The Quest for Spirituality in the Sixteenth Century," in Jewish Thought in the Sixteenth Century, 446, Isadore Twersky highlights Yehiyel's aspiration to completion, or spiritual perfection, which manifests itself in an exaltation of religious practice over pure intellectual activity. Indeed, the allusions to corporeality in his writings are not few: in Minhath, p. 78, he speaks of the corporeal remains in the soul after death. The service of God is described in the Discourse on the Righteous Man and the Purpose of the World as an activity "of feelings and of all the members of the body" (and in Yehiyel, Minhath, 88: "the soul's perfection is in its union with the body"). Moreover, a certain importance is granted to the sense of touch, in contrast to Aristotle's and Maimonides' devaluation of said sense (Maimonides, Guide of the Perplexed II:36; Yehiyel, Minhath, 81). This change in sensibility also merits further study.

74 Yehiyel, Minhath, 36. Moscato mentions the idea of the superiority of the Torah to the secular sciences: mathematics, which deals only with abstract concepts; physics, whose object is unstable; and metaphysics, the result of simple hypotheses, changeable according to differing opinions, are comparable to "slags of silver covering objects of clay." (Compare this with the image invoked by Maimonides, in the introduction to Guide of the Perplexed, of the Torah as a golden apple covered with a net of silver.) Cf. Y. Moscato, Sermons, vol. 2, sermon 13/7-9, 19-20.

75 Yehiyel, Minhath, 22.

76 See J. Gutmann, Philosophies of Judaism (Philadelphia: Holt, Rinehart And Winston 1964), 232. Maimonides, Guide of the Perplexed I:51-54; Crescas, Or Adonai 1, III, 3.

77 Yehiel, Minhath, 43; Maimonides, Guide of the Perplexed II:36. For the analogous theory of Avicenna, see S. M. Afnan, Avicenna, His Life and Works (London: G. Allen and Unwin, 1958). Eliyah Genazzano elaborated the same kind of critique of this idea, referring, however, not to Maimonides, but to Yosef Albo's Book of Principles. See Genazzano, Iggereth Hamudoth, 11.

78 Yitzhaq Abravanel, in his commentary on this passage of Maimonides, highlights the role of the intellect as well. The philosopher and political man of Spanish origin had been in close contact with Yehiyel of Pisa, grandfather of our Yehiyel Nissim. See the quoted articles by Kaufmann and Cassuto mentioned above.

79 The references to this distinction are in the Talmud Bavly, Yevamot 49b sub fine, and Zohar I:170.

80 Yehiyel, Minhath, 44. 


\section{2: Can Fundamentalism be Modern? The Case of Avraham Portaleone, the Repentant Scientist Pages 30-61}

${ }^{1}$ Critical references are Robert Bonfil, "Preaching as Mediation between Elite and Popular Cultures: The Case of Judah Del Bene," in Preachers of the Italian Ghetto, ed. David B. Ruderman (Berkeley: University of California Press, 1992) and David B. Ruderman, Jewish Thought and Scientific Discovery in Early Modern Europe (New Haven: Yale University Press, 1995).

2 Cf. Marco Mortara, "Un important document dans la famille des Portaleone," in Revue des études juives 12 (1886): 113-116; D. Kaufmann, Testament of Abraham Sommo Portaleone', JQR 4 (1892): 333; Shlomo Simonsohn, The History of the Jews in the Duchy of Mantua (Hebrew) (Jerusalem: Kiryath Sepher, 1977), 294, 312, and 387 note 83.

3 Shiltey ha-Gibborym (Mantua, 1612), folio 185b, column 1.

4 This work consists of 626 folio and was compiled by Avraham's son David, himself a physician, in 1607: Abrahamo Portaleone, responsorum et consultationum medicinalium liber. Per me David eius filium collectae et conscriptae cum indice locupletissimo Anno MDCVII, Paris, Bibliothèque Nationale de France, ms Latin 13004. See Andrew Berns, "Abraham Portaleone and Alessandro Magno: Jewish and Christian Correspondents on a Monstrous Birth," European Journal of Jewish Studies 5, no. 1 (2011): 53-66. Cf. Simonsohn, The History of the Jews, 295.

5 According to the Shiltey ha-Gibborym, folio 185b, column 2, Guillaume was the third Duke of Mantua. In the De Auro, he simply mentions a "Vir prestantissimus," a "very famous figure." The only existing mention of the "Dialogues on gold" in scholarly literature, to my knowledge, is in L. Thorndike, A History of Magic and Experimental Science (New York: History of Science Society Publications, 1941), 645-647.

${ }^{6}$ Shiltey ha-Gibborym, ibid. Portaleone mentions here that he wrote the dialogues De auro " "al regel ehad" (sic), "on only one leg"; in a rush, that is. The entire title is De Auro dialogi tres. In quibus non solum de Auri in re Medica facultate, verum etiam de specifica eius, \& ceterarum rerum forma, ac duplici potestate, qua mixtis in omnibus illa operatur, copiose disputatur. Abrahamo e Porta Leonis Mantuano Medico Hebrceo Auctor. The book is is possibly a comprehensive survey of Portaleone's scientific and medical opinions. This is how we interpret the quick exchange between Achryvasmus and Dynachrisus on p. 20: "A.: A few days ago, a person told me your opinion, but in synthesis. But why did you not bring up so many things worth (in my opinion) knowing in your writings? D.: The little time available and the difficulty of the subject mutilated their writing. But I gave the opportunity to many scientists and erudite persons to attain the core of the thing in greater depth, with art and elegance." 
The expressions "the little time available and the difficulty of the subject," and "the core of the thing" are irresistibly reminiscent of the lexicon of Maimonides in his Guide of the Perplexed (I:34 and introduction respectively). This is probably a rare instance of importation of expressions from Jewish literature into scientific literature.

${ }^{7}$ Marie-Thérèse Jones-Davies, ed., Gold in the Time of Renaissance (Paris: Université de Paris-Sorbonne, Institut de recherches sur les civilisations de l'Occident moderne, 1978); Allen G. Debus, The Chemical Philosophy: Paracelsian Science and Medicine in the Sixteen and Seventeenth Centuries (New York: Science History Publications, 1977); J.C. Margolin and S. Matton, eds., Alchimie et philosophie à la Renaissance (Paris: Vrin, 1993). On the issue of drinkable gold at a former time, see Chiara Crisciani, "Oro potabile fra alchimia e medicina: due testi in tempo di peste," volume 115 of Memorie di Scienze Fisiche e Naturali. Rendiconti della Academia Nazionale delle Scienze detta dei $X L, 5^{\text {th }}$ series, vol. XXI/2, t. II (1997): 83-93.

8 This notion of quintessence was probably inspired by Paracelsus, who in $D e$ Auro dialogi tres, p. 5, is referred to as "Paracelsus aureolus" ("the golden Paracelsus"). Cf. Walter Pagel, Paracelsus: An Introduction to Philosophical Medicine in the Era of the Renaissance (Basel: S. Karger, 1958), 99-100, who cites Paracelsus, De vita longa, chapter 1. Cf. on this subject L. Thorndike's negative view of De Auro in A History of Magic and Experimental Science.

9 As an example, Gabriel de Castaigne published a small book in Paris in 1611 entitled L'or potable qui guarit de tous maux (Drinking Gold to Heal All Ills), which largely consists of a list of attestations by patients healed by drinking gold produced by the author.

${ }^{10}$ On the literary form of medical writings in that period, and especially in Portaleone's writings, see A. Berns, "Abraham Portaleone and Alessandro Magno," 58: "Humanist trends that emerged in Italian culture in the Renaissance influenced the medical profession as well and elevated the importance of, and social value placed on, good writing, especially in Latin."

11 Shiltey ha-Gibborym, f. 2v.

12 On Shiltey ha-Gibborym see Abraham ben David Portaleone, Die Heldenschilde, German translation and commentary by Gianfranco Miletto (Frankfurt am Main: Lang, 2001); Gianfranco Miletto, Glauben und Wissen im Zeitalter der Reformation. Der salomonische Tempel bei Abraham ben David Portaleone (1542-1612) (Berlin: De Gruyter, 2004). See also Samuel S. Kottek, "Jews between Profane and Sacred Science in Renaissance Italy: the Case of Abraham Portaleone," in Religious Confessions and the Sciences in the Sixteenth Century, ed. J Helm and A. Winkelmann (Leiden: 2001), 108-18. A recent contribution is the article by Andrew Berns, "Judah Moscato, Abraham Portaleone, and Biblical Incense in Late Renaissance Mantua," in Rabbi Judah Moscato and the Jewish Intellectual World of Mantua in the $16^{\text {th }}-17^{\text {th }}$ Centuries, ed. Giuseppe Veltri 
and Gianfranco Miletto (Leiden: Brill, 2012), 105-119. Berns deals with the connection made by many scientists in late-sixteenth-century Italy (including Portaleone) between natural philosophy and the Bible.

${ }^{13}$ The expression is from the De auro, 20.

${ }^{14}$ De auro, 63.

${ }^{15}$ In lieu of "barking" by the alchemists, cries of joy and encouragement performed by the necromancer, cf. Leonardo da Vinci, Scritti letterari, ed. A. Marimoni (Milano, 1974), 163.

${ }^{16}$ This position is directly reminiscent of Francis Bacon's statement in The Advancement of Learning, published in 1605: "The search and endeavors to make gold have brought many useful inventions and instructive experiments to light" (I quote the New York edition: Colonial Press, 1900, 19).

${ }^{17}$ De auro, 18-19.

${ }^{18}$ Cf. Nancy Siraisi, Avicenna in Renaissance Italy (Princeton, NJ: 1989), esp. 68-70. Cf. also the text written by doctor Leonardo Fioravanti, Dello specchio di Scientia Universale (Venice: 1564), 96a, on alchemy, with an opinion similar to Dynachrysus/Portaleone's; $281 \mathrm{~b}$ on overestimating the medical theory in relation to practice; and 276a, against the blind worship of the authorities of the past.

${ }^{19}$ De auro, 74. See also ibid., 76: "Is your love for Pliny making you blind?" Niccolò Leoniceno, Professor of Medicine at Ferrara University, debuted in 1492 the critical series on Natural History by Pliny the Elder: Nicolai Leoniceni de Plinii et aliorum in medicina erroribus, Ferrara, Laurentius de Valentia et Andreas de Castronovo, 1492. See, for example, page 5 (pages are not numbered): "I am inclined to believe that numerous things [Pliny] wrote about in his natural history books were not fully verified and explored."

${ }^{20}$ De auro, 36-37.

${ }^{21}$ Ibid., 20: Achryvasmus: "Experientia quidem, rerum omnium naturalium magistra celebratur, quod si denegaris, non repræhensione tantum, sed pœna etiam dignus esse videaris." The Frenchman Alexandre de la Tourrete's propos are very close to Portaleone's. Cf. his Bref discours des admirables vertus de l'or potable. Avec une apologie de la tresutile (sic) science d'alchimie (Short Discourse on the Admirable Virtues of Drinking Gold. With an Apology for the Very Useful Science of Alchemy) (Lyon, 1575), 36 recto: "Their ignorance [that of the Greek and Arab medical authorities] on the one hand, with their incredulity on the other, are the cause, if they know nothing of the said illnesses or of the medicines necessary to heal them, in which the uncertainty of their science is manifestly revealed, since it is founded simply on dead words not on the light of nature, which has its physical reasons and ocular demonstrations for true and certain experiences."

${ }^{22}$ Shiltey ha-Gibborym.

${ }^{23}$ Ibid., f. 37b, col. 2. 
${ }^{24}$ Ibid., f. 39b. Portaleone's "technological" texts must be read in the background of the situation of Mantua in those years. A Jewish contemporary of Portaleone, Abraham Colorni (born ca. 1530) was an engineer, a polymath, an inventor of military technology, and the author of a book on cryptography, Scotographia o Vere (sic) Scienza di Scrivere Oscuro Facilissima et Securissima per Qualsi Voglia Lingua (Prague: 1593).

${ }^{25}$ On this figure see Deuteronomy 20:1-9; Mishnah Sota 8:1; Maimonides, Mishneh Torah, Hilkhoth Melakhym, 7.

${ }^{26}$ Ibid., "Iggereth" or introductory "Epistle."

27 Ibid., f. 101 b. col. 2.

28 Ibid., "Iggereth," cit., f. 2b, col. 2.

${ }^{29}$ For the origin of the comparison, cf. Plato, Phaedo, 85 d-e.

${ }^{30}$ De auro, 37-39.

31 Cf. also ibid., 48.

32 Ibid., 15.

33 Abraham Melamed, Wisdom's Little Sister (Hebrew), unpublished Ph.D. Thesis, University of Tel Aviv, 1976.

${ }^{34} \mathrm{Cf}$. for instance the similar position of Azariyah de' Rossi, The Light of the Eyes, trans. Joanna Weinberg (New Haven: Yale University Press, 2001), 699-709, and of Portaleone's contemporary, the well-known Samuel Archivolti, in his linguistic treatise 'Arugath ha-bosem (Venice, 1603), 92a. Also to be considered, of course, is the critical attitude of Eliyahu Levita, in Massoreth ha-masssoreth (Basel, 1538).

${ }^{35}$ For a historical survey of the punctuation in that period, cf. Nina Catach, La Ponctuation (Paris: Presses Universitaires de France, 1994), 28.

${ }^{36}$ Cf. on this topic, Jacques Poirier, L'âge d'or, Dijon, 1996. For an analysis of the visual treatment of the subject, see Élinor Myara Kelif, "De l'Eden païen au paradis terrestre: l'allégorie et le mythe des Âges de l'humanité," in Le noyau de l'écorce. Les arts de l'allégorie XVe-XVIIe siècle, ed. Colette Nativel et al. (Rome: SOMOGY, 2009), 165-187.

37 De auro, 83-84.

38 Ibid., 90.

${ }^{39}$ Cited in D. Aricò, 'Les 'Yeux d'Argos' et les 'Étoiles d'Astrée' pour mesurer l'univers. Les Jésuites italiens et la science nouvelle,' Revue de Synthèse 120 (1999): 297.

${ }^{40}$ Cf. Andrea Battistini, Galileo e i Gesuiti. Miti letterari e retorica della scienza (Milan: Vita e Pensiero, 2000).

${ }^{41}$ Shiltey ha-Gibborym, f. 58b.

${ }^{42}$ Shiltey ha-Gibborym, f. 97a, col. 1. He uses the same explanation (a flaw in the transmission of the text) to account for the mistake in the Talmud in the passage describing the oil fabrication for the anointment of the priests. Portaleone uses here the same argument as Pliny's supporters used against Leoniceno's attacks. 
Cf. N. Siraisi, Avicenna in Renaissance Italy, 68. Nathan ben Yehiyel (twelfth century), the author of the 'Arukh, one of the authorities whose work was considered inadequate by Portaleone, is justified by the fact that the medical literature of his time was generally inadequate and would simply iterate words that did not have any connection with reality. The same critical posture can be seen in the De auro.

43 Shiltey ha-Gibborym, f. 92b, col. 2.

${ }^{44}$ Ibid. f. 100b, col. 1.

45 Ibid., f. 96 a, col. 1.

${ }^{46}$ Ibid., f. 96b, col. 1. Cf. also f. 95b, col. 1, the "fixative" or pre-Linnean classification of species in nature, considering them as determined at creation, without any possibility of variation.

47 For Portaleone's messianic attitude, see the chapter "The Myth of Politics."

${ }^{48}$ Portaleone refers to the previous description of the rites in the Jerusalem Temple made by the prestigious kabbalist Menahem 'Azariyah Fano, Seder 'avoda litemydin w-le-musafyn (Venice: 1583).

49 Shiltey ha-Gibborym, f. 49a: "My opinion is somewhat different from theirs [i.e. from the philosophical and scientific authorities], since I have my own ideas on the truths of [natural] philosophy. I spoke about them at length in my Latin book printed in Venice on the subject of mineral gold [Hebrew: mahtzavy, which corresponds to the "common gold" in De Auro] and its supposed medical properties, written at the behest of His Excellence Lord Guglielmo, Duke of Mantua and Monferrato." One notes the great prudence of tone vis-à-vis De Auro with regard to the scientific authorities, even if they are non-Jewish authorities.

${ }^{50}$ De auro, 20-21. To be compared with the position of Leonardo da Vinci, who defined himself as "a man lacking literary knowledge, but who was schooled by experience," Scritti letterari, 148-149.

${ }^{51}$ Even the phrase, "I left ... the opportunity" seem to be inspired by a text of rabbinical literature, especially Talmud Bavly, Hullin 7a.

52 This is a reference to Juvenal, Satire VI, v. 165: Rara avis nigroque simillima cycno ('a rare bird, similar to a black swan').

53 Portaleone owned the Decameron, see G. Miletto, La Biblioteca di Avraham ben David Portaleone secondo l'inventario della sua eredità, p. 78, in the edition expurgated by Luigi Groto. Surprisingly, this edition presents the whole novel (pp. 471-473) in spite of its erotic content.

54 The Guide of the Perplexed II:36.

55 The Shiltey ha-Gibborym can be read as a fulfillment of David Provenzali of Mantua's pedagogical agenda. Provenzali suggested the creation of a type of Jewish High School, in which sacred and profane study would be mixed. Provenzali's Hebrew text is in S. Assaf, Meqoroth le-toledoth ha-hinnukh be-Yisrael, 4 vol. (Tel Aviv: 1926-47), t. II, pp. 115-120. For an analysis of the agenda, see A.M. Lesley, "Il richiamo agli 'antichi' nella cultura ebraica fra Quattro e 
Cinquecento," in Storia d'Italia. Gli Ebrei in Italia, 2 vol., ed. C. Vivanti (Turin: Cristina Galasso, 1996), t. I, pp. 385-409, especially pages 394-400. See also G. Miletto, "The Teaching Program of David ben Avraham and His Son Abraham Provenzali in its Historical-Cultural Context," in Cultural Intermediaries, ed. David Ruderman and Giuseppe Veltri (Philadelphia: University of Pennsylvania Press, 2004), 127-148.

${ }^{56}$ Cf. Isaac Barzilay, Yoseph Shlomo Delmedigo (Yashar of Candia) (Leiden, 1974), 93.

${ }^{57}$ Cf. Judah Messer Leon, The Book of Honeycomb's Flow: Nopheth Suphim, ed. and trans. Isaac Rabinowitz (Ithaca, NY: Cornell University Press, 1983), especially pp. 142-143.

${ }^{58}$ See Miletto, Glauben und Wissen, 108-175.

${ }^{59}$ Shiltey ha-Gibborym, f. 4a. More recent readers of Portaleone have not failed to criticize this position, even using irony to do so. If Portaleone's Latin translator, Ugolini, wrote that the Jewish author, dealing with military subjects, was fast asleep (see chapter "The Myth of Politics"), and the important Hebraist Giovanni Bernardo De Rossi spoke of him as follows in his Ditionario storico degli autori ebrei e delle loro opere (Parma, 1802): "This work [Shiltey ha-Gibborym] contains much curious and rare information, which deserves to be read, and which one will search in vain to find elsewhere, [as it has] been drawn and gathered together from an infinity of ancient sources and books, introduced in the table of contents, and accompanied by the luminaries of learned men of other nations, and their exotic languages, which he speaks of at length in the introduction. But in the midst of so many beautiful things, his opinion sometimes seems new and bizarre, for instance when he writes that $[. .$.$] the antiquity of the printing press$ dates back to the first centuries of the world and was known since the time of Job, an assumption for which he presents some texts, interpreted in his own way, as proof, condemning the error of all the learned men of his own time who, he says, sold it as a new invention created not more than a hundred years before."

${ }^{60}$ Ibid. See also f. 42b. Azariyah de' Rossi uses the same word, tzedeq, with reference to the contribution of Jewish and non-Jewish sages to knowledge. See Azariyah de' Rossi, The Light of the Eyes: "It would be our duty to investigate and search out a solution, applying correct methods and not useless tools [i.e. use all valid sources irrespective of their origin] in order to ensure that faithfulness [tzedeq] and truth [emeth] are met."

${ }^{61}$ Shiltey ha-Gibborym, f. $31 \mathrm{~b}$.

${ }^{62}$ The complete absence of reference to Meor 'einayim in Shiltey ha-Gibborym, given that both authors were from the same town and shared the same culture, should be attributed to the misgivings that certain rabbis had expressed concerning the contents of the former work. The Portaleone of the second half of his life probably did not want to be seen to be close to a controversial figure. See Azariyah de' Rossi, Selected Chapters from "Sefer Meor Einayim” and "Matzref 
la-Kessef," ed. Reuven Bonfil (Jerusalem: Bialik Institute, 1991), with a bibliography on pp. 131-133.

${ }^{63}$ De Auro, 54.

${ }^{64}$ Francesco Roheo, or François de la Rue (Lille, 1520-1585), the author of De gemmis aliquot iis presertim, quarum divus Ioannes in sua Apocalypsi meminit, de aliis quoque, quarum usus hoc aevi apud omnes percrebuit, Libri duo (Paris: 1547; Zürich: 1565). The full information is in Abraham ben David Portaleone, Die Heldenschilde, 67, and Miletto., Glauben und Wissen, 288. See also Samuel S. Kottek, "Jews between Profane and Sacred Science in Renaissance Italy: the Case of Abraham Portaleone."

${ }^{65}$ Shiltey ha-Gibborym, ff. 46a-b.

${ }^{66}$ The sapphire is like the heavens without stars, the ruby like the sphere of the stars, the diamond like the sun; the amethyst and the emerald like the spheres of some stars and the moon. Achryvasmus reacts admiringly to these parallels drawn by Dynachrisus: "Oh, human intellect, how penetrating you are!" Portaleone reuses exactly the same comparison in Shiltey ha-Gibborym, f. 80a, with biblical verses to support it.

${ }^{67}$ Ibid., $43 \mathrm{~b}$.

${ }^{68}$ Miletto, Die Heldenschielde, 427, note 466, discovered that the source of this comparison is the Jesuit Francisco Ribera, Francisci Riberae Villacastinensis, presbyteri Societas Iesu, Doctorisque Theologi, De Templo, et de iis quae ad templum pertinent, libri quinque (Antwerp, 1602), 241. It is interesting to remark that, in order to satisfy the rabbis, the very orthodox Portaleone drew from a Christian source.

${ }^{69}$ Ibid., f. 49a

${ }^{70}$ Ibid., p. 51b. This affirmation is reminiscent of the exaltation of experience in De Auro, xx: "Without experience, there would be no real difference between man and the most intelligent animals."

${ }^{71}$ Shiltey ha-Gibborym, f. 49 b.

72 Blasio Ugolini, Thesaurus antiquitatum sacrarum [...] opuscula in quibus veterum Hebraeorum mores, leges, instituta, rituus sacri et civiles illustrantur (Venice: 1744-1769).

${ }^{73}$ For other quotations and commentaries of the book, cf. Eliacin Carmoly, Histoires des médecins juifs anciens et modernes (Bruxelles, 1844), 167; Julius Fürst, Bibliotheca Judaica (Leipzig: 1863), vol. 3, 114. Another interesting judgement is in Auguste-Arthur Beugnot, Les Juifs d'Occident, ou Recherches sur l'état civil, le commerce et la littérature des Juifs, en France, en Espagne et en Italie, pendant la durée du Moyen âge (Paris: 1824), 265-6. For a complete review of the early modern and modern readers of Portaleone, see Gianfranco Miletto, "La rappresentazione dello Stato ideale negli Shilte ha-gibborim di Avraham ben David da Portaleone," in Annali di Storia dell'esegesi 18/2 (2001): 447-463. 


\section{3: Allegorical Space and Geometrical Space: Representations of the Temple of Jerusalem in the Works of Italian Jewish Authors}

\section{Pages 62-77}

${ }^{1}$ On the notion of "image" in the Jewish tradition, see J. Gutmann, ed., No Graven Images: Studies in Art and the Hebrew Bible (New York: Ktav, 1971); R. Prigent, Le judaïsme et l'image (Tübingen: Mohr, 1990); K. P. Bland, The Artless Jew: Medieval and Modern Affirmations and Denials of the Visual (Princeton: Princeton University Press, 2000); V. B. Mann, Jewish Texts on the Visual Arts (Cambridge: Cambridge University Press, 2000).

${ }^{2}$ Maimonides, The Guide of the Perplexed, Introduction.

${ }^{3}$ The Guide of the Perplexed III:51, trans. Shlomo Pines (Chicago: University of Chicago Press, 1974), vol. II, 618-619.

${ }^{4}$ Rieti is a city northwest of Rome. On Mosheh of Rieti, see A. Guetta "Mosheh da Rieti (XIVe-XVe s.), philosophe, scientifique et poète," Revue des Etudes Juives 158, nos. 3-4 (July-December 1999): 577-586; A. Guetta, "Renaissance et culture juive: le cas de Moshe ben Yitzhaq de Rieti” Tzafon 48 (2004-2005): 4357; D. Bregman, The Golden Way: The Hebrew Sonnet during the Renaissance and the Baroque (Tempe, AZ: ACMRS, 2006).

${ }^{5}$ This poem was published in J. Goldenthal, Il Dante Ebreo ossia il Picciol Sanctuario (Hebrew with an introduction in Italian) (Vienna, 1865). For a presentation of the poem, with an English translation and an annotated version of the first two chapters, see D. Bergman, A. Guetta, and R. P. Scheindlin, eds., Prooftexts 23, no. 1 (2003), special issue of Medieval Jewish Literature.

${ }^{6}$ This chapter was remarkably popular with Italian Jews, among whom it enjoyed a longer-lasting success than the poem as a whole; it was extracted from its context and translated into Italian verse (transcribed into Hebrew or Latin characters) by four different writers between the end of the sixteenth and the beginning of the seventeenth centuries. Various Jewish Italian scholars, including Azariyah de' Rossi, also transcribed the original Hebrew version, evidently considering it to exemplify the Italian school of Hebrew poetry. See chapter 6, "The Italian and Latin Works of Lazzaro da Viterbo...."

${ }^{7}$ Goldenthal, second part, chap. 3, pp. 51a-52b.

${ }^{8}$ Ibid., chap. 4, p. 53b.

9 A. Guetta, "Ya' ar ha-Levanon ou la quête de la connaissance perdue. Un texte en prose rimée de Moshe de Rieti," Revue des études juives 164 (2005): 67-129 (critical edition of an unpublished text with an introduction, French translation and notes).

${ }^{10}$ Moshe da Rieti, Filosofia naturale e fatti de Dio, ed. Irene Hijmans-Tromp (Leiden: Brill, 1989). 
11 The original text can be found in ibid., 409-415. For a more extensive French translation, see A. Guetta, "Renaissance et culture juive."

12 On this subject, see L. Bolzoni and P. Corsi, eds., La cultura della memoria (Bologna: Il Mulino, 1992); L. Bolzoni, La chambre de la mémoire: modèles littéraires et iconographiques à l'âge de l'imprimerie (Genève: Droz, 2005).

13 Shiltey ha-Gibborym, introduction.

14 Philippe d'Aquin, Discours des sacrifices de la loy mosaique (Paris: Jean Laguehay, 1623), Part I: "Explications literales, allégoriques et moralles du Tabernacle, que Dieu commanda à Moyse de faire."

${ }^{15}$ Hieronymi Pradi et Ioannis Baptistae Villalpandi e Societate Iesu, In Ezechielem explanationes et apparatus Urbis, ac temple Hyerosolymitani commentariis et imaginibus illustrates opus tribus tomis distinctum (Rome, 1596-1605).

16 The work of the French Hebraist François Vatable (died 1542), who taught at the Collège de France, constitutes a noteworthy exception: Vatable illustrated the Bible that Robert Estienne published in 1538-40 with images of the Temple drawn from Jewish sources which neither allegorized nor symbolized it. On the predominantly Christian seventeenth-century representations of the Temple, see Helen Rosenau, Vision of the Temple: The Image of the Temple of Jerusalem in Judaism and Christianity (Londres: Oresko, 1979); Hendrik Bude and Andreas Nachama, eds., Die Reise nach Jerusalem (Berlin: Argon, 1996), particularly the chapter entitled "Der wiedererstandene Tempel: Architektonische Visionen."

17 The expression is inspired by the book of G. Camillo, L 'idea del theatro (1550, new edition Palermo: Sellerio, 1991).

18 B. Ugolini, Thesaurus antiquitatum vol. 9, col. CCI-CCII, CCIX-CCXX, CCLIII-CCLIX, CCICVII-CCXCVIII, CCCXI-CCCXII.

${ }^{19}$ On this author, see H. Rosenau, “Jacob Judah Leon Templo's Contribution to Architectural Imagery," Journal of Jewish Studies 23, no. 1 (1972): 72-81; A. L. Shane, "Rabbi Jacob Judah Leon (Templo) of Amsterdam (1603-1675) and his Connections with England," Transactions of the Jewish Historical Society of England 25 (1977): 120-136; A. K. Offenberg, "Jacob Jehuda Leon (1602-1675) and his Model of the Temple," in Jewish-Christian Relations in the Seventeenth Century, ed. J. Van Den Berg and E. Van Der Wall (Dordrecht: Springer, 1988): 95-115.

${ }^{20}$ R. H. Popkin, "Christian Jews and Jewish Christians in the $17^{\text {th }}$ Century," in Jewish Christians and Christian Jews: From Renaissance to the Enlightenment, ed. R. H. Popkin and G. M. Weiner (Dordrecht: Springer, 1994), 57-72.

${ }^{21}$ Cf. D. B. Ruderman, Kabbalah, Magic and Science: The Cultural Universe of a Sixteenth-Century Jewish Physician (Cambridge, MA: Harvard University Press, 1988). Leone Sommo, who composed several Italian plays as well as a treatise of dramatic theory written in Italian, was also the author of what is considered to be the first dramatic work written in Hebrew, Tzahuth bedihuta de-kiddushin (The Comedy of Marriage). On this author, see R. Bonfil, "Lo spazio culturale degli 
ebrei d'Italia fra Rinascimento ed Età barocca," in, Storia d'Italia. Annali 11. Gli ebrei in Italia, vol. 1, pp. 413-473, ed. C. Vivanti (Turin: Einaudi, 1996), particularly pp. 457-472. A later Mantuan author of a book with a description of the Temple was the seventeenth-century scholar Malkyiel Ashkenazy. The book was published by Avraham Sofer, as Beur 'al masekheth middoth le-ha-gaon Mosheh Caze. We-nilweh elayw sefer hanukath ha-bayit 'al tzurath beyt ha-miqdash lehe-hakham rabby Malkyiel Ashkenazy mi-Mantovah, in Jerusalem in 1963.

${ }^{22}$ There is one exception (f. $14 \mathrm{v}$ ): a quotation from a "contemporary scholar," whose name is not revealed, which endorses his position.

${ }^{23}$ F. 17a. See Talmud Bavly Sanhedrin 51b.

${ }^{24}$ Azariyah de' Rossi, Meor 'eynayim, section Imrey bynah, chapter 29. English translation by Joanna Weinberg, The Light of the Eyes, 406.

${ }^{25}$ Mishkeney 'elyon was published for the first time by H. Friedlander in Ginzey Ramhal (Bnei-Braq: 1984), 149-205. On M. H. Luzzatto, see in particular S. Ginzburg, The Life and Works of Moses Hayyim Luzzatto (Philadelphia: Dropsie College for Hebrew and Cognate Learning, 1931); J. Hansel, Moïse Hayyim Luzzatto (1707-1746). Kabbale et philosophie (Paris: Editions du Cerf, 2004); N. Danieli, L'epistolario di Moshe Hayyim Luzzatto (Florence: Giuntina, 2006).

${ }^{26}$ Y. ben Abraham Gikatilla, Sha 'arey Orah ("Gates of Light"), ed. Y. ben Shelomo (Second edition, Jerusalem: 1989), vol. 1, p. 49. On Kabbalah and representation, see G. Busi, Qabbalah visiva (Turin: Einaudi, 2005).

${ }^{27}$ Friedlander, 157.

\section{4: The Myth of Politics in the Jewish Communities of the Italian City-States}

\section{Pages 78-91}

${ }^{1}$ Luzzatto, Simone, Discorso circa il stato de gl'hebrei (Venice, 1638) (reprinted in facsimile, Bologna: Arnaldo Forni, 1976), 37b. Now in Simone Luzzatto, Scritti politici e filosofici di un ebreo scettico nella Venezia del Seicento, ed. Giuseppe Veltri, Milano, Bompiani, 2013.

${ }^{2}$ For a select bibliography on Alemanno, see chapter 1.

${ }^{3}$ On Alemanno's political thought see Erwin I.J. Rosenthal, "Some Observations on Yohanan Alemanno's Political Ideas," in Studies in Jewish Religious and Intellectual History. Presented to Alexander Altmann in Occasion of His Seventieth Birthday, ed. Siegried Stein and Raphael Loewe (Tuscaloosa, AL: University of Alabama Press, 1979), 247-261, and Abraham Melamed, "The Hebrew 'Laudatio' of Yohanan Alemanno - in Praise of Lorenzo il Magnifico and the Florentine Constitution," in Jews of Italy: Studies Dedicated to the Memory of U. Cassuto (Jerusalem: Magnes Press,1988), 1-34. 
${ }^{4}$ Hesheq Shelomo, quoted in Joseph Perles, "Les savants juifs à Florence à l'époque de Laurent de Médicis," in Revue des études Juives 13 (1886): 253.

5 Ibid., 253-255.

6 Shiltey ha-Gibborym, 34a. For an analysis of this section of Portaleone's work and its relationship to the political thought of the Counter-Reformation, see Gianfranco Miletto, "La rappresentazione dello Stato ideale negli Shilte ha-gibborim di Avraham ben David da Portaleone."

7 Piero Camporesi, Le belle contrade. Nascita del paesaggio italiano (Milano: Garzanti, 1992).

8 Shiltey ha-Gibborym, 34a.

9 See supra, chapter 2.

${ }^{10}$ Ibid., 42b.

${ }^{11}$ On the historical consciousness of the Jews of this period, see Abraham Melamed, "The Perception of Jewish History in Italian Jewish thought of the Sixteenth and Seventeenth Centuries: A re-examination," Italia Judaica 2 (1986): 139-170.

12 Ibid., 36b.

${ }^{13}$ On the juridical status of Mantuan Jews in Portaleone's time, see Shlomo Simonsohn, History of the Jews in the Duchy of Mantua (Hebrew), vol. I, 78-86.

${ }^{14}$ In his Latin translation of excerpts from Shiltey ha-Gibborym, Blasio Ugolini appends a remark to this passage on artillery: "It is astonishing how, when speaking on military matters, a man as intelligent and learned as our Abraham would not only fall asleep, but snore." Thesaurus Antiquitatum Sacrarum, vol 9, col. CCCLXXV.

${ }^{15}$ Compare, for example, the illustration which represents a soldier armed with a musket in the work of the Dutch engraver Gheyn in Maniement d'armes d'arquebuses, mousquetz, et piques. En conformité de l'ordre de Mgr le Prince Maurice, Prince d'Orange,... Représenté par figures, par Jaques de Gheyn (By order of Sir Prince Maurice, Prince of Orange [...] depicted with figures by Jacques de Gheyn. Written tuition for every amateur of weapons, captain and commandant, so that they may readily instruct inexperienced soldiers in all aspects of the perfect art of the military drill. Amsterdam, 1608) with the following description from Shiltey ha-Gibborym, 37b: "Do not forget to ascertain that each soldier carries a sword on his left thigh and a dagger on his right hip, in close proximity to the other weapons he is equipped with. Thus, for example, a musketeer (ha-nose ha-qesheth nehushah) should hold his musket (ha-qesheth) in his left hand, propped against his shoulder. The fork rest and the fuse should be in his right hand. Other small vessels should hang over his chest from a shoulder strap."

${ }^{16}$ In the Varsaw 1862 edition of the Perush 'al ha-Torah, pages 34v-37r.

${ }^{17}$ Ibid., 31v. This last comment was written in a period later than the previous. See Benzion Netanyahu, Don Isaac Abravanel: Statesman and Philosopher (Philadelphia: Jewish Publication Society, 1953, Hebrew trans. Jerusalem, 
2005), 186-192. For a global analysis of Abravanel and his thought, see Roland Goetschel, Isaac Abravanel: Conseiller des princes et philosophe (1437-1508) (Paris: Albin Michel, 1996).

${ }^{18}$ Cf. Abraham Melamed, "The Myth of Venice in Italian Renaissance Jewish Thought," in Italia Judaica. Atti del I Convegno internazionale, Bari, 18-22 May 1981 (Rome: P.U.G. di Roma, 1983), 401-413.

${ }^{19}$ This author will be discussed in detail in subsequent chapters.

${ }^{20}$ Cf. Guido Bartolucci, "Venezia nel pensiero politico rinascimentale: un testo ritrovato di David de Pomis," in Rinascimento, seconda serie, vol. XLIV (2004): 225-247.

${ }^{21}$ Bartolucci notes this difference in his article, and justly cites the entry melekh (king) in the important Tzemah David. Dittionario ebraico/italiano/latino by De Pomi (Venice, 1587).

${ }^{22}$ Bartolucci, "Venezia nel pensiero politico rinascimentale," 244.

${ }^{23}$ Tzemah David. Dittionario, $126 \mathrm{v}$.

${ }^{24}$ On S. Luzzatto, see Benjamin Ravid, Economics and Toleration in SeventeenthCentury Venice: The Background and Context of the Discorso of Simone Luzzatto (New York: H. Kraus, 1978) Abraham Melamed, "Simone Luzzatto on Tacitus: Apologetica and Ragione di Stato," in Studies in Medieval Jewish History and Literature, vol. 2, ed. Isidore Twersky (Cambridge, MA: Harvard University Press, 1984), 143-170; Giuseppe Veltri, "The City and the Ghetto: Simone Luzzatto and the Development of Jewish Political Thought," in his Renaissance Philosophy in Jewish Garb: Foundations and Challenges in Judaism on the Eve of Modernity (Leiden: Brill, 2009), 195-225; and Giuseppe Veltri, "Dannare l'universale per il particolare? Colpa individuale e pena collettiva nel pensiero di Rabbi Simone Luzzatto," Rassegna Mensile di Israele 77, n. 1-2 (2011): 65-81.

${ }^{25}$ Socrate overo dell'humano sapere (Venice, 1651).

${ }^{26}$ Cf., for example, Luzzatto's introduction to Yosef Shelomo Delmedigo's Sefer Elym (Amsterdam, 1629), an important book on philosophy, geometry, and astronomy, which rather stood out in the Hebrew canon: "My heart rejoices and my mind gloats over that wonderful knowledge; the mouths of those who look down upon us — saying that we lack science and wit—shall be sealed. Today, Greek and Roman scholars shall say: 'So they have the same minds as us, and have shown their true worth.' This text ought to be translated because it would bring us prestige. I pray to God in His dwelling-place that the author may be acknowledged and praised and that the knowledge of God spreads over the earth!"

${ }^{27}$ Avraham Melamed, "Simone Luzzatto on Tacitus: Apologetica and Ragione di Stato," 143-170. This argument had already been developed by Riccardo Bachi; cf. ibid., 156.

${ }^{28}$ Ibid. Luzzatto's defense against the accusations of superstition directed at the Jews takes on an extra dimension when one considers that this was the central charge leveled at the Jews by his contemporary, the Venetian Samuel Nahmias 
alias Giulio Morosini, a Jew who converted to Catholicism and was the author of Derekh Emunah. Via della fede mostrata a'gli ebrei (Roma, 1683). Cf. Discorso circa il stato de gl'hebrei, 66, and Derekh Emunah, 108 and passim.

${ }^{29}$ Ibid., 155.

${ }^{30}$ Discorso, 66a: "In much the same way, craftsmen work on leather, scouring it this way and that ("con il casuale stropiciamento"), stretching it, and softening it until it is ready to be handled and shaped."

31 Ibid.

32 Here, he quotes Curtius Rufus' Historiae Alexandri Magni: "Nulla res multitudinem efficacius regit, quam superstitio." Ibid., $67 \mathrm{~b}$.

${ }^{33}$ Ibid.

34 Niccolò Machiavelli, The Prince, chapter 18. The Prince, according to Machiavelli, must be capable of acting "like both the fox and the lion."

${ }^{35}$ On this question, see also Melamed, op. cit., 168.

${ }^{36}$ Discorso, 73a. Cf. Melamed, 169-170.

37 Discorso, 72b. Cf. Melamed, 167.

${ }^{38}$ Cf. for example, Abravanel's comment on Deuteronomy XVII, 14-20. See also Yosef Kaplan, "Political Concepts in the World of the Portuguese Jews of Amsterdam During the Seventeenth Century: The Problem of Exclusion and the Boundaries of Self-Identity," in Menasseh ben Israel and His World, ed. Yosef Kaplan, Henry Méchoulan, and Richard H. Popkin (Leiden: Brill, 1989); and Isaac Cardoso, Las excelencias y calunias de los Hebreos (Amsterdam, 1679); on the latter, see Yosef Hayim Yerushalmi, From Spanish Court to Italian Ghetto: Isaac Cardoso: A Study in Seventeenth-Century Marranism and Jewish Apologetics (Seattle: University of Washington Press, 1981).

39 René Girard, Des choses cachées depuis la fondation du monde (Paris: Grasset, 1978), 35. Quoted by Kaplan, 53. (Translated into English by Jean-Michel Oughourlian and Guy Lefort: Things Hidden Since the Foundation of the World [New York: Athlone, 1987], 95).

${ }^{40}$ See also chapter three: "De hebraeorum vocatione."

\section{5: A Link to Humanity:}

\section{Judaism as Nation and Universal Religion}

Pages 92-104

${ }^{1}$ Hebraic Political Studies 1, no. 1 (2005): 24-56. This journal is entirely dedicated to Jewish political thought. See also Abraham Melamed, Wisdom's Little Sister: Studies in Medieval and Renaissance Jewish Political Thought (Boston: Academic Studies Press, 2011); and Abraham Melamed, "Medieval and Renaissance Jewish Political Philosophy," in History of Jewish Philosophy, ed. Daniel H. Frank and Oliver Leaman (London: Routledge, 1997), vol. I, 
pp. 415-449. For a key work in this field see Michael Walzer, Menachem Lorberbaum, Noam J. Zohar, and Yair Lorberbaum, eds., The Jewish Political Tradition, 2 vols. (New Haven: Yale University Press, 2000-2003). Confirming interest in the subject, the American journal Association of Jewish Studies also dedicated its Fall 2006 issue to "Jewish Political Studies."

2 On this issue, see Lea Campos Boralevi, "Mitzvoth beneh Noah: il diritto noaico nel dibattito seicentesco sulla tolleranza," in La formazione storica della alterità. Studi di storia della tolleranza nell'età moderna offerti a Antonio Rotondo, ed. H. Méchoulan, E.H. Popkin, G. Ricuperati, and L. Simonutti (Olschki, Florence: Leo S. Olschki, 2001), 473-494, and Lea Campos Boralevi, "La Respublica hebraeorum nella tradizione olandese," in Politeia biblica 35, no. 3 (2003): 431463 (in an issue entirely devoted to "Political Thought").

${ }^{3}$ See Amnon Raz-Krakotzkin, "A National Colonial Theology: Religion, Orientalism and the Construction of the Secular in Zionist Discourse," in Tel Aviver Jahrbuch für Deutsche Geschichte 30 (2002): 312-326.

${ }^{4}$ Simone Luzzatto, Discorso circa il stato de gl'Hebrei, et in particolar dimoranti nell'inclita città di Venetia.

${ }^{5}$ But see the differing opinion in Giuseppe Veltri, "Ceremonial Law: History of a Philosophical-Political Concept," in Renaissance Philosophy in Jewish Garb, 169-194.

${ }^{6}$ On Luzzatto's Socrate see Giuseppe Veltri, "Principles of Jewish Skeptical Thought: The Case of Judah Moscato and Simone Luzzatto," in Rabbi Judah Moscato and the Jewish Intellectual World of Mantua in the $16^{\text {th }}-17^{\text {th }}$ Centuries, ed. Giuseppe Veltri and Gianfranco Miletto (Leiden: Brill, 2012), 15-36.

7 See Roberto Bonfil, "Changing Mentalities of Italian Jews Between the Periods of the Renaissance and the Baroque," in Italia XI (1994): 61-79. Significantly, there was a movement at the time advocating the translation of the Bible, as well as philosophical and literary works, from Hebrew into Italian-as opposed to Judeo-Italian. On this subject, see Alessandro Guetta, "La traduzione italiana cinquecentesca del Moreh nevukhim di Maimonide," in Percorsi di storia ebraica, ed. P. C. Ioly Zorattini (Udine, 2005), 281-303, and Alessandro Guetta, "Italian Translation of Hebrew Literature and Jewish Philosophy in the Renaissance" in Tov Elem: Memory, Community and Gender in Medieval and Early Modern Jewish Societies: Essays in Honor of Robert Bonfil, ed. E. Baumgarten, A. Raz Krakotzkin, and R. Weinstein (Jerusalem: Bialik Institute, 2011), 153-177.

${ }^{8}$ The poet and philosopher Mosheh of Rieti (1388-ca. 1465) used the same metaphor two centuries earlier, though to much more dramatic effect, in a text also written in Italian - or rather Umbrian: "Vidi un tempeštoso e terribil fjume, largo e profondo molto. Nascea appede de una città deserta. Lo cammino suo era longhissimo, e pjù perché rotava per salvatichi pagesi e girava nelle pjù štreme parti del mundo. Me parea quasi tornasse propio in quello lo', o vero poco da longa. 
Una nave, carica de donne e mammoli e pochi omini grandi, chi nudi e chi poco meno che nudi, se movea da la città deserta, tirava via verso el fine del fjume, ben che fosse lontano.

“... Nave nulla altra non se scontrao mai, ma per terra de là e de qua trovavano štranie genti che poco li antendeano; cercavano nogiarli, o tirarli a terra, o farli affocare." ("I saw a stormy, terrible river, very wide and deep. It sprung at the foot of a desert city, and its course was very long, winding through wild countryside in the most remote parts of the world. A ship loaded with women and children, and a few adult men, all more or less naked, jouneyed from the desert city to the distant end of the river... They never encountered other ships, but on either side of the river, there were strange people who barely understood them, and attempted either to drag them ashore or drown them.") (Mosè da Rieti, Filosofia naturale e fatti de Dio. Testo inedito del secolo XV, ed. Irene HijmansTromp (Leiden: Brill, 1989) 416-417. After this excerpt, the text takes a messianic turn: a youth that has become a wise man takes the wheel of the ship and firmly leads it to its destination, which was also its starting point. There, the people that had watched the ship wander unite for battle but they all get killed, "and that magnificent city remained the queen of the world." The city in question is Jerusalem, of course.

${ }^{9}$ Cfr. B. Ravid, Economics and Toleration in Seventeenth Century Venice.

${ }^{10}$ As we have already seen (in the chapter on "The Myth of Politics"), in his introduction to Shelomo Yosef Delmedigo's scientific text Sefer Elym (Amsterdam, 1629), Luzzatto expounded on the scientific abilities of contemporary Jews, declaring them ahead of their Christian counterparts, and suggesting that Delmedigo's book drew on a Latin tradition. The Venetian rabbi thus showed an implicit desire for cultural collaboration between Jews and Christians.

${ }^{11}$ See Yosef H. Yerushalmi, "Clio and the Jews: Reflections on Jewish Historiography in the Sixteenth Century," in Essential Papers on Jewish Culture in Renaissance and Baroque Italy, ed. David Ruderman (New York: New York University Press, 1992), 191-218; Robert Bonfil, "How Golden was the Age of the Renaissance in Jewish Historiography?," History and Theory 27 (1988): 78-102; and "Jewish Attitudes Toward History and Historical Writings in PreModern Times," Jewish History 11, no. 1 (1997): 7-40.

${ }_{12}$ This term invites caution, as it also refers to the local community. Nevertheless, the unification of the Jews from all over the world, whatever their particular customs, was an important part of what Luzzatto meant by it.

${ }^{13}$ A. Melamed, "Simone Luzzatto on Tacitus: Apologetica and Ragione di Stato," in Studies in Medieval Jewish History and Literature, ed. Isadore Twerski, 2.

${ }^{14}$ In the introduction to Sefer Elym (see note 10 and chapter 4 note 18), Luzzatto bemoaned the loss of the Jewish sciences that the author of the book was restoring. As well as rehearsing a notion of intellectual decadence that was a commonplace of Jewish literature, these words may be understood as denouncing 
the popularization of Kabbalah in many social spheres. In his introduction to the same book, Leone Modena was more explicit than his Venetian colleague, arguing that the so-called "ascetic wise men of Israel" only denounced scientific books in order to conceal their own ignorance.

${ }_{15}$ The word "modern" was in fact used by another proponent of this project: Leone Modena. See below, chapter 7.

${ }^{16}$ Baruch Spinoza, A Theological-Political Treatise, translated by R. H. M. Elwes (Rockville, MD: Arc Manor, 2008), 53.

${ }^{17}$ Ibid., 60 .

${ }^{18}$ See Gianfranco Miletto, "Die Bibel als Handbuch der Kriegskunst nach der Interpretation Portaleones," in An der Schwelle zur Moderne. Juden in der Renaissance, ed. Giuseppe Veltri and Annette Winkelmann (Leiden: Brill, 2001), 99-107.

${ }^{19}$ These three figures are linked, if not through personal acquaintance, at least through the references which were made to their respective works. Shiltey haGibborym (cf. Matzref la-Hokhmah, Odessa 1846, 16) was praised and commended by Delmedigo, although he was one of the rare Jewish authors to approve of the book, probably because of its composite character. As we have already noted, Luzzatto believed that Delmedigo's work was proof that the Jews were capable of science, and he wished to see it translated.

${ }^{20}$ De medico haebreo, 2.

${ }^{21}$ Ivi, 4.

${ }^{22}$ See Emilio Teza, "Delle operette minori di David De' Pomi," in Atti del R. Istituto di Scienze, Lettere ed Arti, Tomo VI, Serie VII (Venice, 1895), 965-984.

${ }^{23}$ Ivi, 14.

${ }^{24}$ Ivi, 40.

${ }^{25} \mathrm{Ivi}, 40$ e $65-66$.

${ }^{26}$ Ivi, 44, 66.

${ }^{27}$ Ivi, 54.

${ }^{28}$ The work of the Venetian Sara Copio Sullam (1588?-1641) constitutes an interesting evidence of universalistic religiosity without renouncing the Jewish particularity. In the following century, the poet Salomone Fiorentino (1743-1815) took up the same stance of fidelity to one's original culture and spiritual adhesion to a non-confessional religiosity. See chapter "The Immortality of the Soul."

${ }^{29}$ Ivi, 52.

${ }^{30}$ Published in Venice in 1572.

${ }^{31}$ L'Ecclesiaste di Salomone. Nuovamente dal testo hebreo tradotto e secondo il vero senso nel volgar idioma dichiarato (Venice, 1571).

${ }^{32}$ Leone Modena, Historia de' riti ebraici (Paris, 1637).

${ }^{33}$ See chapter "Leone Modena's Magen we-herev as an Anti-Catholic Apologia"; Talya Fishman, "Changing Early Modern Jewish Discourse about Christianity: The Efforts of Rabbi Leon Modena," in The Lion Shall Roar: Leon Modena 
and His World (Italia, Conference Supplement Series, 1), ed. R. Bonfil and D. Malkiel (Jerusalem: Magnes, 2003), 159-194.

${ }^{34}$ Leone Modena, Py ha-Ariyeh (Venice, 1640) (Hebrew-Italian Biblical dictionary), introduction: “... The method of ancient interpretation in use among us is at present awkward and devoid of grace ... and that is why I believe we need the light of a modern interpretation." See Umberto Cassuto, "Saggi delle antiche traduzioni giudeo-italiane della Bibbia," Annuario di studi ebraici 1 (1934): 101-132.

35 See Talya Fishman, Shaking the Pillars of Exile: "Voice of a Fool": An Early Modern Jewish Critique of Rabbinic Culture (Stanford: Stanford University Press, 1997).

36 There is an abundant bibliography on this question. See Roberto Bonfil, "Lo spazio culturale degli ebrei d'Italia fra Rinascimento ed Età barocca," in Storia d'Italia. Annali 11: Gli ebrei in Italia, t. I: Dall'alto Medioevo all'età dei ghetti, ed. Corrado Vivanti (Turin: Einaudi, 1996), 433-441. On the relative "modernity" of Kabbalah in Italy, see A. Guetta, "L'Italia e la 'via ebraica alla modernità'," in David Bidussa (a cura di), Ebraismo, vol II by Giovanni Filoramo (a cura di), Le religioni e il mondo moderno (Turin: Einaudi, 2008), 5-24.

${ }^{37}$ Cf.. Yeshayahu Tishby, "Ha-pulmus 'al sefer ha-Zohar ba-meah ha-shesh-'esreh be-Italiyah," in Perakim: Yearbook of the Schocken Institute for Jewish Research of the Jewish Theological Seminary, 1967-68, pp. 131-192.

38 Although Modena wrote an anti-kabbalistic work around 1640, it was only published two centuries later, as Ary nohem ("A lion roaring”), in Leipzig in 1840. See Yaacob Dweck, The Scandal of Kabbalah: Leon Modena, Jewish Mysticism, Early Modern Venice (Princeton: Princeton University Press, 2011).

39 On this issue, see David Ruderman, Jewish Thought and Scientific Discovery in Early Modern Europe (New Haven: Yale University Press, 1995), 213-228, in particular its chapter on "Kabbalah and Rationalism."

\section{6: The Italian and Latin Works of Lazzaro da Viterbo, Sixteenth-Century Jewish Humanist \\ Pages 105-133}

${ }^{1}$ David Kaufmann, “Lazarus de Viterbo's Epistle to Cardinal Sirleto concerning the Integrity of the Text of the Hebrew Bible," The Jewish Quarterly Review 7, no. 2 (1895): 278-296.

${ }^{2}$ François Secret, ed., "Le Tractatus de Anno Jubilaei de Lazaro de Viterbo, Grégoire XIII et la Kabbale chrétienne," Rinascimento 17 (December 1966): 305-333.

${ }^{3}$ Lazzaro's teshuvah, written in 1578, figures in a responsa manuscript by Italian rabbis: see Mosè Giacomo Montefiore, "Un recueil de consultations rabbiniques 
rédigé en Italie au XVIIe siècle," in Revue des études juives 10 (1885): 185. Paul Rieger (Geschichte der Juden in Rom, zweiter Band 1420-1870 [Berlin: 1895], 262-264) attributes another responsum to him, this one printed in Mashbyth milhamoth ("He who makes the battles cease," [Venice, 1606], ff. 91b-92a), which, however, is signed "Hamul Matzliah Kohen son of Gaon, Rabbi Yitzhaq Kohen da Viterbo." This would indicate that the author is the nephew of Lazzaro (his brother's son). Therefore, Rieger's description of Lazzaro/Eli'ezer as "a very important Roman Jewish jurist" ("Halachist"), erroneously based on this responsum, does not seem justified. According to Rieger, Lazzaro had been "fattore," or lay leader, of the Roman Jewish community as of 1570. The rabbinical title also derived from two legal documents published by Kenneth R. Stow in The Jews in Rome, vol. 2 (Boston: Brill, 1996), 562 and 570, in which "ha-aluf Rabbi Eli“ezer Matzliah ha-Kohen ben Avraham Kohen mi-Viterbo" is named as arbiter of a dispute been the Sicilian Scola and the Scola Nova of the Roman Jewish community.

${ }^{4}$ On the medical title, see note 6. Lazzaro had previously lived, from 1549 to 1556 , in Amelia, a town between Umbria and Lazio, where he was one of the owners of the local lending bank. See Michele Luzzati, Le Famiglie de Pomis da Spoleto e Cohen da Viterbo e l'emigrazione ebraica verso la Toscana meridionale nella seconda metà del Cinquecento, at http://www.consultacultura.org/santa_fiora/ storia/gli\%20ebrei.htm. Lazzaro was probably the son-in-law of the famous doctor, exegete, and philosopher 'Ovadiyah (Servadio) Sforno (1475-1550); see Michele Procaccia, "Non daberà': gli ebrei di Roma nei primi cinquanta anni del '500 attraverso le fonti giudiziarie," in Italia Judaica. Gli ebrei nello Stato pontificio fino al Ghetto (1555). Atti del VI Convegno internazionale, Tel Aviv, 18-22 June 1995 (Rome: Ministero per i Beni Culturali e Ambientali, 1998), 8093. On his kinship with David de Pomi, see note 6. For other information, see Jewish Encyclopedia, 1906, sub voce. However, the claim that Eli'ezer/Lazzaro can be identified with Theodorus de Sacerdotibus, appointed personal physician to Pope Julius III in June of 1550 (cf. Simonsohn, The Apostolic See, VI, doc. 2924), appears to be unfounded. The name Theodorus does not correspond to the Hebrew Eli'ezer (possibly to Nethanel), and Eli'ezer ha-Kohen mi-Viterbo had a Latin/Italian name, Lazzaro/Lazarus. The Theodorus de Sacerdotibus who was the Pope's doctor is probably the same doctor who was in Genoa and other places in the Republic of Genoa from 1538 to 1548; cf. Rossana Urbani and Guido Nathan Zazzu, The Jews in Genoa, vol. I (Leiden: Brill, 1999), doc. 258 et seq. The Jews were expelled from Genoa in April of 1550; Theodorus had to move to Rome and was immediately called into the service of the Pope.

5 Allatino, native of Spoleto, is the author of the Latin translation of the Hebrew version of Themistius's paraphrases of Aristotle's De caelo: Paraphrasis in libros IV Aristotelis (Venice: Galignano, 1574); reprinted in Samuel Landauer, ed., 
Themistii in libros Aristotelis De Caelo paraphrasis hebraice et latine (Berlin: Reimer, 1902). Another of his translations, the second part of Avicenna's Canon, is lost. He lived in Ferrara. (For the last two points, see Tzemah David, next note).

${ }^{6}$ De Pomi (born in 1525, also in Spoleto) wrote various essays in Latin and Italian, as well as a translation of Ecclesiastes that has survived and translations of other books of the Bible, which were never published and are now lost, and an important Hebrew-Italian-Latin dictionary, Tzemah David (1587). In the brief autobiography in the Hebrew introduction to the Tzemah David, reference is made to a kinship with Lazzaro, who is called hakham we-rofe muvhaq (wise and excellent doctor), and to Lazzaro's brother, Rabbi Yizhaq da Viterbo "sublime sage (gaon) and great philosopher." In the same introduction, De Pomi cites Mosè Allatino ("excellent philosopher and doctor") as stepbrother of his teacher of logic, Yehyiel Rehavia, in the city of Todi.

7 The Mantuan Sommo (1527-1592) was a prolific playwright and author of a treatise in Italian on the art of theater. He also translated a part of the book of Psalms into Italian. He composed various poems in Hebrew and wrote the play Tzahuth bedihuta de-Kiddushin.

${ }^{8}$ De' Rossi (c. 1513-1578, born in Mantua and subsequently living in Ferrara) referred extensively to Latin sources for his magnum opus, Meor 'eiynayim, which also includes a Hebrew translation of the Latin version of the Letter to Aristeas. He also wrote a brief treatise in Italian on the language of the Gospel, published in 2005 by Joanna Weinberg as Azariah de' Rossi's Observation on the Syriac New Testament: A Critique of the Vulgate by a Sixteenth-Century Jew (London: Warburg Institute, 2005).

${ }^{9}$ In 1584, Portaleone published De auro dialogi tres, which displays the knowledge and attitude of a humanist scientist critical of the medieval tradition. In the Hebrew volume Shiltey ha-Gibborym, published in 1612, Portaleone uses a great many Greek and Latin sources and terms, which he often cites in the original language, but transliterated into Hebrew. He also edited the Consilia medica, a collection of scientific manuscripts in Italian and Latin.

${ }^{10}$ Lazarus de Viterbo's Epistle to Cardinal Sirleto, 278.

${ }^{11}$ For a general recognition, see Moses A. Shulvass, "The Knowledge of Antiquity among the Italian Jews of the Renaissance," in the Proceedings of the American Association of Jewish Research 18 (1948-49): 291-299. See also Giuseppe Veltri, Renaissance Philosophy in Jewish Garb (Leiden: Brill, 2009).

12 On the importance of Dante among Italian Jews see Asher Salah, "A Matter of Quotation: Dante and the Literary Identity of Jews in Italy," The Italia Judaica Jubilee Conference, ed. Sh. Simonsohn, J. Shatzmiller (Leiden: Brill, 2013), 167-197.

13 On Mosheh da Rieti, see previous chapters. 
14 Two of these translations are in Hebrew characters:

1) Shemuel da Castelnuovo, Me'on ha-shoalym (Venice: Giovanni De Gara, 1609). Shemuel had been one the leading rabbis in Rome starting in 1620. See Andrea Yaakov Lattes, Una società dentro le mura. La comunità ebraica di Roma nel Seicento, forthcoming, passim.

2) Anonymous, manuscript preserved at the Bodleian Library at Oxford, MS Michael 11 ff. 13r-32r, Jerusalem Microfilm F 19150. This last translation (prior to 1554, the year it was submitted to censorship) appears in four other manuscripts, two in Hebrew characters and two in Italian characters, with some variants that likely attest to an evolution toward literary Italian: Rome, Biblioteca Casanatense 2728, ff. 35r-42v, Jerusalem Microfilm F25G; Milan, Biblioteca Ambrosiana X157 Sup, Jerusalem Microfilm F18669, ff. 56v77r; Cambridge, Trinity College ff.12-41, Jerusalem Microfilm F12226; and Florence, Medicea Laurenziana Plut. II. 29, Jerusalem Microfilm 17669, ff. $1 \mathrm{r}-6 \mathrm{v}$ (this last is a codex that contains the Hebrew text and the Italian translation of Keter malkhuth and the beginning of the Ke'arath kesef; see note 16).

In Italian characters, and both printed, are:

3) Eli‘ezer Matzliạ ben Avraham Kohen (Lazzaro da Viterbo), Me'on haShoalym (Venice: Giovanni De Gara, c. 1585), date attributed by Steinschneider in his Catalog of Manuscripts in the Bodleian Library of Oxford (Berlin 1852-1860 col. 1987);

4) Debora Ascarelli, Me'on ha-Shoalym (Venice: Daniel Zanetti, 1602). (A re-transcription in Hebrew characters was done by Yehuda Hayyim Carpi di Casale Monferrato, in the collection of Hebrew texts in the translation he did at Rivalta in 1612: manuscript preserved in Moscow at the Russian State Library, MS Guenzburg 669, Jerusalem Microfilm F47961, ff. 127r-141v).

On these translations, see Moritz Steinschneider, "Die italienische Litteratur der Juden," in Monatschrift für Geschichte und Wissenschaft des Judentums 2 (1898): 91-93.

15 Of about fifty complete or partial manuscripts of Miqdash me 'at reviewed by the Institute of Microfilmed Hebrew Manuscripts at the National Library of Jerusalem, about a dozen present only this chapter, copied from the early decades of the sixteenth century (a copy made by Azariyah de' Rossi in 1531 is particularly significant) until the seventeenth century (presumably in the early decades as well).

${ }^{16}$ In a manuscript preserved by the Magyar Tudomanyos Akademia of Budapest, MS Kaufmann A 428 (The Institute of Microfilmed Hebrew Manuscripts F 15810), the Me'on ha-shoalym appears in the same codex with the Keter malkhuth of Shelomo Ibn Gabirol (Andalusia, eleventh century), the Ke 'arath kesef 
of Yosef Ezobi (Provence, thirteenth century), and other penitential compositions. Furthermore, Lazzaro da Viterbo, in his Hebrew dedication [see infra] identifies the text as a "powerful prayer [noraah], a psalm of thanksgiving, a confession for the terrible day [an allusion to Kippur] that purifies [ha-malbyn] the sins of Israel."

${ }^{17}$ Lazzaro's text presents none of the formal defects visible in other versions, which are, however, faithful and relatively fluent, especially when one considers the difficulty of translating such a long text in rhyme: 1) the hendecasyllable is always maintained; he does not do as other authors do (though rarely) by using verses of ten (Ascarelli: "S'altro onor dispregi esser beato") or twelve syllables (Ascarelli: "Unite nei gradi lor alte, e supreme," Castelnovo: “ché l'error mio nissun termine comparte"), or even thirteen (Ascarelli: "Perdona, perdona ohimé Signor clemente," Castelnovo: "E scrivirò sul libro e sopre il cor che serra"); 2) The rhythmic accents always respect the semantics of the verse (while in Ascarelli we see: "Poi ch'il peccato non I merta perdono") or the tonic accent of the word (Ascarelli: "Porgemi, e fammi fe-I-lice vedere"); 3) the anaphoras of the Hebrew text are partially maintained in the translation.

18 Tractatus, 309, Psalm 110: "Principium sapientiae est timor Domini."

19 Ibid., 318: "The Hebrew scholars say that in another time, there will be no food or drink, but the just will be seated with a crown on their heads, feeding on divine beauty and making use of the wisdom of God," reference to Talmud Bavly, Berahoth 17a, taken up by Maimonides in Commentary to the Mishnah, introduction to the Sanhedrin treatise (Pereq heleq) and Mishneh Torah, Hilkhoth Teshuva 8:2. The explicit reference to the Talmud, which was forbidden at that time, is interesting in itself.

${ }^{20}$ Ibid., "Pietas nihil aliud est quam Dei notio."

21 Tractatus, 316.

22 Ibid.

${ }^{23}$ Ibid., 323. See also 328: "If by the grace of God the veil of the body will be lifted, and the light of knowledge will shine above us, we will make use of its wisdom, which is none other than the joining in pleasure, and remaining in it."

${ }^{24}$ Ibid., 329.

25 On 326, Lazzaro criticizes Aristotle, who "did not understand or did not want to understand" the meaning of certain statements of Parmenides and Melissus, which were in his opinion close to the rabbinical conception of God as beginning, middle, and end of each thing.

${ }^{26}$ Direct or indirect citations by Maimonides are on 312 and 318. On 317, Lazzaro refers to biblical metaphors relating to God, taking them up again without citing the sources of the passages from the first part of the Guide.

27 For the first, see 314 and 315 on the properties of the number seven; for the second, see 313 on the meaning of the word yovel. 
28318.

29321 .

30 Another rabbinical interpretation on the piercing of the ears of slaves who reject freedom (Talmud Bavly Kiddushin 22b) is introduced by a statement of Plato based on the "authority of Homer." See 324.

31 Tractatus, 330.

32 De doctrina christiana, De fide et symbolo, In expositione Psalmi 92, Epistolae, De gratia et libero arbitrio, Enchiridion.

33 Tractatus, 330-331.

${ }^{34}$ For example, the importance of the number fifty in the Bible, 322; the identification between the attribute of sefyrah Bynah (equivalent to Jubilee), and the "requies aeterna" and "pietas absoluta," 321 and 322; and the idea that the Hebrew letters are the "simulacrum sublimis sapientiae per quam creata sunt omnia," 325. In this regard François Secret cites Johannes Reuchlin, Paulus Ricius, Egidio da Viterbo, and Francesco Zorzi, as well as Guillaume Postel. Lazzaro da Viterbo possessed a manuscript of ancient kabbalistic texts, now preserved at the Vatican Library (Hebrew 505).

${ }^{35}$ Manuscript from the Vatican Apostolic Library, Boncompagni, F, 32, folio 209 $\mathrm{V}$ (thanks to Michela Torbidoni, who allowed me to obtain a reproduction of the manuscript). For the graphic transposition of psalm 67 (66 in the Catholic Bible), into the shape of the Menorah, common among all Jewish communities, associated in some cases with kabbalistic considerations, and going back to at least the fourteenth century, see Esther Juhasz, The Shiviti-Menorah: A Representation of the Sacred-Between Spirit and Matter, PhD thesis, Jewish University of Jerusalem, 2004, and Shubert Spero, "The Menorah Psalm," in Jewish Bible Quarterly 33, no. 1 (2009): 11-17. For the same transposition of the Latin text of the psalm among Christian scholars of Judaism, see Anthony Grafton and Joanna Weinberg, I Have Always Loved The Holy Tongue: Isaac Casaubon, The Jews, and a Forgotten Chapter in Renaissance Scholarship (Cambridge, MA: Harvard University Press, 2011), 84.

36314 , on the divine attributes in 1 Chronicles 29 and in Revelation 7:12;320 on the remission of sins according to the Torah and the famous formula in Matthew (6:12) "Dimitte nobis debita nostra, sicut et nos dimittimus debitoribus nostris"; 332 on the seven prayers of the Sunday oration inspired by Matthew.

37 Tractatus 324.

${ }^{38}$ Kenneth R. Stow, The Jews in Rome, passim.

${ }^{39}$ Kenneth. R. Stow, "A Tale of Uncertainties: Converts in the Roman Ghetto," in Shlomo Simonsohn Jubilee Volume, ed. D. Carpi et al (Tel Aviv: Tel Aviv University Press, 1993), 257-281, reproduced in his Jewish Life in Early Modern Rome: Challenge, Conversion and Private Life (Hampshire: Ashgate, Variorum, 2007). The reference to this episode is on p. 265. Caffiero 269 note 2. Medici 
catalogo de' neofiti, 53-59. On the conversion of Salomone Corcos and his son Lazzaro in 1572, see Paolo Sebastiano Medici, Catalogo de' neofiti illustri (Florence, 1701), 53-57. Salomone and Lazzaro, who became respectively Ugo and Gregorio, attained high-level positions and honors, for themselves and their descendants. See also Marina Caffiero, Legami pericolosi: Ebrei e cristiani tra eresia, libri proibiti e stregoneria (Rome: Einaudi, 2012), passim.

${ }^{40}$ On Sirleto and the Jews, see Ch. Dejob, "Documents tirés des papiers du cardinal Sirleto," Revue des etudes juives 9 (1884): 77-91; Kenneth R. Stow, "The Burning of the Talmud in 1553, in the Light of Sixteenth Century Catholic Attitudes towards the Talmud," Bibliothèque d'Humanisme et Renaissance 34 (1972): 435-459, reproduced with updates in Stow, Jewish Life. Sirleto's name is also connected to an index of the most severely prohibited books issued by the Congregazione dell'Indice, of which he was President starting in 1571. See Gigliola Fragnito, La Bibbia al rogo (Bologna: Il Mulino, 1997), 116-121.

${ }^{41}$ The other authors recalled were Pythagoras, Hermes Trismegistus, Homer, Hippocrates, Seneca, Justinian, Averroes, and Ficino.

42 The author translates leshon ha-qodesh very precisely with "lingua sanctitatis" (Lazarus de Viterbo's Epistle, 284). Lazzaro, like all Jewish and Christian writers of the time, considers Hebrew the language of creation, of consequence, one that has a "natural" and not conventional relationship with things.

${ }^{43}$ Ibid., 287: "An hoc sit verum nec ne, tanquam manifestissimum aliorum iudicio relinquo."

44 Ibid., "By their own fault they are oppressed everywhere."

45 Talmud Bavly Yoma 9b.

46 294. I was unable to find this statement of Thomas Aquinas. The phrase was coined by Jerome, who refers to the apostle Paul as "vas electionis," or "great expert on Law and Scripture" (Acts 9:15). See Jerome, Epistle 3:53.

${ }^{47}$ Christian commentators and translators read the Hebrew ka-ary (like a lion) as karu (they pierced [the hands and feet]).

48 Jeremiah 23:6, on the name of the Messiah and on those who attribute this name to him.

49 Elia Levita also uses the wording masera. See following notes.

${ }^{50}$ Lazarus de Viterbo's Epistle, 289.

${ }^{51}$ Masoreth ha-masoreth (Venice: Bomberg, 1538). The position of Elia Levita on the dating of the vowel points and singing/chanting tones is enunciated in the first and the third introduction, on 5 and 20-30 respectively.

52 "Divrey emeth nikkarym," Masoreth ha-masoreth, 3.

53 See A. de' Rossi, Sefer meor 'eynayim, English translation by Joanna Weinberg, The Light of the Eyes, 699-709.

${ }^{54}$ In 1620, Johannes Buxtorf published Tiberias, sive Commentarius Masoreticus, in which he criticized Levita's conclusions. His son, Johannes Buxtorf II, confirmed his father's thesis in an argument with Louis Cappel. On these discussions, 
see Gérard F. Weil, Elie Lévita humaniste et massorète (1469-1549) (Leiden: Brill, 1963), 286-343, and Stephen G. Burnett, From Christian Hebraism to Jewish Studies: Johannes Buxtorf (1564-1629) and Hebrew Learning in the Seventeenth Century (Leiden: Brill, 1996), 203-239.

${ }^{55}$ On this subject, see A. Guetta, "The Crisis of Medieval Knowledge in the Work of the Fifteenth-Century Poet and Philosopher Moses da Rieti," in Renewing the Past, Reconfiguring Jewish Culture: From al-Andalus to the Haskalah, ed. Ross Brann and Adam Sutcliffe (Philadelphia: University of Pennsylvania Press, 2004), 59-68.

56 This passage was certainly inspired by a religious poem (a "request," baqqashah) by Sa'adiyah Gaon (ninth to tenth centuries). See I. Davidson, S. Assaf, and B. I. Joel, eds., Siddur R. Saadja Gaon (Jerusalem: Mekize Nirdamim, 1941), 64-81.

${ }^{57}$ In the text: filla.

${ }^{58}$ In the text: Tarando.

59 In the text: Del.

${ }^{60}$ In the text: darvi.

${ }^{61}$ In the text: ci.

62 Proposed addition in the text.

${ }^{63}$ In the text: $\mathrm{i}$.

\section{7: Leone Modena's Magen we-herev as an Anti-Catholic Apologia}

\section{Pages 134-152}

${ }^{1}$ See Daniel J. Lasker, Jewish Philosophical Polemics against Christianity in the Middle Ages (New York: Ktav, 1977); Idem, "Jewish Anti-Christian Polemics in the Early Modern Period: Change or Continuity?," in Tradition, Heterodoxy and Religious Culture: Judaism and Christianity in the Early Modern Period, ed. Chanita Goodblatt and Howard Kreisel (Beer Sheva: Ben-Gurion University of the Negev, 2007), 469-88; David Berger, "On the Use of History in Medieval Jewish Polemic against Christianity: The Quest for the Historical Jesus," in Jewish History and Jewish Memory: Essays in Honor of Yosef Hayim Yerushalmi, ed. Elisheva Carlebach et al. (Hanover, NH: Brandeis University Press, 1998), 25-39.

${ }^{2}$ Cf. note by Modena's nephew Yitzhaq min ha-Levyyim in the margin of his copy of Magen we-herev (in Abraham Geiger, Leon da Modena Rabbiner zu Venedig [1571-1648] [Breslau: 1856], 11a): "He [Modena] had the idea of writing this book five years before his death. [ ... ] He took note of the opinions of all their most important scholars so as to answer them by striking them with their own sword, thus bringing true the verse (Psalms 37:15) 'Their sword shall enter into their own heart."” 
${ }^{3}$ On Magen ve-Zinnah see the French translation, with an excellent introduction by Jean-Pierre Osier, Le Bouclier et la Targe (Paris, 1980), republished in his D’Uriel da Costa à Spinoza (Paris, 1983).

${ }^{4}$ Magen we-herev: hibbur neged ha-Natzruth meeth Yehudah Ariyeh mi-Modena (Latin title, Clipeus et gladius. Leonis Mutinensis tractatus antichristianus) (Jerusalem, 1960). The words "Magen we-herev" are a quotation from Psalms 76:4 and 1 Chronicles 5:18. A doctoral thesis on the work is Lou Silberman, The Magen wa-herev of R. Judah Aryeh of Modena, D. H. L. Thesis, Hebrew Union College, 1943. English translation: A Translation of the Magen We-Hereb by Leon Modena, translated by Allan Howard Podet (Lewiston-QueenstonLampeter: The Edwin Mellen Press, 2001).

5 Magen, 42.

6 Ibid., 44.

7 Ibid., 46.

${ }^{8}$ Ibid., Introduction, p.3.

9 The historical reconstitution of the life of Jesus aside, for which Modena recognised (ibid. 43) he had "formulated an interpretative framework" (hotzety klal).

${ }^{10}$ De arcanis catholicae veritatis was first published by Soncino in Ortona in 1518. At least another six editions were catalogued between 1550 and 1672, published in Basel, Paris, and Frankfurt. On this subject, see Arduino Kleinhans, O.F.M., "De vita et operibus Petri Galatini, O.F.M., Scientiarum Biblicarum cultoris (c. 1460-1540)" Antonianum, Periodicum Philosophico-Theologicum, Annus I Tomus I (1926): 145-179 and 327-356. The reference to the editions is on 174. I have quoted the Basel edition of 1550.

${ }^{11}$ Howard Adelman, "Rabbi Leon Modena and the Christian Kabbalists", in Renaissance Rereadings: Intertext and Context, ed. M. C. Horovitz, A. C. Cruz, and Wendy A. Furman (Urbana: University of Illinois Press, 1988), 271-286.

12 Magen, 51. See also ibid., 11. In fact Galatino had drawn freely on Raimondo Martini's Pugio fidei, though Modena could not have been aware of it, since the work was published for the first time in 1651. Iohannes Benedictus Carpzovius, in his edition of Pugio fidei (Lipsie 1687), drew up an index of the passages Galatino had borrowed from Martini.

${ }^{13}$ De arcanis, caput VII.

14 Ibid., Caput VI, p. 20.

15 Ibid., Prefatio autoris.

16 Ibid., 50 and 196.

${ }_{17}$ These manuscript texts were described by Kleinhans, 157-15 and 164, and analysed in Anna Morisi, "Galatino et la Kabbale chrétienne," in Kabbalistes chrétiens. Cahiers de l'Hermétisme (Paris: Albin Michel, 1979), 213-231. See also Roberto Rusconi, Profezia e profeti alla fine del Medioevo (Rome: Viella, 1999) (especially pages 212-221 and 265-294, with bibliography) and Kenneth R. Stow, "The Burning of the Talmud in 1553," in Essential Papers on Judaism and 
Christianity in Conflict: From Late Antiquity to Reformation, ed. Jeremy Cohen (New York: New York University Press, 1991), 401-428.

${ }^{18} \mathrm{Cf}$. Morisi, 217 and 219.

19 De arcanis, caput VI, p. 21.

${ }^{20}$ Cf., e. g., François Secret, Les Kabbalistes Chrétiens de la Renaissance, new ed., 1985, passim and esp. 102-106. Cf. also Encyclopaedia Judaica, sub voce Galatino, Pietro. On the importance of Kabbalah in the work of Galatino, see Rusconi, Profezia e profeti, 271-272. Galatino considered authentic Gale Rezayah and Iggereth ha-Sodoth, the two Kabbalist texts written by the Aragonese Paul de Heredia. Cf. A. Freimann, "Paulus de Heredia als Verfasser der Kabbalistischen Schriften Igeret ha-Sodot und Galie Raze," in Festschrift Jakob Guttman (Leipzig, Fock, 1915), 206-209, and Gershom Scholem, "Zur Geschichte der Anfänge der christlichen Kabbala," in Essays Presented to Leo Baeck (London: East and West Library, 1954), 158. Modena had already denied the authenticity of these two texts, basing his opinion on textual and logical arguments. Cf. Magen we-herev, 51.

${ }^{21}$ Ibid., 9, where the opinion of the Talmudic scholars is mentioned after the rational proofs, on the subject of the repentance of Adam: "And I say that not to offer a proof against the Christians using the affirmations of our masters, but because the notion is correct from any point of view"; 65: "In this work my intention is not to explain the verses used against us, with a few exceptions, nor a fortiori [to explain] the affirmations of our masters."

${ }^{22}$ Ibid., 23. The affirmation is to be found in the chapter contesting the conceivability of the Trinity, defined by Modena as "fundamental" ( iqaryth) because in it he states the criteria that, in his opinion, should decide the truth of religious dogma. On this idea see Yosef Albo, Sefer ha- 'iqqarym III, 25, 3 and Eliyah Del Medigo, Sefer Behynath ha-dath, ed. and trans. Jacob J. Ross, 77.

23 This figure, naturally, is an exaggeration. It demonstrates, however, how an Italian Jew saw the world in the era of geographic discoveries.

24 Ibid., 18.

25 Ibid., 14.

${ }^{26}$ Modena's terminology would appear to be not entirely religious. Sometimes he uses the term tziyyur to denote the imagination (p. 21, criticizing Christian "inventions") and sometimes to denote the concept (p. 22, defining the thinkable object).

27 Ibid., 21-22.

${ }^{28}$ Ibid., 22. Modena's text is a paraphrase which summarises the three relevant passages of Maimonides which referred to men who mechanically repeat beliefs with no adequate intellectual representation, whom he contrasts with the philosophers; his concern is thus with the dichotomy between philosophers and non-philosophers. Modena was closer to Albo in his religious polemical logic. 
29 Ibid., 16-17.

30 Ibid., 13.

${ }^{31}$ Ibid., 14.

32 For an outstanding bibliography of the religious polemic of the Middle Ages, see Hanne Trautner-Kromann, Shield and Sword: Jewish Polemics against Christianity and the Christians in France and Spain from 1100-1500 (Tübingen: Mohr-Siebeck, 1993), 201-208.

${ }^{3}$ Cf. "The dispute between Nahmanides and Pablo Christiani (1263)," in Kitvey Ramban, vol. 1, ed. David Chavel (Jerusalem: Mosad Harav Kook, 1963), 299320: "My soul is as alike to that of my first ancestor as to that of Pharaoh; and Pharaoh's sins do not condemn my soul to hell. The punishment for the sin of the first man was corporal, for my body does come from my father and mother." Modena was familiar with the text of this dispute; cf. Magen, 69; Hasdai Crescas, Maamar be-Vittul 'Iqqarey Dath ha-Notzrym (A Treatise on Negation of the Foundations of the Christian Religion, trans. Yosef ben Shem Tov in 1451) in Judah David Eisenstein, 'Otzar Wiqquhym (A Collection of Polemics and Disputations) (New York, 1928), 298; Yitzḥak ben Avraham Troki, Sefer Hizzuq haEmunah (ed. David Deutsch, Befestigung im Glauben) (Sohran-Breslau, 1873), 88. On religious controversy after Modena, cf. Yair ben Shabbetay da Correggio, Herev Pifiyoth (ed. Judah Rosenthal, A Two-Edged Sword) (Jerusalem: Mosad Harav Kook, 1958), 97.

${ }^{34}$ On this question in rabbinical literature, see Israël Lévi, "Le péché originel dans les anciennes sources juives," in École pratique des hautes etudes, Section sciences religieuses (Paris, 1907), 1-28; Ephraim E. Urbach, The Sages, Their Concepts and Beliefs (Jerusalem: Magnes Press, 1975), ch. XV.

35 Y. Troki mentioned Ambrose (Hizzuq ha-Emunah, 91), but only to correct the Greek text of the Gospels.

${ }^{36}$ Magen, 10.

37 Thomas Aquinas, Summa Theologica, Primae secundae, quaestio LXXXI, articulus I., in Sancti Thomae Aquinatis, Opera omnia, vol. VI (Rome: 1891), 87-88: "Omnes homines qui nascuntur ex Adam, possunt considerari ut unus homo, inquantum in natura, quam a primo parente accipiunt." Modena's position can also be seen in the context of the debate on the transmission of the soul, and therefore of the original sin, by way of carnal generation. Luther and Calvin diverged on that issue; Calvin strongly opposed the notion.

38 Magen, 11.

39 De arcanis, caput V, 445 and following.

${ }^{40}$ Cf. Cecil Roth, "Leone da Modena and the Christian Hebraists of his age," in his Studies in Books and Booklore (Fornborough: Gregg Publishing, 1972), 200. See also Modena's own declaration in the same letter (ibid., 201): "1 corpi si hanno da lui [Adamo] con quelle maledittione e difficoltà al ben operare che per 
il peccato furono causate nel suo, come corpi originati dal suo corpo, ma l'anima non mai sia stata dannata né impedita per il suo peccato essendo da Dio immediatamente infusa nella creatione."

${ }^{41}$ Magen, 42.

${ }^{42}$ The book was first published in London in 1619, under the pseudonym of Pietro Soave Polano, and went through a number of editions. I cite the following edition: Paolo Sarpi, Istoria del concilio tridentino, ed. Corrado Vivanti (Turin: Einaudi, 1974). The discussion of original sin is on pages 292-307.

${ }^{43}$ Istoria, 294. The formula approved by the Council was the following: "If a person maintains that $[\ldots]$ only death and bodily suffering were communicated and passed on to all humankind by Adam and not the sin which is the death of the soul, that person shall be anathema [...]." In Carl Joseph Hefele, Histoire des Conciles, vol. X: A. Michel, Les décrets du Concile de Trente (Paris, 1938), 48.

${ }^{44}$ The idea that original sin was more an illness than a perversion had been formulated by Ulrich Zwingli. Cf. U. Zwingli, De peccato originale, in Opera, eds. M. Schuller and L. Schultes (Zurich, 1822-1842), vol. III, p. 629.

${ }^{45}$ For the Jewish attitude to Protestantism, see Hayyim Ben-Sasson, "Ha-Yehudim mul ha-Reformatziyah" (The Reformation in Contemporary Jewish Eyes), Proceedings of the Israel Academy of Sciences and Humanities 4, no. 5 (1970): 62-116, and Roberto Bonfil, "Gli ebrei d'Italia e la riforma: una questione da riconsiderare," Nouvelles de la Republique des lettres 2 (1996): 47-60, which corrects the theories of Ben-Sasson.

${ }^{46}$ On the beginnings of criticism of the Trinity in the modern period - in Spain in particular, namely Erasmianism and the works of Juan de Valdès and Miguel Servet - as well as its propinquity to the culture of the "new Christians," see Richard H. Popkin, "Marranos, New Christians and the Beginnings of Modern Anti-Trinitarianism," in Dor gerushey Sefarad, ed. Yom Tov Assis and Yosef Kaplan (Jerusalem: Zalman Shazar Center for Jewish History, 1999), 143-160 of the English section.

${ }^{47}$ The Guide of the Perplexed I:6.

${ }^{48}$ Magen, 26. Modena draws other references in this vein (Hermes Trismegistus, Philo Judaeus) from Meor 'eynayim (Enlightenment of the Eyes), published in 1575 by Azariyah de' Rossi, whom he called "One of our recent writers."

${ }^{49}$ Thomas Aquinas (Summa Theologica, pars prima, quaestio XXXII, art. I, in Opera omnia, vol. IV, p. 349) recognised the incapacity of natural reason to come to this understanding, for God is known through his creatures and - since the creative power is common to all three persons - we know only the unity of the divine essence. But, for Thomas, the idea of the Trinity did not run counter to reason.

${ }^{50}$ Magen, 31.

${ }^{51}$ Nicolai Parutae Viri Pientissimi, De Uno Vero Deo Iehova Fragmenta Quaedam Disputationum. The text was rediscovered by Massimo Firpo in a manuscript 
which reproduced the text of the book, which had been published in 1575 and disappeared during the activities of the Inquisition. It is published in Massimo Firpo, Antitrinitari nell'Europa orientale del '500. Nuovi testi di Simon Budny, Niccolò Paruta e Iacopo Paleologo (Florence: La Nuova Italia, 1977), 329-360. On Paruta, whose wandering fate was that of Italian "heretics" in his time, see the detailed presentation in ibid., 186-271.

${ }^{52}$ Hizzuq ha-Emunah, cil., p. 86. Troki also mentions the work of the Polish Anabaptist Martin Czechowitz (1532-1613). Judah Rosenthal studied the encounters between Christian sectaries and Jews in fifteenth-century Poland in his "Rabbi Ya'aqov mi-Belzyce and his book of religious polemic" (in Hebrew), in Galed 1 (1973): 13-30, with a bibliography of previous articles on the subject by the author. It is interesting to note that the Catholics referred to these sectaries as "Judaisers."

${ }^{53}$ De Uno Vero Deo, 336.

${ }^{54}$ Ibid., 353.

${ }^{55}$ Ibid., 360.

${ }^{56}$ Ibid., 354.

${ }^{57}$ On the description of the paths taken by other individual which have in common doubts on the divinity of Christ and a desire to become familiar with the Bible in the Hebrew original, see Aldo Stella, Anabattismo e antitrinitarismo in Italia nel XVI secolo (Padua: Liviana, 1969), and E. Pommier, "L'itinéraire religieux d'un moine vagabond italien au XVIe siècle,", in Mélanges d'archéologie et d'histoire, École française de Rome, 66 (Paris, 1954) 293-322. According to Stella, the source of inspiration for this heresy on Venetian soil was rationalistAverroist thinking.

${ }^{58}$ See for example Magen, 42: "Nowhere in the Gospels is Jesus defined as being God, for - on the contrary - he called himself a man, and the humblest of them all."

${ }^{59}$ Ibid., 11 and 15. See also 66-68. On Jewish authors' portrayal of Jesus, see Avigdor Shinan's anthology, Oto ha-Ish: Yehudym mesapperym 'al Yeshu (Tel Aviv: Chemed Books, 1999).

${ }^{60}$ Magen, 20.

${ }^{61}$ Ibid.

${ }^{62}$ Ibid., 43. On the Toledoth Yeshu, see Jean-Pierre Osier, L'Evangile du Ghetto, ou comment les Juifs se racontaient Jésus (Paris: Editions Berg International, 1984), and Riccardo Di Segni, Il Vangelo del Ghetto (Milan: Newton Compton, 1985); Riccardo Di Segni, "La tradizione testuale delle Toledoth Jeshu: Manoscritti, edizioni a stampa, classificazione," Rassegna Mensile di Israel L (January-April 1984): 83-100; and "Due nuove fonti sulle Toledoth Jeshu," Rassegna Mensile di Israel LV (1989): 127-132.

${ }^{63}$ Modena's Jewish source was the Sefer Yosippon. 
${ }^{64}$ De Republica hebraeorum, 2. The historical context of Jesus is described on 223-233. Sigonio's sources are the Bellum Iudaicum and Antiquitates of Flavius Josephus, Philo Judaeus, the Shalsheleth ha-Qabbalah of Avraham Zakut, the Gospels and Acts of the Apostles, Pliny (Book V), Epiphanius, Tertullian (De prescritionibus), Jerome, Origen, Eusebius, and Isidore of Seville (Liber etymologiarum).

${ }^{65}$ Magen, 43.

${ }^{66}$ Mt 15: 1-9; Lc 11: 37-44. The historical reconstruction is on pages 43-46 of Magen we-herev.

${ }^{67}$ Magen, 45.

${ }^{68}$ Cf. Tanhuma, ed. Shlomo Buber (New York: H. Horowitz, 1946), vol. 1, p. 135.

${ }^{69}$ It is tempting to perceive the equivalence, suggested but not stated by Modena, between the terms "son of God" and "Messiah" attributed to the person of Jesus as an allusion for the reader. But an allusion to what? If Jesus considered himself to be the Messiah, he could have referred directly to the midrash, without relying on the new definition of "son of God." Perhaps Modena thought that the midrash was posterior to Jesus? That would justify his argument's use of other biblical verses to support his understanding of the "son of God" title. Some mystery nonetheless remains.

${ }^{70}$ Cf. Eisenstein, Otzar Wiqquhym, 90. This midrash had been touched on before Modena, in the sixteenth century, by Yair Shabbetai da Correggio, in the apologia Herev Pifyoth (Double-Edged Sword), 51-52.

${ }^{71}$ Going back to the text of the midrash (Magen, 64), Modena held to the affirmation that the Messiah would do more than the prophets and angels to facilitate universal recognition of God.

${ }^{72}$ Cf. Bezalel Safran, "Leone da Modena's Historical Thinking," in Jewish Thought in the Seventeenth Century, ed. Isadore Twerski and Bernard Septimus (Cambridge, MA: Harvard Unviersity Press, 1987), 381-398. Safran (386) claims for Modena an "historical imagination actively reaching out to the past" despite the thin documentary evidence and also finds the same historical spirit in the Venetian rabbi's responsa, Ziqnei Yehudah.

${ }^{73}$ Cf. Jean-Pierre Osier, Faust Socin ou le christianisme sans sacrifice (Paris: Le Cerf, 1996); Valerio Marchetti, I simulacri delle parole e il lavoro dell'eresia. Ricerca sulle origini del socinianesimo (Bologna: Cisec, 1999).

${ }^{74}$ Luigi Salvatorelli, Da Locke a Reitzenstein. L indagine storica delle origini cristiane (Cosenza: L. Giordano, 1988).

75 Albert Schweitzer, Geschichte der Leben-Jesu-Forschung, in his Gesammelte Werke, Munich s. d., vol. 3. Cf. esp. pp. 95 and 105. The authors in question are Karl Friedrich Behrdt (Briefe über die Bibel im Volkston [Halle, 1782]) and Karl Heinrich Venturini (Natürliche Geschichte des großen Propheten von Nazaret [Copenhagen, 1800-1802]). 
${ }^{76}$ Magen, 63.

77 Ibid., 64.

78 Ibid.

${ }^{79}$ Composed in 1616-17 and first published in 1638 in Venice.

${ }^{80}$ Magen, 64.

${ }^{81}$ Maimonides, Mishneh Torah, Hilkhoth melakhym, 11, 4.

${ }^{82}$ Modena showed himself to be disenchanted regarding the possibility of the Jews constituting themselves into a political subject. See David Malkiel, A Separate Republic: The Mechanics and Dynamics of Venetian Jewish Self-Government, 1607-1624, supplement to Italia (Jerusalem: Magnes Press, 1991); in the same anthology, see Marina Cavarocchi Arbib's article on the tragedy L'Ester.

${ }^{83}$ On the use of the term sevara to cast doubt on the logical grounds of Christian dogma, cf. Kuzary by Yehudah ha-Levy I:5, in Yehudah ibn Tibbon's Hebrew translation. Gianfranco Miletto, La biblioteca di Avraham ben David Portaleone secondo l'inventario della sua eredità (Firenze: Leo S. Olschki, 2013).

${ }^{84}$ Nicolas Antoine, "Un pasteur protestant brulé à Genève en 1632 pour crime de Judaïsme," Revue des Études Juives (1899): 36-37. Cf. also Elisabeth Labrousse, "Vie et mort de Nicolas Antoine," Études théologiques et religieuses 52 (1977): 421-433. I would like to thank Myriam Silvera for directing my attention to the latter article.

85 Ibid., 164.

${ }^{86}$ Leone Modena, Ziqney Yehudah, ed. Shlomo Simonsohn (Jerusalem: 19551956), responsum 6. See also Israel Adler, La pratique musicale savante dans quelques communautés juives en Europe, aux XVIIe et au XVIIIe siècle (Paris: Mouton and Co., 1966), 254. A few lines earlier, Modena had drawn attention to the fact that disordered singing was a feature of Ashkenazic synagogues.

${ }^{87}$ Giulio Morosini, Derekh Emunah. Via della fede mostrata a'gli ebrei (Rome,1683).

${ }^{88}$ Cf. for example ibid., 184, 566.

${ }^{89}$ Ibid., 108. In a letter to the Catholic theologian Vincenzo Noghera, Modena admitted having written Historia de' riti hebraici to reply to Johannes Buxtorf the Elder's Synagoga Judaica ( $1^{\text {st }}$ ed. 1603), emphasizing “the essential things, leaving aside those which even our own (those endowed with ingegno [understanding]) consider to be superstitions" (my italics). Cf. C. Roth, "Leone da Modena and the Christian Hebraists," 196.

90 Encyclopédie ou Dictionnaire raisonné des sciences des arts et des métiers, vol. XV (Neufchastel: André le Breton, Michel-Antoine David, Laurent Durand, and Antoine-Claude Briasson, 1765), 669. Spinoza had already defined "superstition" as adoration of the scriptures rather than the Word of God. Cf. Tractatus theologicus philosophicus, Gebhardt Edition, transl. Samuel Shirlay (Leiden: Brill, 1989) 54. 
${ }^{91}$ If we accept the hypothesis put forward by a series of scholars, including most recently_and quite brilliantly_-Talya Fishman (Shaking the Pillars of Exile [Stanford: Stanford University Press, 1997]), according to which Qol sakhal (Voice of a Fool), a Jewish anti-rabbinical work, was written by Modena under an assumed name, then the image of the Venetian rabbi would be, finally, enriched in a consistent way. For where Magen we-herev, with Christianity-an essentially dogmatic religion - as its polemical target, defines the outline of a religion that does not run counter to the laws of reason, Qol sakhal, which attacks Judaism - a religion based on the keeping of commandments - from the inside, sketches a religion pared down to the minimum and in strict conformity with the text of the Bible, putting it in a position to lay claim to being a universal religion. Cf. Shaking the Pillars of Exile, 35 and 64-65.

\section{8: The Immortality of the Soul and Opening Up to the Christian World}

\section{Pages 153-184}

${ }^{1}$ One of the best surveys on this topic is still Giovanni Di Napoli, L'immortalità dell'anima nel Rinascimento (Turin: Societa Editrice Internationale, 1963).

2 The champion of the Christian orthodox position was Thomas Aquinas, who decided in favor of the permanence of the individual intellect after death in De unitate intellectus contra Averroistas (written in 1270; On the Unity of Intellect against Averroists, trans. Beatrice H. Zedler [Milwaukee: Marquette University Press, 1968]). The polemics had little echo among the Jews, even if Maimonides seems to held an "averroistic" position, i.e. argued for the reality of an unique intellect; see Alexander Altmann, "Maimonides on the Intellect and the Scope of Metaphysics," in his Von der Mittelalterichen zur modernen Aufklärung (Tübingen: Mohr, 1987), especially 87-90. A remarkable exception to this lack of interest in that issue is Tagmuley ha-nefesh by Hillel ben Shemuel of Verona (ca. 1220-ca. 1295), in which the first chapter of Thomas' work is translated into Hebrew. See Yosef B. Sermoneta, ed., Sefer Tagmuley ha-nefesh (Jerusalem, 1981), 100-145. The first part of the book deals with theoretical issues, the second one with practical ones, such as the destiny of the soul according to its merits and faults.

${ }^{3}$ Paul Richard Blum, "The Immortality of the Soul," in The Cambridge Companion to Renaissance Philosophy, ed. James Hankins (Cambridge: Cambridge University Press, 2007), 211-233.

${ }^{4}$ Guide I: 74, trans. Shlomo Pines (Chicago: University of Chicago Press, 1963), 220-221: "A modern philosopher maintains that the creation of the world in time is established by what the philosophers say regarding the permanent existence of the souls. He says: if the world is eternal, the number of men who died in the 
limitless past is infinite. There would therefore be an infinite number of souls existing simultaneously. Now, this is a thing of which it has been indubitably demonstrated that it is false-I mean the simultaneous existence of an infinite number of numerable things. This is a wondrous matter, for it makes clear something hidden by something even more hidden."

${ }^{5}$ Guide III:27.

${ }^{6}$ Ibid. III:51.

${ }^{7}$ Maimonides, commentary to the Mishnah, introduction to Sanhedrin X (Pereq heleq) (Hebrew trans. by Yosef Qafị in Mishnah 'im perush Rabbenu Mosheh ben Maimon (Jerusalem: Mossad Harav Kook, 1968), 195-209; Mishneh Torah, Hilkhoth teshuvah, 8; Epistle on the Resurrection of the Dead, in Iggeroth Ha-Rambam, ed. Yitzhaq Shelat (Jerusalem, 1995), 319-376. Cf. Herbert A. Davidson, Moses Maimonides: The Man and Hits Works (Oxford: Oxford University Press, 2005), 241-243; 377.

${ }^{8}$ Sha'ar ha-gemul, in Kitvey ha-Ramban, ed. Hayyim Dov Shavel (Jerusalem, 1964), 309.

9 Sha 'ar ha-gemul, 264-311.

${ }^{10}$ Seymour Feldman translated this section in English: cf. Gersonides, The Wars of the Lord, Part One: The Immortality of the Soul (Philadelphia: Jewish Publication Society, 1984).

${ }^{11}$ The Wars of the Lord, 213.

${ }_{12}$ Hasdai Crescas, Or Adonai, ed. Shlomo Fisher (Jerusalem: Sifre Ramot, 1990), Maamar 2, Kelal 6, pereq 1, p. 239.

${ }_{13}$ Ibid., Maamar 3, helek 1, kelal 2, pereq 1, pp. 318-323.

${ }^{14}$ Ibid., Maamar 2, kelal 6, pereq 1, pp. 238-239.

${ }^{15}$ The so-called pre-Socratic philosopher Empedocles (490-430c. B.C.) theorized that life and death are a result of the tension between Love and Hatred (Strife), which act on the four basic elements, binding and separating them.

${ }^{16}$ Ibid., 244. Crescas is extremely reserved on the notion of the transmigration of the souls (gilgul; see infra), affirmed by tradition but not by religion. As for physical or spiritual nature, or both, in Gan 'eden (Paradise) and in Gehynnom (Inferno), he evaluates all possibilities, on traditional and rational bases.

${ }^{17}$ Sefer ha-'Iqqarym (first edition Soncino, 1485); critical edition and English translation by Isaac Husik (Philadelphia: Jewish Publication Society, 1946).

${ }^{18}$ On Albo, see Sina Rauschenbach, Josef Albo (um 1380-1444): jüdische Philosophie und christliche Kontroverstheologie in der frühen Neuzeit (Leiden: Brill, 2002). See a synthesis of the different positions on the subject in the introduction of Mosè Maimonide, Immortalità e Resurrezione (Immortality and Resurrection), ed. Giuseppe Laras (Brescia: Morcelliana, 2006).

19 To this "kabbalistic" period belongs Tofteh 'arukh (The Prepared Inferno, Venice, 1743) of the important kabbalist Mosheh Zacuto (ca. 1610-1697) a long poem on the infernal sorrows that the sinner will suffer, based on midrashic 
and kabbalistic sources. See the new edition edited by Dvora Bregman with an introduction in Dehaq 2 (April 2010): 333-376. We will not deal here with this important text. Moreover, the important work of Aharon Berehiyah da Modena, Ma 'avar Yabboq ("The Passing of the River Yabboq," Mantua, 1626), a collection of rites and prayers for the sick and the dead, which synthesizes the Kabbalistic beliefs regarding the passing from life to death, must be noted.

${ }^{20}$ Alessandro Guetta, "Ya 'ar ha-Levanon, ou la quête de la connaissance perdue. Un texte en prose rimée de Moshe de Rieti."

${ }^{21}$ The sole printed edition is the one by Ya 'aqov Goldenthal, Il Dante ebreo, ossia Il Picciol Santuario (Vienna, 1851). A presentation of the poem and its meter, the Hebrew text, vocalized with an English translation and notes on the first two chapters can be found in Prooftexts 23, no. 1 (2003): 1-93.

22 Il Dante ebreo, ff. 43a e 43b.

${ }^{23}$ F. $22 b$.

${ }^{24}$ A. Guetta, "Lev levavy ha-neehav: ha-qinah shel Mosheh-mi-Rieti 'al petirath ishto" (Critical Edition and Notes of the Unedited Elegy of Mosheh da Rieti on the Death of his Wife, with an introduction of the author and his work), in $T e$ 'udah 19, Studies in Hebrew Literature of the Middle Age and the Renaissance in Honor of Professor Yona David, ed. Tova Rosen and Avner Holzmann (2002): 309-327.

${ }^{25}$ A similar relationship between a firm conviction in the immortality of the soul and, on the other hand, simple suppositions on the particulars of the afterlife, such as the possibility of encounter among the souls, can be found in the first and third dialogue of the Phaedo by Moses Mendelssohn, first and third dialogue. See Phaedon oder über die Unsterblichkeit der Seele in drey Gesprachen, bey Friedrich Nicolai (Berlin-Stettin, 1767), republished in Gesammelte Schriften. Jubiläumausgabe III i (Stuttgart: Fromman-Holzboog, 1972), 5-9, 39-128. In his Phaedo, Plato had affirmed with certainty the immortality of the soul: as far as the specifics of its fate in the afterlife, he tells a "fable" (113-114c), and concludes with the following words: "I do not mean to affirm that the description which I have given of the soul and her mansions is exactly true - a man of sense ought hardly to say that. But I do say that, inasmuch as the soul is shown to be immortal, he may venture to think, not improperly or unworthily, that something of the kind is true" (trans. B. Jovett, classics.mit.edu/Plato/ phaedo.html).

${ }^{26}$ Il Dante ebreo, f. $102 \mathrm{v}$.

${ }^{27}$ A. Guetta, "The Crisis of Medieval Knowledge in the Work of the FifteenthCentury Poet and Philosopher Moses da Rieti," in Renewing the Past, Reconfiguring Jewish Culture: From al-Andalus to the Haskalah, ed. Ross Brann and Adam Sutcliffe (Philadelphia: University of Pennsylvania Press, 2004) 59-68.

${ }^{28}$ Yoḥanan Alemanno, Sha 'ar ha-hesheq (Leghorn, 1790). 
${ }^{29}$ Giorgio Inglese, L'intelletto e l'amore. Studi sulla letteratura italiana del Due e Trecento (Florence: La Nuova Italia, 2000).

30 At the beginning of the eighteenth century, one can witness a hesitant propinquity between Kabbalah and philosophy; this is not, however, an Aristotelian or Platonic philosophy but rather, a post-Cartesian rationalism. See chapter 9.

${ }^{31}$ Cf. Robert Bonfil, ed., Selected Chapters from Sefer Meor 'Einayim (Jerusalem: Bialik Institute, 1991), 30 (Hebrew).

32 Cf. Dan Pagis, Change and Tradition in the Secular Poetry: Spain and Italy (Jerusalem: Keter, 1976), esp. 283-285; Michela Andreatta, Poesia religiosa ebraica di età barocca (Padova: Gordini, 2007).

${ }^{33}$ Cf. the classic work of Benzion Netanyahu, Don Isaac Abravanel: Statesman and Philosopher (Philadelphia: Jewish Publication Society, 1953).

34 The idea of the transmigration of the soul is treated in his Commentary to Deuteronomy 25, 5-6, Jerusalem, 1999; the idea of the reincarnation at the beginning of the cosmic cycles is in Mif'aloth Elohim (The Deeds of God, Venice, 1592). On Abravanel's conception of the soul, compared with that of his contemporary Marsilio Ficino, see the ample analysis of Brian Ogren, "Circularity, The Soul-Vehicle and the Renaissance Rebirth of Reincarnation: Marsilio Ficino and the Possibility of Transmigration," Accademia. Revue de la société Marsile Ficin VI (2004): 63-94. The author of the article dwells particularly on the relationship between philosophical and theological thought in Ficino and in Abravanel. While the first, in order to justify the Platonic and Neo-Platonic theory of transmigration from a Christian point of view, considers it a metaphor, the later accepts the kabbalistic teaching without problems, which he sees as origins of analogous philosophical conceptions: Plato was a pupil of Jeremiah. The article has been expanded into the book Renaissance and Rebirth: Reincarnation in Early Modern Kabbalah (Leiden: Brill, 2009). In this book, B. Ogren points out that the Italian kabbalists Eliyah ben Hayyim da Genazzano and Yohanan Alemanno (fifteenth century) believed in metempsychosis.

${ }^{35}$ Ogren, "Circularity," cit. 90.

${ }^{36}$ On the respective attitudes of the Italian and Spanish Jews in regards to the Kabbalah, see Moshe Idel, Particularism and Universalism in Kabbalah, in Essential Papers on Jewish Culture in Renaissance and Baroque Italy, ed. David B. Ruderman (New York: New York University Press, 1992), 324-344.

${ }^{37}$ Leone Modena composed a book in 1636 against the belief in gilgul, Sefer Ben David, still in manuscript. Talya Fishman (Shaking the Pillars of Exile [Stanford: Stanford University Press, 1997], 204) assumes that the Venitian rabbi participated with this book to the controversy between Saul Levi Mortera and Isaac Aboab de Fonseca on the destiny of the soul. See below note 78 .

38 The judgment is commonly accepted among the historians of Jewish philosophy. Among the most recent, see Mauro Zonta, La filosofia ebraica medievale. Storia e testi (Bari: Editori Laterza, 2002), 210. But see also 'Ovadiyah Sforno's 
position in his Or 'ammym (Light of Peoples, Bologna, 1537) and in Commentary to the Psalms (Venice, 1586). Both texts have been edited and published by Zeev Gottlieb: Kitvey Rabby 'Ovadiyah Sforno (Jerusalem, 1987). The first book has a chapter on the immortality of the soul (in this case, a synonym for intellect), where the discussion is made on a dialetical, aristotelian basis, with a large number of quotations from Aristotle, Averroes, Plato, and Al-Ghazali. Besides some biblical quotations which show, according to Sforno, that the intellective soul is immortal, the emphasis on free will as "a gift of God" is remarkable. In the second book the exegesis of Psalm 1 is completely philosophical and focused on the immortality of the intellective soul. A thorough study on the work of this important Italian scholar is still a desideratum. On this topic see R. Bonfil, "Torath ha-nefesh we-ha-kedushah be-mishnath R. 'Ovadiyah Sforno" (The Doctrine of the Soul and of the Sanctity in the Teaching of R. Ovadiyah Sforno), Eshel Beer Sheva'1 (1976).

${ }^{39}$ The most recent synthesis of Del Medigo is by Seymour Feldman, in The Cambridge Companion to Medieval Jewish Philosophy, ed. Daniel H. Frank and Oliver Leaman (Cambridge: Cambridge University Press, 2003), 416-420.

${ }^{40}$ Kalman P. Bland, "Elijah Del Medigo, Unicity of Intellect, and Immortality of Soul," American Academy for Jewish Research LXI (1995): 1-22.

${ }^{41}$ Cf. Colette Sirat, La philosophie juive médiévale en Pays de Chrétienté (Paris: Presses du CNRS, 1988), 227.

${ }^{42}$ Jacob Joshua Ross, ed., Sefer Behinat hadat of Elijah Del-Medigo (Tel-Aviv: Chaim Rosenberg School of Jewish Studies, 1984), 78.

${ }^{43}$ Ibid., 84

${ }^{44}$ Ibid., 81

${ }^{45}$ Ibid.

${ }^{46}$ On Y. Moscato see Adam Shear, The Kuzari and the Shaping of Jewish Identity (Cambridge: Cambridge University Press, 2008), 135-169; Judah Moscato, Sermons, edited by Gianfranco Miletto and Giuseppe Veltri, two volumes published to date (Leiden: Brill, 2011).

${ }^{47}$ Nefutzoth Yehudah, f. 49v.

${ }^{48}$ Ibid., f. $52 \mathrm{v}$.

${ }^{49}$ Ibid., f. 52 r.

${ }^{50}$ F. $52 \mathrm{v}$.

${ }^{51}$ F. $50 \mathrm{v}$.

${ }^{52}$ F. $51 \mathrm{v}$.

${ }^{53}$ A more "technical" and traditional discourse on the remuneration of the soul after death can be found in sermon 41, ff. 193r-195r.

${ }^{54}$ Besides the Italian translations of the chapter of Rieti's Miqdash me 'at, an interesting work is L'angelica tromba (Ferrara, 1589), by Yohanan Yehudah ben Shelomo Alatrini, which contains the Italian translation in terza rima (the meter of Dantes's Divina Commedia) of the piyyut Barekhy nafshy by R. Bahiyah 
b. Joseph. See A. Guetta, "Le Traduzione liturgiche italiane cinque-seisentesthe come esempio di "poesia spirituale ebraica'," in Archivio Italiano per la Storia della Pietà 25 (2012): 11-33.

${ }_{55}$ Discorso intorno a l'humana miseria, Introduction.

56 "Si come interviene al rustico, che per non conoscere le delicattezze della città, non si vuol partir dalla libertà della villa, ancor che piena di fatica gli sia, cosi parimente occorrere allo stolto: il quale, per non comprendere le delicie del paradiso, se dà agli piaceri terreni: onde poi gli ne succede un'eterno stento" (f. 37r).

57 F. 12 v.

58 See chapter "A Link to Humanity."

59 The available bibliographic material on Sara Copio Sullam is by now quite rich. The most comprehensive contributions are Umberto Fortis, La "bella ebrea". Sara Copio Sullam poetessa nel ghetto di Venezia del "600 (Turin: Umberto Fortis, 2003), with Sara's sonnets and Don Harran, trans. and ed., Sarra Copia Sullam: Jewish Poet and Intellectual in Seventeenth-Century Venice (Chicago: University of Chicago Press, 2009). The controversy between Bonifaccio and Copio Sullam is acutely analyzed in the context of the philosophy and theology of the time by Giuseppe Veltri, in Renaissance Philosophy in Jewish Garb (Leiden: Brill, 2009), 226-248.

${ }^{60}$ Manifesto di Sarra Copia Sulam Hebrea. Nel quale è da lei riprovata e detestata l'opinione negante l'immortalità dell'anima, falsamente attribuitale dal Sig. Baldassare Bonifaccio (Venice, 1621).

${ }^{61}$ Ansaldo Cebà, Lettere di Ansaldo Cebà scritte a Copio e dedicate a Marc'Antonio Doria (Genoa, 1623).

${ }^{62} \mathrm{Cf}$. the translation of Qol sakhal (Voice of a Fool), possibly written by Leone Modena, and particularly the chapter on the immortality of the soul, in Talya Fishman, Shaking the Pillars of Exile, 90-92. For the Hebrew version, see Isacco Reggio, Examen Traditionis. Duo inedita et poene incognita Leonis Mutinensis Opuscula Complectens (Gorizia, 1852), 13-15. The author of Qol sakhal argued-probably quoting a passage from Gersonides' The Wars of the Lord: Book One: The Immortality of the Soul (a translation can be found by Seymour Feldman [Philadelphia: Jewish Publication Society, 1984], 120) — that there are no decisive demonstrations of the immortality of the soul, and even fewer scriptural proofs. Nevertheless, "analysis greatly inclines - if it does not compel usto believe that the soul has existence after the death of the body" (Shaking the Pillars of Exile, 91). This analysis was grounded on the superiority of Man-as an intellectual being - over the animals. Were his intellect mortal, Man-who forecasts physical death - would be unhappier than animals, and therefore inferior to them. In the same years and in the same city Paolo Sarpi, the official religious consultant of the Venetian Republic, denied the idea of human superiority based on intellect, and maintained that the immortality of the soul was but a human projection. See Vittorio Frajese, "Maimonide, il desiderio di immortalità 
e l'immagine de Dio. Problemi di interpretazione dell'insegnamento esoterico di Sarpi," in Ripensando Paolo Sarpi (Venezia: Ateneo Veneto, 2006), 153-181. This idea, together with other similar conceptions that crossed the frontiers of atheism, was contained in the so-called "esoteric writings" of Sarpi, obviously unpublished during their author's lifetime. Cf. Paolo Sarpi, Pensieri naturali, metafisici e matematici, eds. L. Cozzi and L. Sosio (Milan: Ricciardi, 1995).

${ }^{63}$ Dell'immortalità dell'anima. Discorso di Baldassare Bonifaccio (Venice, 1621). Available online on the site of the Herzog-August-Bibliothek in Wolfenbüttel, http://diglib.hab.de/drucke/83-12-quod-3/start.htm.

${ }^{64}$ Manifesto di Sarra Copio, "Al lettore."

${ }^{65}$ Ibid.

${ }^{66}$ See Corinna da Fonseca-Wollheim, "Acque di Parnaso, acque di Battesimo: fede e fama nell'opera di Sara Copio Sullam," in Le donne delle minoranze. Le ebree e le protestanti d'Italia, ed. Claire E. Honess and Verina R. Jones (Turin: Claudiana, 1999), 159-170.

${ }^{67}$ In U. Fortis, La bella ebrea, p. 115: "Signor, che dal mio petto arderti avanti / Mai sempre scorgi in olocausto il core / E sai ch'altro desìo che frale onore / M'instiga a porger preghi, a versar pianti."'

${ }^{68}$ Ibid., 123: "O di vita mortal forma divina / E dell'opre di Dio mèta sublime." The issue of the immortality of the soul is also one of the main interest of a Venitian rabbi, the poet-philosopher with rationalistic orientations Yehoshua Yosef Levi (ca. 1655 - after 1704). See Joshua Joseph Levi, A Cup of Consolation and Other Elegies. Edited from early printings and manuscripts, with an introduction and notes by Ariel Rathaus ( Jerusalem, Ben-Zvi Institute, 2013).

${ }^{69}$ Yosef Kaplan uses the word "karaite," referring to the texts of some excommunications pronounced in Amsterdam. Cf Y. Kaplan, An Alternative Path to Modernity: The Sephardi Diaspora in Western Europe (Leiden: Brill, 2000).

${ }^{70}$ Uriel da Costa, Examination of Pharisaic Traditions. Exame das tradições phariseas. Supplemented by Semuel da Silva's "Treatise on the Immortality of the Soul. Tratado da immortalidade da alma," trans., notes, and introduction by H. P. Salomon and I. S. D. Sassoon (Leiden: Brill, 1993).

${ }^{71}$ Moses Raphael d'Aguilar, Reposta a certas propostas contra a tradição, still in manuscript. Cf. An Alternative Path to Modernity, 245. He also wrote a Tratado da immortalidad da alma (Treatise on the Immortality of the Soul), on which see M. de Jong, "O 'Tratado da Immortalidade da Alma' de Moses Rephael de Aguilar," Biblos 10 (1934): 488-499. See Sina Rauschenbach, "Mediating Jewish Knowledge: Menasseh ben Israel and the Christian Respublica Litteraria", Jewish Quarterly Review vol. 102 n. 4 (Fall 2012), 561-588.

${ }^{72}$ Isaac Cardoso, Las excelencias de los hebreos (Amsterdam, 1679). On Cardoso see Yosef H. Yerushalmi, From Spanish Court to Italian Ghetto: Isaac Cardoso: A Study in Seventeenth-Century Marranism and Jewish Apologetics (Seattle: University of Washington Press, 1981). 
${ }^{73}$ De resurrectione mortuorum libri III (Amsterdam, 1636).

74 James W. Nelson Novoa, "Las Opiniones sacadas de los más auténticos y antigos philósofos que sobre la alma escrivieron y sus definiciones, de Daniel Arón Afia," Sefarad 68-1 (2008): 89-103.

75 On this author see Moisés Orfali, Isaac Aboab da Fonseca: Jewish Leadership in the New World (Eastbourne, UK: Sussex Academic Press, 2012).

76 See Marc Saperstein, "Saul Levi Morteira's Treatise on the Immortality of the Soul," Studia Rosenthaliana 25, no. 2 (1991): 131-148.

77 Nishmath hayyim. Kolel derushym 'al 'iniyan ha-neshamah (Living Soul. With Some Discources on the Soul) (Amsterdam, 1651 or 1652).

78 An important controversy, linked to the subject of the immortality of the soul, took place in Amsterdam between two rabbis: Saul Levi Mortera and Isaac Aboab de Fonseca. The first maintained the eternity of punishment for great sins, such as apostasy, which included the numerous ex-conversos present in the city. The second, through the kabbalistic theory of the gilgul, affirmed that even a sinful soul could end up being completely purified. Cf. Alexander Altmann, "Eternality of Punishment: A Theological Controversy Within the Amsterdam Rabbinate in the Thirties of the Seventeenth Century," Proceedings of the American Academy for Jewish Research (1972): 1-88.

79 Steven Nadler, Spinoza's Heresy: Immortality and the Jewish Mind (Oxford: Oxford University Press, 2002).

${ }^{80}$ I quote from Sina Rauschenbach's article "Über die Auferstehung der Toten: Uriel da Costa, Menasse ben Israel und die christliche Respublica litteraria," in Kritische Religionsphilosophie; eine Gedenkschrift für Friedrich Niewöhner, ed. Wilhelm Schmidt-Biggemann and Georges Tamer (Berlin: De Gruyter, 2010). Menasheh himself explained that denial of resurrection implied the denial of religion as such, and denial of religion implied the denial of law and thus the denial of any ordered human society. Jews and Christians should ally to defend the notion, "because we all do worship one God, submit to His commandments and expect a better life after the difficulties of this life on earth. Hence, our effort aims at nothing less than having everybody eventually arrive at an understanding that in dealing with that most necessary resurrection we must find a common position against the Sadducees, who are destroying souls and states in an abnormal way." (M. Ben Israel, De resurrectione mortuorum libri III (Amsterdam, 1636), Epistola dedicatoria.)

${ }^{81}$ Uriel da Costa, Examination of Pharisaic Traditions, 34.

${ }^{82}$ In 1799 Fiorentino witnessed the anti-Jewish violence of the reactionary groups of "Viva Maria!," and found refuge in Florence, which was occupied by the French at the time. Here he found the support of the commander of the body of the Napoleonic expedition, general Sextius Alexandre de Miollis. Cf. Gabriella Milan, voce "Fiorentino, Salomone," in Dizionario biografico degli italiani (Rome: Instituto dell' Enciclopedia Italiana, 1997), vol. 48, 160-162. In 
1805 he composed the short poem "La giornata di Austerlitz" (Austerlitz day) (published in Livorno in 1840) and translated "Il Tempio di Gnido" (Gnido's temple) by Montesquieu (in Poesie di Salomone Fiorentino, vol. 2 [Florence, 1826], 52-114), a poem in which sentiment is exulted to the detriment of sensuality. For the historic context on Fiorentino, see also Gli Ebrei a Monte San Savino (Comune di Monte San Savino, 1994), with bibliography; Encyclopaedia judaica, 2007, sub voce; and, for literary history, Giuseppe Nicoletti, "Le 'Elegie' di Salomone Fiorentino: a source of the Pisan-Recanati canti?," in Una giornata leopardiana in ricordo di Walter Binni, ed. M. Martelli (Rome: Bulzoni 2000), 123-130.

83 Poesie di Salomone Fiorentino (Pisa, 1803).

${ }^{84}$ Elegie di Salomone Fiorentino in morte di Laura sua moglie (Arezzo, 1789).

${ }^{85}$ Ibid., "Ma sospirando ancor cerco il conforto," 24.

${ }^{86}$ Ibid., "In tal atto amoroso, e in tal sembiante / che trasformati avria gli uomini in Dei," 20.

${ }^{87}$ Ibid., "Serbava il volto amabilmente umile / E dagli occhi umidetti un certo raggio / Sovrumano piovea, e signorile," 21.

${ }^{88}$ Ibid. It is evident this recalls the famous verse of Petrarch "Erano i capei d'oro a l'aura sparsi" (Canzoniere, sonnet XC).

${ }^{89}$ Ibid., 19. To compare with sonnet XXXV of Petrarch's Canzoniere: "Solo e pensoso i più deserti campi / vo mesurando a passi tardi e lenti."

${ }^{90}$ Ibid., 22.

91 Ibid., 19.

92 Ibid., 15.

93 Exceptions are the literary scientific academies, created by the ex-conversos of the Sephardic communities, such as Amsterdam e Livorno. These academies were inspired by the Spanish model, and their activities and productions are essentially in Spanish. For Livorno, see Lucia Frattarelli Fischer, Vivere fuori dal ghetto. Ebrei a Pisa e Livorno (secoli XVI-XVIII) (Turin: Zamorani, 2008), 167.

94 A remarkable exception is the case of the humanist Giovanni Pontano (14261503 ), author of the collection of lyric poems De amore coniugali. On this work, see Liliana Monti Sabia, "Un canzoniere per una moglie," in Poesia umanistica latina, ed. Giuseppe Catanzaro and Francesco Santucci (Assisi: Accademia Properziana del Subasio, Centro studi poesia latina in distici elegiaci, 1999).

95 Elegie, 3: "Che un Marito pianga la propria Moglie rapita da morte nel fiore degli anni è certamente facil cosa a truovarsi; ma che un Marito pianga una Consorte quasi novilustre, e colle lacrime del più acerbo dolore, non è facil pruova della moderna coniugale sensibilità."

96 Reference to Song of Songs 4:9: "My sister, my bride."

97 Mosheh of Rieti, Lev levavy ha-neehav.

98 Elegie, 22: "Vita è quella che il Tempo non misura / Quella che in faccia ha il sempre, e a tergo il mai /Mentre scorre beata, e và secura." 
99 In Poesie di Salomone Fiorentino, vol. 2 (Florence, 1826), 7-52.

${ }^{100}$ Cf. David Malkiel, "The Rimini Papers: A Resurrection Controversy in Eighteenth-Century Italy," The Journal of Jewish Thought and Philosophy 11, no. 2 (2002): 89-115.

101 The argument recalls the long similar development in Mendelssohn's Phädon.

102 In 1924, Emanuele Benamozegh gave a lecture entitled "Dietro il sipario della vita, ovvero della immortalità dell'anima umana" (Behind the Curtain of Life, or About the Immortality of the Soul, [Leghorn, 1924]). Emanuele was the son of a well-known rabbi, the philosopher and kabbalist Elijah Benamozegh, a prolific author who wrote a text deducing the immortality of the soul from implicit biblical allusions. See Elia Benamozegh, L'immortalità dell'anima. La luce di Dio nelle viscere dell'uomo, ed. Marco Morselli (Rome: Edizioni La Parola, 2008). The son, while insisting on the presence of that belief within traditional Judaism, also believed that the immortality of the soul was a universal truth.

${ }^{103}$ In Shemuel Romanelli, Masa ' ba-a 'rav, ed. J. H. Schirmann (Jerusalem, 1968), 158-169. Masa' ba- 'arav, Romanelli's most famous work is the chronicle of a long sojourn of the author in Morocco. It has been translated by Norman and Yedida Stillman, Travail in an Arab Land (Tuscaloosa, AL: University of Alabama Press, 1989). On Romanelli, see J. H. Schirmann, Romanelli, ha-meshorer we-ha-noded (Romanelli, the Poet and the Traveller, Jerusalem, 1969) and Asher Salah, ed., Samuele Romanelli, Visioni d'Oriente. Itinerari di un ebreo italiano nel Marocco del Settecento (Florence: Giuntina, 2006).

104 Masa' ba 'rav, 165.

105 Francés, however, called for prudence in the polemic with the affirmations of the kabbalists, who claimed to know the secrets of the universe and the divine world. See below, "Kabbalah and rationalism."

${ }^{106}$ Masa ' ba 'rav, 168. It is interesting to note that Romanelli refers, in the notes, to the book of Menasheh Ben Israel De la Resurreción de los muertos (Amsterdam, 1636).

107 Poesie di Salomone Fiorentino (Pisa, 1803), 17. "Fu propizia la sorte al desir mio, / Che pur mi dié di rimirarti alfine, / E ne' tuoi carmi, ravvisar che un Dio / Grazie t'ispira ignote, e pellegrine. / [...] Or se attonita in te fisso il pensiero; / Che fora mai, se per la stessa via / Meco venissi a rintracciare il vero?"

108 "Segui tra i carmi pur gli estri vivaci; / Ma il vel che cela tante sorti e tante / Vedi che in fronte ha scritto: Adora e taci."

109 "The Rimini Papers," 104.

${ }^{110}$ Fiorentino taught at the Hebrew school in the Livorno community and rendered an Italian translation of the form of prayer. Some of these translations were published among his poems Poesie (Florence, 1826), and are beautiful examples of religious poetry.

111 "In lode di Galileo Galilei," in Poesie, 143-147.

112 VI Elegia, "La visione," in Poesie di Salomone Fiorentino (Pisa, 1803), 71. 


\section{9: Kabbalah and Rationalism In the Works of Mosheh Hayyim Luzzatto and some Kabbalists of his time} Pages 185-226

${ }^{1}$ Leopold Zunz, Literaturgeschichte der Synagogalen Poesie (Berlino, 1865), 449; Hayyim N. Bialik, "Ha-bahur mi-Padova," in Kol kitvey H. N. Bialik (Tel Aviv, 1938), 228-229.

2 Y. Tishby, "Darkhey hafatzatam shel kitvey kabbalah le-Ramhal be-Polin u-veLyta," in his Hiqrey kabbalah w-sheluhoteya: mehqarym w-meqoroth (Jerusalem, 1982-1983), vol. III, pp. 911-940.

3 See Y. Leibowitz's reflections on Luzzatto's ethics (which were probably spurred by the interest which Eliyahu, the Gaon of Vilna, showed in this question) in Sihoth 'al Mesillath Yesharym le-Ramhal (Jerusalem: Keter, 1995), and Hamishah sifrey emunah (Jerusalem: Keter, 1995), 81-86. The annotated manuscripts of Luzzatto's kabbalistic works edited by Moshe Friedländer (Bnei Brak in the 1970s-80s) constitute essential reading. The Makhon (Institute) Ramhal organized by Mordekhai Chriqui has for the last decade carried out the important work of disseminating the works of the Paduan author through new book editions, conventions, seminars, and other initiatives. For a general bibliography of Luzzatto, see Natascia Danieli, L'epistolario di Mošeh Hayyim Luzzatto (Florence: Giuntina, 2006), 291-308.

${ }^{4}$ In May 2007, for example, Gai Biran organised a series of events celebrating Luzzatto's work by staging conversations with poets, public readings, and musical performances at the Beth Avyhay Theater in Jerusalem. Spanning several days, this initiative met with great success and attracted both religious and secular audiences.

${ }^{5}$ S. D. Luzzatto, Lezioni di teologia dogmatica israelitica (Trieste, 1863), 42. S. D. Luzzatto went on to illustrate this assessment with a passage taken from the then-unpublished Da'ath tevunoth (see infra), acknowledging both that Mosheh Hayyim Luzzatto was an excellent poet, and that he was among the first to recognize the literary value of the Bible.

${ }^{6}$ Yosef Almanzi, "Toledoth Rabbi Mosheh Hayyim Luzzatto mi-Padova," in Kerem Hemed 3 (1838): 112-168. See in particular p. 114: "Wishing to study and probe major questions in depth, he led a group dedicated to unfounded pursuits." See also the piece by Mordekhay Shemuel Ghirondi in Kerem Hemed 2 (1836): 53-67, which is more sympathetic and attempts to exculpate Luzzatto from the accusations of Sabbateanism.

7 S. Ginzburg, The Life and Works of Moses Hayyim Luzzatto (Philadelphia: Dropsie College, 1931; 2nd ed. Westport, CT: Greenwood Press, 1975), Introduction.

8 Ibid., 28.

9 Ibid., 43.

${ }^{10}$ Luzzatto's dramaturgical and poetic works have not been comprehensively examined as yet. Benami Feingold's article ("Le opere teatrali di Moshe Chayyim 
Luzzatto," Rassegna Mensile d'Israel 60, special issue "Poesia ebraica italiana. Mille anni di creazione sacra e profana," [1994]: 146-182) constitutes a significant step forward in the investigation of the relationship between Luzzatto's kabbalistic and poetic works. Ariel Rathaus' analysis of poetics ("Poetiche della scuola ebraico-italiana," ibid., 189-226, in particular 221-226) is the best attempt to date at understanding the place of Luzzatto's theory of poetry in the Italian tradition.

${ }^{11}$ N. Danieli, L'epistolario.

${ }^{12}$ Meir Benyahu and Y. Tishby have written extensively on this question. See in particular Meir Benyahu, "Ha-maggid shel Ramhal" (The Celestial Voice of Luzzatto), Sefunoth 5 (1961): 297-336. See also Y. Tishby, "Ha-tesysah hameshyhiyth be-hugo shel Moshe Hayyim Luzzatto le-oram shel ketubah weshyrym meshyhiym” (Messianic Ferment in M.H. Luzzatto's Group in Light of the Nuptial Contract and Messianic Poetry), in Hiqrey kabbalah, 729-755, and Mordekhay Chriqui, Le maguid et les écrits zohariques de Rabbi Moché Hayim Luzzatto (Montreal: Editions Ramhal, 1991).

${ }^{13}$ Elliot R. Wolfson, "Tiqqun ha-shekhynah: Redemption and the Overcoming of Gender Dimorphism in the Messianic Kabbalah of Moses Hayyim Luzzatto," History of Religions 36, no. 4 (1997): 289-332.

${ }^{14}$ Hansel, Moïse Hayyim Luzzatto (1707-1746). Cabbale et philosophie (Paris, 2004).

15 An important contribution is Charles H. Manekin, “On Moses Hayyim Luzzatto’s Logic, and on Ramist Influence in His Writings," Daat: A Journal of Jewish Thought 4 (1998): 5-27.

16 These two terms can be associated here, because for Luzzatto, as for Aristotle, logic is the study of human discurse.

${ }^{17}$ On the vow he made to no longer disseminate writings dictated by the celestial voice, and to refrain from composing any more such writings, see the document dated the $3^{\text {rd }}$ of the month of Av 5490 (July 17, 1730), in S. Ginzburg, R. Mosheh Hayyim Luzzatto w-vney doro: Osef iggeroth w-te'udoth (R.M.H.L. and His Contemporaries: A Collection of Letters and Documents) (Tel Aviv, 1937), 176177 and 401-402.

18 A dialogue between a kabbalist and a rationalist, Maamar ha-wikkuah dates from 1734. Luzzatto insisted on being granted permission by his teacher, Yeshayahu Bassan, before publishing this work (S. Ginzburg, RM.H.L. w-vney doro, 242249). This could imply that Luzzatto intended to publicize the non-mystical-messianic aspects of his thought, even at that difficult time. The theological treatise Da 'ath tevunoth — in which Kabbalah is never explicitly mentioned - also dates from 1734, when Luzzatto was preparing to leave Padua for Amsterdam. For more on these works, see infra.

${ }^{19}$ It is only after young Samuel David Luzzatto openly questioned the authenticity of the Zohar that the Jewish-Italian intellectual elite lost faith in Kabbalah. Although Luzzatto's questions initially perplexed Italian scholars, they quickly 
came to share his views. See A. Guetta, "The Last Debate on Kabbalah in Italian Judaism: I.S. Reggio, S.D. Luzzatto, E. Benamozegh," in The Jews of Italy: Memory and Identity, ed. B. D. Cooperman and Barbara Garvin (Bethesda, MD: University Press of Maryland, 2000), 256-275.

${ }^{20}$ Cf. Yeshayahu Tishby, "The Controversy about the Zohar in Sixteenth Century Italy" (in Hebrew), Peraqim: Yearbook of the Schocken Institute for Jewish Research of the Jewish Theological Seminary (1967-68): 131-192 (in Hebrew).

${ }^{21}$ Is it possible that some form of censorship blocked the publication this text? See Moshe Carmilly-Weinberger, Censorship and Freedom of Expression in Jewish History (New York: Sepher-Hermon Press with Yeshiva University Press, 1977), 75: "The rabbis of Italy, notably R. Samuel Meldola and R. Aviad Sar-Shalom Basilea, directed the full force of their opposition against the publication of Ari nohem. They went so far as to request the government to prevent the book from being published." However, Carmilly-Weinberger gives no source for this information. Self-censorship on the part of the author is a more likely explanation.

22 Ary nohem, ed. Julius Fürst (Lipsia, 1840), 47. On Modena's opposition to Kabbalah, see Yaacob Dweck, The Scandal of Kabbalah: Leon Modena, Jewish Mysticism, Early Modern Venice (Princeton: Princeton University Press, 2011).

${ }^{23}$ Ibid., 11.

${ }^{24}$ Ibid., 67, on Luria and his supposed miracles.

${ }^{25}$ Magen we-herev, ed. S. Simonsohn (Jerusalem, 1960). For more on this text, see the chapter on Leone Modena's Magen we-herev.

${ }^{26}$ Novo dittionario hebraico et italiano (Padova: 1640), introduzione.

${ }^{27}$ See Talya Fishman, Shaking the Pillars of Exile on Qol sakhal (The Voice of the Fool), an anti-rabbinic work attributed to Yehudah Ariyeh Modena.

${ }^{28}$ See Robert Bonfil, "Halakhah, Kabbalah and Society: Some Insights into Rabbi Menahem Azaria da Fano's Inner World," in Jewish Thought in the Seventeenth Century, ed. I. Twerski and B. Septimus (Cambridge, MA: Harvard University Press, 1987), 39-61; Robert Bonfil, "Cultura e mistica a Venezia nel Cinquecento," in Gli ebrei e Venezia, ed. G. Cozzi, 469-506; and Moshe Idel, "Les renaissances culturelles européennes et la mystique juive," in Réceptions de la cabbale, ed. P. Gisel and L. Kennel (Paris: Éd. de l'Éclat, 2007), 13-55.

${ }^{29}$ It is said that Mosheh Zacuto (ca. 1625-1697) fasted in order to forget his knowledge of Latin (see, among others, L. Zunz, Literaturgeschichte, 441). Yosef Ergas and M. H. Luzzatto's rare remarks on the subject of Christians were harsh. For Ergas, see Pery megadym, published with Minhath Yosef (Leghorn, 1832), cap. 34: "It is forbidden to praise a non-Jew [...] because one will then become attached to him and learn from his evil actions." In general, Luzzatto was disdainful of non-Jews. Interestingly, though, when he listed all those who did not believe in the absolute unity of God in an important passage of his Da ath tevunoth (10-12), he only mentioned the Gentiles (goyye ha-aratzoth) because of their refusal to accept the election of Israel. In other words, Luzzatto did not 
seize on this occasion to radically criticize Christian doctrine. Nevertheless, one should not lose sight of the climate of fear created by the Inquisition.

30 See Peninah Naveh, ed., Kol shirey Ya 'aqov Francés (Jerusalem: Mossad Bialik, 1969), 401-408.

31 Vv. 13-14.

${ }^{32}$ Vv. 19-20.

${ }^{33}$ In truth, kabbalists such as Ergas and Luzzatto insist on the ineffability and incomprehensibility of God (eyn sof), while Kabbalah speaks only of the world of divine emanations, which man may know in part.

${ }^{34}$ Kol shirey, vv. 31-35.

35 Ibid., vv. 65-68.

${ }^{36}$ Ibid., vv. 53-54.

${ }^{37}$ Meyr Benayahu claims that Francés "criticizes Kabbalah while seeming to praise it." Cfr. Haskamah we-reshuth bidefusey Venetziyah (Copyright, Authorization and Imprimatur for Hebrew books printed in Venice) (Jerusalem: Mahon Ben Tzevy and Mosad ha-Rav Kook, 1971), 107. In another poem (Kol kitvey, 167174), Francés proposed the model of "wise ignorance," while awaiting the Redeemer who would clear up all doubts.

${ }^{38}$ Vv. 75-80. Facetiously, Francés went on to present himself as that ideal Jew. The interesting aspect of this auto-panegyric concerns his self-portrait as a poet who weighs and measures his words, and who considers the constrictions placed on poetry "more precious than jewels." The ability to compose beautiful verse is another requisite for the ideal Jew, because "the purity of his words captures hearts / which become slaves of the superior King," i.e. God (vv. 92-93).

39 Evidently, Rabbi Yehiyel Finzi of Florence issued a judicial act condemning Francés. The poet replied to this condemnation (which is no longer extant, and the content of which is no longer known) with a very harsh poem against the rabbi. See Naveh, 418-420. See H. Brody, Meteq sefatayim, hebräische Prosodie von Immanuel Frances (Cracovia, 1892), 74, and H. Brody, Wikkuah Livny weShim 'y, in Hahoqer 1 (1893): 213 (cit. in Benayahu 107 note 4).

${ }^{40}$ Behynath 'olam (Venice: Vendramin, 1704).

${ }^{41}$ For more on Shimshon Morpurgo, see Asher Salah, La République des Lettres. Rabbins, écrivains et médecins juifs en Italie au XVIII siècle (Leiden: Brill, 2007), 455-460. The rabbi of Ancona took a moderate position in the argumentation that surrounded Luzzatto's kabbalistic works and led to their condemnation. It is possible that the title of Morpurgo's book contains a veiled polemical reference to the well-known work by Hayyim Vital, 'Etz Hayyim ("Tree of Life").

${ }^{42}$ Emunath hakhamym (Mantua: S. Benedetto, 1730), 31r-31v. For more on A.S.S. Basilea, see A. Salah, La République 70-73. For more on this controversy, see the wide-ranging study by D. Ruderman, Jewish Thought and Scientific Discovery in Early Modern Europe (New Haven, CT: Yale University Press, 1995), 213228. Ruderman downplays the ideological stakes of the conflict between the 
kabbalists and the anti-kabbalists. He rightly notes that Morpurgo and Basilea were both admirers and practitioners of experimental science, and had a cordial personal relationship. He attributes their conflicting positions to a shared desire to safeguard the Jewish religion from strong Christian pressures. Whereas Morpurgo sought to achieve this by downplaying the importance of Kabbalah, which provided theological fodder for the Christians, Basilea tried to bolster all Jewish intellectual energies in the name of a single tradition. On some interesting details on Basilea's biography see M. Caffiero, Legami pericolosi, passim.

${ }^{43}$ In one of his many polemical poems attacking Shabbetay Tzevy and his followers, Francés cited and attacked a certain "Basilea," describing him as a Sabbatean sympathizer. Cfr. Naveh, 457. If the Basilea in question was meant to be Menahem Basilea, Avi'ad Sar Shalom's father (as suggested in Shlomo Simonsohn, History of the Jews in the Duchy of Mantua [Jerusalem: Kiryath Sepher, 1964], passim), then the latter's polemic against the poet could be personal. If this was the case, an interesting chapter could be written on the subterranean permanence of Sabbateanism in eighteenth-century Italy, i.e. in an era and location in which it should have been totally eradicated. It is curious to note that, while A. S. S. Basilea was probably the son of a Sabbatean, his contemporary, Yosef Ergas - a protagonist in the polemic against Nehemiyah Hayyun, accused of professing Sabbatean and Christianizing doctrines - was the grandson of Mosheh Pinheiro, who was a faithful friend of Shabbetay Tzevy and student of the famous Sabbatean kabbalist Binyamin ha-Cohen of Reggio Emilia. Cf. Malakhy ha-Cohen's introduction to the collection of "responsa" Divrey Yosef (Leghorn: 1742). As for Luzzatto, it is known that he wrote a work, Qinath ha-Shem tzevaoth (The Zeal of the Lord of Hosts), refuting Sabbatean ideas (v. Sh. Ginzburg, R.M.H.L. w-vney doro, 153156). However, Luzzatto's insistence on certain ideas - that redemption would come when the negation of God's unity would be more diffuse, and that good was recognized by evil—lent his thought an apocalyptic quality bordering on heresy. See, above all, Da' ath tevunoth, 32-33.

${ }^{44}$ Emunath hakhamym, ff. 11r, 32r.

${ }^{45}$ S. D. Luzzatto (Lezioni di Teologia, 41) judged Basilea rather severely: "R. Aviad Basilea, of Mantua, published in 1740, in that city, his Emunath hakhamym, where, without philosophy and without criticism, he takes on the philosophers, as well as those in favor of criticizing the Sacred Writings and interpreting them literally. There, deploying the weapons of authority and disparagement, he defends the infallibility of the Talmudists' decisions and the divine origin of kabbalistic doctrines."

${ }^{46}$ Emunath hakhamym, 11v.

$4730 \mathrm{r}$.

$482 \mathrm{v}$.

${ }^{49} 6 \mathrm{r}$.

${ }^{50} 29 \mathrm{v}$ and $48 \mathrm{v}$. 
$5138 \mathrm{r}$.

52 22v.

$5322 \mathrm{v}$.

${ }^{54}$ Basilea seems not to have picked up on the criticisms which Pietro Galatino directed at modern Jews in De arcanis catholicae veritatis (1518) for not following the doctrines of their Talmudic teachers. According to Galatino, this implied that the rabbis of the Talmud implicitly accepted the Christian message.

55 Yosef Ergas, Divrey Yosef (Leghorn, 1742), ff. 9r and 9v. Developing his legal argument, Ergas noted that Yitzhaq Luria's opinion was applicable because "he received inspiration from the holy spirit in his school." This demonstrates the influence Kabbalah — and especially prophetic Kabbalah — had on juridical decisions, even if in this case what was at stake was a secondary question, which essentially touched on a matter of principle.

${ }^{56}$ Cfr. Benayahu, Hadpasah, 107-108; the anonymous introduction to Yehudah Ariyeh (Leone) Modena, Ary nohem (Lipzig, 1840), xvii; and Giulio Bartolocci, Bibliotheca Rabbinica (Rome, 1675), part IV, p. 56. See also Moshe CarmillyWeinberger, Censorship and Freedom of Expression in Jewish History, 231 (which lacks quotations from the source material).

${ }^{57}$ In a letter to Luzzatto's teacher, Yeshayahu Bassan, Yosef Ergas described his Shomer Emunym, which was still in manuscript form, as "a book small in volume, but great in quality"; see S. Ginzburg, R.M.H.L. w-vney doro, 102. The importance Luzzatto placed on the publication of his dialogue, Maamar ha-wiqquah, is evidenced by his insistence on obtaining his master Bassan's authorization; see note 18. Bassan saw his student's text as an apologia for Kabbalah, answering skeptical works such as Yosef Delmedigos' Matzref la-hokhmah and even Basilea's Emunath hakhamym; see S. Ginzburg, R.M.H.L. w-vney doro, 246.

58 Shomer emunym, Introduction, p. 4. All quotes are from the 1965 Jerusalem edition. On Ergas, see Beracha Sacq's general presentation, "Yiun be-qabbalato shel R. Yosef Ergas" (Examination of the Kabbalah of Yosef Ergas), in Yahaduth: sugiyoth, keta 'ym, panym, zehuyioth, Sefer Rivqah ("Judaism: Topics, Extracts, Aspects, Identities. The Book of Rebecca-In Honor of Rivka SchatzUffenheimer"), ed. Chaviva Pedaya and Efraim Meir (Beer Sheva: Ben Gurion University, 2007), 393-407. For discussions of particular aspects of this work, see Roland Goetschel, "Kawwanah' et finalité de la prière dans le 'Shomer Emûnîm' de Joseph ben Emmanuel Ergaz (1685-1730)," Jewish Studies at the Turn of the Twentieth Century II (1999): 34-39; Roland Goetschel, "La notion de simsum dans le "Somer 'Emunim" de Joseph Ergaz," in Hommage à Georges Vajda, ed. G. Nahon and Ch. Touati (Paris: Peters, 1980), 385-396; Roland Goetschel, "La justification de la cabbale dans le Shomer Emunim de Joseph Ergas (16851730)," in Jewish Studies in a New Europe, ed. U. Haxen, H. Trautner-Kromann, and K.L. Goldschmidt-Salamon (Copenhagen: Reitzel, 1994), 269-283; Joëlle Hansel, "La figure du 'mashal' dans l'herméneutique du XVIe au XVIIIe siècle," 
in Revue des études juives 160, no. 1-2 (2001): 135-154; Joëlle Hansel, "La lettre ou l'allégorie: la controverse sur l'interprétation du 'Simsum' dans la cabbale italienne du XVIIIe siècle," in La controverse religieuse et ses formes, ed. Alain Le Boulluec (Paris: Ed. du Cerf, 1995), 99-125. In addition to these theoretical sources, see a complete bibliography in A. Salah, La République des Lettres, 227-230.

${ }^{59}$ For more on the superficial study of Kabbalah, see Ergas' "responsum" in Divrey Yosef, ff. 45v-46r.

${ }^{60}$ Ibid., 6.

${ }^{61}$ Shomer emunym, 46. The emphasis Ergas places on the continuity between the Talmud and Kabbalah evokes both Basilea and another important Livornese kabbalist who lived in the following century, Elia Benamozegh. For more on Benamozegh, see A. Guetta, Philosophy and Kabbalah: Elijah Benamozegh and the Reconciliation of Western Thought and Jewish Esotericism (Albany, NY: State University of New York Press, 2009).

${ }^{62}$ Shomer emunym, 45. It should be noted that these assertions appeared in the introduction to the second part of the dialogue, not in the dialogue itself.

${ }^{63}$ Luzzatto later made repeated use of this term in his own theoretical argumentation.

${ }^{64}$ Ibid., 13-14.

${ }^{65}$ Ibid., 34.

${ }^{66}$ This dialogue, probably written in 1734 , was published posthumously on several occasions and under two different titles: Hoqer w-mequbbal and Maamar hawikkuah. For comprehensive bibliographies of Luzzatto's writings, see A. Salah, La République, 382-389, and Natascia Danieli, L'epistolario di Moŝe Hayyim Luzzatto (Florence: Giuntina, 2007), 291-308. This dialogue was the Paduan kabbalist's only work to receive a haskamah (authorization for publication) from his teacher, Yeshayahu Bassani.

${ }^{67}$ Luzzatto was committed to reawakening Israel from its slumber. A parallel could be drawn between his vision of Jewish cultural decadence and reawakening and the way in which, in the following century, the German maskylym conceived of their own work as the rebirth of Judaism after dark centuries of exile. Indeed, it is possible to argue that Luzzatto's historical vision anticipated the maskylym even though its content was different. For the historical vision of the haskalah, see Shmuel Feiner, Haskalah and History: The Emergence of a Modern Jewish Historical Consciousness (Oxford: Littman Library, 2004), esp. 45-50.

${ }^{68}$ Maimonides, Mishneh Torah, Introduction: "In our days, severe vicissitudes prevail, and all feel the pressure of hard times. The wisdom of our wise men has disappeared; the understanding of our prudent men is hidden. Hence, the commentaries of the Geonim and their compilations of laws and responses, which they took care to make clear, have in our times become hard to understand so that only a few individuals properly comprehend them. [...] The Talmud itselfthe Babylonian as well as the Palestinian - the Sifra, the Sifre, and the Tosefta 
require, for their comprehension, a broad mind, a wise soul and considerable study." Luzzatto probably saw himself as a new Maimonides, though he replaced Talmudic knowledge with Kabbalah. For more on the prophetic mission which Maimonides may have imagined to be his, see Israel Yuval, "Moshe redivivus: ha-Rambam ke-'ozer la-melekh ha-mashiah"” (Moses redivivus: Maimonides as an "Assistant to the King Messiah"), Zion 72, no. 2 (2007): 161-188.

${ }^{69}$ Mosheh Hayyim Luzzatto, Maamar ha-wikkuah (B’nai Brak, 1989), 33.

${ }^{70}$ In a letter sent to the rabbi of Altona, Yehezkel Katzenellenbogen, in 1730, the rabbis of Padua clearly realized that Luzzatto's intellectual contribution was "reestablishing the knowledge of the subject matter of the holy Luria, insofar as these are obscure and hard to understand." See S. Ginzburg, R. M.H.L. w-vney doro, 88 .

71 Ibid., 37.

72 Ibid., 62.

73 Emunath hakhamym, f. 11v.

74 Ibid., f. $35 \mathrm{v}$.

75 F. $7 \mathrm{~V}$.

${ }^{76}$ Y. Alemanno, Hay ha- 'olamim, L'immortale, ed. Fabrizio Lelli (Florence, 1995); Moshe Idel, La Cabbalà in Italia (1280-1510) (Florence: Giuntina, 2007).

77 E. Benamozegh, Teologia dogmatica e apologetica (Leghorn, 1877); A. Guetta, Philosophy and Kabbalah.

${ }^{78}$ Emunath hakhamym, f. 19r.

79 Ibid., 19r, ff 8r and v.

${ }^{80}$ Ibid., f. 9 r.

81 Ibid., f. 43 v.

${ }^{82}$ Ibid., ff. 4r, 4v, 16v, 26r, 26v, 30v.

${ }^{83}$ Ibid., f. 7v.

${ }^{84}$ Shomer emunym, 26-27.

85 Ibid., 31.

${ }^{86}$ Ibid., 42.

87 Ibid., 13.

88 Ibid., 35.

89 Ibid., 83-84.

90 Ibid., 28.

91 Ibid., 29.

92 Ibid., 34.

93 Ibid., 21.

94 Ibid., 76. In other cases, Ergas provides a philosophical exegesis of entire passages of the Zohar, which he reproduces in Aramaic and translates into Hebrew: see p. 40, on the sefyrah keter, the absolute Unity, which corresponds to the philosophical categories of "knowledge," "knowing," and "known," based on Maimonidean notions (Guide of the Perplexed I:68). 
95 Joëlle Hansel, "La lettre et l'allégorie."

${ }^{96}$ It is significant that although Ergas seeks to give a rational account of the doctrine of Yitzhaq Luria, the author to whom he refers most frequently in the Shomer emunym is Mosheh Cordovero, the most "philosophical" (or theological) of the sixteenth-century kabbalists.

97 Cf. Roland Goetschel, "La notion de Simsum."

98 Yitzhaq Abrabanel, Rosh amanah, ed. Menahem Kellner (Ramat Gan: Bar-Ilan University Press, 1992).

99 See, especially, Menahem Kellner, Must a Jew Believe Anything? (London: Littman Library, 1999).

100 Shomer emunym, 63.

${ }^{101}$ Ibid., 58-63. Benamozegh also composed a series of articles of faith, which he titled Il mio credo and defined as "philosophical-religious." See E. Benamozegh, Teologia dogmatica e apologetica, Vol. 1: Dio (Leghorn, 1877); New edition Il mio Credo (Pisa: Edizioni ETS, 2002).

102 Shomer emunym, 91-96.

103 See the introduction by Yitzhaq Stern to Shomer emunym.

104 The Guide of the Perplexed III:17.

105 On Yosef Attias, see A. Salah, La République, 50-2; and Lucia Frattarelli Fischer, "Lo specchio di un intellettuale cosmopolita: La biblioteca di Giuseppe Attias," forthcoming.

106 Meir Benayahu, Rabbi Hayyim Yosef David Azulay (Jerusalem: Mossad ha-Rav Kook, 1959), 134-141. On the intellectual atmosphere in Tuscany during the first half of the eighteenth century, see Ulrich Wyrwa, "'Perché i moderni rabbini pretendono di dare ad intendere una favola chimerica...' L'illuminismo toscano e gli ebrei," Quaderni storici 103, XXXV.1 (2000): 139-161. This article divides the eighteenth century into two periods. Whereas Jewish and Christian intellectuals were still at odds in the first half of the eighteenth century, this hostility died out in the second half, particularly during the 1770 s, when German and French ideas on religious tolerance reached that area. On Livorno see A. Guetta, "Livorno, un centro di qabbalah?," in Livorno 1606-1806. Luogo d'incontro tra popoli e culture, ed. Adriano Prosperi (Turin: Allemandi, 2010), 375-381.

107 David Ruderman, Jewish Thought and Scientific Discovery.

108 Emunath hakhamym, 22r and v. It may be that this "great philosopher" was none other than Simhah, or Simone Luzzatto, a rational mind par excellence and a famous scientist.

109 Maamar ha-wikkuah, 60.

${ }^{110}$ Ibid., 45. Beyond the reference to spectacles, Luzzatto's position may be considered "modern" insofar as it integrated the hermeneutic conception of the author's intention, which the works of Protestant thinkers were developing during that period. See Jakob Rambach, Institutiones hermeneuticae sacrae, 1723. 
111 Maamar ha-wikkuah, 49.

112 Ibid., 74-5.

113 Ibid., 55.

114 Ibid., 40.

115 Sa'adiyah ben Yosef Al-Fayyumi, known as Sa'adiyah Gaon, Ha-nivhar ba-emunath we-ha-de 'oth (Selection of beliefs and opinions), trans. Y. Qafih (Jerusalem, 1993), 28.

${ }^{116}$ Maamar ha-wikkuah, 70; Qelah pithhey hokhmah, 44: "We are forbidden to know the reason for the existence [of the sefyroth] [...] but we have to study and know their precise and wisely executed operation (hanhagah)."

117 Da'ath tevunoth, 64.

118 The Guide of the Perplexed I:64.

119 Da'ath tevunoth, 65.

${ }^{120}$ There are a few instances in Luzzatto's thought where the relationship between human and divine action seems unresolved: in these instances it is not clear whether the human act of comprehension is the cause or consequence of the influx of divine light.

${ }^{121}$ Da'ath tevunoth, 64.

122 Ibid., 103.

${ }^{123}$ Written in 1734, it remained in manuscript form until Shemuel Luria's edition (Warsaw, 1889). All quotations refer to Hayyim Friedlander's edition (Bnei Brak, 1998).

124 Shemuel David Luzzatto wrote (in his Lezioni di Teologia, 42) that he "set out his system with great clarity in various works, principally in one entitled One Hundred Thirty-Eight Doors to Wisdom (Qelah pithhey hokhmah). Without using kabbalistic terms, he laid it out in a dialogue between the intellect and the soul (Wikkuah beyn ha-sekhel we-ha-neshamah), which only exists in manuscript form, in the possession of the afore-praised, most excellent Rabbi Ghirondi."

${ }^{125}$ Da 'ath tevunoth, 57, 59 (Midrash ha-ne 'elam), and 71 (Ra 'iya meheymna, called "the midrash of Shim'on bar Yohay"). On page 63, Luzzato attributes a quotation from the Zohar 3,113 to Hazal, i.e. to the Talmudic masters.

${ }^{126} \mathrm{Da}$ 'ath tevunoth, introduction by Friedlander, $11 \mathrm{n} 12$.

127 Ibid., 68.

${ }^{128}$ According to Luzzatto, the advantage of the Lurianic doctrine over Cordovero's is that while Cordovero limits himself to general statements about the ten sefyroth and what they produce, Luria defines this process in detail. Cf. Maamar ha-wikkuah, p. 66.

129 Kelalym rishonym, p. 172 in the same volume that contains the Da 'ath tevunoth.

${ }^{130}$ Ibid., 287.

131 Essentially a theoretician, Luzzatto seldom made references to other works.

132 Da'ath tevunoth, 91.

133 See notes 84 and 85. 
${ }^{134}$ On the diffusion of Cartesianism in Italy, see Vincenzo Ferrone, Scienza natura religione. Mondo newtoniano e cultura italiana nel primo Settecento, Naples, 1982; and in particular 151: "The reference [...] to Descartes meant clear and distinct ideas, methodical doubt, and an exultant and convincing vision of science at odds with Aristotelianism, for entire generations of intellectuals (from Valletta to Muratori)." See also 465, on the Discours de la méthode and the greater impact it had than the Principia philosophicae.

135 This quotation is taken from Y. Spiner's edition, with critical notes by M. Chriqui (Jerusalem, 2007).

${ }^{136}$ Derekh ha-Shem, 1, 5, 2, 48. On this image in kabbalistic literature see Moshe Idel, Enchanted Chains: Techniques and Rituals in Jewish Mysticism (Los Angeles, CA, 2004).

${ }^{137}$ Ibid., 2, 7, 1, 114-6.

${ }^{138}$ Ibid., 3, 2, 1-9, .137-50. Luzzatto briefly alluded to the power of invoking God's names in Qelah pithhey hokhmah. He made this remark in the context of an analysis of the correspondence between the letters of the tetragrammaton and sefyroth (see 55-57).

${ }^{139}$ Ibid., 2, 8, 1-2, 117-21.

${ }^{140}$ The Guide of the Perplexed III:17 and 18.

${ }^{141}$ For a comprehensive account of Luzzato's perspective on Maimonides, and in particular on the distinction between the essence and existence of God, see Joëlle Hansel, Moïse Hayyim Luzzatto (1707-1746), 205-210. Hansel's book constitutes the most exhaustive study of the relationship between logic and Kabbalah in Luzzatto's thought. Among her many important insights is the suggestion that internal kabbalistic sources - in particular Hayyim Vital's Etz Hayyim - may have inspired the logical orientation of the Paduan author.

${ }^{142}$ Derekh ha-Shem, 1, 1, 2, 9-10. One may also find a certain similarity between Luzzatto and Gersonides. The Provençal philosopher and scientist believed the Agent Intellect possessed "the Law of the existing things here (i.e. in this sublunar world), their right plan, and their order"(Sefer Milhamoth Ha-Shem (Rive del Garda, 1560), f. 7v. My translation differs slightly from Seymour Feldman's in Gersonides, The Wars of the Lord (Philadelphia: Jewish Publication Society, 1984), 146.

${ }^{143}$ See Ghislain Lafont, Histoire théologique de l'Église catholique. Intinéraires et formes de la théologie (Paris: Éditions du Cerf, 1994), 252-275: Le temps des ruptures (1563-1774); Battista Modin, Storia della teologia, vol. 3 (Epoca moderna) (Bologna: Edizioni Studio Domenicano,1996), 259; José Luis Illanes and Josep Ignasi Saranyana, Historia de la teologia (Madrid: Biblioteca de autores cristianos, 1996), 237.

${ }^{144}$ For an attempt to alter this traditional perspective, see Hava Tirosh-Rothschild, "Jewish Philosophy on the Eve of Modernity," in History of Jewish Philosophy, ed. Daniel H. Frank and Oliver Leaman (London: Routledge, 2003), 499-573. 
${ }^{145}$ Qelah pithey hokhmah (Bnei Brak, 1992), 1.

${ }^{146}$ Ibid., 38, 53.

${ }^{147}$ Ibid., 76, 89.

148 Ibid., 19.

149 Benedict Spinoza, Ethics, trans. Stuart Hampshire. (London: Penguin Classics, 1996), Part I, def. IV, p. 1.

${ }^{150}$ Qelah pithhey hokhmah, 49.

${ }^{151}$ Benedict Spinoza, Ethics, Part I, def. V, p. 1.

${ }^{152}$ Ibid., Part II, prop. I and II, pp. 32-33. For a comparison between kabbalistic theology and Spinoza's system, see the astute observations of the philosopherkabbalist Elia Benamozegh in his Spinoza et la cabbale, published in various numbers of the Univers Israélite in 1864 before being republished separately in Padua in 1962 and then Jerusalem in 1988.

${ }^{153}$ Qelah pithey hokhmah, 58-70.

${ }^{154}$ Ibid., 176-177.

${ }_{155}$ Da'ath tevunoth, 25.

${ }^{156}$ Ibid., 32-33.

157 This was almost obviously in reference to Descartes' clear and distinctive knowledge. The French philosopher was well known in Italy by this time, including by Jewish scholars. As already noted, in his Emunath hakhamym, Basilea described Descartes as the author whose physics had supplanted Aristotle, exposing the vanity of the scientific pretension to definitive truth.

${ }_{158}$ Maamar ha-wikkuah, 43.

${ }^{159}$ Ibid., 44, 56. Qelah pithey hokhmah, 89. On the importance of the idea of God's unity, see Da'ath tevunoth, 10.

${ }^{160}$ Da'ath tevunoth, 21.

${ }^{161}$ Maamar ha-wikkuah, 48.

${ }^{162}$ Ibid., $62,76$.

${ }_{163}$ Da'ath tevunoth, 9.

${ }^{164}$ Maamar ha-wikkuah, 68.

${ }^{165}$ Qelah pithey hokhmah, 124.

166 Ibid., 168.

${ }^{167}$ Da'ath tevunoth, 74.

${ }^{168}$ Maamar ha-wikkuah, 65.

169 The lexical and semantic echoes between Derekh tevunoth and Da'ath tevunoth (a theological treatise grounded in Kabbalah) are significant.

${ }^{170}$ Derekh tevunoth (Amsterdam, 1742), f. 3r.

${ }^{171}$ Ibid., author's introduction (no pages numbers).

172 There were two types of conventional demonstrations: those that were common to everyone (e.g., "modesty is praiseworthy") and those that were the reserve of Israel (e.g., "the oral and written Torah is true").

${ }^{173}$ Ibid., ff 17v-19r. 
${ }^{174}$ First edition published in Warsaw in 1897. The quotations are from the Jerusalem edition, published in 1993.

175 Mostly Petrus Ramus, according to C. H. Manekin. See above, note 15.

176 Sefer ha-higayon, 3.

${ }^{177}$ It is worth pointing out that both this aesthetic criterion (which is surprising in a Jewish text) and the pragmatic criterion of utility are attributable to a "modern" sensibility.

178 Sefer ha-higayon, 1-2. The rhetorical treatise Luzzatto composed at the age of 19, Leshon limmudym ("A Cultured Language," published in Mantua in 1727), also proceeded rigorously: praising distinctions from its opening pages, it began with general definitions (geder) and gradually progressed to particulars.

179 Derekh ha-Shem, 3.

${ }^{180}$ Da'ath tevunoth, 262-263.

${ }^{181}$ Ibid., 102. "The supreme will wanted man to have power over numerous [superior] beings, which all move according to his acts and movements. This great contrivance is like a clock, the gears of which meet each other in such a way that a small gear puts many other larger gears in motion. Thus did the blessed Lord connect all of His creatures with many points of contact, and He connected all to man, who acts, thus putting the totality in motion with all His acts. He also covered everything with a membrane of skin and a layer of flesh, so that only the bodily surface is seen. But all this has a meaning: the great device created by God in His world operates according to man's acts and worship, elevating him and sanctifying him, or diminishing him — may this not happen! — thus producing manifold situations. And all this depends on the soul, its parts and the roots that He put in the human body." The same image of the clock gears is taken up in Kelalym rishonym, chapter 12, p. 256. Ergas deploys the more traditional metaphor of a chain hanging between the worlds; see Shomer emunym, 88.

182 Maamar ha-wikkuah, 53. Cf. Qelah pithey hokhmah, 202, on the precise relationships that unite the sefyroth. As well as having an adverse impact on the exposition of a system, disorder may affect its operation. This occured after the shevyrath ha-kelym, before the action of the sefyroth was coordinated and unified by the sefyrah malkhuth. Cf. Qelah pithey hokhmah, ibid.

183 Qelah pithey hokhmah, 25. In Da'ath tevunoth, 98, Luzzatto insists that measure (middah, shi 'ur) and hierarchy or gradation (hadragah) are divine creations and that every being occupies a precise position (ish 'al meqomo).

184 Ibid., 1.

185 Da'ath tevunoth, 22.

186 Ibid., 36.

187 Ibid.

188 Ibid., 87, 92.

189 Ibid., 46.

${ }^{190}$ Maamar ha-wikkuah, 53. 


\section{Index}

A

Abravanel, Yitzhaq, 85, 157, 165-166

Achryvasmus, 34

Adolph, King Gustav, 84

Albo, Yosef, 149, 157, 161

Alemanno, Yohanan, 15-17, 20, 78-80, 201

Alighieri, Dante, 65, 106, 177

Allatino, Mosè, 106

Almanzi, Yosef, 186

Antiquitates hebraicae, 50

Antoine, Nicolas, trial of, 150-151

Aquinas, Thomas, 110, 140-141, 155

Aristotelianism, 13, 153-154

Aristotelian metaphysics, 27

Aristotelian philosophy, 155

theory of knowledge, 153-154

Attias, Yosef, 207

auctoritates, 43-44, 82

Augustine, 110

Azulay, David, 207

\section{B}

Bacon, Francis, 42

Bagnoregio, Bonaventura of, 65

Bartolocci, Giulio, 195

Basilea, Avi ‘ad Sar Shalom, 193-194, 201-202, 207

Battle of Lepanto, 86

The Beautiful Lands, 81
Bedersi, Yeda'yiah, 12, 193

Benamozegh, Eliyahu, 201

Bible reading, 39

Bibliotheca Rabbinica, 195

Blum, Paul Richard, 154

Boccaccio's crow, 46

Bonfil, Robert, 12, 18, 22

Bonifaccio, Baldassare, 156, 171

Brucioli, Antonio, 40

Burnet, Thomas, 183

C

The Cambridge Companion to Renaissance Philosophy, 154

Camporesi, Piero, 81

Catarino, Ambrosio, 142

Catholic Counter-Reformation, 69

Catholic doctrine of justification, 24-25

Catholic theology, 190-191

Cebà, Ansaldo, 171

Christian belief system, 138-142

Christian doctrine of punishment and reward, 154

Christian Kabbalist, 136-137

Christian scholars of Judaism, 112

Consilia medica, 31

Corcos, Donna, 107, 111

Cordovero, Mosheh, 102, 190

Council of Trent, 25 
Counter-Reformation, 105

Crescas, Hasday, 27, 149, 157,

159-160

\section{D}

Da Pisa family, 12, 16

d'Aquin, Philippe, 70

De arcanis catholicae veritatis,

135-136

De auro dialogi tres, 3, 32, 44-45, 55-56

Decameron, 46

Delmedigo, Yosef Shelomo, 49, 59

de' Medici, Lorenzo, 79

De Republica hebraeorum libri VII, 145

De sacra scriptura recte interpretanda, 136

Descartes, René, 42

De Uno Vero Deo Iehova, 143

Deuteronomy, 85

De vera theologia, 136

dialogues (Dialogi), 31

Dialogue with Trypho, 112

strategy of, 196-201

Discorso sull'immortalità dell'anima, 172

Discourse on Eternal Life, 17

Discourse on the Righteous Man and the Purpose of the World, 12, 21

Discourse on the Ten Sefyroth, 12

Divine Comedy, 65, 106, 177

Divrey Yosef, 195

Dynachrysus, 34 statement of humility in De auro, 45-50

use of intertextuality, 45-46

vs Achryvasmus, 34-35

\section{E}

Emunath hakhamym, 202

Ergas, Yosef, 196, 202, 204-205

kabbalistic-theological dogmas, 206

mashal and sod, notions of, 205

principles of faith, 205

sefyroth, 203-204

similarities with Luzzatto, 213-214

"theological" dimension of work, 205

theses on providence, 206

tzimtzum, notion of, 205

ziwwug, notion of, 204

Essay for the Understanding

of St. Paul's Epistle, by

Consulting St. Paul Himself, 147

European historiography, 19

Euthydemus, 47

Examen Vanitatis, 23

Ezekiel, Prophet, 63

Ezra, Avraham Ibn, 194

F

Ficino, Marsilio, 155, 166

Fiorentino, Salomone, 176-180

Elegie (Elegies), 176-177 
Jewish subjects in poetry, 176

process of the loss of a loved one, 179

reference to God, 177

social references in poetry, 177

Flavius, Joseph, 101

Fonseca, Isaac Aboab de, 175

Francés, Ya'aqov, 191-192

\section{G}

Gabbay, Meyr ibn, 190

Galatino, Pietro Colonna, 135, 195

Galen, 34

Galilei, Galileo, 42, 184

Geiger, Abraham, 134

Genazzano, Eliyah di, 15

Gentiles, 148

Gersonides, 15

Gikatilla, Yosef, 36,111

Ginzburg, Simon, 186

Giustiniani, Agostino, 113

gold, medicinal value of, 31-32, 46-47

Aristotelian-Platonic philosophical tradition, 35

capacity to cauterize wounds, 32

contemporary thoughts, 31-32

Dynachrysus's criticism, 47

Dynachrysus vs Achryvasmus, 34-35

Greek-Arabic medical tradition, 35

Latin dialogues on, 34-37

military use, 36

Gregory XIII, Pope, 106, 112
Guide of the Perplexed, 15, 45, 63-64, 157, 215

H

Ha-Levy, Yehudah, 39

Hanukath ha-bayith, 73-74

Hayyim, Yitzhaq Mar, 16-17

Ḥefetz, Mosheh ben Gershom, 73-74

Hilkhoth Beyth ha-behyrah, 70

Hippocrates, 34

Historia de riti ebraici, 149

hokhmah, 190, 194, 208, 224

Holy Spirit, 144, 191

I

Idel, Moshe, 19, 79

Iggereth Hithnatzeluth (Letter of Justification), 12-13

Immanuel of Rome, 178

intertextuality, 45

Israel, Menasheh ben, 175

Istoria del concilio tridentino, 142

Italian city states

Abravanel's view, 85-87

Florence of the Medici, 78-80

modern Jewish society, 80-85

Venetian Republic, 85-87

Italian Jewish community, 92-93

Italian Jewish literature, 178

Italian Jews, scientific and religious mind-frames of, 33

Italian "university philosophy," 13 


\section{$\mathbf{J}$}

Jesuitic Model of Portaleone, 50-52

Jesus-Christ, Lord, 144

Jewish articles of faith, 161

Jewish “ghost-army,” 83

Jewish historiography, 19

Jewish humanists, 106

Jewish polemical tradition, 134-135

of Basilea, 194

Judeo-Christian, 137

Jewish religiosity, 182-184

Jewish Scriptural Tradition, 112-115

Jewish thought, Middle Ages and

Renaissance era, 92, 157-161

K

Kabbalah

Christian Kabbalist, 136-137

critiques of, 188-196

dialogue between a kabbalist and a rationalist, 196-201

Italian Jews and, 102-104

Italian Kabbalah's philosophical tendency, 17

Kabbalah and philosophy, 17-19

kabbalistic images in Temple of Jerusalem, 75-77

particularity and superiority of Jewish people, 102-103

rational reductions of, 201-209

rational theology for, 209-216

of Safed, 161

as a science of knowable, 223-226

and scientific method, 220-223 study of, 102

as a system, 216-220

transmigration of souls, 165-166

Kaufmann, David, 106

knowledge

authorities of past, concerns about, 40-45

Counter-Reformation era and, 39

division between scientific and religious spheres, 38-39

experience as source of, 34-37

limits of, 37-40

Portaleone's approach, 39-45

Kohen mashuah, 84

Kohen meshuah milhamah, 36

Kuzary, 15, 25, 39, 168

\section{$\mathbf{L}$}

Lactantius, Lucius Caecilius

Firmianus, 109

Latin punctuation, 39-40

Lelli, Fabrizio, 79

Leon, Jacob Judah, 71

Lesley, Arthur M., 79

Locke, John, 147

love for God, notion of, 160-161

Luria, Yitzhaq, 102, 189, 197, 204

Lurianic Kabbalah, 26, 50, 75, 166, 189, 200-201

Luther, Martin, 35

Luzzatto, Mosheh Hayyim, 75-77, 196. see also Kabbalah apologia of order and distinctions, 223 
centrality of intellectual knowledge, 215-216

critiques of Kabbalah, 188-196

Da 'ath tevunoth, 209-212

Derekh ha-Shem, 214-215

Derekh tevunoth, 222

dialogue, 199-200

fields of application of Kabbalah, 208-209

finalism, 213-214

gnoseology, 225-226

human history, 209

infinity and finitude, relationship between, 219

intellectualism, 209

kabbalistic influences, 211

kabbalistic knowledge, 199

kabbalistic studies, 185-226

Kelalym rishonym, 211-212

logical/rhetorical treatises, 187

malkhuth (kingship), 212-213

Mesyllath yesharym, 214

parallels between Kabbalah and science, 223-226

Qelah pithhey hokhmah, 216-217, 220

rational constructions, 210

rationalistic aspects of thoughts, 187-188

the sefyroth and the eyn sof, relationship between, 218-219

similarities with Ergas, 213-214

study of Talmud, 222

Torah, 199
Luzzatto, Samuel David (Shadal), 185-186

Luzzatto, Simone (Simḥah), 78, 8889, 93, 99-100, 103

Catholic tradition, 113-114

Discorso circa il stato de gl'hebrei

(Discourse Concerning the Condition of the Jews), 88, 93-99, 113

Jewish community of Venice, 88-91

Jewish faithfulness, 113-114

Jewish nation, 78

Socrate, ovvero dell'humano sapere, 88

\section{M}

Ma'aseh Hoshev, 75

Machiavelli, Niccolò, 90-91

Magen we-herev (The Shield and the

Sword), 134-135. see also

Modena, Leone

people-belief correlation in, 150

polemical target of, 135-136

sections, 134

Maimonides, 15, 19, 21-22, 25 , 27-29, 45, 63-64, 87, 92, 110, 136, 138, 150, 157, 169, 215, 217

immortality of soul, $157-158$

Torah as an allegory, 63-64

Malkiel, David, 183

Mantuan rabbi, 195, 200, 202

Martyr, Justin, 112

mashal, 67 
Medigo, Eliyah Del, 157, 160,

166-168, 217

Behynath ha-dath, 189

Christian theologians, criticism against, 166-167

fundamental notions of the Jewish religion, 168

immortality of the soul, 167-168

Melamed, Abraham, 79, 89, 92

$\mathrm{Me}$ 'on ha-shoalym, Italian translation of, 105-108, see also Viterbo,

Lazzaro da

allegory of the "City of God," 107

biblical language, 107

Lazzaro's translation, 107-108

paraphrases of the Hebrew text, 116-133

Middle Ages, Jewish thought in, 92, 157-161

midrash, 36-37

Midrash Tanhuma, 146-147 dim.

Milhamoth Adonay, 159 dim.

Minhath Kenaoth, 12, 17, 21, 24

Mirandola, Gianfrancesco Pico della, 28

Mirandola, Giovanni Pico della, 20

Mishneh Torah, 87

Modena, Leone Yehudah Ariyeh, 102, 172, 189, see also Magen we-herev (The Shield and the Sword)

on "adapting" the Torah, 138

Catholic theology, 190-191

Christian theology, 138-139

criterion for a belief, 139 defence of the Jewish religion, 137-140

erroneous interpretation of the Gospels, 144-148

good sense and good manners, $150-152$

Hebrew of, 135

hierarchy of "slave," "servant," and "son," 146

historical Jesus, 144-146

Jewish prayers, 151

legitimacy of singing in synagogue, 151

messianic belief of Jews, 149

modernity of, 147

nation, concept of, 150

Pietro Galatino's De arcanis catholicae veritatis and, 135-137

positive alternative to Kabbalah, 191

Protestant proposition, 142-144

reference to Sarpi's work, 142-143

refutation of Christianity and original sin, 138-142

success of Christianity, 148-149

modern Jewish society, 80-85

Morosini, Giulio, 151-152

Morpurgo, Shimshon, 193

Morteira, Saul Levi, 175

Moscato, Yehudah, 156, 168-169, $232 n 46$

Mosheh of Rieti, 65-66, 68, 105-106, $156,162-165,168,178$ 
analysis of works, 57-58, 60-61

Nahmanides (Naḥman, Mosheh ben), $15,150,157$ immortality of soul, 158-159 "national" Jewish identity, 30 Nebuchadnezzar, King, 62 neo-scholasticism, 216-220 Nifo, Agostino, 18, 25 nimshal, 67

O

Olivétan, Pierre Robert, 40

Olympica, Corilla, 182

original sin, 140-142

\section{$\mathbf{P}$}

Paruta, Niccolò, 143-144

Pliny the Elder, 35

political expressions, Middle Ages and Renaissance era, 92

Pomi, David De, 86-87, 106, 253n6 Discorso intorno a l'humana miseria, e sopr'al modo di fuggirla, 170

immortality of soul, 169-171

Judaism as a religion based in ethics, 169-171

Judeo-Christian civilization, 101

universalism of, 100-102

Pomponazzi, Pietro, 26, 155

Popkin, Richard, 71

Portaleone, Avraham ben David, 30, 35-36, 38, 40-45, 106

biblical references about artillery market, 84

description of architecture of Temple in Jerusalem, 44

Hebrew, 61

High Priest's clothing, 56-57

Jesuitic Model, 50-52

as a mediator between Jewish and Christian cultures, 49

methodological probity, 53-54

modern Jewish society, 80-85, 90-91

music and songs of the Levites, 53

notion of kawwanah, 50

oscillation between modernity and tradition, 55-57

perception of historical time, 52-58

portrait of military sphere and activities, 82,84

precious stones, properties of, 55-56

reservations about past, $42-45$

role of spiritual and intellectual teacher, 49

scientific discourses in Hebrew, 48

sedentary merchants, description of, 81

Temple as encyclopedia, 68-71

Temple of Jerusalem, 52, 54-58

types of Israelites, 80

Protestant propositions, 142-144

Provenzali, Mosheh David, 26-27, 30 
Q

Qol Yehudah, 168

quintessence, notion of, 32, 38, $236 n 8$

$\mathbf{R}$

Rabbis and Jewish Communities in Renaissance Italy, 12

rabbis of the Talmud, 42-43, 53

rational religion, model for, $137-140$

reason, 37

Recanati, Menahem, 15-16, 202

Renaissance Italy, 157

Retrato del templo de Selomo, 71

Reuchlin, Johannes, 136

Ricchi, Immanuel ben Abraham Ḥay, 75

Riccioli, Giovan Battista, 41

Romanelli, Shemuel immortality of soul, 181-182

religiosity, 182-183

Roman Jewish community, 111

Rosh Yeshivah, 30

Rossi, Azariyah de', 49, 54, 60, 106

$\mathbf{S}$

Salvatorelli, Luigi, 147

Sancta sanctorum, 64-65

Sa'adiyah Gaon, 209

Sarpi, Paolo, 142

Schweitzer, Albert, 147

scientific ethics, 37-38

Sefer ha-'Iqqarym, 161
Sefer Yetzyrah, 111

sefyroth, 16-17, 19, 76, 187, 195, 197, 201, 203-204, 215, 217-218, 224

Sephardic Jews, 90-91

"servant will" doctrine, 24

Sforno, 'Ovadiyah, 23-24, 26-27

Sha 'arey orah, 111

Shiltey ha-Gibborym, 32-33, 35, $38-39,44,48,50,55-56$, $59,69-71,80,83,99,235 n 6$, 239n55, 240n59, 240n62

Shomer emunym, 196-197

Sigonio, Carlo, 145

Simonsohn, Shlomo, 134

Sirleto, Cardinal Guglielmo, 105, 112

Socin, Faust, 147

sola scriptura, 35

Solomon, King, 62, 80, 89

Sommo, Leone (Yehudah), 71, 106

Song of Songs, 16

soul, immortality of, 153-157

Abravanel's doctrine on, 165-166

Aristotelian epistemological dimension, 153-155

common Italian Jewish-Christian view on, 175

conflict of intellectualism with the Torah and the tradition, 159-160

Del Medigo's thoughts, 166-168

de Pomi's thoughts, 169-171

Descartes' thoughts, 156

Fifth Lateran Council on, 155

Fiorentino's thoughts, 176-180

gilgul, 202 
Jewish belief, 175

Maimonides' thoughts, 157-158

Mendelssohn's Phaedon, 180

Middle Ages, Jewish thought in, 92, 157-161

Moscato's thoughts, 168-169

in Mosheh of Rieti's poetry, 162-165

Nahmanides' thoughts, 158-159

Neo-Platonic thoughts, 155-157

public controversy on, 174-175

Renaissance Italy, assertions in, 157

Romanelli's thoughts, 181-182

Sara Copio Sullam's thoughts, 171-174

Uriel da Costa, case of, 174-175

Spanish Kabbalah, 16

Spinoza, Baruch, 16, 68, 71, 89, 91, $98,109,175,214,218-219$

Sullam, Sara Copio, 156

immortality of soul, 171-174

Manifesto, 172-173

Summum Bonum, 160

superstition, 151

\section{$\mathbf{T}$}

Talmud Bavly Sanhedrin, 110

te 'amym of Torah, 39-40

Temple of Jerusalem, 32, 44

Afbeeldinge van den Tempel

Solomonis, 72

allegorical representation in, 65-68 bi-dimensional representations of, 75-77

as encyclopedia, 68-71

Jewish perceptions and representations of space, 62

kabbalistic images of, 75-77

Maimonides and, 63-64

Portaleone's description, 52, 54-58

Rieti and, 65-68

scale models, 71-75

as Theatrum memoriae, 52

Toledoth Yeshu, 145

Tractatus de Anno Jubilaei, 105-106, 108-112. See also Viterbo, Lazzaro da

as a description of the Jewish roots, 109

intellectual space common to Jews and Christians, 111

interpretation of the Jewish Sabbath, 109-110

Lazzaro's translation, 109-110

purpose, 108

Tractatus de immortalitate animae, 155

Trinity, 134, 139, 144, 149

Troki, Isaac, 144

tzaddyq, 169

Tzevy, Shabbetay, 188

tzimtzum, notion of, 205

$\mathbf{U}$

Uriel da Costa, case of, 174-175 
link with Aristotelianism, 13, 18

Venetian Republic, 85-87, 142

Villalpando, Juan Battista, 70

Vital, Ḥayyim, 204

Viterbo, Lazzaro da, 251n3, 252n4

defense of Jewish Scriptural

Tradition, 112-115

Italian translation of $\mathrm{Me}^{\text {' }} \mathrm{on} \mathrm{ha-}$ shoalym, 106-108

Tractatus de Anno Jubilaei, 105-106, 108-112

work of, 105-106

Voltaire, 147

Y

Ya'ar ha-Levanon ("The Forest of Lebanon"), 66

Yehiyel, Yehudah ben, 49

Yehiyel (Vitale) Nissim of Pisa, $12-13$

alternative way to philosophy, 14 financial activities of Jews, 17 Italian Kabbalah's philosophical tendency, 17

Kabbalistic thoughts, 17-19

Maimonides, 21-22, 25, 27-29

modernity and tradition, 25-29

Nahmanides, 15

philosophical thoughts, 14-17

prophecy, 14-15

relationship between God and the world, 17

as a Renaissance man, 19-21

reservations about philosophy, 25

responses to Bedersi's Letter,

12-13

sefyroth, 16-17, 19, 29

spirituality, 19-20

Torah, 13-14

understanding of man, 21

uniqueness of Israel and Jews, 22-25

vs Alemanno, 20

works, 12-13

Yitzhaq of Pisa, 16

Z

Zacuto, Mosheh, 166, 194

Zohar, 18, 75, 102, 188 

